2012

\title{
Factors Affecting Peer Tutoring Programs in Higher Education As Perceived by Administrators
}

Debbi J.Pariser

West Virginia University

Follow this and additional works at: https://researchrepository.wvu.edu/etd

\section{Recommended Citation}

Pariser, Debbi J., "Factors Affecting Peer Tutoring Programs in Higher Education As Perceived by Administrators" (2012). Graduate Theses, Dissertations, and Problem Reports. 277.

https://researchrepository.wvu.edu/etd/277 
Factors Affecting Peer Tutoring Programs in Higher Education As Perceived by Administrators

Debbi J. Pariser

\begin{abstract}
Dissertation submitted to the College of Human Resources and Education at West Virginia University in partial fulfillment of the requirements for the degree of
\end{abstract}

Doctor of Education

in

Educational Leadership Studies

Helen M. Hazi, Ph.D., Chair

Reagan P. Curtis, Ph.D.

Ernest R. Goeres, Ph.D.

Patricia A. Haught, Ed.D.

Thomas S. Sloane, Ph.D.

Department of Curriculum \& Instruction/Literacy Studies

Morgantown, West Virginia

2012

Key Words: Peer Tutoring; Institutionalization; Higher Education; Academic Support 


\begin{abstract}
Factors Affecting Peer Tutoring Programs in Higher Education

As Perceived by Administrators
\end{abstract}

Debbi J. Pariser

This study examined a) institutional factors that administrators see as facilitating peer tutoring programs and $b$ ) institutional factors that administrators see as forming barriers to peer tutoring programs. In addition, a comparison was made of administrators' perceptions based on the following institutional demographic factors: department affiliation, enrollment, highest degree awarded, and Carnegie classification. The data were collected through an electronic survey instrument, Administrative and Faculty Factors that Contribute to the Institutionalization of Peer Tutoring in Higher Education, developed specifically for this study and based on the work of Dr. Anthony Pina (2005, 2008a, 2008b), who studied the institutionalization of distance learning programs and factors that institutionalize programs in higher education; and Dr. Vincent Tinto (1997, 2006-7), an expert on both retention and peer tutoring, who identified a gap in the literature on policies and practices in higher education which enable peer tutoring programs to endure and become institutionalized and in so doing, enable schools to be more successful in increasing student GPAs and retaining students. The sample included 192 administrators and faculty, who were members of Region II in the National Association of Student Personnel Administrators (NASPA), with an interest in and knowledge about academic tutoring programs, and who were involved in their supervision, evaluation, and delivery of services. Most of the respondents (87 percent) were administrators from public institutions, who oversaw peer tutoring programs but were not involved in the day-to-day operations. Results of the study revealed that centralization - having one department oversee the implementation, supervision, and assessment of peer tutoring; and collaboration - having regular meetings between Student Affairs and Academic Affairs to plan and access the program, are key to the success of peer tutoring. In addition, the results of this study presented new research on peer tutoring and provided guidance that may be used by administrators and faculty to a) evaluate existing peer tutoring programs to determine strengths, weaknesses, and areas for improvement; b) establish priorities in developing new peer tutoring programs; and c) develop strategies that will lead to the improvement and institutionalization of peer tutoring. The institutionalization factors identified in this study provided a model that may be used as a basis for cooperation between those who oversee the supervision, evaluation, and assessment of peer tutoring (administrators) and those who oversee the day-to-day operations of peer tutoring (faculty). 


\section{DEDICATION}

This dissertation is dedicated to my family and friends who encouraged me and inspired me to pursue my educational goals. I would like to thank my parents, Max and Bette Rovner, for providing, by example, the foundation for achieving success and encouraging me to pursue my dreams; my family, David, Marea, and Ashley, for inspiring me; and Dr. Anna Elfenbein, Barbara Jacowitz, and Dr. Chunmei Yao for your encouragement, support, and inspiration. 


\section{ACKNOWLEDGEMENTS}

I would like to thank my doctoral committee, Dr. Helen M. Hazi, Chair; Dr. Reagan P. Curtis; Dr. Ernest R. Goeres; Dr. Patricia A. Haught; and Dr. Thomas S. Sloane, for guiding me and helping me to reach my educational goals. Your dedication to your students is exemplary.

I would like to thank Dr. Curtis for also serving on my panel of experts and for your expert guidance and assistance with the statistical analysis of the data. I would also like to thank Dr. Hazi for serving as chairperson of my doctoral committee and for your dedication, support, encouragement, and expert guidance. Your outstanding writing, organization, and research skills taught me to focus and become a critical thinker. Your attention to detail taught me to have a critical eye. Your perseverance and encouragement taught me "reach for the stars" and strive to do my best. Your dedication has made me the confident scholar I am today. 


\section{TABLE OF CONTENTS}

\section{TABLE OF CONTENTS}

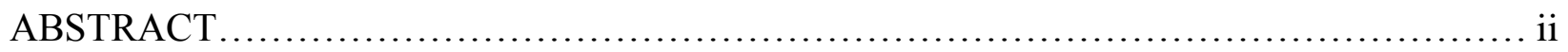

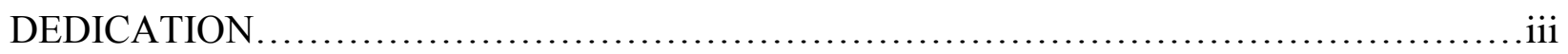

ACKNOWLEDGEMENTS ................................................................

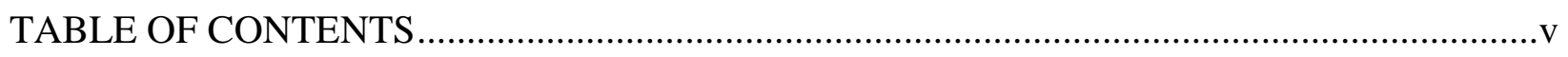

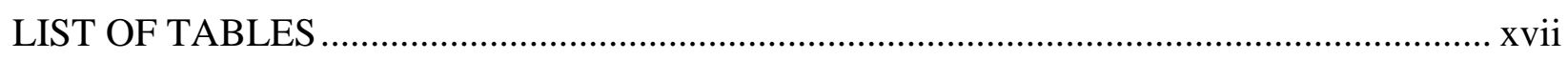

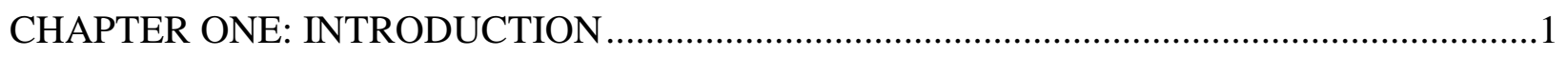

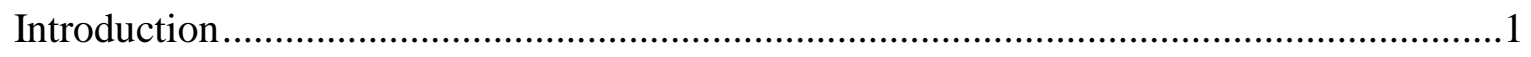

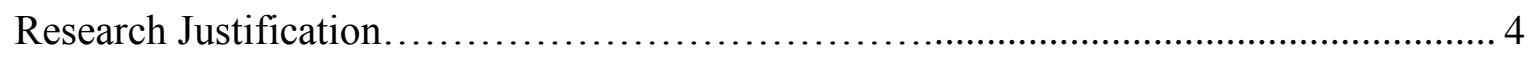

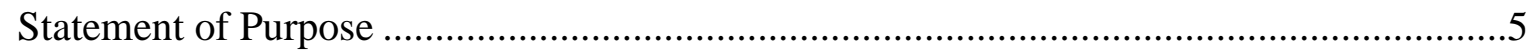

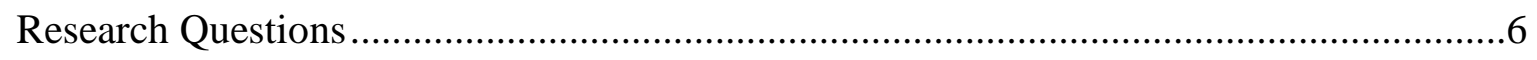

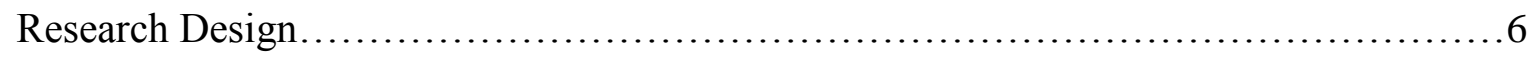

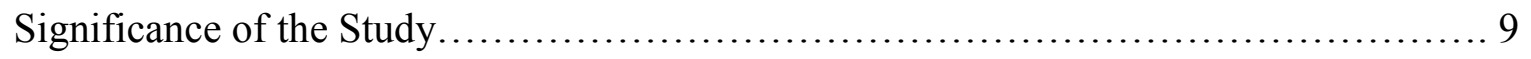

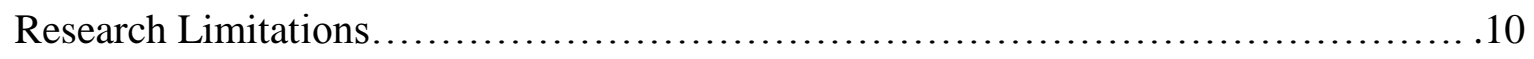

Use of Electronic Survey Program …………………...........................................10

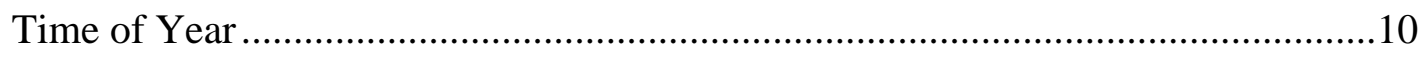

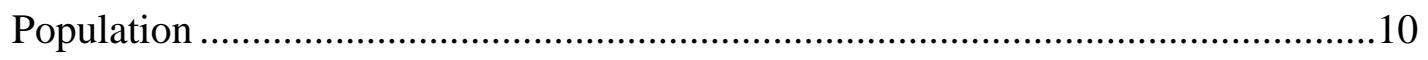

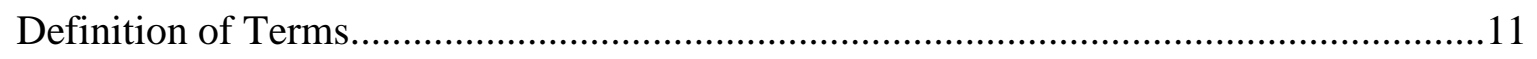

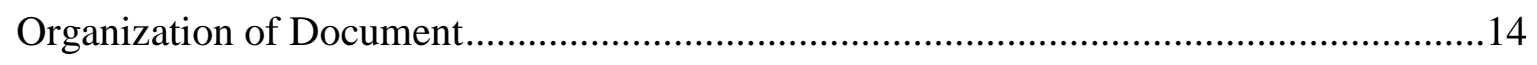

CHAPTER TWO: REVIEW OF RELATED LITERATURE.....................................................

Part One: Peer Tutoring in Higher Education..............................................................16

The History of Peer Tutoring ................................................................................16 


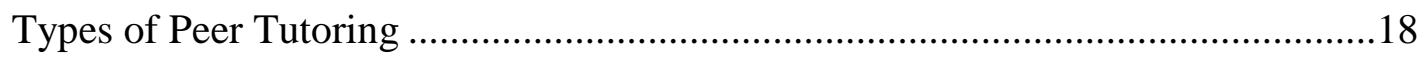

Reciprocal Peer Tutoring ..........................................................................

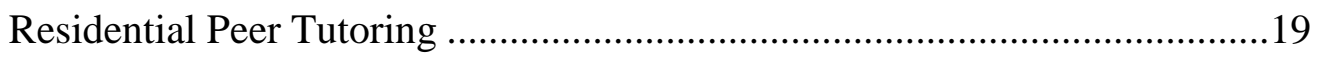

Learning Center-based Tutoring ..................................................................2

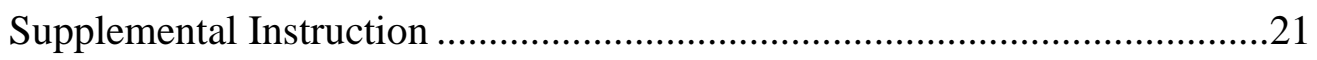

The Benefits of Peer Tutoring..........................................................................22

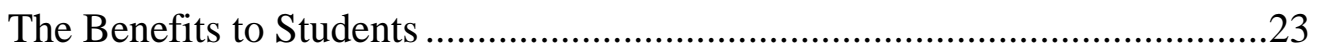

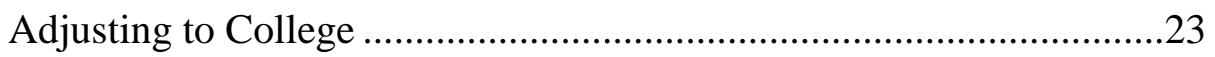

Providing Academic Support ..........................................................24

Providing Personal and Social Support...............................................25

Providing Psychological Support.........................................................26

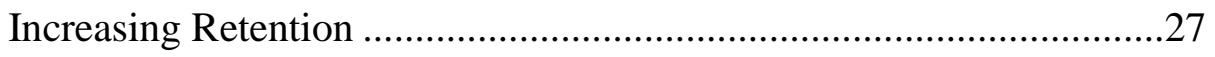

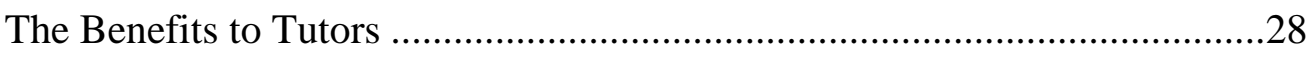

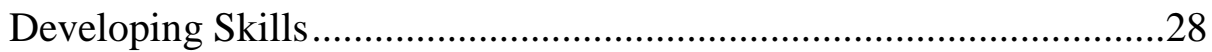

Providing Social and Psychological Support........................................29

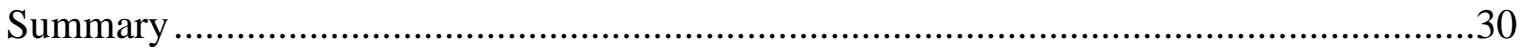

Part Two: Administrative Issues in Higher Education ....................................................32

Factors that Contribute to the Growth of Peer Tutoring ……....................................32

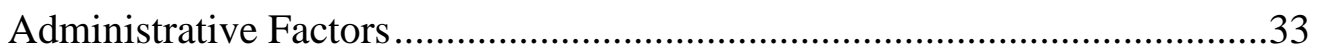

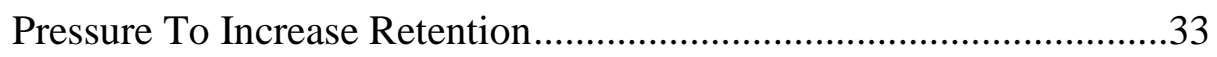

Difficulty To Transition from High School to College ..........................34

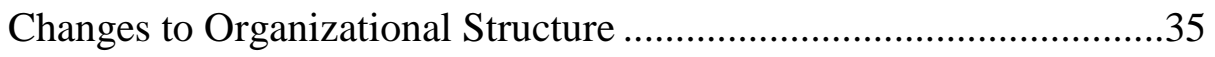

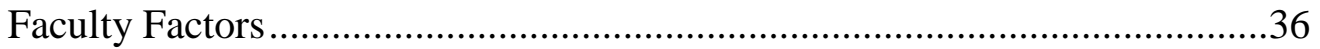




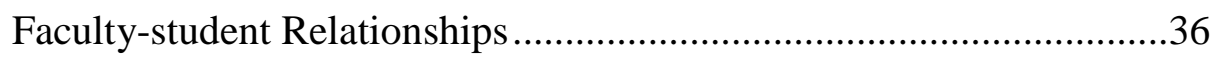

The Role of Faculty in Interactive Learning ...........................................37

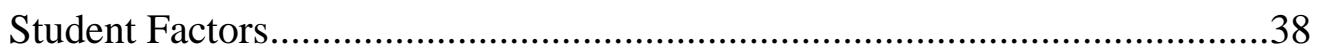

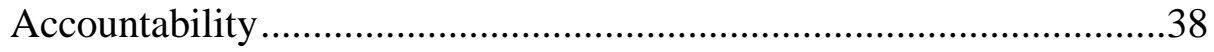

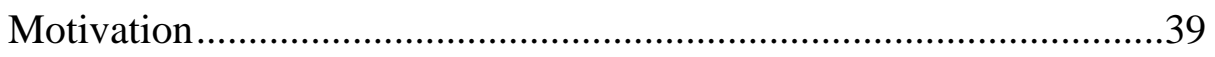

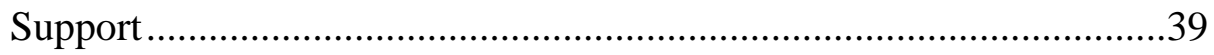

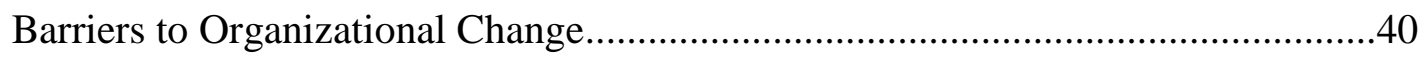

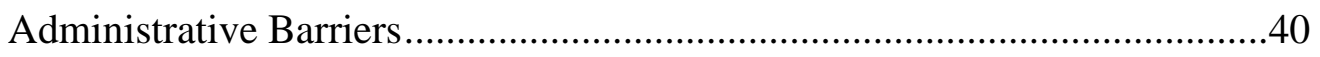

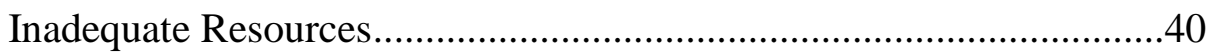

Issues of Coordination and Control .....................................................41

Accountability to University and/or Other Governing Agencies .........43

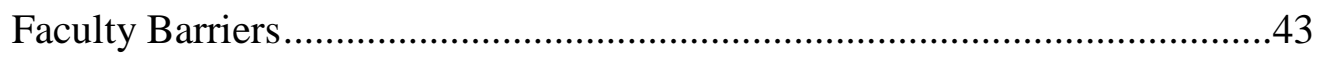

The Change of Faculty Roles................................................................44

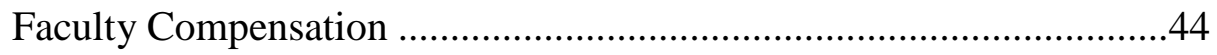

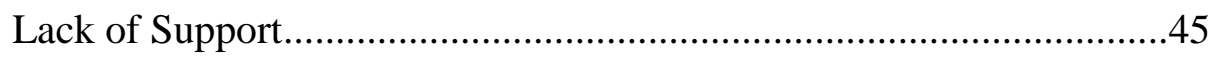

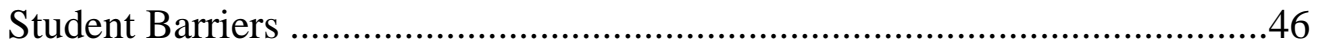

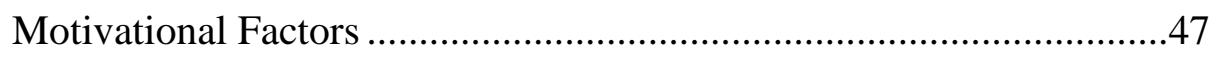

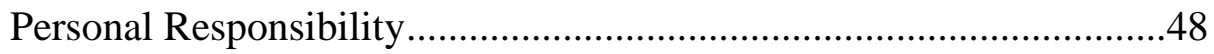

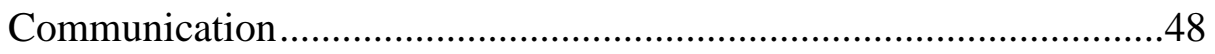

Factors that Institutionalize Programs in Higher Education ......................................49

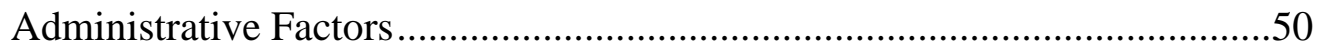

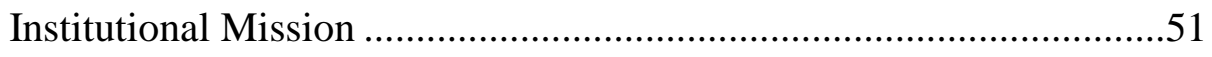

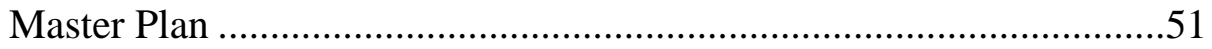


Policies and Procedures ................................................................51

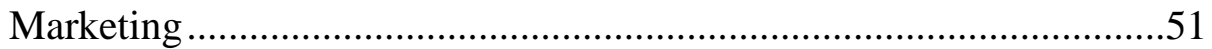

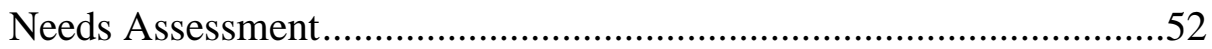

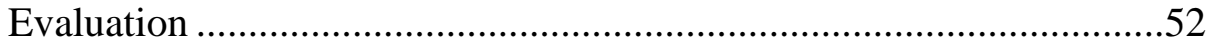

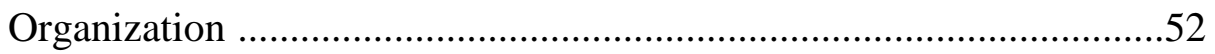

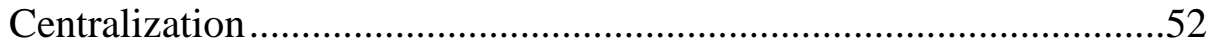

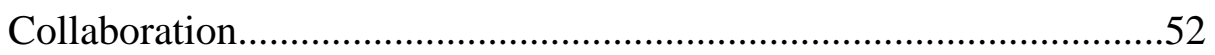

Leadership Authority .........................................................52

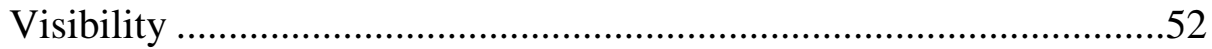

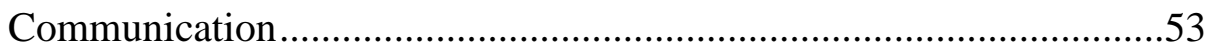

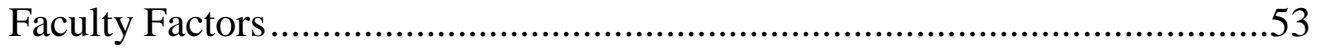

Program Design Support............................................................53

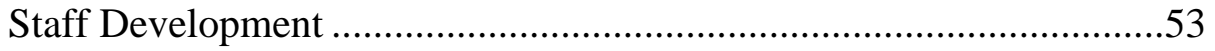

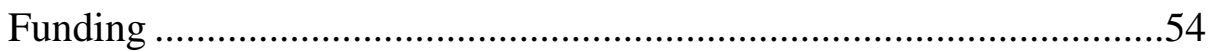

Faculty Participation .............................................................54

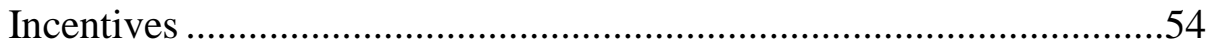

Student Factors............................................................................54

Library/Research Services ..........................................................55

Advising, Counseling, and Tutoring ..........................................55

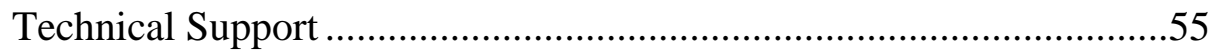

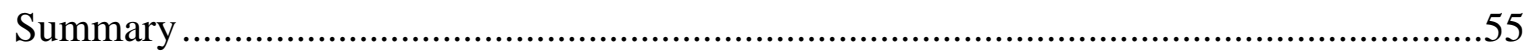

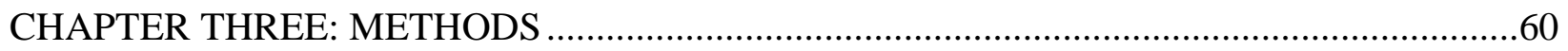

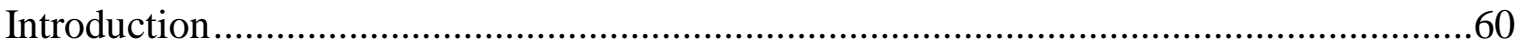




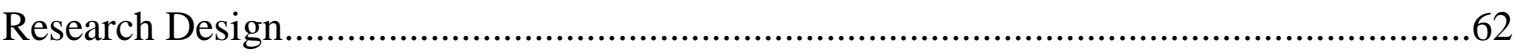

Sample

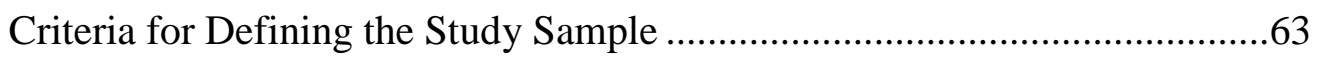

Carnegie Classification of Institutions of Higher Learning ...................64

Procedure for Selecting the Study Sample..............................................65

Review of Research Methods and Procedures.................................................................68

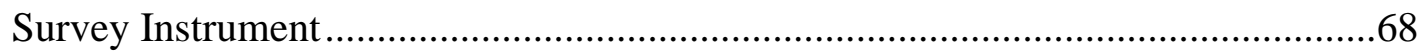

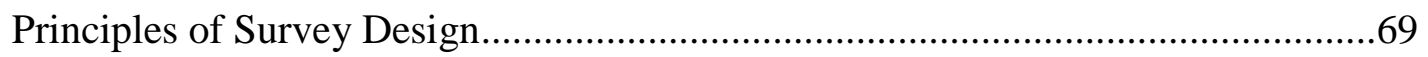

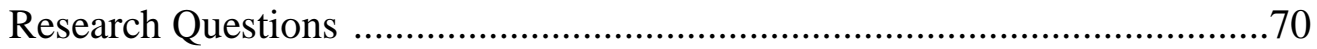

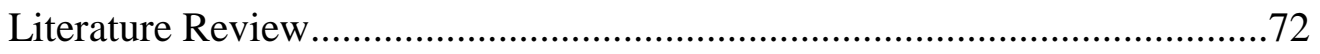

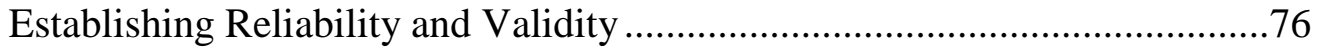

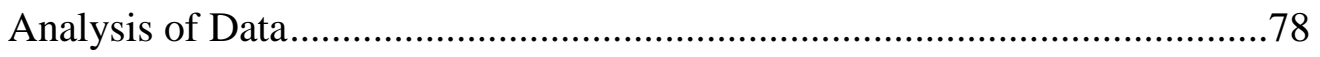

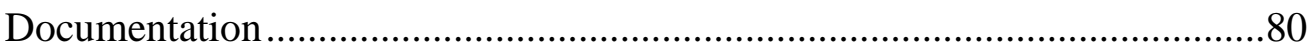

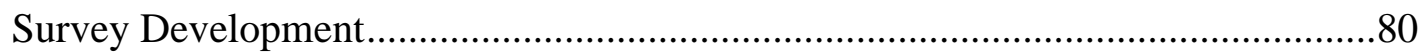

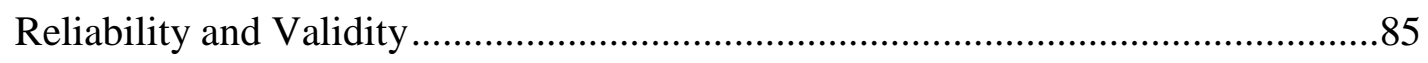

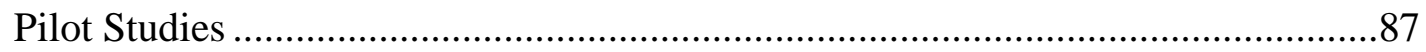

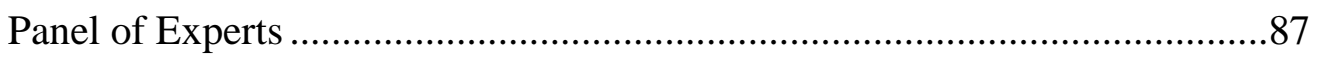

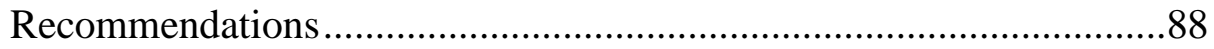

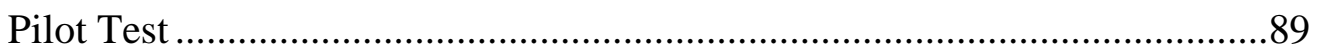

Data Dissemination and Collection ...................................................................93

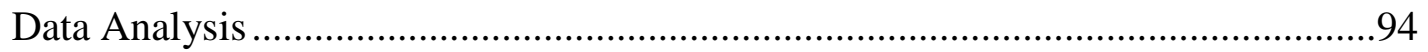

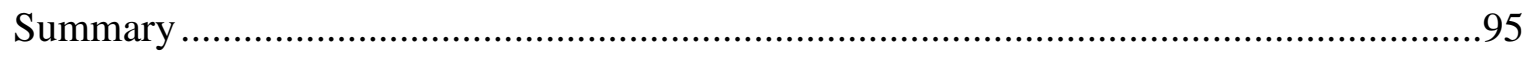

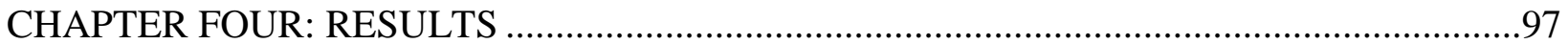




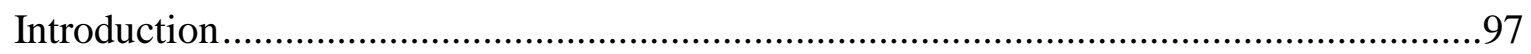

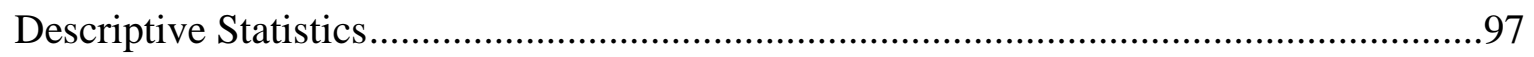

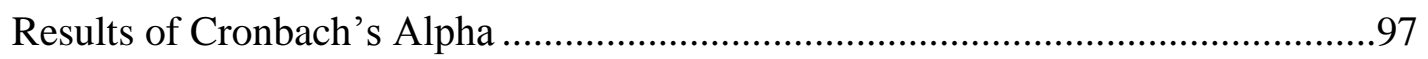

Descriptive Statistics for Demographic and Survey Items .....................................100

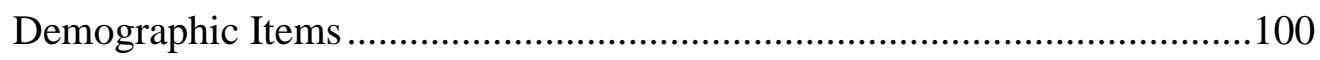

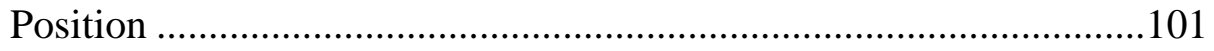

Involvement in Peer Tutoring .........................................................102

Location of Peer Tutoring Programs...................................................103

Supervision of Peer Tutoring ...........................................................104

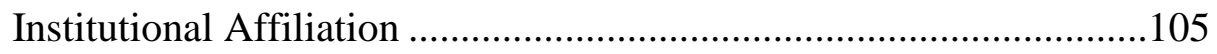

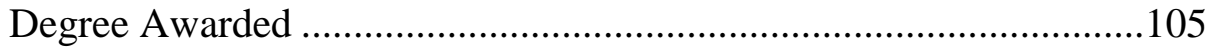

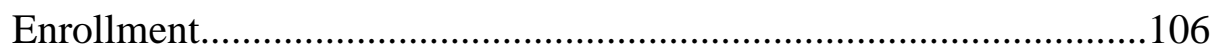

Carnegie Classification ....................................................................106

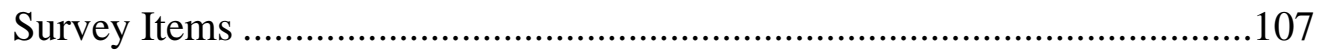

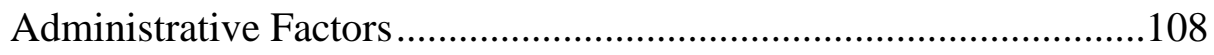

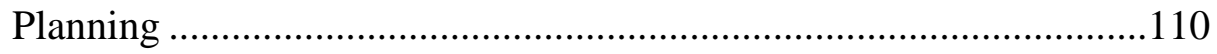

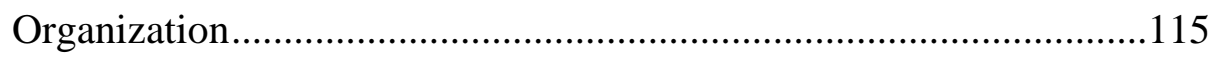

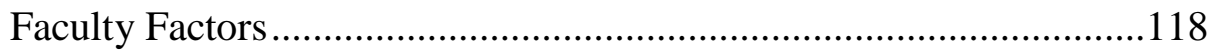

Demographic Responses of Other Groups..........................................128

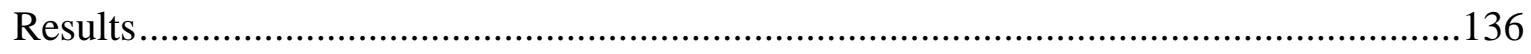

Data Analysis of Research Questions ..................................................................136

Research Question One ................................................................................137

Administrative Factors for Planning ............................................................139 


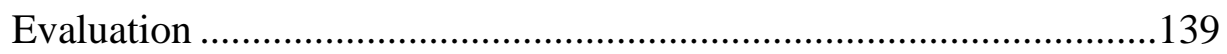

Needs Assessment - Students .......................................................139

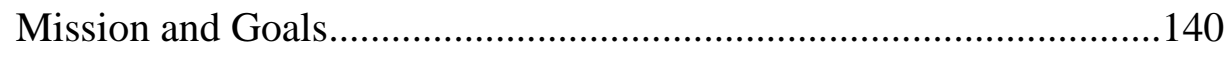

Policies and Procedures ..............................................................140

Needs Assessment - Institutional ..............................................140

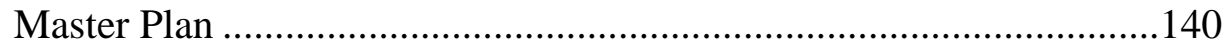

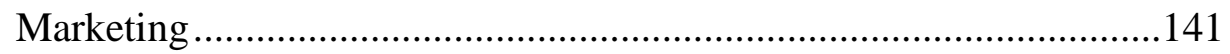

Needs Assessment - Faculty .................................................141

Administrative Factors for Organization ..............................................141

Centralization ...................................................................... 141

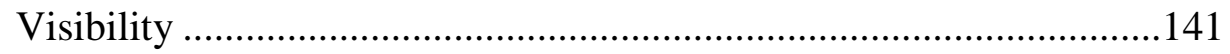

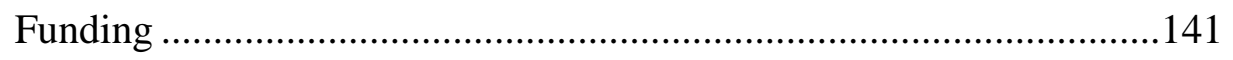

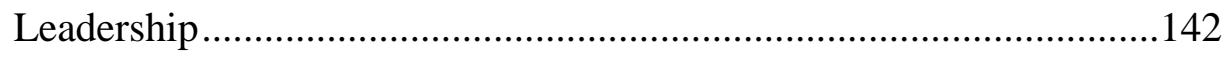

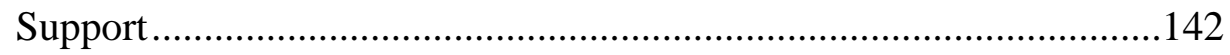

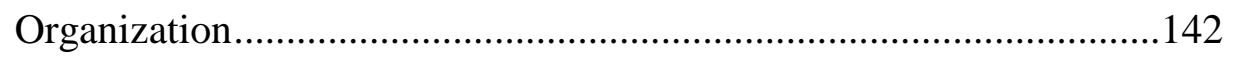

Faculty Factors for Administrator and Faculty Collaboration ....................142

Staff Development …..........................................................142

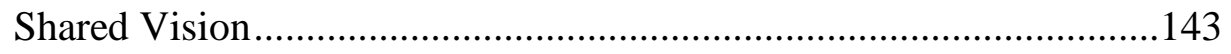

Collaboration - Plan Programs .................................................143

Collaboration - Implement Programs .........................................143

Collaboration - Access Program Effectiveness ...............................143

Faculty Factors for Faculty/Student Interaction ....................................144

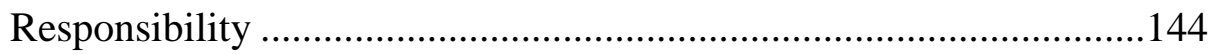


Communication - Encourage Student Engagement .144

Communication - Support Different Teaching Styles

Communication - Support Different Learning Styles

Research Question Two

Administrative Factors for Planning ....................................................147

Needs Assessment - Faculty .................................................147

Administrative Factors for Organization ..............................................147

Faculty Factors for Administrator and Faculty Collaboration ....................147

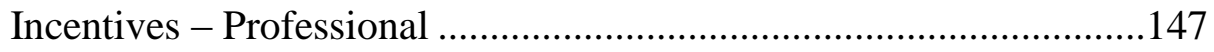

Incentives - Financial ...................................................... 147

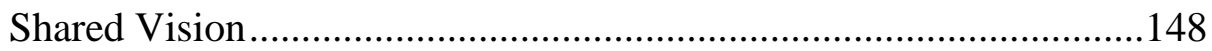

Collaboration - Decide Budget.................................................148

Collaboration - Plan Programs ...............................................148

Collaboration - Implement Programs .........................................148

Collaboration - Access Program Effectiveness ..............................149

Faculty Factors for Faculty/Student Interaction ....................................149

Communication - Support Different Learning Styles .....................149

Communication - Support Different Teaching Styles....................150

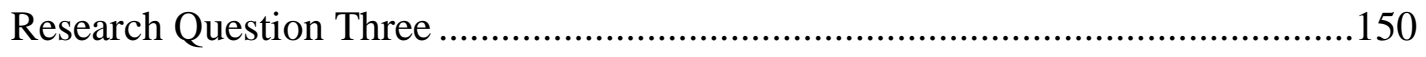

Differences in Perception of Administrative Factors...............................151

Factors that Facilitate Peer Tutoring - Department Affiliation ..........151

Factors that Facilitate Peer Tutoring - Enrollment.........................153

Factors that Facilitate Peer Tutoring - Highest Degree Awarded ......157 
Factors that Facilitate Peer Tutoring - Carnegie Classification .161

Factors that Form Barriers to Peer Tutoring - Department Affiliation.

Factors that Form Barriers to Peer Tutoring - Enrollment.....

Factors that Form Barriers to Peer Tutoring - Highest Degree

Awarded

Factors that Form Barriers to Peer Tutoring - Carnegie

Classification.

Differences in Perception of Faculty Factors.........................................182

Factors that Facilitate Peer Tutoring - Department Affiliation ..........182

Factors that Facilitate Peer Tutoring - Enrollment..........................185

Factors that Facilitate Peer Tutoring - Highest Degree Awarded ......189

Factors that Facilitate Peer Tutoring - Carnegie Classification .........193

Factors that Form Barriers to Peer Tutoring - Department

Affiliation....

Factors that Form Barriers to Peer Tutoring - Enrollment

Factors that Form Barriers to Peer Tutoring - Highest Degree

Awarded

Factors that Form Barriers to Peer Tutoring - Carnegie

Classification.

Findings.

Factors that Facilitate Peer Tutoring

Department Affiliation

Enrollment.

Highest Degree Awarded

Carnegie Classification 
Factors that Form Barriers to Peer Tutoring. .223

Department Affiliation .223

Enrollment

Highest Degree Awarded .225

Carnegie Classifications

Related Findings .233

Factors that Are Both Facilitators and Barriers to Peer Tutoring. .233

CHAPTER FIVE: CONCLUSION. .235

Summary .235

Demographic Findings . .237

Question One: What Is Your Position? .237

Question Two: How Are You Involved in Peer Tutoring at Your Institution? .238

Question Three: Where Does Peer Tutoring Occur at Your Institution?

Question Four: Which Unit Supervises Peer Tutoring at Your Institution? .238

Question Five: Is Your Institution Public or Private? .239

Question Six: What is the highest degree awarded by your institution?

Question Seven: What Is the Enrollment at Your Institution?

Question Eight: Which Carnegie Classification Best Describes Your Institution?

Findings and Conclusions .240

Research Question One. .240

Research Question Two .243 


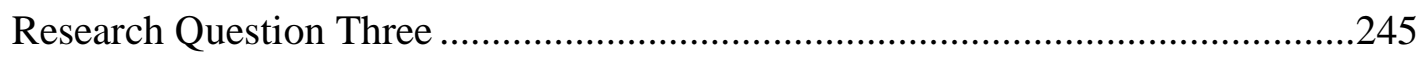

Differences in Perception of Factors that Facilitate Peer Tutoring................245

Differences in Perception of Factors that Form Barriers to Peer Tutoring

Discussion .261

Question One: Why Did Fewer Faculty Respond to This Study? .261

Time of Year .262

Faculty Roles and Department Allegiance ...............................................262

Lack of Support and Recognition ...........................................................263

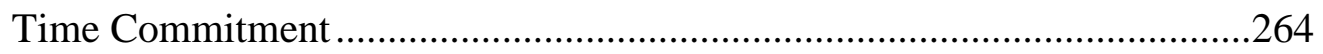

Question Two: Why Do Administrators Believe that Faculty Present Barriers to Peer Tutoring? .264

Faculty Roadblocks to Peer Tutoring ……………………………….......264

Question Three: How Can We Improve Peer Tutoring Based on the Results of this study? .265

Factors that Contribute to the Growth of Peer Tutoring ...............................265

Question Four: Can Peer Tutoring Programs Become Institutionalized?...............268

Question Five: What Makes for a Successful Peer Tutoring Program? .................269

Factors that Contribute to the Success of Peer Tutoring................................270

The Role of Peer Tutoring in Retention......................................................22

The Role of Faculty/Student Relationships in Retention.............................272

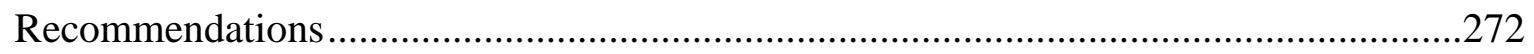

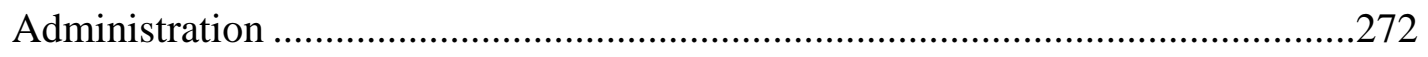

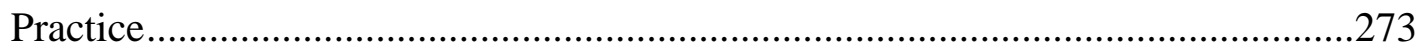

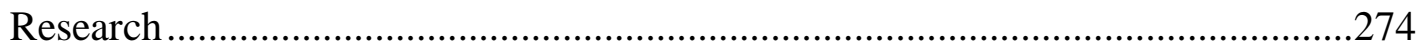


REFERENCES

APPENDICES

Appendix A: Sample Letter of Solicitation for Participation on Panel of Experts

Appendix B: Responses of Participants on Panel of Experts .298

Appendix C: Reviewer Directions for Panel of Experts ...........................................299

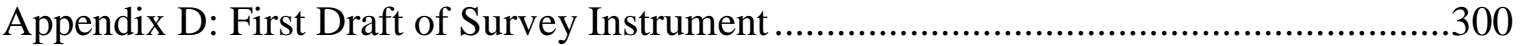




\section{LIST OF TABLES}

Table 1: Administrative. Faculty, and Student Factors that Contribute to the Institutionalization of Programs in Higher Education

Table 2: Carnegie Classifications of Institutions in NASPA and in Region II .67

Table 3: Relationship between Categories and Institutionalization Factors .83

Table 4: Pilot Study: Demographic Characteristics of Survey Respondents. .91

Table 5: Participant Response Rate . .98

Table 6: Cronbach's Alpha for Reliability of Importance Factors and Difficulty Factors .100

Table 7: Question One: What Is Your Position? .101

Table 8: Question Two: How Are You Involved in Peer Tutoring on Your Campus? 102

Table 9: Question Three: Which Peer Tutoring Programs Occur at Your Institution? 103

Table 10: Question Four: Which Unit Supervises Peer Tutoring at Your Institution? 104

Table 11: Question Five: Is Your Institution Public or Private?

Table 12: Question Six: What Is the Highest Degree Awarded by Your Institution? 105

Table 13: Question Seven: What Is the Enrollment at Your Institution? 106

Table 14: Which Carnegie Classification Best Describes Your Institution? 107

Table 15: Administrative Factors and Corresponding Survey Items

Table 16: Mean Scores for Importance of the Administrative Factors for Planning. .111

Table 17: Mean Scores for Difficulty in Implementation of the Administrative Factors for Planning

Table 18: Mean Scores for Importance of the Administrative Factors for Organization 115

Table 19: Mean Scores for Difficulty in Implementation of the Administrative Factors for Organization

Table 20: Faculty Factors and Corresponding Survey Items

Table 21: Mean Scores for Importance of Faculty Factors 
Table 22: Mean Scores for Difficulty in Implementation of Faculty Factors

Table 23: Comparison of Mean Scores for Importance of the Administrative Factors for Planning

Table 24: Comparison of Mean Scores for Difficulty in Implementation of the Administrative Factors for Planning

Table 25: Comparison of Mean Scores for Importance of the Administrative Factors for Organization......

Table 26: Comparison of Mean Scores for Difficulty of Implementation of the Administrative Factors for Organization

Table 27: Comparison of Mean Scores for Importance of Faculty Factors.

Table 28: Comparison of Mean Scores for Difficulty in Implementation of Faculty Factors.....135

Table 29: Mean Scores and Ranking of Administrative and Faculty Factors that Facilitate Peer Tutoring Programs in Region II NASPA Institutions.

Table 30: Mean Scores and Ranking of Administrative and Faculty Factors that Form Barriers to Peer Tutoring Programs in Region II NASPA Institutions....

Table 31: Mean Scores for Differences in Perception of Administrative Factors that Facilitate Peer Tutoring Based on Department Affiliation

Table 32: Mean Scores for Differences in Perception of Administrative Factors that Facilitate Peer Tutoring Based on Enrollment

Table 33: Mean Scores for Differences in Perception of Administrative Factors that Facilitate Peer Tutoring Based on Highest Degree Awarded

Table 34: Mean Scores for Differences in Perception of Administrative Factors that Facilitate Peer Tutoring Based on Carnegie Classification

Table 35: Mean Scores for Differences in Perception of Administrative Factors that Form Barriers to Peer Tutoring Based on Department Affiliation .

Table 36: Mean Scores for Differences in Perception of Administrative Factors that Form Barriers to Peer Tutoring Based on Enrollment

Table 37: Mean Scores for Differences in Perception of Administrative Factors that Form Barriers to Peer Tutoring Based on Highest Degree Awarded .175 
Table 38: Mean Scores for Differences in Perception of Administrative Factors that Form Barriers to Peer Tutoring Based on Carnegie Classification

Table 39: Mean Scores for Differences in Perception of Faculty Factors that Facilitate Peer Tutoring Based on Department Affiliation.

Table 40: Mean Scores for Differences in Perception of Faculty Factors that Facilitate Peer Tutoring Based on Enrollment.

Table 41: Mean Scores for Differences in Perception of Faculty Factors that Facilitate Peer Tutoring Based on Highest Degree Awarded

Table 42: Mean Scores for Differences in Perception of Faculty Factors that Facilitate Peer Tutoring Based on Carnegie Classification

Table 43: Mean Scores for Differences in Perception of Faculty Factors that Form Barriers to Peer Tutoring Based on Department Affiliation

Table 44: Mean Scores for Differences in Perception of Faculty Factors that Form Barriers to Peer Tutoring Based on Enrollment

Table 45: Mean Scores for Differences in Perception of Faculty Factors that Form Barriers to Peer Tutoring Based on Highest Degree Awarded .205

Table 46: Mean Scores for Differences in Perception of Faculty Factors that Form Barriers to Peer Tutoring Based on Carnegie Classification .208

Table 47: One-way ANOVA for Differences in Perception of Administrative Factors that Facilitate Peer Tutoring Based on Department Affiliation

Table 48: Bonferroni Correction for Differences in Perception of Administrative Factors that Facilitate Peer Tutoring Based on Department Affiliation

Table 49: One-way ANOVA for Differences in Perception of Administrative Factors that Facilitate Peer Tutoring Based on Enrollment.

Table 50: Bonferroni Correction for Differences in Perception of Administrative Factors that Facilitate Peer Tutoring Based on Enrollment.

Table 51: One-way ANOVA for Differences in Perception of Administrative Factors that Facilitate Peer Tutoring Based on Highest Degree Awarded .216

Table 52: Bonferroni Correction for Differences in Perception of Administrative Factors that Facilitate Peer Tutoring Based on Highest Degree Awarded 
Table 53: One-way ANOVA for Differences in Perception of Administrative Factors that Facilitate Peer Tutoring Based on Carnegie Classification .218

Table 54: Bonferroni Correction for Differences in Perception of Administrative Factors that Facilitate Peer Tutoring Based on Carnegie Classification

Table 55: One-way ANOVA for Differences in Perception of Administrative Factors that Form Barriers to Peer Tutoring Based on Department Affiliation

Table 56: Bonferroni Correction for Differences in Perception of Administrative Factors that Form Barriers to Peer Tutoring Based on Department Affiliation

Table 57: One-way ANOVA for Differences in Perception of Administrative Factors that Form Barriers to Peer Tutoring Based on Enrollment

Table 58: Bonferroni Correction for Differences in Perception of Administrative Factors that Form Barriers to Peer Tutoring Based on Enrollment.........................225

Table 59: One-way ANOVA for Differences in Perception of Administrative Factors that Form Barriers to Peer Tutoring Based on Highest Degree Awarded .226

Table 60: Bonferroni Correction for Differences in Perception of Administrative Factors that Form Barriers to Peer Tutoring Based on Highest Degree Awarded

Table 61: One-way ANOVA for Differences in Perception of Administrative Factors that Form Barriers to Peer Tutoring Based on Carnegie Classification. .228

Table 62: Bonferroni Correction for Differences in Perception of Administrative Factors that Form Barriers to Peer Tutoring Based on Carnegie Classification.

Table 63: Mean Scores for Faculty and Administrative Factors that Facilitate and Form Barriers to Peer Tutoring Programs in Region II NASPA Institutions.

Table 64: Factors that Facilitate Peer Tutoring Programs in Region II NASPA Institutions ......241

Table 65: Factors that Form Barriers to Peer Tutoring Programs in Region II NASPA Institutions

Table 66: Differences in the Perception of Factors that Facilitate Peer Tutoring Based on ANOVA .246

Table 67: Differences in the Perception of Factors that Facilitate Peer Tutoring Based on the Bonferroni Correction

Table 68: Differences in Perception of Factors that Form Barriers to Peer Tutoring Based on ANOVA..... 
Table 69: Differences in Perception of Factors that Form Barriers to Peer Tutoring Based

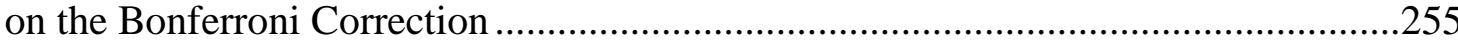




\section{Chapter One}

\section{Introduction}

Peer tutoring has played an important role in education and scholars have long considered tutoring an effective means of supplementing instruction (Dabkowski, 2000; Shumow, Farlowe, \& Bray, 2002). Peer tutoring is defined as a system in which learners help each other and learn by teaching (Mynard \& Almarzouqi, 2006). Peer tutoring involves more advanced learners, who already have the knowledge and skills, helping less advanced learners, who have not yet acquired them (Saunders, 1992; Topping, 1996).The main role of peer tutors is to facilitate learning by helping students to understand and apply information (Moust \& Schmidt, 1995).

Factors that influence a student's decision to participate in peer tutoring programs include a) motivation to learn (Cohen, Kulik, \& Kulik, 1982; Lau, 2003; Luca \& Clarkson, 2002; Schramm, Brown, \& Street, 2009; Tinto, Goodsell, \& Russo, 1993), b) self-confidence (Hendriksen, Yang, Love, \& Hall, 2005; Loos, Menzel, \& Poparad, 2004), c) perceived readiness of meeting the academic challenges of college (Topping, 1996), and d) the interaction of peers (Mynard \& Almarzouqi, 2006). Peer tutoring connects learning experiences and forms a bridge between student life and academics (Tinto, 1997).

Peer tutoring began with an idea from Andrew Bell, school superintendent at the Egmore Military Male Asylum in Madras, India from 1789-1796, who saw older students on the beach teaching younger students to write by tracing letters in the sand. Bell's method of teaching, called the Madras Experiment, involved older students who had mastered concepts teaching the concepts to younger students (Bowyer-Bower, 1954). Bell's idea has become a common practice in higher education and findings of his early studies on peer tutoring parallel the findings of today (Goodlad, 1998): a) tutoring enabled students to keep up with their classes, b) tutoring 
established good habits in both the tutor and student, and c) both tutors and students went on to become good students and achieve success.

William Bentley Fowle opened the first school in America based on the Madras system of education in 1851. Fowle conducted studies on his students and wrote down his observations from the time the school opened until its closing in 1860. Fowle's observations are consistent with current data on peer tutoring (Dabkowski, 2000): a) peer tutoring pairs students with a peer who has gone through, or is going through, the same thing they are experiencing and can tell them what to expect, b) peer tutoring enables students to keep up with their classes by helping them understand and apply information, c) tutors who are close in age to the students relate better with the students than teachers, d) students feel more comfortable working with the tutors than teachers as teachers make the students afraid of failing, which hinders their work, and f) students who teach students do better academically.

As the population in higher education has increased and the large size of freshman classes has resulted in less interaction between professors and students, the need for peer tutoring has also increased (Tovar \& Simon, 2003). By the 1980s student retention became an issue, intensifying the need for more student support (Lau, 2003), and peer tutoring became an important factor in student retention (Fantuzzo, Riggio, Connelly, \& Dimeff, 1989; Goldschmid \& Goldschmid, 1976; Good, Halpin, \& Halpin, 2000; Tinto, 2002; Topping, 1996). Peer tutoring has been used in higher education to assist students in making the adjustment from high school to college (Good et al., 2000; Leung \& Bush, 2003; Mynard \& Almarzouqi, 2006), as a motivator to improve students' work (Bruffee, 1980), and as a retention strategy in undergraduate education (Leung \& Bush, 2003; Tovar \& Simon, 2003). 
Pressure from college presidents to increase retention and grade point averages (GPAs) has caused retention in higher education to become one of the most significant issues that college administrators must deal with in today's competitive market (Lau, 2003; Leone \& Tian, 2009) and has called for an increase in student support services (Pina, 2008a). "In fact retaining a student is fundamental to the ability of an institution to carry out its mission. A high rate of attrition is not only a fiscal problem for schools, but a symbolic failure of an institution to achieve its purpose" (Leone \& Tian, 2009, p. 122).

According to Act, Inc. (2010a), a research group that has compiled a comprehensive database of first-year to second-year retention rates since 1983, retention rates increased by only one per cent for the 2008-9 academic year with 67 percent of first-year college students returning to the same institution for their second year of college. However, retention rates varied among different institutional types and between public and private institutions. Act, Inc. (2010a) reported that retention rates are higher for four-year colleges (68 percent, down three percent from the previous year) than two-year colleges (57 percent, up three percent from the previous year) and slightly higher for private institutions. The highest retention rates were reported by research institutions with doctoral programs (79 percent).

Research shows that retention improves when students are given assistance (University Leadership Council, 2009) and "the retention and engagement of students can be directly attributed to the level of involvement both inside and outside of the classroom" (MGT of America, Inc., 2009, p. 2-1). There is currently much interest in not only access to higher education, but also student success (Thomas, 2002). Declining student enrollment, decreased state and federal funding, and competition for students with other institutions, paired with increased pressure on college presidents from parents, students, and faculty to provide programs 
to ensure academic success, has lead to an increase in student support services, such as peer tutoring (Leone \& Tian, 2009).

Lau (2003) reported that one of the main reasons students leave an institution is that the institution has not provided programs that meet the students' learning and educational needs. Therefore, if institutions want to increase retention, one of the most important roles of higher education administrators is to ensure student success by providing academic support programs to meet students' learning and educational needs. "Higher education administrators must help students adjust to their new living and learning environments, and ensure that the institution is accommodating to the student's...learning styles" and "services are readily available to students" (Lau, 2003, p. 128). Furthermore, an effort must be made to make sure that these programs endure (Tinto, 2006-7).

This chapter is divided into six sections. Section one, Research Justification, identifies the objectives of the research and explains why the research is important; section two, Statement of Purpose, defines the purpose of the study; section three, Research Questions, discusses the research questions; section four, Research Design, describes the research methodology used in this study; section five, Definition of Terms, discusses the terminology used in this study; and section six, Organization of Document, addresses the organization of the study.

\section{Research Justification}

Although there has been considerable research on peer tutoring in higher education, there is a gap in the literature on institutional policies and practices that lead to the institutionalization of peer tutoring programs (Tinto, 2006-7). Experts agree that

...we need research that sheds light on the types of programs and institutional practices

that lead to successful implementation of programs and do so in ways that ensure 
that they endure over time. Equally important, we need to know more about how it is that some programs are able to endure at the center of institutional life and become institutionalized, while others remain isolated at the margins of that life. (Tinto, 2006-7. p. 10)

Institutionalization in higher education occurs when an idea or program that has been implemented becomes part of an ongoing practice (Pina, 2008a). When a program becomes institutionalized "it is no longer considered to be an innovation-it is now looked upon as a normal and vital part of the organization" (Pina, 2008a, p. 428). In order to determine what institutions of higher education can do to establish, implement, and maintain high quality programs, it is necessary to identify factors that influence their institutionalization (Pina, 2008b).

\section{Statement of Purpose}

The purpose of this study was to identify:

a) institutional factors that administrators and faculty see as facilitating peer tutoring programs.

b) institutional factors that administrators and faculty see as forming barriers to peer tutoring programs.

c) differences in perceptions of peer tutoring between administrators and faculty.

However, there was a low response rate of faculty, which resulted in nonresponse error and made the faculty data unusable. Sivo, Saunders, Chang, and Jiang (2006) reported that nonresponse error occurs when the number of respondents from a targeted population that respond differs substantially from those who did not respond, making it difficult to make generalizations from the sample about the entire population. Therefore, just administrative data was reported and faculty data was used for demographic and descriptive purposes only. 


\section{Research Questions}

This study addressed the following research questions:

a) What institutional factors facilitate peer tutoring programs in Region II NASPA institutions, according to administrators who are members of Region II?

b) What institutional factors are barriers to peer tutoring programs in Region II NASPA institutions, according to administrators who are members of Region II?

c) What are the differences in perceptions of peer tutoring among administrators based on the following demographics: department affiliation (e.g. Academic Affairs, Student Affairs), enrollment, highest degree offered, and Carnegie classification?

\section{Research Design}

The objective of this study was threefold: a) to identify administrative factors that facilitate peer tutoring programs, b) to identify administrative factors that form barriers to peer tutoring programs, and c) to identify the differences in perceptions of peer tutoring among administrators based on the following demographics: department affiliation (e.g. Academic Affairs, Student Affairs), enrollment, highest degree offered, and Carnegie classification?

This study was based on the research of Anthony Pina (2005, 2008a, 2008b). Pina studied actions that influence the institutionalization of distance learning in higher education. The purpose of his study was to determine actions that institutions can take to institutionalize programs. Pina identified 30 factors from a literature review of a) educational technology, b) distance learning, and c) educational change that influence the institutionalization of programs in higher education. Although there is no relationship between distance learning and peer tutoring programs, factors affecting the institutionalization of any program in higher education 
could be related to peer tutoring. These factors were later confirmed by the panel of experts as relevant to peer tutoring.

Quantitative research was chosen for this study for the following reasons:

- "The primary aim of quantitative research is to collect, count, measure, and assess the meaning behind specific variables - and ultimately, devise statistical explanations for what the researchers have learned" (Kelton Research, 2008, para. 3).

- Quantitative research offers accurate measurement and analysis (Jenkins, 2009).

- In quantitative research, the problem is defined (Suskie, 1996).

- Results are statistically reliable and are projectable to the population (McCullough, n.d.).

- Quantitative research creates meaning through collected data and "can be used in response to relational questions of variables within the research" (Williams, 2007, p. 65). On completion of the literature review, 26 factors were identified that a) facilitate peer tutoring or b) present barriers to peer tutoring. A questionnaire was developed using a 4-point Likert scale to determine a) the importance of each factor to facilitating peer tutoring programs and b) the difficulty in implementation of each factor. Data was collected via a web-based questionnaire from administrators and faculty members of Region II NASPA institutions (the National Association of Student Personnel Administrators) who have an interest in and knowledge about academic tutoring programs, and who are involved in their supervision, evaluation, and delivery of services. A panel of experts established validity of the survey instrument. Reliability of the survey instrument was established by Cronbach alpha and a pilot study. Mean scores, standard deviations, and item ranking of institutionalization factors were calculated for each of the 26 factors for a) importance to peer tutoring and b) difficulty of implementation. The study looked at the differences between responses of administrators based 
on the following demographic data: a) departmental affiliation, b) enrollment, c) highest degree awarded, and d) Carnegie classification. These demographics were selected as they represent the categories around which the Carnegie classifications are organized: a) what is taught (degrees awarded and program classifications), b) who are the students (enrollment), and c) function of faculty and staff (department affiliation). A response rate of $20 \%$ was expected. Although the initial response rate was 23 percent, most of the surveys returned by faculty were not completed and, therefore, unusable. This brought the response rate of useable surveys to 9 percent, which is comparable to similar studies using a population of administrators and faculty who are members of an organization such as NASPA (Kezar, 2003; Pina, 2005).

A research schedule included the following:

Stage 1: Dissertation prospectus was submitted to the dissertation committee for approval in April 2011 and successfully defended in May 2011.

Stage 2: Once the prospectus was successfully defended, approval to conduct the study was solicited from the West Virginia University Institutional Rev1ew Board for the Protection of Human Subjects (IRB). Approval to proceed with the study was received in May 2011.

Stage 3: In May 2011, the survey was sent to a panel of experts for review.

Stage 4: Minor adjustments were made to the survey instrument based on the recommendations of the panel of experts and a pilot study was conducted in June 2011.

Stage 5: Potential respondents were sent an email in June 2011, with an invitation to participate in the survey, along with an offer to receive survey results. The Information included the website address of the online survey form, a statement 
of confidentiality, and instructions on how to receive a printed copy of the survey results.

Stage 6: A reminder email was sent out six weeks after the first email to those who had not yet responded.

Stage 7: Data was collected during Summer 2011.

Stage 8: After two months, the survey was closed and data analysis began in September 2011.

\section{Significance of the Study}

The results of this study present new research on peer tutoring and provide guidance that may be used by administrators and faculty to a) evaluate existing peer tutoring programs to determine strengths, weaknesses, and areas for improvement; b) establish priorities in developing new peer tutoring programs; and c) develop strategies that will lead to the improvement and institutionalization of peer tutoring.

Second, the findings of this study have positive implications for institutions wishing to institutionalize peer tutoring and identify key factors that support the endurance of peer tutoring programs: a) collaboration between administrators and faculty on planning, implementation, and assessment of peer tutoring; b) communication between faculty and students to encourage student engagement and support different teaching and learning styles; c) centralization of the supervision and evaluation of peer tutoring; d) ongoing staff development; and e) permanent funding for peer tutoring.

Third, the institutionalization factors identified in this study provide a model for cooperation between those who oversee the supervision, evaluation, and assessment of peer 
tutoring (administrators) and those who oversee the day-to-day operations of peer tutoring (faculty).

\section{Research Limitations}

Several factors that may have affected the results of this study include a) the use of an electronic survey program, b) the time of year the research was conducted, and c) the population.

Use of electronic survey program. The survey was sent via email through a program in SurveyMonkey, which included the following options: selection of a) survey recipients, b) date to send survey, c) date to resend survey to those who did not respond, and d) date to close survey. The survey was scheduled to be sent in June 2011, with a resend date of two weeks later. However, due to technical difficulty, the survey was not sent out to those who had not responded and the discovery made in August, shortly before the survey was to close. Therefore, the second mailing of the survey occurred six weeks after the first mailing, and the survey was closed three weeks later. The use of SurveyMonkey and the time lapse between mailings may have affected the percentage of participation.

Time of year. The survey was conducted during Summer 2011. The time of year the survey was conducted may have affected the results of this study, as many faculty may have been away from campus.

Population. The population may have also affected results of this study. The total population consisted of 2,159 administrators and faculty, who were members of Region II in the National Association of Student Personnel Administrators (NASPA), and who may not be representative of the entire population of administrators and faculty. 


\section{Definition of Terms}

Academic support: Academic support provides "the prerequisite learning and thinking skills that are basic to content mastery" (Blanc, DeBuhr, \& Martin, 1983, p. 82). These services include a) reciprocal peer tutoring, b) residential peer tutoring, c) learning center-based tutoring, and d) supplemental instruction.

Carnegie Classification: The Carnegie Classification of Institutions of Higher Education includes all colleges and universities in the United States that are degree-granting and accredited by an agency recognized by the U.S. Secretary of Education and identifies similarities and differences among institutions. Developed in 1970 and most recently updated in 2010, the Carnegie Classification has "been widely used in the study of higher education, both as a way to represent and control for institutional differences, and also in the design of research studies to ensure adequate representation of sampled institutions, students, or faculty ("About the Carnegie Classifications,” n.d., para. 1). “...They are organized around three fundamental questions: what is taught (Instructional Program classifications), who are the students (Enrollment Profile), and what is the setting (Size \& Setting)" ("About the Carnegie Classifications," n.d., para. 2).

Institutionalization: Institutionalization in higher education occurs when an idea that has been implemented becomes part of an ongoing practice (Pina, 2008a). When a program becomes institutionalized "it is no longer considered to be an innovation - it is now looked upon as a normal and vital part of the organization" (Pina, 2008a, p. 428).

Learning center-based tutoring: Learning centers, also called academic resource centers, provide students with additional academic support to help them become independent thinkers and more efficient learners (“Learning Center/Academic Resources," 2010). The difference between learning center-based tutoring and other types of tutoring is that academic learning 
centers offer "one-stop shopping" for tutoring with free academic review sessions, drop-in peer tutoring sessions, and workshops in academic disciplines, as well as writing and computer skills. NASPA: NASPA (National Association of Student Personnel Administrators) serves as a voice for student affairs administration, policy, and practice and its membership is comprised of approximately 1400 institutions with more than 11,000 student affairs administrators and faculty representing a large range of two-year and four-year institutions in seven regions, including the United States, Canada, and Europe (“About Us,” n.d.). NASPA is led by volunteers from member institutions who are elected as regional and national officers. NASPA's mission is to provide professional development and advocacy for student affairs educators and administrators who share the responsibility for a campus-wide focus on the student experience. NASPA's vision is to educate the whole student and integrate student life and learning ("Goals," n.d.).

NASPA Region II: NASPA Region II includes 233 institutions with 2176 members in six states (Delaware, Maryland, New Jersey, New York, Pennsylvania, and West Virginia) plus the District of Columbia and the Virgin Islands. West Virginia University is a member of Region II.

Peer tutoring: Peer tutoring is defined as a system in which learners help each other and learn by teaching (Mynard \& Almarzouqi, 2006). It involves more advanced learners, who already have the knowledge and skills, helping less advanced learners, who have not yet acquired them (Saunders, 1992; Topping, 1996). The main role of peer tutoring is to facilitate learning by helping students to understand and apply information (Moust \& Schmidt, 1995).

Reciprocal peer tutoring: Reciprocal peer tutors are students of similar class standing who exchange roles with the students they teach (Fantuzzo et al., 1989). What differentiates reciprocal peer tutoring different from other types of tutoring is that a relationship is established between two students who share work and learn to trust each other; tasks are accomplished 
because there is a mutual effort that promotes a sense of community among tutors and students (Hawkins, 1980).

Residential peer tutoring: Residential peer tutors are students who live in the residence halls where they tutor and are committed to helping other students in their halls succeed academically and socially. The difference between residential peer tutoring and other academic support programs is that in residential peer tutoring, the service is brought to the student, as opposed to the student having to seek the service, creating an environment that encourages student participation, promotes collaborative learning, and helps students to become independent and active learners (Pariser, 2007).

Study population: The population for this study included administrators and faculty in the National Association of Student Personnel Administrators (NASPA) Region II, who are interested in and have knowledge about academic tutoring programs, and who are involved in their supervision, evaluation, and delivery of services.

Student accountability: With the "move toward student-centered learning and academic self-regulation, the responsibility for learning is shifting from teacher to student" (Xu, Hartman, Uribe, \& Mencke, 2001, para. 4). “As universities have cut back on overall staff numbers..., students have stepped into the breach to provide various functions previously funded by universities" (Pendleton, 2005, p. 8).

Supplemental instruction: Supplemental Instruction (SI) is an academic support program that targets traditionally difficult courses to improve student performance and provides shared, connected learning experiences by grouping students together in the classroom by academic discipline, and outside the classroom, in course related peer tutoring or study groups. The difference between SI and other peer tutoring programs is that in SI, students are part of a 
learning community that is connected by a theme, which gives meaning to their connection; and in study groups and tutoring together, which provides out-of-class experiences and gives tutoring a social connection to academics (Tinto, 1998b).

\section{Organization of Document}

This study is divided into five chapters. Chapter One, Introduction, addresses the background of the research problem and includes the following sections: section one, Research Justification, identifies the objectives of the research and explains why the research is important; section two, Statement of Purpose, defines the purpose of the study; section three, Research Questions, discusses the research questions; section four, Research Design, describes the research methodology used in this study; section five, Definition of Terms, discusses the terminology used in this study; and section six, Organization of Document, addresses the organization of the study.

Chapter Two, Review of Related Literature, gives a summary of related literature is divided into two sections. Section one, Peer Tutoring in Higher Education, addresses a) the history of peer tutoring, b) types of peer tutoring, and c) the benefits of peer tutoring. Section two, Administrative Issues in Higher Education, includes a) factors that contribute to the growth of peer tutoring, b) barriers to organizational change, and c) factors that institutionalize programs in higher education. The purpose of this chapter is to establish a) how this study developed from prior research, b) how it fills a gap in the existing literature, and c) why it is important.

Chapter Three, Methods, addresses the proposed procedures and research methodology used in this study and is divided into two sections. Section one, Research Design, includes a) the study population, b) criteria for defining the study sample, and c) the procedure for selecting the study sample. Section two, Review of Research Methods and Research Procedures, addresses a) 
the survey instrument, b) principles of survey design, c) survey development, d) reliability and validity, e) pilot studies, f) data dissemination and collection, and g) data analysis.

Chapter 4, Results, discusses the results of the analysis of data used to address the research questions of this study and is divided into two sections. Section one, Descriptive Statistics, provides a) the results of Cronbach's alpha and b) descriptive statistics for each of the demographic and survey items. Section two, Results, discusses the results of the data analysis for the three research questions.

Chapter Five, Conclusion, addresses conclusions that are drawn from the results of the study and is divided into four sections: a) summary, b) findings and conclusions, c) discussion, and d) recommendations for administration, practice, and research. 


\section{Chapter Two}

\section{Review of Related Literature}

This literature review is divided into two sections. Section one, Peer Tutoring in Higher Education, addresses a) the history of peer tutoring, b) types of peer tutoring, and c) the benefits of peer tutoring. Section two, Administrative Issues in Higher Education, includes a) factors that contribute to the growth of peer tutoring, b) barriers to organizational change, and c) factors that institutionalize programs in higher education.

\section{Peer Tutoring in Higher Education}

The history of peer tutoring. Peer tutoring has played an important role in education and scholars have long considered tutoring an effective means of supplementing instruction (Dabkowski, 2000; Shumow, Farlowe, \& Bray, 2002). Peer tutoring is defined as a system in which learners help each other and learn by teaching (Mynard \& Almarzouqi, 2006). Peer tutoring involves more advanced learners, who already have the knowledge and skills, helping less advanced learners, who have not yet acquired them (Saunders, 1992; Topping, 1996).The main role of peer tutors is to facilitate learning by helping students to understand and apply information (Moust \& Schmidt, 1995).

The first recorded use of peer tutoring was by Andrew Bell, school superintendent at the Egmore Military Male Asylum in Madras, India from 1789-1796. Bell observed older students on the beach teaching younger students to write by tracing the letters in the sand and applied the concept to the classroom. Bell used older students who had mastered the concepts to teach the concept to younger students (Bowyer-Bower, 1954).

Bell's method of teaching became known as the Madras system of education ("Joseph Lancaster," 2010) and his practices were adopted in England at St. Botolph's School in 
Aldgate, London and the industrial schools in Kendal (Gilroy, n.d.). Bell's research showed the following results (Goodlad, 1998):

a) Tutoring enabled students to keep up with their classes.

b) Tutoring established good habits in both the tutor and student.

c) Both tutors and students went on to become good students and achieve success.

In 1798 Joseph Lancaster established a school in London based on Bell's system. In Lancaster's school, students who had learned material were rewarded for successfully passing it on to the next student (“Joseph Lancaster," 2010). In 1801 Lancaster modified Bell's method by giving tutors instructional materials to help them teach others, including answer keys, which they could use to test other students; enabling students who were not familiar with the subject to teach others (Dabkowski, 2000).

William Bentley Fowle opened the first school in Boston based on the Madras system of education in 1851. Fowle conducted studies on his students and wrote down his observations from the time the school opened until its closing in 1860 . From his observations, Fowle concluded the following (Dabkowski, 2000):

a) Tutors who were close in age to the students related better with the students than teachers.

b) Tutors were more considerate of the students' feelings.

c) Students felt more comfortable working with the tutors.

d) Teachers made the students afraid of failing, which hindered their work.

By the early 1900s, tutoring was seen as a way of enriching higher education (Goodlad, 1998). Expansion in higher education created large lecture halls and the need for tutoring 
(Thelin, Edwards, \& Moyen, 2010). Tutoring benefited faculty who did not have time to spend with each student (Dabkowski, 2000).

Tutoring has been in place in medical schools and law schools since the mid-1960s (Goodlad, 1998) and has been shown to stimulate students' interest in learning medicine and law (Moust \& Schmidt, 1995). Research by Fantuzzo et al. (1989) reported that tutoring has also been shown to improve exam scores, reduce stress, and increase student satisfaction.

By the 1980s student retention became an issue, intensifying the need for more student support (Lau, 2003), and peer tutoring became an important factor in student retention (Fantuzzo, et al., 1989; Goldschmid \& Goldschmid, 1976; Good et al., 2000; Tinto, 2002; Topping, 1996). Research shows that retention improves when students are given assistance (University Leadership Council, 2009) and "the retention and engagement of students can be directly attributed to the level of involvement both inside and outside of the classroom" (MGT of America, Inc., 2009, p. 2.1).

Types of Peer Tutoring. As the population in higher education has increased, and the large size of freshman classes has resulted in less interaction between professors and students, the need for supplemental instruction, such as peer tutoring, has also increased (Tovar \& Simon, 2003). Peer tutoring has been used in higher education to assist students in making the adjustment from high school to college (Good et al., 2000; Leung \& Bush, 2003; Mynard \& Almarzouqi, 2006), as a motivator to improve students' work (Bruffee, 1980), and as a retention strategy in undergraduate education (Leung \& Bush, 2003; Tovar \& Simon, 2003). This section addresses four types of peer tutoring programs: a) reciprocal, b) residential, c) learning centerbased, and d) supplemental instruction. 
Reciprocal peer tutoring. Reciprocal peer tutors are students of similar class standing who exchange roles with the students they teach (Fantuzzo et al., 1989). Reciprocal peer tutoring is designed to promote a high degree of student interaction and mutual support (Blanc et al., 1983). What differentiates reciprocal peer tutoring from other types of tutoring is that a relationship is established between two students who share work and learn to trust each other; tasks are accomplished because there is a mutual effort that promotes a sense of community among tutors and students (Hawkins, 1980).

Reciprocal peer tutoring decreases some of the stress associated with academic performance. "Students are paired, with the goal of teaching one another while facing similar academic stressors. The relationship is equitable in nature and requires the offering of mutual assistance and support in preparing for course exams" (Fantuzzo et al., 1989, p, 177).

Leung and Bush (2003) conducted a mixed-method study on the effects of peer tutoring on academic achievement, adjustment to college, and retention at Hong Kong Baptist University. The population included 456 students and 79 tutors who participated in the tutoring program, plus five faculty. Data were collected in three stages: in stage one, the students were surveyed; in stage two, the tutors were surveyed; and in stage three, interviews were conducted with tutors and faculty. Results showed that reciprocal peer tutoring is an ongoing process in student development that helps students to achieve their goals by providing information, opportunities, guidance, mutual support, and suggestions in problem solving and learning techniques.

Residential peer tutoring. Residential peer tutors are students who live in the residence halls where they tutor and are committed to helping other students in their halls succeed academically and socially. The difference between residential peer tutoring and other academic support programs is that in residential peer tutoring, the service is brought to the student, as 
opposed to the student having to seek the service, helping students to become independent and active learners by creating an environment that encourages student participation and promotes collaborative learning (Pariser, 2007).

Pariser (2007) conducted a qualitative study on the effects of residential peer tutoring on the academic success of students living in the residence halls at West Virginia University. Data were collected from tutor applications and student and tutor interviews. Results indicated that residential peer tutors have the ability to a) develop the attitude among students that getting help is good and b) create a residential environment that encourages student participation and enables students to perceive the benefits of tutoring. Students identified the benefits of residential peer tutoring as a) convenience, b) one-on-one tutoring, c) getting help from a peer "who's been there," and d) helping with the transition from high school to college.

Learning center-based tutoring. Learning centers, also called academic resource centers, provide students with additional academic support to help them become independent thinkers and more efficient learners ("Learning Center/Academic Resources," 2010). The difference between learning center-based tutoring and other types of tutoring is that academic learning centers offer "one-stop shopping" for tutoring with free academic review sessions, drop-in peer tutoring sessions, and workshops in academic disciplines, as well as writing and computer skills.

Learning centers help students not only to learn, but also to adjust to college by a) providing students with academic support to reinforce and enhance their learning, b) increasing students' ability to transfer learning from one situation to another, c) providing students with the knowledge and skills needed to achieve their academic goals, d) promoting active learning, and e) maintaining a friendly student-centered learning environment that 
promotes diversity, academic success, and life-long learning (“Academic Learning Center Objectives," 2010).

Hendriksen et al. (2005) conducted a mixed-methods study on the effects of learning center-based tutoring on academic achievement and retention at Northampton Community College (Bethlehem, PA). The population included all students and faculty who used the learning center during the 2003-2004 academic year. Data collection included student self-reports, final grades in the courses students participated in tutoring, and end of the year retention rates. Results indicated that learning center-based tutoring helped students develop self-awareness, selfdirection, and self-confidence needed to meet the academic demands of college, be successful, and go on to graduate. Eighty-eight percent of the students who participated in tutoring succeeded and performed as well or better than students who did not participate in tutoring; eighty-two percent of tutored students re-enrolled as compared to the institutional average of seventy percent.

Supplemental instruction. Supplemental Instruction (SI) is an academic support program that targets traditionally difficult courses to improve student performance and provides shared, connected learning experiences by grouping students together in the classroom by academic discipline and outside the classroom in course related peer tutoring or study groups. The difference between SI and other academic support programs is that in SI, students are part of a learning community that is connected by a theme, which gives meaning to their connection; and in study groups and tutoring together, which provides out-of-class experiences and gives tutoring a social connection to academics (Tinto, 1998b). Research has shown "that students who study in groups often get the higher grades and survive college better" (Gardner \& Jewler, 1997, p. 5). 
Astin (1993) conducted a longitudinal mixed-methods study on how student outcomes are affected by peer groups who participated in supplemental instruction in a college setting. The population included 25,000 students randomly selected from 200 institutions that participated in the Cooperative Institute Research Program. Data were collected over a four-year period from questionnaires administered in the beginning and end of the study, statistics on academic performance and retention, admissions test scores, and graduate and professional school admission test scores. Findings showed that a) student involvement had a positive influence on learning and student development, b) the more time students spent in a supplemental instruction program, the stronger the correlation between academic outcomes and retention, and c) peers were the most important influence on student achievement and retention.

Research has shown that a) students who participated in campus activities early on, including tutoring, are more involved on campus, have a more positive attitude, and have more developed educational plans; and b) students, who participated in living and learning programs offered in the residence halls and in supplemental instruction, achieved higher scores in the areas of critical thinking and in applying knowledge they learned in class to other areas than students who did not participate (MGT of America, Inc., 2009).

The benefits of peer tutoring. Research indicates that peers have more influence on student success and retention than any other group on campus, including faculty (Astin, 1993; Bean, 1985), and the most influential peer interactions are those that reinforce learning in nonclassroom settings, such as peer tutoring (Pascarella \& Terenzini, 2005). Centered on the needs and schedule of the student, "peer tutoring is one of the most student-centered learning experiences" (Schotka, n.d., para. 2). Peer tutoring promotes the understanding of the benefits of 
students helping each other learn and instills confidence in the students' ability to complete the required coursework (Loos et al., 2004).

This section discusses the benefits of peer tutoring and is divided into two parts. Part one, The Benefits to Students, addresses the following topics: adjusting to college; providing academic, personal, social, and psychological support; and increasing retention. Part two, The Benefits to Tutors, includes the following topics: developing skills and providing social and psychological support.

\section{The benefits to students.}

Adjusting to college. Peer tutoring helps students adjust to college by providing academic, personal, social, and psychological support. First-year students face many challenges in adjusting to college, "such as being unsure of what is expected of them and possessing only a limited awareness of strategies for learning” (Mynard \& Almarzouqi, 2006, p. 13). Peer tutoring has been shown to be an effective way to help students adjust to college and improve academic performance (Blanc et al., 1983; Fantuzzo et al., 1989; Good et al., 2000; Luca \& Clarkson, 2002; Mynard \& Almarzouqi, 2006; Tovar \& Simon, 2003) and to encourage them to take an active role in thinking, questioning, and sharing knowledge through social interaction (Luca \& Clarkson, 2002).

The one to one ratio most often practiced in peer tutoring situations allows the pace and level of instruction to adjust to the tutee's individual learning needs, which is particularly beneficial to college freshmen as they make the oftentimes difficult social adjustment and academic transition to college life. (Schotka, n.d., para. 1)

Mynard and Almarzouqi (2006) studied the benefits and challenges of peer tutoring and its effect on adjusting to college. Thirty-four students and twenty peer tutors participated in the 
study. Data were collected from the tutors' written records of the tutoring sessions, surveys completed by both the students and tutors, and open-ended interviews with the tutors and students after the surveys were completed, giving the researchers the opportunity to ask more questions relating to themes that emerged from the surveys. Results of the study indicated that peer tutoring helped to make the students' adjustment to college easier by enabling them to make friends, build confidence and self-esteem, and develop networking opportunities and leadership skills.

Providing Academic Support. Before students can learn course concepts, they must master "the prerequisite learning and thinking skills that are basic to content mastery" (Blanc et al., p. 82). Studies have shown that peer tutoring helps students understand the material studied and assists students in achieving their own goals by providing academic support in the areas of problem solving, learning strategies, time management, and study skills (Leung \& Bush, 2003). Peer tutors also teach students strategies for reading a textbook and show them how to use a daily planner, take notes, prepare for exams, and prepare class schedules (Pariser, 2007).

In order to benefit from their courses, students need help with assessing what they know (Chickering \& Gamson, 1987). Peer tutoring supports academics by giving students the opportunity to review what they have learned and assess what they still need to know, emphasizing that learning is an ongoing process of improvement (Mynard \& Almarzouqi, 2006), and enhancing the teaching process by providing the student with prompt feedback (Beck, 1978; Chickering \& Gamson, 1987).

Peer tutoring is interactive and encourages sharing ideas and responding to others' reactions, which sharpens thinking and deepens understanding (Good et al., 2000; Tinto et al., 1993). In this way, peer tutoring promotes students' active participation in and taking greater 
ownership of the learning process (Topping, 1996) and helps students achieve a better understanding of their work (Leung \& Bush, 2003).

Blanc et al. (1983) studied the effects of tutoring on academic performance and attrition. The population included 746 students enrolled in seven arts and sciences courses that were labeled high risk during the Spring 1980 semester. High risk courses were defined as courses in which most students received a grade of D or F. Data were collected from students' admission records (test scores and high school GPA), present classroom performance, and re-enrollment information. Results indicated that students who participated in peer tutoring made the same gains in academic performance and had similar re-enrollment rates as students with higher admission test scores and high school GPAs.

Providing personal and social support. "Peers exert influence through socialization processes involving information exchange, modeling, and reinforcement of peer norms and values both inside and outside the classroom" (Benjamin, 2001, p. 3). Peer tutoring encourages students to take an active role in thinking, questioning, and sharing knowledge through social interaction (Luca \& Clarkson, 2002), encourages reciprocity and cooperation between students (Chickering \& Gamson, 1987; Hawkins, 1980), and enables students to share experiences and views on different issues (Leung \& Bush, 2003), forming a bridge between student life and academics (Tinto, 1997).

Peer tutoring provides experience in relationship building and developing interpersonal skills (Benjamin, 2001) and promotes friendship between students by connecting learning experiences (Tinto et al., 1993). It helps students develop support systems (Good et al., 2000; Mynard \& Almarzouqi, 2006), provides role models and leadership to students (Good et al., 2000), and encourages students to emulate tutors' behavior (Beck, 1978; Benjamin, 2001). 
Tinto et al. (1993) studied the effects of peer tutoring on academic and social development. Their research sought to answer two questions: 1) Do collaborative learning programs, such as peer tutoring, make a difference and 2) if so, how? The population, although not mentioned specifically, included a sample of first-year students who participated in tutoring at the University of Washington and Seattle Central Community College. Data were collected both qualitatively, through observations and interviews of program participants during the 1992 academic year and quantitatively, through end of the semester surveys. Results indicated that peer tutoring a) helped students build a network of peers that functioned as both an academic and social support system by providing study partners, sources of class notes, and help with homework and class assignments and b) encouraged students to actively participate in their learning both inside and outside class and to incorporate their out-of-class experiences into the learning process. Students reported that they received not only academic support, but also social and emotional support, which led to their feeling more comfortable participating in tutoring and more actively involved in the learning process.

Providing psychological support. Peer tutoring creates a positive attitude among students in achievement and motivation for continuing their education (Cohen et al., 1982; Goldschmid \& Goldschmid, 1976; Rings \& Sheets, 1991) and contributes to the students' belief that tutoring is the reason for their success (Luca \& Clarkson, 2002). Students who participate in peer tutoring are more successful because they have a more positive perception of not only the learning experience, but also of their ability to cope with stressful academic situations such as tests and assignments (Fantuzzo et al., 1989). Peer tutoring has also been shown to encourage the development of trust between the tutor and student and make things less stressful for both (Fantuzzo et al., 1989; Luca \& Clarkson, 2002). 
Fantuzzo et al. (1989) examined the effects of peer tutoring on academic achievement and psychological adjustment. The population was comprised of one hundred students enrolled in an abnormal psychology class at California State University, Fullerton, randomly assigned to a reciprocal peer tutoring group. Data were collected from a twenty-five multiple-choice question pre-test administered before instruction began and again at the end of the semester as part of the final exam. Results indicated that students who participated in peer tutoring not only achieved higher test scores; they also experienced lower levels of test anxiety, had a more positive outlook, and were more satisfied with their college experience.

Increasing retention. Research has indicated that peer tutoring has a strong impact on retention, providing students with a social and academic support system that ties them to the college community and encourages their continued attendance (Beal \& Noel, 1980; Bean, 1985; Higgins, 2004; Luca \& Clarkson, 2002; Pascarella \& Terenzini, 1991; Pendleton, 2005; Tinto, 1997). The more socially and academically involved students are and the more they interact with other students, the more comfortable they feel in their new environment and the more likely they are to remain in college (Benjamin, 2001; Chickering \& Gamson, 1987; Tinto, 1998a).

Peer tutoring enhances student success and reduces attrition by providing out-of-class learning opportunities for students (Griswold, 2003; Loos et al., 2004). It identifies at-risk students and provides early assessment and intervention, enabling students to succeed (Higgins, 2004). Pendleton (2005) reported that students who participate in peer tutoring achieve higher grades, progress through their programs at a higher rate, and graduate at higher rates than students who do not participate.

Bean (1985) looked at the effects of peer tutoring on retention. The study sought to answer the following question: Do peers or faculty have a greater influence on retention? The 
population included 1,781 out of 5,235 students randomly selected from a large Midwestern research university. Data were collected through a questionnaire that was mailed to the students. Findings indicated that a) students play an important role in influencing the attitudes of other students, b) a students' peers are more important in socialization than faculty contacts, and c) peer support, such as in the friendships formed through peer interactions like peer tutoring, is an important element in the retention of students.

\section{The benefits to tutors.}

Developing skills. Research indicated that students who teach other students do better academically (Clemence, 1961; Fantuzzo et al., 1989; Hawkins, 1980; Mynard \& Almarzouqi, 2006). Preparation for tutoring sessions helps tutors develop academic goals and become more competent in their study areas (Pariser, 2007) and develop skills necessary for academic success such as communication and cooperative problem solving (, n.d.). "Just preparing to be a tutor enhances cognitive processing by increasing attention to and motivation for the task at hand and reviewing existing knowledge and skills" (Topping, 1996, p. 324).

Peer tutoring creates the opportunity for tutors to practice and develop communication skills (Luca \& Clarkson, 2002) and test what they know by making sense of it to others (Bruffee, 1980). Sharing ideas and responding to others' reactions sharpens thinking and deepens understanding (Chickering \& Gamson, 1987). Tutoring also improves tutors' thought processes by encouraging them to think about the process to a solution (Good et al., 2000) and enables tutors to transfer knowledge and learning strategies to other courses (Clemence, 1961; Good et al. 2000).

Tutoring enables tutors to learn students' study habits, what they know about the subject, and their motivation for participating (Luca \& Clarkson, 2002), and promotes flexibility in the 
tutor in adapting to different student personalities and learning styles (Pariser, 2007). Serving as an example to their peers, tutors develop better time management and study skills and become more organized and self-disciplined (Good et al., 2000; Pariser, 2007).

Street, Brown, Schramm, and Gillespie (2005) looked at the effects of peer tutoring on the development of skills in tutors. Although the number of participants was not specifically mentioned, the population included tutors from sophomore level civil engineering classes at Washington State University and Oregon State University. Data were collected qualitatively, through interviews, and quantitatively, through surveys administered at the end of the semester. Survey questions were based on responses during the interviews. Results indicated that peer tutoring helped tutors develop the social skills needed for listening, understanding, giving help, and communicating clearly.

Providing social and psychological support. "Students who tutor other students profit not only on a cognitive level...but also on an interpersonal, affective one: their self-esteem increases and their attitude towards the course and the school or teaching and learning in general becomes more positive" (Goldschmid \& Goldschmid, 1976, p. 26). Research indicated that students who learn in order to teach other students are more motivated and perceive themselves to be more actively engaged with their environment than students who learn only to recall information for an examination (Fantuzzo et al., 1989). By being actively involved within the university environment, tutors have the opportunity to get to know people from different social backgrounds and gain insight into how other students see subjects (Luca \& Clarkson, 2002), enabling tutors to become more sociable and more accepting of different personalities, learning styles, and beliefs (Benjamin, 2001; Pariser, 2007).

Peer tutoring improves tutors' confidence in their own ability and helps develop 
interpersonal and social skills (Good et al., 2000). It “offers a less formal way of problem solving on a more personal and intimate level" (Luca \& Clarkson, 2002, p. 5) and creates a sense that tutors are doing something worthwhile (Mynard \& Almarzouqi, 2006) by seeing others grow and succeed (Penner, 2001).

Good et al. (2000) conducted a qualitative study on the effects of peer tutoring on academic achievement and interpersonal growth among tutors. The population included nineteen peer tutors. Data were collected over the course of one semester from the tutors' journal entries, which were coded into three areas of academic growth - study skills, improved understanding of concepts, and improvement in critical thinking and problem solving; and three areas of interpersonal growth - development of responsibility and leadership skills, ease of social interaction and communication, and personal self-satisfaction.

Results indicated that the tutoring process not only provided role models and leadership to the students and created social support networks among students, it also helped both the students and tutors improve in the areas of study skills, critical thinking, and problem solving. The study also indicated that the tutoring process significantly improved the tutors' academic growth, resulting in a deeper understanding of the concepts and subject areas they tutor in, as well as improved personal skills in the areas of social interaction and communication, development of responsibility and leadership skills, and a sense of self- satisfaction and belonging.

\section{Summary}

Peer tutoring began with an idea from Andrew Bell, who saw older students in Madras, India on the beach teaching younger students to write by tracing letters in the sand. Bell's method of teaching, called the Madras Experiment, involved older students who had mastered 
concepts teaching the concepts to younger students. Bell's idea has become a common practice in higher education and findings of his early studies on peer tutoring parallel the findings of today (Dabkowski, 2000; Goodlad, 1998):

- Peer tutoring pairs students with a peer who has gone through, or is going through, the same thing they are experiencing and can tell them what to expect.

- Both the students and tutors benefit from peer tutoring.

- Peer tutoring enables students to keep up with their classes by helping them understand and apply information.

- Peer tutoring establishes good habits and promotes success in both the tutor and student.

- Tutors who are close in age to the students relate better with the students than teachers.

- Tutors are more considerate of students' feelings and make them feel more comfortable.

- Students who teach students do better academically.

- Peers have more influence on student success than any other group.

- Students who participate in peer tutoring are more likely to achieve their goals than non-participants.

There are four common types of peer tutoring: reciprocal, residential, learning centerbased and supplemental instruction. Factors that influence a student's decision to participate in peer tutoring programs include motivation to learn (Cohen et al., 1982; Lau, 2002; Luca \& Clarkson, 2002; Tinto et al., 1993; Schramm et al., 2009), self-confidence (Hendriksen et al., 2005; Loos et al., 2004), perceived readiness to meeting the academic challenges of college 
(Topping, 1996), and the interaction of peers (Mynard \& Almarzouqi. 2006). The main role of peer tutoring is to facilitate learning by helping students to understand and apply information (Moust \& Schmidt, 1995).

Peer tutoring helps students adjust to college by providing academic, personal, social, and psychological support. Peer tutoring has been an effective tool is helping students adjust to college (Good et al., 2000; Leung \& Bush, 2003; Mynard \& Almarzouqi, 2006), as a motivator to improve students' work (Bruffee, 1980), and as a retention strategy in undergraduate education (Leung \& Bush, 2003; Tovar \& Simon, 2003). Peer tutoring connects learning experiences and forms a bridge between student life and academics (Tinto, 1997).

\section{Administrative Issues in Higher Education}

This section is divided into three parts. Part one includes factors that contribute to the growth of peer tutoring, part two addresses barriers to organizational change, and part three examines factors that institutionalize programs in higher education.

Factors that contribute to the growth of peer tutoring. There is currently much interest in not only access to higher education, but also student success (Thomas, 2002). Declining student enrollment, decreased state and federal funding, and competition for students with other institutions, paired with increased pressure on college presidents from parents, students, and faculty to provide programs to ensure academic success, has lead to an increase in student support services (Leone \& Tian, 2009). A study by Thomas (2002) reported that university support services, such as peer tutoring, are one of the main factors in student retention.

A study by Rendon (1995) identified two critical factors that influence students' decision to remain in college as a) successfully making the transition to college supported by orientation and tutoring programs and b) making positive connections with college personnel and students 
during their first semester. This section addresses administrative, faculty, and student factors that contribute to the growth of peer tutoring.

Administrative factors. The challenges of planning and implementing peer tutoring programs include institutional issues and organizational structure (Berge \& Schrum, 1998). This section addresses the following administrative factors: a) pressure to increase retention, b) difficulty to transition from high school to college, and c) changes to organizational structure.

Pressure to increase retention. Bushong (2009) reported in The Chronicle of Higher Education that retention rates are down in all institutions except two-year colleges. Pressure from college presidents to increase retention and grade point averages (GPAs) has caused retention in higher education to become one of the most significant issues that college administrators must deal with in today's competitive market (Lau, 2003; Leone \& Tian, 2009) and has called for an increase in student support services (Adams, 2011) and the centralization of programs (Pina, 2008b). "In fact retaining a student is fundamental to the ability of an institution to carry out its mission. A high rate of attrition is not only a fiscal problem for schools, but a symbolic failure of an institution to achieve its purpose" (Leone \& Tian, 2009, p. 122). Lau (2003) reported that failure to provide programs to support academic success not only increases the chances of attrition, but also becomes a determining factor in obtaining outside funding.

According to Act, Inc. (2010a), a research group that has compiled a comprehensive database of first-year to second-year retention rates since 1983, retention rates increased by only one percent for the 2008-9 academic year with 67 percent of first-year college students returning to the same institution for their second year of college. However, retention rates varied among different institutional types and between public and private institutions. Act, Inc. (2010a) reported that retention rates are higher for four-year colleges (68 percent, down three percent 
from the previous year) than two-year colleges (57 percent, up three percent from the previous year) and slightly higher for private institutions. The highest retention rates were reported by research institutions with doctoral programs (79 percent).

Lau (2003) looked at the role of higher education administrators in student success and retention. The results of her research showed that a) one of the main reasons students leave an institution is that the institution has not provided programs that meet the students' learning and educational needs, b) student retention is directly related to the students' institutional experiences, c) academic support, such as peer tutoring, is essential to student success, and d) institutions that pay attention to student learning styles and accommodate students' needs by providing academic support programs have higher retention rates. Therefore, if institutions want to increase retention, one of the most important roles of higher education administrators is to ensure student success by providing academic support programs to meet students' learning and educational needs.

Difficulty to transition from high school to college. Difficulty in the transition from high school to college is another major factor influencing student retention. "To ease the students' transition from high school to college, higher education administrators must help students adjust to their new living and learning environments, and ensure that the institution is accommodating to the student's...learning styles" and "services are readily available to students" (Lau, 2003, p. 128). "It is clear that when a college cannot satisfy their students' academic needs the students will definitely select to leave for those colleges that can meet their academic needs" (Leone \& Tian, 2009, p. 128).

Leone and Tian (2009) supervised a study on institutional factors that influence student retention and their effect on students' transition to college conducted by twenty students enrolled 
in a Marketing Management and Strategy course at Medaille College in the 2008 Fall semester. The population included 122 former Medaille College students who had either dropped out or transferred to other colleges since the 2005 academic year. Data were collected in two stages. In stage one, a literature review was conducted on "push" factors that influenced students to leave and "pull" factors that influenced students to go to another college. In stage two, former students received a questionnaire that was made up of factors identified from the literature review. Openended interviews with former students were also conducted. Results indicated that campus life, both academic and social, and having the resources to help students transition into college life and meet individual students' needs, are major factors that influence whether students stay at a particular college.

Changes to organizational structure. Once an institution begins to increase its tutoring programs it faces two choices: a) remain decentralized with each department responsible for its own programs or b) establish an institution-wide tutoring program that is overseen by one department (Pina 2008b). A report by the Ad Hoc Committee for First Year \& Second Year Experiences at West Virginia University (2010) indicated that a) although students are more likely to use support services when those services come to them, tutors need to be centrally trained and students would be better served by learning centers that are sponsored by departments with subject-area expertise and b) academic resource centers need a central organization and a central location. Although the learning centers would rely on peer tutors, "they would also need to have full-time coordinators," someone "who is trained in the relevant discipline - such as English, Math, or one of the Sciences, who would provide research, training, support, supervision and assessment of the tutoring center" (Ad Hoc Committee for First Year \& Second Year Experiences at West Virginia University, 2010, p. 7). 
Bastedo (2007) conducted a longitudinal case study at California State University, Monterrey Bay. He looked at factors that influence the growth and development of institutional programs, such as peer tutoring. The population included a total of 18 faculty, administrators, and university leaders. Data were collected from interviews with faculty, program administrators, and university leadership; analysis of documents, and media coverage over a six-year period between 1998 and 2004. Findings indicated that a) in order to be successfully implemented, programs must be profitable and compatible to the goals and mission of the institution, b) in order to be successful, ideas and decision making must be shared among members of the college community, and c) programs that are adopted may fail at the institutional level, but be very successful at a department level.

Faculty factors. Research has indicated that the retention rate of students is greatly affected by the level and quality of their interactions with faculty (Astin 1993). "Students who interact with faculty outside of class tend to stay in college longer" (Gardner \& Jewler, 1997, p. 5). Tinto (2002) reported that the most common factors in students dropping out are: a) academic difficulty, b) limited student-faculty interaction, and c) lack of integration within the college community. This section addresses the following faculty factors: a) student-faculty relationships and $b$ ) the role of faculty in interactive learning.

Faculty-student relationships. Relationships between students and faculty are essential to the development of students' attitudes towards learning and coping with academic difficulties, and important to understanding the institutional norms and practices (Thomas, 2002). It "is now a widely accepted notion that the actions of the faculty... are key to institutional efforts to enhance student retention. Though it is true...that student retention is everyone's business, it is now evident that it is the business of the faculty in particular" (Tinto, 2006-7, p. 5). 
The emphasis placed on retention programs and the interaction of faculty with students in the campus environment can help or hinder students in their first year (Leone \& Tian, 2009). As a result, retention can be highly affected by increasing a) student interaction with faculty (Leone \& Tian, 2009) and b) student support services, such as peer tutoring (Bean, 1985).

Thomas (2002) looked at the effect of institutional factors, specifically faculty-student relationships, on student success. The population included 32 full-time students from six focus groups and represented a cross-section of gender, major, and class standing. Methods included a review of literature, focus groups, and follow-up questionnaires. Results indicated that a) relationships between students and faculty are directly related to students' attitudes towards learning and coping with academic difficulties, b) students believed faculty played a role in promoting student involvement through collaborative learning and teaching practices, c) students performed better and gained both self-confidence and motivation when they perceived that faculty believed in them and cared about their learning outcomes, and d) students who felt respected by staff were more likely to seek academic support services.

The role of faculty in interactive learning. "Faculty play a crucial role in promoting educational growth among students" (Lau, 2003, p. 131). Lau (2003) reported that students who are encouraged by faculty to learn cooperatively through group projects, group discussions, and group presentations; and collaboratively, through study groups and peer tutoring, are more likely to be successful and stay in school.

Tinto (1997) looked at the role of faculty in learning communities. The study sought to determine to what degree learning strategies enhanced student learning and persistence and, if so, how. The population included 517 students at Seattle Central Community College; 210 from a coordinated studies program and 307 from comparison classes. Data were collected both 
qualitatively through participant observation, interviews, and document review; and quantitatively, through surveys. Results indicated that a) faculty involvement matters and has a positive influence on student retention, b) students who participated in learning communities where faculty were highly involved had a more positive perception of their classes and their learning experience, c) students saw faculty-student associations as an important part of their educational experience, and d) study groups and group projects promoted by collaborative learning in the learning communities contributed to a high level of student participation in the learning process.

Student factors. "To date, education research shows that good teachers matter a lot, class size may be less important than once thought, and nothing improves student performance as much as one-on-one...tutoring" (Lohr, 2010). This section addresses the following student factors: accountability, motivation, and support.

Accountability. With the "move toward student-centered learning and academic selfregulation, the responsibility for learning is shifting from teacher to student" (Xu et al. 2001, para. 4). Thomas (2002) reported that teaching and learning provide interactions between students and their peers, which have a fundamental role in changing institutional culture.

Large "increases in student numbers, both domestic and international students, along with the continued decline in government funding has placed unreasonable pressure on higher education institutions to seek cost-saving measures....As universities have cut back on overall staff numbers..., students have stepped into the breach to provide various functions previously funded by universities." (Pendleton, 2005, p. 8) Pendleton (2005) conducted a literature review on peer tutoring in higher education. Results indicated that peer tutors have helped institutions to be more accountable to student 
learning by a) helping students succeed and b) helping students develop learning skills, interpersonal skills, leadership skills, and work-related skills.

Motivation. Research has indicated that motivation is a prerequisite for student learning and students can further motivation by being active learners in the learning process and participating in study groups and peer tutoring programs (Lau, 2003).

Schramm et al. (2009) conducted a mixed-method study on motivational factors that influence tutor participation in peer tutoring. Although not specifically mentioned, the population included a random sample of tutors in the Engineering program at Washington State University. Data were collected qualitatively in the middle of the Fall 2008 semester by observation and interviews, and quantitatively in the middle of the Spring 2009 semester through open-ended surveys. Results indicated that a) the main motivational factor in becoming a peer tutor was the possibility to help their peers succeed; b) although not the main factor, receiving compensation for tutoring and being recognized for their efforts was a big factor in students deciding to participate; and c) tutors appreciated the opportunity to improve their knowledge about the subject area, as well study for exams, and improve their communication skills.

Support. Research has indicated that students are more likely to persist and graduate in settings that provide academic, social, and personal support (Tinto, 2002). This section addresses support factors that influence students to seek peer tutoring.

Street (2010) conducted a mixed-methods study on factors that contribute to students seeking peer tutoring. The purpose of the study was to identify factors that influence student access to resources pertinent to their academic achievement. The population included Engineering students enrolled in two statistics classes, one at Oregon State University and the other at Washington State University. Data were collected during the Spring 2009 semester by 
mid-semester interviews with half of the class, followed by surveys given to all of the students. Results indicated that a) support services most commonly used by students were human resources such as study groups with classmates and peer tutoring, b) accessibility and approachability of the tutors were two factors found to impact student access, c) faculty encouragement contributed to the use of peer tutoring, and d) resources available were affected by the difficulty of subject matter.

Barriers to organizational change. A number of policies and procedures form barriers to the efforts of institutions that wish to implement academic support programs (Berge \& Schrum, 1998). The development of an institutional strategy for developing academic support programs must acknowledge current barriers within higher education (Blustain, Goldstein, \& Lozier, 1998). This section addresses administrative, faculty, and student factors that form barriers to organizational change.

Administrative barriers. Berge and Schrum (1998) identified the following administrative barriers to organizational change and the implementation of academic support programs, which will be addressed in this section: a) inadequate resources, b) issues of coordination and control for those who are charged with developing the programs and standardizing educational efforts, and c) accountability to university and/or other governing agencies.

Inadequate resources. At a time when the demand for academic support programs is growing, most college campuses do not have the financial, faculty, or staff resources to implement programs and make changes that will meet the demand (Berge \& Schrum, 1998). Nightingale (n.d.) reported that although it is important for educators to know what recent research tells us about student learning and how best to develop it, it has been increasingly 
difficult to get funding to conduct the research. A current view in higher education is that institutions "must ensure that there is adequate funding for the conduct and dissemination of research about teaching and learning in higher education and about the effects of policy decisions at all levels in higher education"(Nightingale, n.d., para. 9).

Berge and Schrum (1998) looked at administrative barriers to program implementation. Results indicated that a) inadequate resources available on most college campuses make implementation of programs a challenge, b) on-campus programs often use the same resources; therefore, standardizing efforts reduces duplication of programs and lowers expenditures, and c) coordination of planning reduces implementation challenges. Study recommendations included: a) identifying the purposes and goals of the program to be implemented, b) collecting and summarizing information on current programs and the strategic plans of similar programs in different academic departments, c) evaluating program strategies including advantages, disadvantages, costs, and resource commitments, d) looking at successful models at other institutions, and f) identifying needs and incentives for faculty and administrators who are involved in developing, supervising, and evaluating the program and the delivery of services.

Issues of coordination and control. Kezar (2003) identified the following cultural and structural barriers to collaboration in organizational change that administrators face: ...organizational fragmentation and division of labor, specialization among faculty, lack of common purpose or language, few shared values, history of separation, different priorities and expectations, cultural differences between academic and student affairs in terms of personality styles, and competing assumptions about what constitutes effective learning. (Kezar, 2003, p. 3) 
Although administrators agree that faculty should be involved in academic support services, the trend has been to place peer-tutoring programs under the guidance of student affairs rather than academic affairs (Tinto, 1997).

Though it is evident that classrooms matter, especially as they may shape academic integration, little has been done to explore how the experience of the classroom matters, how it comes, over time, to shape student persistence. The same may be said of institutions of higher education. Though they have certainly not ignored the classroom, most have not seen it as the centerpiece of their efforts to promote student persistence, preferring instead to locate those efforts outside the classroom in the domain of student affairs. (Tinto, 1997, p. 599)

Kezar (2003) conducted a quantitative study on barriers to collaboration in implementing programs in higher education. Specifically Kezar looked at collaboration and coordination of programs among student affairs and academic affairs. The population consisted of a random sample of 260 student affairs senior administrators by institutional type from a base of 3500 members of the National Association of Student Personnel Administrators (NASPA). Senior student affairs officers were chosen as the sample because it was presumed that they would have the most knowledge about collaboration among academic and student affairs. Data were collected through electronic surveys. Results indicated that a) cooperation, staff attitudes, common goals, and personalities were believed to make the most difference in the success of collaborative efforts; and b) communication among departments, setting expectations, planning, creating a common vision, generating enthusiasm, and staff development were identified as important factors in the process of facilitating collaboration. 
Accountability to university and/or other governing agencies. Because the collaboration of student affairs and academic affairs is necessary for the implementation of new student support programs (Kezar 2003), the support of campus leaders is essential to the success of campus programs (Berge \& Schrum, 1998). A shared vision, a strategic plan, and leaders within the institution who are knowledgeable and supportive of student support programs are essential to implementing new programs (Cho \& Berge, 2002).

To centralize or decentralize has been an ongoing question within higher education and in an effort to create programs that support their mission and culture, many institutions have moved to creating a senior-level position, such as an assistant provost who has ties to both student affairs and academic affairs, to coordinate the implementation and supervision of these programs (Holland, 2009).

Cho and Berge (2002) looked at barriers to administrative structure and organizational change. Data were collected through a review of case studies. Results showed that a) administrative structure and organizational change are two important issues that need to be considered simultaneously; b) teamwork is important in implementing new programs, however a centralized policy-making or administrative structure is necessary to implement new programs in a consistent, effective, and efficient manner; c) centralization ensures consistency in management, supervision, and training; d) the best way to bring about organizational change, such as implementing new student support services, is to find a supporter among the institution's faculty and administrators; and e) when partnerships are formed among units, barriers become fewer.

Faculty barriers. "Despite its obvious virtues, face-to-face classroom interaction limits the reach of each instructor," however, "faculty are often resistant to moving in new areas, and 
opportunities to develop new programs may result either in a commitment to new faculty lines or to the use of adjuncts that have little institutional commitment" (Blustain et al., p. 26). This section addresses the following faculty barriers: a) the change of faculty roles, b) faculty compensation, and c) lack of support.

The change of faculty roles. While the role of faculty is in transition in American higher education and a greater emphasis is being placed on learning (Omara-Otunnu, 2004), there has been a decrease in external support for new academic programs (Diamond, 2006; Turoff, 2006). Also, responsibility for meeting academic goals has been given to faculty, yet responsibility for developing educational support programs has been taken from faculty and given to administrators (Turoff, 2006). In fact, it is this change in administrative and faculty roles that has created barriers to developing supplemental academic programs, such as peer tutoring (Berge \& Muilenburg, 2001).

Berge and Muilenburg (2001) examined faculty roles and how they become barriers to implementing programs. Results indicated that a) managing supplemental academic programs can be problematic in most existing organizational structures with faculty answering to an administrator, such as the provost or chief academic officer; b) if programs are to work, there must be a shared vision among departments and collaboration with faculty and administrators on factors such as planning, costs, compensation, distribution of revenue, and course schedules; and c) cultural changes, such as changes in faculty roles within their department and the institution, create roadblocks to the implementation of supplemental academic programs.

Faculty compensation. Faculty compensation has been identified as a barrier to the development of academic support programs in higher education (Berge \& Muilenburg; 2001; Levine \& Sun, 2002; Moser, 2007). Diamond (2006) reported that before new programs can be 
developed and implemented a reward system of faculty compensation and recognition must be in place. In addition to faculty salaries, institutions must also factor in costs for designing and administering new academic support programs, equipment, and stipends and release time for faculty (Levine \& Sun, 2002).

Factors that deter faculty from developing and participating in academic support programs include the lack of credit towards promotion and tenure, lack of recognition or rewards, lack of support from department heads and colleagues, and lack of grants and/or merit pay (O'Quinn \& Corey, 2002). Therefore it is important to maintain a meaningful system of faculty recognition through faculty recognition days and awards for program design, research, and service (Faculty Compensation, 2009), and provide incentives such as application towards promotion and tenure, merit pay, new equipment, and grants for future research (Maguire, 2005).

Shea (2006) looked at factors that enable faculty to participate in academic programs. The population included 386 faculty from a cross-section of thirty-six two-year and four-year institutions that are part of a state university system in the Northeastern United States. Data were collected through surveys. Results indicated that a) faculty participation increased with compensation, b) flexibility in time teaching served as a motivating factor in participation, c) younger faculty were motivated by the opportunity to demonstrate competency for promotion and tenure, and d) faculty at four-year institutions were more concerned about recognition than faculty at two-year institutions.

Lack of support. Faculty support has been identified as a critical factor in the success of educational support programs (Berge \& Schrum, 1998; Moser, 2007). Maguire (2005) reported that the biggest concern among faculty in taking on more responsibility is the additional time needed to prepare. He also found that more faculty would participate in supplemental educational 
support programs if they received recognition from their departments for taking on additional work and support in the form of decreased course workloads and staff support.

"Students... are affected by the campus expectation climate and by their perceptions of the expectations...faculty and staff hold for their individual performance" (Tinto, 2002, p. 2) and for students to succeed, faculty support is needed to ensure that academic support services are available and that they "provide a coherent, shared learning experience that is tailored to the needs of the students" (Tinto, 2002, p. 6).

Moser (2007) conducted a mixed-methods study on factors that influence faculty support of educational programs. The population included nine institutions in the Boston area that are leaders in developing educational programs. Data were collected through surveys, case studies, interviews, document analysis, observation, and focus groups. Findings indicated that faculty support and commitment depend on the following factors: a) time commitment - how much time faculty have to commit and how much time is expected of them - is the number one factor influencing faculty commitment to educational support programs, b) time commitment depends on both organizational incentive structures (extrinsic motivation, such as course release time, recognition by their department, increase in salary, or research support) and on individual variables (intrinsic motivation, such as the desire to develop programs to help students achieve success and satisfaction in helping students), c) student feedback has a positive effect on faculty involvement, and d) negative faculty experiences have an impact on future faculty involvement.

Student barriers. The quality of the college experience has the potential to impact both student retention and preparation for a career (Schramm et al., 2009). Academic support programs, such as peer tutoring, have been shown to have a big impact on both retention and student success (Beal \& Noel, 1980; Bean, 1985; Griswold, 2003; Higgins, 2004; Luca \& 
Clarkson, 2002; Pascarella \& Terenzini, 1991; Pendleton, 2005; Street et al., 2009; Tinto, 2002). Schramm et al. (2009) identified three factors that can become barriers to student participation in academic support programs, which will be addressed in this section: a) motivational factors, b) personal responsibility, and c) communication.

Motivational factors. One of the factors that motivate students to attend an institution is the support programs it offers (Blustain et al., 1998). Street et al. (2009) reported that the quality of support programs, such as peer tutoring, has the potential to impact students' attitudes toward retention. Schramm et al. (2009) identified the following motivational factors that influence student participation in peer tutoring: a) personal gain, b) educational improvement (the opportunity to improve their knowledge about the subject area and prepare for a career), and c) faculty recognition.

Muilenburg and Berge (2005) conducted a mixed methods study on student barriers to supplemental academic programs. Data were collected through a literature review, which was used to create survey questions. The population included a mix of 1056 technology and distance learning students, administrators, and faculty who had participated in training conferences, workshops, seminars, and professional meetings. For the purpose of their study, motivation was defined as processes that cause students to persist in meeting their learning goals. Results showed that a) motivation to meet learning goals is directly related to student participation in supplemental programs; b) the most frequently reported barrier to student learning was the lack of social interaction, followed by the lack of faculty support and the lack of student motivation; c) students with the highest level of comfort in participating in supplemental academic programs perceived fewer barriers than students who were unsure of their skills; d) there was a high correlation between learning effectiveness, faculty support, and student motivation to achieve 
their educational goals; e) interaction was strongly related to learning enjoyment, effectiveness of learning, and the likelihood of participating in another academic support program; and f) barriers to learning decreased as participation in academic support programs increased.

Personal responsibility. One of the challenges in higher education has been to improve institutional effectiveness; and although it is the responsibility of higher education to provide instruction and academic support, the responsibility for learning is the students' (Boggs, 1998; Davis \& Murrell, 1993). Therefore, it is imperative that "institutional policies and practices must be oriented toward developing a climate in which students' responsibility and active participation in their own collegiate experience are promoted (Davis \& Murrell, 1993, p. 7).

Davis and Murrell (1993) looked at the role of student responsibility in the college experience. Data were collected through a review of current literature on learning and student responsibility. Results indicated that a) colleges must provide opportunities for interaction and involvement and establish a climate conducive to responsible student participation, b) responsibility is the key to student development and learning, c) learning outcomes are tied to the effort that students put into their work and the degree to which they are involved with their studies, d) institutional policies that stress the importance of student responsibility for achievement are essential for student growth, and e) programs, such as peer tutoring, are means through which students may become more fully engaged with academic material.

Communication. A growing concern of students in higher education is the inability to review their coursework due to the lack of support services such as peer tutoring (Galusha, 1997). A key element in the formation of learning groups in higher education is communication (Lane, 2010). Lane (2010) identified the following communication factors of learning groups: a) learning groups, such as peer tutoring, are defined by two characteristics: norms and 
interdependence; b) norms are rules, such as meeting times and preparation, that guide the interactions of group members and determine how interactions will be carried out; c) interdependence is a necessary part of group dynamics that enables members of learning groups to be successful, as members of the group rely on each other for mutual assistance and support; and d) good communication is important in order for learning to be successful.

Students today "have a penchant for collaboration and constant communication" (O’Neill, 2009, p. 2). O'Neill (2009) looked at the role of communication in learning. The population included a random sample of 387 graduate students and faculty. Data were collected qualitatively through a case study, and quantitatively through surveys. Findings indicated that a) the ability to change the type of communication between students and faculty is important to support both different teaching styles and different learning styles, b) students prefer to attend schools that provide learning environments where it is easy for faculty to communicate and collaborate with students, c) there is a high correlation between communication and faculty and student engagement, d) there is a relationship between levels of communication between students and faculty and students' feelings of being valued, and e) faculty and students must be able to control the learning environment and there must be a high level of communication in order to produce a successful teaching and learning experience.

Factors that institutionalize programs in higher education. The model for this section is based on the work of Anthony Pina. Pina (2005, 2008a, 2008b) studied actions that influence the institutionalization of distance learning in higher education. The purpose of his study was to determine actions that institutions can take to institutionalize programs. Pina identified 30 factors from a literature review of a) educational technology, b) distance learning, and c) educational change that influence the institutionalization of programs in higher education. Pina surveyed a 
group of 170 administrators and faculty who were involved in the planning, implementation, supervision, and evaluation of distance learning programs at their institutions. Survey questions were grouped into five topic areas: planning, organization, resources, personnel, and student services. Although there is no relationship between distance learning and peer tutoring programs, factors affecting the institutionalization of any program in higher education could be related to peer tutoring. These factors were later confirmed by the panel of experts as relevant to peer tutoring. This section addresses administrative, faculty, and student factors that contribute to the institutionalization of peer tutoring programs in higher education.

Institutionalization in higher education occurs when an idea that has been implemented becomes part of an ongoing practice (Pina, 2008a). When a program becomes institutionalized "it is no longer considered to be an innovation-it is now looked upon as a normal and vital part of the organization" (Pina, 2008a, p. 428). In order to determine what institutions of higher education can do to establish, implement, and maintain high quality programs, it is necessary to identify factors or characteristics that influence their institutionalization (Pina, 2008a). Pina (2005) identified the following factors that contribute to the institutionalization of programs in higher education.

Administrative factors. Growth in higher education has caused changes in decisionmaking policies. Expanded access and growing government investment in higher education has increased the need for an administration that is involved in planning for the future (Thelin et al., 2010). Pina (2005) identified the following twelve administrative factors that influence the institutionalization of programs in higher education. The first six factors (institutional mission, policies and procedures, needs assessment, master plan, marketing, and evaluation) involve the planning of institutional programs and the last six factors (organization, collaboration, visibility, 
centralization, leadership authority, and communication) involve the organization of institutional programs (Pina, 2005).

Institutional mission. Administrators identified the institution's mission as the factor that most influences the institutionalization of programs in higher education (Pina, 2005). To receive the financial resources and support of faculty, staff, and administrators necessary for programs to become "a stable and routine part of the institution" (Pina, 2005, p. 64), administrators felt that the program must be consistent with the institution's mission “to provide high-quality programs of instruction... and stimulate and foster...scholarship (The Mission of West Virginia University, 2011, para. 2).

Master plan. Administrators felt that if institutional programs are to be thought of as ongoing, it is important to develop a master plan that outlines: a) their relevance and importance, b) educational objectives, and c) administrative costs. Furthermore, to ensure that the programs become an integral part of the education process, they need to be included in the institution's strategic plan.

Policies and procedures. "Planning is put into practice when institutions adopt formal policies and procedures..." (Pina, 2005, p. 65). Policies and procedures provided administrators with structure for the implementation of programs and consistency and guidelines for program evaluation.

Marketing. Administrators believed that a) a marketing plan that meets the institution's goals and is geared to the target audience (students, faculty, and parents) is essential to promote an institutional program and b) before a program can be implemented, the institution must have a marketing plan that is aligned with the institution's mission, educational goals, and students' needs. 
Needs assessment. An assessment of institutional programs provided administrators with important data to a) evaluate the relevance of existing programs and design new ones, b) assess students' needs and determining how to better serve the students to meet those needs, c) develop training programs, and d) provide feedback to administrators, faculty, and support staff.

Evaluation. An ongoing evaluation of institutional programs provided administrators with important data which was used to a) assess the programs and make changes to better serve the students and $b$ ) ensure that the programs meet institutional goals and educational objectives.

Organization. Through needs assessment and evaluation of institutional programs, administrators are able to see clearly how programs that help students succeed academically should be part of a campus-wide effort and not part of a particular department or academic discipline.

Centralization. Administrators believed that programs worked best when coordinated from one central office or department that is responsible for the planning, implementation, supervision, and assessment of the programs.

Collaboration. Collaboration with faculty, students, support staff, and technology services provided administrators with a broad base of support for institutional programs and a means for informing the campus community about the programs and their success.

Leadership authority. Administrators believed that leadership authority and decisionmaking for institutional programs should be delegated to university experts in the field. In the case of peer tutoring, leadership would come from the provost's office, which oversees academic research and retention.

Visibility. Pina (2005) found that in order for an institutional program to be implemented and become part of an ongoing practice, it must be first be advertised by the administration as a 
vital part of the intuition's goals and mission. Therefore, in order for a program to become part of an ongoing and accepted practice and a part of the culture of the institution, students must be told about it at new student orientation, in the residence halls, and in their classrooms; and it must be advertised in the university newsletters and bulletins, on the university website, and in posters and flyers posted throughout campus.

Communication. A formal method of communication between administrators and the campus community provided the opportunity for ongoing dialogue that is necessary to form positive working relationships. Before a program can become an integral part of the institution, there must be open lines of communication between departments and academic disciplines.

Faculty factors. It is a common practice for programs to first be implemented by faculty before administration becomes involved in system-wide planning (Pina, 2008a). In order for programs to be successful once they become institution-wide, faculty must be loyal to the university rather than his/her individual department (Bastedo, 2007). Pina (2005) saw faculty as the resources for institutional programs and identified the following five faculty factors that influence the institutionalization of programs in higher education:

Program design support: Support for faculty in the form of release time for planning institutional programs was viewed as the most important factor for faculty involvement. If faculty are expected to be involved in the planning, implementation, supervision, and evaluation of institutional programs, the success of the programs depends on the support faculty receive from their department and program administrators.

Staff development. Staff development programs provided faculty with training and program materials in the areas of research, program design and development, course materials, 
and assessment tools. Faculty felt that staff development was an important factor in the success of institutional programs.

Funding. Additional funding added to the institution's budget is an important factor in faculty involvement in institutional programs. Faculty were more likely to participate in institutional programs when funds were permanently added to the institution's budget to provide compensation for their time and technical and staff support.

Faculty participation. Faculty participation was considered vital to the success of institutional programs. However, faculty were more likely to participate in institutional programs when their positions were secure and had permanent status. Faculty believed that in order for new programs to be successful, faculty must be committed to the program and it is important for administrators to understand faculty motivation, or lack of motivation, for participating in institutional programs.

Incentives. Faculty participation in institutional programs increased when they received financial incentives such as stipends for developing the program; however, faculty considered incentives such as release time or a decreased workload to develop courses and/or conduct research, access to technology services for personal use, travel to conferences, and evaluation for promotion and tenure more important than monetary incentives in making a decision to take on more responsibility and participate in institutional programs.

Student factors. The need for the development of institution-wide programs has been influenced by declining enrollment and pressure from students, with increased student interest resulting in policies being developed to catch up with practice (Pina, 2008a). Pina (2005) viewed students as needing and using institutional services and identified the following three student factors that influence the institutionalization of programs in higher education: 
Library/research services. Students who had access to instruction in library resources did better academically and were more likely to persist in college. These resources include access to databases, online journals, reserve materials, and printed text.

Advising, counseling, and tutoring. Access to advising, counseling, and tutoring services was considered a vital part of student success and students who had access to student support services were more likely to succeed.

Technical support. Technical support was considered an important factor in student success. Students are using technology to register for classes, access their assignments, interact with faculty, take quizzes, turn in their assignments, find out about institutional programs, and access student support services.

\section{Summary}

Institutionalization in higher education occurs when an idea that has been implemented becomes part of an ongoing practice (Pina, 2008a). When a program becomes institutionalized "it is no longer considered to be an innovation - it is now looked upon as a normal and vital part of the organization" (Pina, 2008a, p. 428). In order to determine what institutions of higher education can do to establish, implement, and maintain high quality programs, it is necessary to identify factors that influence their institutionalization (Pina, 2008a). This section addressed administrative, faculty, and student factors that a) contribute to the growth of peer tutoring, b) create barriers to organizational change, and c) contribute to the institutionalization of programs in higher education. Table 1 summarizes the administrative, faculty, and student factors that play a role the institutionalization of programs in higher education. 


\section{Table 1}

Administrative, Faculty, and Student Factors that Contribute to the Institutionalization of Programs in Higher Education

\begin{tabular}{ll} 
Category & Factor \\
\hline Administrative & \\
$\begin{array}{l}\text { Institutional Mission } \\
\text { and Goals }\end{array}$ & $\begin{array}{l}\text { Program is compatible with the } \\
\text { institution's and mission and goals. }\end{array}$ \\
Master Plan & $\begin{array}{l}\text { A master plan has been developed } \\
\text { that outlines program relevance and } \\
\text { importance, educational objectives } \\
\text { and outcomes, and administrative costs. }\end{array}$
\end{tabular}

Policies and Procedures $\quad$ Formal policies and procedures are

\section{Application} implemented.

Program success is related to the ability of an institution to carry out its mission and goals.

A well thought out master plan is essential to program success, but it does not guarantee the program will become an ongoing practice. To ensure permanency, the program must be included in the institution's strategic plan.

Policies and procedures provide structure for the implementation of programs and and consistency and guidelines for program evaluation.

A marketing plan that meets the institution's goals and is geared to the target audience (students, faculty, and parents) is essential to promote an institutional program. and students' needs.

An ongoing assessment of administrative, faculty and student needs is in place.

An evaluation is in place to ensure that programs meet institutional goals and educational objectives.

An organizational chart is in place that indicates who is in charge of program implementation, supervision, assessment, and evaluation.

One central office oversees the planning, implementation, supervision, and assessment of the program.
An assessment is vital to evaluating the relevance of existing programs, assessing students' needs and determining how to better serve the students to meet those needs, developing training programs, and providing feedback to administrators, faculty, and support staff.

An ongoing evaluation provides important data to assess the programs and make changes to better serve the students and faculty.

An organizational chart creates a common purpose and expectations by determining the roles each department plays in program implementation, supervision, assessment, and evaluation.

A centralized policy-making structure ensures consistency. 


\section{Table 1 (Cont.)}

Administrative, Faculty, and Student Factors that Contribute to the Institutionalization of Programs in Higher Education

\begin{tabular}{lll} 
Category & Factor & Application \\
\hline Collaboration & $\begin{array}{l}\text { Administrators regularly meet with } \\
\text { faculty, students, and support staff. }\end{array}$ & $\begin{array}{l}\text { Collaboration with faculty, students, } \\
\text { support staff, and technology services } \\
\text { provides a large base of support for } \\
\text { institutional programs and a means for } \\
\text { informing the campus community about the } \\
\text { programs and their success. }\end{array}$ \\
&
\end{tabular}

Leadership Authority A program director with decisionmaking authority has been appointed.

Visibility

Communication

Faculty

Program Design Support Support in the form of release time to

Staff Development

Funding plan programs is available for faculty.

The program is visible on campus and advertised by the administration as a vital part of the intuition's goals and mission.

An open line of communication has been established to inform the campus

Staff development programs are in place for faculty.

Funding has been added to the institution's budget to support programs and ensure their becoming an ongoing and vital practice of the institution.
Programs are strengthened when they are coordinated by an individual or group whose main responsibility is overseeing a particular program, and aligned with the institution's mission and strategic plans.

The program will become an ongoing and accepted practice and a part of the culture of the institution.

A formal method of communication provides the opportunity for ongoing dialogue which is necessary to form positive relationships and to ensure that the program becomes an expected part of the culture of the institution.

Release time for planning enables faculty to be involved in the planning, implementation, supervision, and evaluation of institutional programs.

Staff development provides faculty with training and program materials in the areas of research, program design and development, course materials, and assessment tools necessary for program success.

Additional funding added to the institution's budget enables faculty to be involved in institutional programs in addition to their teaching and research workload and provides faculty with support staff and compensation for their time. 


\section{Table 1 (Cont.)}

Administrative, Faculty, and Student Factors that Contribute to the Institutionalization of Programs in Higher Education

\begin{tabular}{ll} 
Category & Factor \\
\hline Faculty & \\
Faculty Participation & $\begin{array}{l}\text { Faculty are actively recruited to } \\
\text { participate in the planning, implement- } \\
\text { ation, supervision, and evaluation of } \\
\text { institutional programs. }\end{array}$ \\
Incentives & $\begin{array}{l}\text { Professional and financial Incentives are } \\
\text { available for faculty. }\end{array}$
\end{tabular}

\section{Application}

Program success depends on administrative and faculty commitment to the program

Faculty were more likely to participate in tutoring programs if they received financial incentives. However, faculty considered incentives such as release time or a decreased workload to develop courses and/or conduct research, access to technology services for personal use, travel to conferences, and evaluation for promotion and tenure more important than monetary incentives.

\section{Student}

Library/Research Services

Library resources including access to databases, online journals, reserve materials, and printed text are available to students.

Advising, Counseling, Advising, counseling, and tutoring and Tutoring services are available to students.

Students who have access to instruction in library services do better academically and are more likely to persist in college.

Students who have access to services to academic support services are more likely to succeed.

Technical Support

Students are able to access programs and services online.

Students are using technology to register for classes, access their assignments, interact with faculty, take quizzes, turn in their assignments, find out about institutional programs, and access student support services. 
The review of research related to peer tutoring shows a strong connection between peer tutoring and academic success (e.g. Leung \& Bush, 2003), persistence (e.g. Leone \& Tian, 2009), and retention (e.g. Fantuzzio, Riggio, Connelly, \& Dimeff, 1989). Similarly, the review of research related to the institutionalization of academic support programs demonstrates a strong connection between academic success and the institutionalization of academic support programs (e.g. Pina, 2005). This study sought to identify factors that facilitate and lead to the institutionalization of peer tutoring programs and factors that form barriers to peer tutoring programs, as perceived by administrators who are members of Region II NASPA, who have an interest in and knowledge about peer tutoring, and who are involved in the supervision, evaluation, and delivery of services. This study also looked at how demographic factors such as department affiliation, enrollment, degrees awarded, and Carnegie classification affected administrators' perceptions of peer tutoring. The research methodology used to analyze data and identify factors that a) facilitate peer tutoring programs and lead to their institutionalization and b) form barriers to peer tutoring is addressed in chapter three. 


\section{Chapter Three}

\section{Methods}

There has been a vast amount of research on peer tutoring in higher education; however, there is a gap in the literature on institutional policies and practices that lead to the institutionalization of peer tutoring programs (Tinto, 2006-7). Experts agree that ...we need research that sheds light on the types of programs and institutional practices that lead to successful implementation of programs and do so in ways that ensure that they endure over time. Equally important, we need to know more about how it is that some programs are able to endure at the center of institutional life and become institutionalized, while others remain isolated at the margins of that life. (Tinto, 2006-7. p. 10)

The objective of this study was to identify institutional policies and procedures that will help administrators and faculty understand which institutional practices lead to the institutionalization of peer tutoring programs. This study identified institutional factors that a) facilitate and b) form barriers to peer tutoring programs. It also addressed differences in perceptions of these factors between administrators based on the following demographic factors: a) department affiliation, b) enrollment, c) degrees offered, and d) Carnegie classification.

The researcher identified 26 factors (14 administrative and 12 faculty) that contributed to the institutionalization of peer tutoring from a comprehensive literature review of a) factors that contribute to the growth of peer tutoring, b) barriers to organizational change, and c) factors that institutionalize programs in higher education.

This study sought to answer the following research questions:

a) What institutional factors facilitate peer tutoring programs in Region II NASPA 
institutions, according to administrators who are members of Region II?

b) What factors are barriers to peer tutoring programs in Region II NASPA institutions, according to administrators who are members of Region II?

c) What are the differences in perceptions of peer tutoring among administrators based on the following demographics: department affiliation (e.g. Academic Affairs, Student Affairs), enrollment, highest degree offered, and Carnegie classification?

On completion of the literature review, a questionnaire was developed to be used as a measurement instrument. The factors were ranked on a 4-point Likert scale by a) importance and b) difficulty in implementation. Data were collected by a web-based questionnaire from administrators and faculty who are members of Region II in the National Association of Student Personnel Administrators (NASPA), who have an interest in and knowledge about academic tutoring programs, and who are involved in their supervision, evaluation, and delivery of services. The study looked at the means of the following demographic data: a) institutional position, b) institutional affiliation, c) highest degree awarded, d) student population, e) Carnegie classification, and f) involvement in peer tutoring.

This chapter describes the research methodology used in this study and is divided into two sections. Section one, Research Design, includes a) the study population, b) criteria for defining the study sample, and c) the procedure for selecting the study sample. Section two, Review of Research Methods and Research Procedures, addresses a) the survey instrument, b) principles of survey design, c) survey development, d) reliability and validity, e) pilot studies, f) data dissemination and collection, and g) data analysis. 


\section{Research Design}

Research design "gives direction and systematizes the research" and "the method you choose will affect your results and how you conclude the findings" (Experiment Resources, 2008, para. 1). The research method chosen depends on the following factors: a) the purpose of the study (Bevea \& Nicoll, 1997), b) the reliability and validity of the data, c) the cost of the study, and the d) significance of the study (Experimental Resources, 2008).

There are two basic types of research design methods: qualitative research and quantitative research (McCullough, n.d.). According to Trochim (2006c) "there has...been more energy expended on debating the differences between and relative advantages of qualitative and quantitative methods than almost any other methodological topic in social research" (para. 1).

"The primary aim of quantitative research is to collect, count, measure, and assess the meaning behind specific variables - and ultimately, devise statistical explanations for what the researchers have learned" (Schweitzer, 2009, para. 3). "Quantitative research involves large numbers of respondents, typically 100 or more, and yields results that are representative of the total population" (McCullough, n.d., para. 1). According to Lash (2008), qualitative research is better for exploring, understanding, and uncovering information, while quantitative research is generally better for confirming and clarifying information. Quantitative research was chosen for this study for the following reasons:

- Quantitative research offers accurate measurement and analysis (Jenkins, 2009).

- The problem is defined (Suskie, 1996).

- Results are statistically reliable and are projectable to the population (McCullough, n.d.).

- Quantitative research creates meaning through collected data and "can be used in response to relational questions of variables within the research" (Williams, 2007, p. 65). 
"A variable is any entity that can take on different values...Anything that can vary can be considered a variable" (Trochim, 2006b, para. 1). For example, the objective of this study was to identify factors that institutionalize peer tutoring programs. Administrators and faculty who are involved in peer tutoring programs rated 26 factors that were identified to influence the institutionalization of peer tutoring programs for a) their importance to peer tutoring and b) their difficulty in implementation. The views of participants varied, as did the importance of each factor to peer tutoring and the difficulty of implementation. The study also looked at the differences in responses for the following demographic variables: a) department affiliation, b) institutional size (enrollment), c) degrees awarded, and d) Carnegie classification.

Sample. The population for this study included administrators and faculty who are interested in and have knowledge about academic tutoring programs, and who are involved in their supervision, evaluation, and delivery of services. A mailing list of administrators and faculty was identified by the National Association of Student Personnel Administrators (NASPA), which is comprised of student affairs administrators and faculty in higher education. Participants were grouped by a) institutional position (administrator or faculty), b) affiliation (public, private, or public land grant), c) highest degree awarded (Associates, Bachelors, Masters, Professional, or Doctorate), d) student population (less than 1000; 1001-5000; 500110,000; 10,001-20,000; or more than 20,000), e) Carnegie classification, and f) involvement in peer tutoring. This section is divided into two parts. Part one addresses criteria for defining the study sample and part two examines the procedure and reasons for selecting the population.

Criteria for defining the study sample. This section addresses the reasons for the selection of the criteria used in defining the study sample, NASPA and the Carnegie Classification of Institutions of Higher Education. 
NASPA. NASPA serves as a voice for student affairs administration, policy, and practice and its membership is comprised of approximately 1400 institutions with more than 11,000 student affairs administrators and faculty representing a large range of two-year and four-year institutions in seven regions, including the United States, Canada, and Europe ("About Us," n.d.). NASPA is led by volunteers from member institutions who are elected as regional and national officers. NASPA's mission is to provide professional development and advocacy for student affairs educators and administrators who share the responsibility for a campus-wide focus on the student experience. NASPA's vision is to educate the whole student and integrate student life and learning (“Goals," n.d.).

West Virginia University is a member of Region II, which includes 233 institutions with 2176 members in six states (Delaware, Maryland, New Jersey, New York, Pennsylvania, and West Virginia) plus the District of Columbia and the Virgin Islands. Region II of NASPA was selected for the following reasons: a) West Virginia University is a member of Region II and its faculty and administrators serve as regional board members, attend regional meetings, and serve on regional committees; b) Region II is comprised of 2176 administrators and faculty in higher education from 233 institutions and represents a cross-section of institutions similar to the total membership; and c) the proportion of peer institutions in Region II is comparable to the peer institutions in the total NASPA membership.

Carnegie classification of institutions of higher education. The Carnegie Classification of Institutions of Higher Education includes all colleges and universities in the United States that are degree-granting and accredited by an agency recognized by the U.S. Secretary of Education and identifies similarities and differences among institutions. Developed in 1970 and most recently updated in 2010 , 
...the Carnegie Classification has been the leading framework for describing institutional diversity in U.S. higher education. It has been widely used in the study of higher education, both as a way to represent and control for institutional differences, and also in the design of research studies to ensure adequate representation of sampled institutions, students, or faculty. (“About the Carnegie Classifications," n.d., para. 1)

The Carnegie classifications "provide different lenses through which to view U.S. colleges and universities....They are organized around three fundamental questions: what is taught (Instructional Program classifications), who are the students (Enrollment Profile), and what is the setting (Size \& Setting)" (“About the Carnegie Classifications," n.d., para. 2). The Carnegie Classification of Institutions of Higher Education was selected for the following reasons: a) the Carnegie Classification identifies groups of comparable institutions, b) the Carnegie Classification identifies institutions by function and faculty and students by characteristics which can be used in analyzing demographic data, and c) the classifications were designed to change continually to accurately reflect the nature of higher education at the time (Patterson, 2001).

Procedure for selecting the study sample. A group of West Virginia University peer institutions was identified from the Carnegie Classification of Institutions of Higher Education and further defined by Region II members of NASPA. West Virginia University is classified as a large four-year residential public research university with high research activity, high undergraduate enrollment, and a comprehensive doctoral program with medical and veterinary programs. The following Carnegie classifications were used to identify West Virginia University peer institutions: 
- Basic Classification of Research Activity: This classification addresses institutions that award at least twenty doctoral degrees each year. High research activity indicates that these institutions receive a large portion of their income from sponsored research (“Postsecondary Institutions," n.d.).

- Enrollment Profile: This classification examines the student population and determines the educational mission and the institutional climate and culture ("Classification Description/ Enrollment Profile Classification," n.d.). High undergraduate enrollment means that at least 76 percent of full-time students enrolled are undergraduates.

- Size and Setting: This classification defines the student population and the campus environment. A large residential university indicates that the full-time undergraduate population exceeds 10,000 , with approximately half of the students living on campus (“Classification Description/Size and Setting Classification,” n.d.).

- Graduate Instructional Program: "This classification examines the nature of graduate education, with a special focus on the mix of graduate programs. In this classification, a single graduate-level degree qualifies an institution for inclusion" (“Classification Description/Graduate Instruction Program Classification,” n.d., para. 1). A comprehensive doctoral program with medical and veterinary programs indicates that doctoral degrees are awarded each year in the areas of the humanities, social sciences, engineering, business, education, law, public policy, or social work and degrees in the fields of medicine, dentistry, and/or veterinary medicine.

As shown in Table 2, West Virginia University peer institutions are grouped by the Carnegie classification of institutions in NASPA and in Region II. 
Table 2

Carnegie Classification of Institutions in NASPA and in Region II

\begin{tabular}{lcc}
\hline Classification & NASPA & Region II \\
\hline Basic Classification (RU/H) & 76 & 7 \\
Enrollment Profile (HU) & 238 & 21 \\
Size and Setting (L4/R) & 78 & 10 \\
$\begin{array}{l}\text { Graduate Instruction Program } \\
\text { (CompDoc/MedVet) }\end{array}$ & 50 & 3 \\
\hline
\end{tabular}

Among the approximately 1400 institutions with more than 11,000 members belonging to NASPA, 76 public research universities were identified with high research activity (RU/H), 238 public institutions were identified with a high undergraduate enrollment (HU), 78 public institutions were listed in the large four-year, primarily residential category (L4/R), and 50 public institutions were identified in the comprehensive doctoral with medical/veterinary category (CompDoc/MedVet). Among those institutions belonging to NASPA Region II, which includes 233 institutions with 2176 members, 7 public research universities were identified as a research university with high research $(\mathrm{RU} / \mathrm{H}), 21$ public institutions were identified with a high undergraduate enrollment (HU), 10 public institutions were listed in the large four-year, primarily residential category (L4/R), and 3 public institutions were identified in the comprehensive doctoral with medical/veterinary category (CompDoc/MedVet). 


\section{Review of Research Methods and Research Procedures}

Survey instrument. There has been a debate in higher education on whether it is better to use an existing survey or design your own (Hyman, Lamb, \& Bulmer, 2006; Suskie, 1996). Advantages of using an existing survey include: a) the survey has been extensively tested and "methodological work on conceptualization and measurement has been done" (Hyman et al., 2006, para. 12) and b) reliability and validity have been established (Suskie, 1996).

Recent interest in higher education assessment has produced "a wealth of published questionnaires available on subjects such as freshman attitudes, student retention, faculty views, campus climate" (Suskie, 1996, p. 9), and the effects of peer tutoring on academic achievement (Leung \& Bush, 2003), adjustment to college (Mynard \& Almarzouqi, 2006), academic and social development (Tinto, 1993), and retention (Hendriksen et al., 2005). However, research was not available on institutional policies that contribute to the institutionalization of peer tutoring and no questionnaires were available. Tinto (2006-7) proposed that what was needed is research that will help us understand which "institutional practices...lead to successful implementation of programs" and "how it is that some programs are able to endure at the center of institutional life and become institutionalized, while others remain isolated" (p. 10).

From an extensive review of literature on peer tutoring in higher education and other programs that have become institutionalized, such as distance learning, 14 administrative and 12 faculty factors that contribute to the institutionalization of peer tutoring were identified. A 4point Likert-scale survey was developed to look at the importance of each factor and their difficulty of implementation. The first part of the survey included eight questions which identified the participant by demographic data based on the Carnegie Classification of Institutions of Higher Education (enrollment profile, institutional affiliation, degrees awarded, 
and department affiliation) and level of involvement in peer tutoring. A Likert-scale survey was selected because "Likert-scales are efficient (a great deal of information can be provided quickly and compactly) and permit comparisons among answers within the scale" (Suskie, 1996, p. 33). They are also useful in describing the characteristics of a large population and provide standardized information, which ensures that similar data can be collected from groups (Milne, 1999) and "provides comparable information from everyone taking the survey, which allows for meaningful analysis" (Whelchel, n.d.).

Principles of survey design. Pfleeger and Kitchenham (2001) define a survey as a method for collecting information to describe, compare or explain knowledge, attitudes and behavior. "The design process begins with reviewing...objectives, examining the target population identified by the objectives, and deciding how best to obtain the information needed to address those objectives" (Kitchenham \& Pfleeger, 2002a).

Survey items are based on two things: the objectives of the survey and the information to be collected (SurveyMonkey, 2007) and they play a role in providing unbiased and relevant survey responses (SurveyMonkey, n.d.). Therefore, an important goal in survey design is to construct clear questions and answers using language that is easy for participants to understand (SurveyMonkey, 2007; Suskie, 1996). A good survey design should include items that a) read well and are quick and easy to answer (SurveyMonkey, 2007; Suskie, 1996), b) avoid biased or leading words such as would, should, and might which can produce differences in results (“Survey Design : Writing Great Questions for Online Surveys,” 2011; Suskie, 1996), and c) motivate the respondent to answer (SurveyMonkey, n.d.).

Kitchenham and Pfleeger (2002b) recommend the following procedures of survey design: a) begin with a research question, b) search relevant literature to identify what has already been 
done, how data was collected, and recommendations for future research; c) define research objectives, d) construct the survey instrument making sure that items are constructed in a way that respondents can answer them easily and accurately; e) evaluate the instrument to establish reliability and validity; f) analyze the data, and g) document the results. This section addresses how the researcher followed the principles of survey design described above in this study.

Research questions. The first step in survey design is to identify research questions. (Kitchenham \& Pfleeger (2002b). A research question identifies the topic to be studied and "defines which data you need to collect and which methods you will use to access and analyze your documents" (Cronon, 2009, para. 2). In developing a research question, Danya International, Inc. (2003, para. 3) recommends asking the following questions:

- Do I know the field and its literature well?

- What areas need further exploration?

- Could my study fill a gap? Lead to greater understanding?

- Has a great deal of research already been conducted in this topic area?

- Has this study been done before? If so, is there room for improvement?

- Most importantly, will my study have a significant impact on the field?

Peer tutoring has become an important factor in higher education. Research indicates that peers have more influence on student success and retention than any other group on campus, including faculty (Astin, 1993; Bean, 1985), and the most influential peer interactions are those that reinforce learning in non-classroom settings, such as peer tutoring (Pascarella \& Terenzini, 2005). As the population in higher education has increased, and the large size of freshman classes has resulted in less interaction between professors and students, the need for supplemental instruction, such as peer tutoring, has also increased (Tovar \& Simon, 2003). Peer 
tutoring has also been shown to improve exam scores, reduce stress, increase student satisfaction (Fantuzzo et al., 1989), and increase retention (Fantuzzo, et al., 1989; Goldschmid \& Goldschmid, 1976; Good et al., 2000; Tinto, 2002; Topping, 1996).

A review of the literature on peer tutoring revealed an abundant amount of research on a) the history of peer tutoring (e.g. Dabkoski, 2000), b) different types of peer tutoring methods e.g. Tinto, 1998b), c) the benefits of peer tutoring to both students and tutors (e.g. (Luca \& Clarkson, 2002), and d) the impact of peer tutoring on retention (e.g. Tovar \& Simon, 2003). Research indicated that students are more likely to use support services when those services come to them (Ad Hoc Committee for First Year \& Second Year Experiences at West Virginia University, 2010), however there was a gap in the literature on peer tutoring in the residence halls, also known as residential peer tutoring. This study began with the question: How does residential peer tutoring effect academic achievement and retention?

An examination of the recommendations for further research in the field of peer tutoring identified an important gap in the literature in the area of institutional policies and procedures that enable peer-tutoring programs to endure and become institutionalized. Future research was recommended by Tinto (2006-7), who proposed that what is needed is research that will help us understand which "institutional practices...lead to successful implementation of programs" and "how it is that some programs are able to endure at the center of institutional life and become institutionalized, while others remain isolated" (p. 10).

A further review of the literature revealed a study by Anthony Pina (2005) on the institutionalization of distance learning programs, which became a model for further research and survey development for this study. Through a search of the literature on educational technology, distance learning, and educational change, Pina identified 30 factors that influence 
the institutionalization of programs in higher education. Similarly, an examination of research on administrative, faculty, and student factors that a) contribute to the growth of peer tutoring, b) form barriers to organizational change, and c) institutionalize programs in higher education, revealed a group of 26 factors that either contribute or form barriers to the institutionalization of peer tutoring programs and research questions began to emerge:

- What institutional factors do administrators see as facilitating peer tutoring programs?

- What institutional factors do administrators see as forming barriers to peer tutoring programs?

- What are the differences in perceptions of peer tutoring between administrators based on the following demographics: a) department affiliation, b) enrollment, c) highest degree awarded, and d) Carnegie classification?

Literature review. The literature identifies what has already been done, how data was collected, and recommendations for future research (Kitchenham \& Pfleeger 2002b) and establishes a "clear tie between the works that you have cited and the topic that you are writing about" ("Importance of Literature Review, 2009, para. 1). The literature review shows the reasons why the research needs to be carried out and how it adds to the research that has already been done ("Review of Literature," n.d.). It is important to conduct an extensive review of existing literature and surveys before designing a questionnaire to ensure the questionnaire meets the researcher's needs and corresponds to the survey's statement of objectives ("Questionnaire Design," 2009).

Taylor (n.d., para. 3) suggested the following questions the researcher should ask while conducting a literature review:

- What is the specific problem the research seeks to define? 
- What type of study will be conducted?

- What is the extent of the research available?

- Has the literature been critically analyzed?

- Is the literature review useful?

The problem this research sought to define is which institutional factors a) facilitate peer tutoring programs and b) form barriers to peer tutoring programs. A quantitative study was conducted using an electronic survey. The survey was developed from 26 factors that influence the institutionalization of peer tutoring programs identified in a literature review on factors that a) contribute to the growth of peer tutoring, b) form barriers to organizational change, and c) institutionalize programs in higher education and modeled on a study by Anthony Pina (2005) on the institutionalization of distance learning programs. Survey items were grouped by a) category (administrative and faculty) and b) factor. Using a 4-point Likert scale, participants were asked to a) rate the importance of each factor to peer tutoring and b) rate the difficulty of implementing each factor at their institution.

The population for this study initially included administrators and faculty from Region II NASPA (National Association of Student Personnel Administrators) who are interested in and have knowledge about academic tutoring programs, and who are involved in their supervision, evaluation, and delivery of services. However, there was a low response rate of faculty, which resulted in nonresponse error and made the faculty data unusable. Nonresponse error occurs when the number of respondents from a targeted population who respond differs substantially from those who did not respond, making it difficult to make generalizations from the sample about the entire population (Sivo et al., 2006). Therefore, just administrative data was reported and faculty data was used for demographic and descriptive purposes only. In addition, a 
comparison was made of administrators' perceptions based on the following demographic factors: department affiliation, enrollment, highest degree awarded, and Carnegie classification. Before a survey instrument can be constructed, the purpose of the survey and the topics or issues of interest must be identified (Houston, n.d.). Guidelines for constructing survey items include (“Developing a Survey," n.d., p. 1):

- Ask only for information that you need.

- Consider the survey's length in time, not pages.

- $\quad$ Keep the format consistent.

"Choosing a research tool or instrument is one of the most important steps in planning a research study. Research instruments must be selected or developed carefully to fit the research design and the plan for data analysis so that the data collected will be useful for answering the research questions (Gaberson, 1997, p. 1). Surveys are easy to administer and most commonly used in quantitative research ("Writing Guide: Survey Research,” 2011).

From the literature review, the researcher identified 26 institutional factors that either contributed or presented barriers to peer tutoring programs. A survey was selected for the research instrument of this study and designed with two parts: Part one identified the participant by demographics and part two asked the participant to rate each of the factors for a) importance to peer tutoring and b) difficulty in implementation. The model for the survey was a study by Pina (2005) on the institutionalization of distance learning programs, which identified factors that influence the institutionalization of programs in higher education.

The survey design consisted of two stages. Stage one began with a review of the literature on peer tutoring which revealed that 20 of Pina's factors also applied to peer tutoring. The 20 common factors were divided into three categories by involvement in institutional programs: 
a) administrative (planning and organization of institutional programs), b) faculty (resources for institutional programs), and c) students (needing and using institutional programs). Next, two tables were constructed. The first table had three headings: a) category, b) factor, and c) application and indicates how each of Pina's factors applies to peer tutoring. The second table had two headings: a) categories and b) factors and shows the relationship between the categories and peer tutoring factors.

In stage two the following demographic information, used to identify the participants in part one of the survey instrument, was selected from the Carnegie Classifications ("Classification Descriptions," n.d.): a) institutional affiliation, b) enrollment, c) degrees awarded, and e) research level. Four institutional demographic items were added: the participant's a) position at the institution, b) department affiliation, and c) level of involvement in peer tutoring and d) the types of peer tutoring offered at the institution. Eighteen factors that apply to peer tutoring were selected from Pina's list and used as categories for each peer-tutoring factor. The categories were grouped by institutional involvement: administrative (12) and faculty (6). Factors were broken down by function and department.

Each factor was followed by two 4-point Likert scales. A Likert scale was chosen for the following reasons: a) options are ranked, with each option equidistant from the next and b) the Likert scale is best suited to measure attitudes (Collie \& Rine, 2009). On the first scale, respondents rated the level of importance for each factor to the institutionalization to peer tutoring. Responses to the first scale were coded as follows: 1, critical; 2, important, but not critical; 3, of minor importance; and 4, not important. On the second scale, respondents were asked to rate how difficult it is for their institution to implement each factor. Responses to the 
second scale were coded as follows: 1 , nearly impossible; 2 , very difficult; 3 , of minor difficulty; and 4 , not difficult.

Establishing reliability and validity. The two most important factors of a measurement procedure are reliability and validity (Miller, n.d.). In fact, "every time research is used, reliability and validity are...the criteria upon which" researchers "should base their evaluation of [the] research" (Buelo \& Hinkle, 2002, p. 370).

In conducting research, two of the main criteria of evaluation are: a) whether we are measuring what we intend to measure and b) whether the same measurement process yields the same results ("Validity and Reliability," n.d.). Reliability is the ability of an instrument to measure something consistently, while validity refers to how well the instrument measures what it says it is measuring (Buelo \& Hinkle, 2002.). "Reliability is necessary but not sufficient for validity....For something to be valid it must be reliable, but it must also measure what it is intended to measure" (Miller, n.d., p. 3).

Researchers believe that validity is the most important consideration in evaluating a survey instrument (Canadian Psychological Association, 1996). Content validity measures the degree to which the test items represent what is being measured (Kay, 1997). Suskie (1996) recommends having a panel of experts look at the survey before it is administered to establish content validity. A panel of experts provide valuable feedback and let the researcher know if a) each item is interpreted the way it was intended, b) each item is clear and easily understood, c) items have a relationship with the study's topic and goals, and d) the intent behind each item is clear to colleagues knowledgeable about the subject (Suskie, 1996).

The survey for this study was submitted to a panel of experts before it was administered to establish validity. The following nationally renowned experts in the areas of peer tutoring and 
institutionalization cited in this study were invited to be on the panel of experts: a) Dr. John. N. Gardner, President of the John N. Gardner Institute for Excellence in Undergraduate Education and Senior Fellow, National Resource Center on the First-Year Experience and Students in Transition, University of South Carolina; b) Dr. Ernest T. Pascarella, Professor and Mary Louise Petersen Chair in Higher Education, University of Iowa and national authority on peer tutoring; and c) Dr. Anthony Pina, Dean of Online Studies, Sullivan University and expert on the institutionalization of programs in higher education. As recommended by Ramirez (2002), the panel also included an expert in survey design and analyzing data: Dr. Reagan Curtis, Associate Professor of Educational Psychology, West Virginia University.

Alternate panel members were: Dr. Andrew Beckett, Dean of the University College at the University of Iowa and authority on the first-year experience; Dr. Marie Leichliter, Coordinator of the West Virginia University Honors College Peer Tutoring Program; Dr. Shawn M. Kuba, Director of the West Virginia Wesleyan Academic Learning Center, and Dr. Richard Walls, Professor of Technology, Learning, and Culture, West Virginia University. Although Dr. Pascarella had agreed to serve on the panel of experts, upcoming surgery prohibited him from participating and Dr. Leichliter agreed to take his place.

Reliability is established in a research instrument by evaluating "the response against a given construct or idea. Different questions that test the same construct should give consistent results. Internal consistency reliability evaluates individual questions in comparison with one another for their ability to give consistently appropriate results” (“Internal Consistency Reliability," n.d., para. 1).

The most common measure of internal consistency is Cronbach's alpha "Cronbach's alpha is a measure of whether or not the questions on a test are measuring the same thing" ("Can 
anyone explain the meaning of "Cronbach Alpha" to me in layman's terms?" 2009, para. 3). It “... is a coefficient (a number between 0 and 1) that is used to rate the internal consistency (homogeneity) or the correlation of the items in a test" ("Cronbach's alpha," n.d., para. 13). This study will use Cronbach's alpha to establish reliability.

The formula for computing Cronbach's alpha is $\alpha=\frac{N \cdot \bar{c}}{(\bar{v}+(N-1) \cdot \bar{c})}$, in which $\mathrm{N}$ represents the number of survey items being measured, $\bar{v}$ equals the average variance for the current sample, "and $\bar{c}$ is the average of all covariances between the components across the current sample..." (“Cronbach's alpha,” 2011, para. 2).

Reliability was also established by "using a pilot test to collect data from...subjects not included in the sample" (Radhakrishna, 2007, para. 10). This study recruited participants for a pilot study from a group of professionals who are interested in and have knowledge about academic tutoring programs and are involved in their supervision, evaluation, and delivery of services from outside the sample.

Analysis of data. "Data analysis and interpretation is the process of assigning meaning to the collected information and determining the conclusions, significance, and implications of the findings" (“Analyzing and Interpreting Data," n.d., para. 1). Data analysis identifies trends and groups and summarizes collected information ("Analyzing and Interpreting Data: Making Sense of It All," n.d.). The three most common calculations used in quantitative data analysis are the mean, standard deviation, and the frequency distribution of each response ("Analyzing and Interpreting Data," n.d.). Mean scores, standard deviations, and item ranking of institutionalization factors were calculated for each of the factors identified in this study for their a) importance to peer tutoring and b) difficulty of implementation. 
Further testing was conducted using SPSS (Statistical Package for the Social Sciences) to determine the difference between groups. An analysis of variance (ANOVA), a test that compares group means by analyzing comparisons of variance estimates, was done in order to determine which groups differ from each other and how they differ (Plonsky, 2011). "The analysis of variance...is the most widely used method of statistical analysis of quantitative data. It calculates the probability that differences among the observed means could simply be due to chance" ("The ANOVA," n.d., para. 1).

Although there are other tests that could have been used to determine the difference in perceptions between groups, such as the t-test, the ANOVA was chosen for the following reasons (“Difference between T-TEST and ANOVA," 2012):

- The t-test is commonly used when the test statistics (means) form a normal distribution. In this study there were several outliers, which means that several means were far apart from the rest of the data.

- The t-test is most commonly used when comparing two means, while the ANOVA is favored when comparing three or more means. In this study multiple comparisons were made between groups for the following factors: a) department affiliation (three comparisons), b) enrollment (four comparisons), c) degrees awarded (five comparisons), and Carnegie classification (8 comparisons).

- The t-test is most commonly used when testing hypotheses. This study did not test any hypotheses.

- Furthermore, "A t-test has more odds of committing an error the more means are used, which is why ANOVA is used when comparing two or more means" ("Difference between T-TEST and ANOVA,” 2012, para. 7). 
A post-hoc test was also calculated to determine the significance of the difference. The Bonferroni correction, a statistical test "that allows many comparison statements to be made (or confidence intervals to be constructed) while still assuring an overall confidence coefficient is maintained" ("Bonferroni's method," n.d., para. 1), was used. This test commonly is used with ANOVA when the researcher has selected a fixed set of comparisons in advance ("Bonferroni's method," n.d.).

Documentation. The final step of the survey process is reporting the results. The report "should include a background of why you conducted the survey, a breakdown of the results, and conclusions and recommendations supported by this material. This is one of the most important aspects of your survey research as it is the key in communicating your findings to those who can make decisions to take action on those results" (Reporting Survey Results, 2011, para. 1). Documentation of the results should also include the following: a) statement of purpose, b) development of the survey instrument, c) administration of the survey instrument, d) explanation of the dissemination and collection of data, e) data analysis, $\mathrm{f}$ ) report of findings, and $\mathrm{g}$ ) recommendations for further research (Collie \& Rine, 2009). This study followed these guidelines.

Survey Development. The development of a survey instrument is based on the identification of the anticipated outcome to be measured (Strachota, 2006). The objective of this study was to identify institutional policies and procedures that will help administrators and faculty understand which institutional practices lead to the institutionalization of peer tutoring programs. From an extensive literature review of administrative, faculty and student factors that a) contribute to the growth of peer tutoring, b) present barriers to organizational change, and c) institutionalize programs in higher education, 26 institutional factors were identified that either 
contribute or present barriers to the institutionalization of peer tutoring programs. It also addressed differences in perceptions of these factors between administrators based on the following demographic factors: a) department affiliation, b) enrollment, c) degrees awarded, and d) Carnegie classification.

A 4-point Likert-scale questionnaire was developed on SurveyMonkey software to collect data on demographic information and the practices in peer tutoring in higher education that lead to the institutionalization of peer tutoring based on the research of Pina (2005, 2008a, 2008b). Pina studied actions that influence the institutionalization of programs in higher education. The purpose of his study was to determine actions that institutions can take to institutionalize distance education programs. Pina identified 30 factors from a literature review of educational technology, distance learning, and educational change that influence the institutionalization of programs in higher education. Pina surveyed a group of 170 administrators and faculty who were involved in the planning, implementation, supervision, and evaluation of distance learning programs at their institutions. Survey questions were grouped into five topic areas: planning, organization, resources, personnel, and student services. Although these factors apply to distance learning, they are relevant to all programs, including peer tutoring.

By reviewing Pina's research and expanding the literature review to include administrative, faculty, and student factors that contribute to the growth of peer tutoring, barriers to organizational change, and factors that institutionalize programs in higher education, a list of 26 (14 administrative and 12 faculty) factors that contribute to the institutionalization of peer tutoring emerged. Eighteen of Pina's factors that also apply to peer tutoring became categories to which each factor was applied. Each factor was rated for importance (1, critical; 2, important, but not critical; 3, of minor importance; and 4, not important) and difficulty of implementation (1, 
nearly impossible; 2 , very difficult; 3 , of minor difficulty, or 4 not difficult). Table 3 illustrates the relationship between the categories and factors that contribute to the institutionalization of peer tutoring in higher education. 
Table 3

Relationship between Categories and Institutionalization Factors

\begin{tabular}{|c|c|c|c|}
\hline Categories & Factors & Categories & Factors \\
\hline \multicolumn{4}{|l|}{ Administrative } \\
\hline $\begin{array}{l}\text { Institutional } \\
\text { Mission and Goals }\end{array}$ & $\begin{array}{l}\text { Peer tutoring is compatible } \\
\text { with the institution's } \\
\text { mission and goals. }\end{array}$ & Organization & $\begin{array}{l}\text { Peer tutoring is a campus-wide } \\
\text { function and not part of a } \\
\text { specific school, department, or } \\
\text { academic discipline. }\end{array}$ \\
\hline $\begin{array}{l}\text { Policies and } \\
\text { Procedures }\end{array}$ & $\begin{array}{l}\text { Formal policies and procedures } \\
\text { for peer tutoring have been } \\
\text { implemented. }\end{array}$ & Visibility & $\begin{array}{l}\text { Peer tutoring is visible on } \\
\text { campus. }\end{array}$ \\
\hline Evaluation & $\begin{array}{l}\text { An evaluation of peer tutoring is } \\
\text { in place to ensure that programs } \\
\text { meet educational goals. }\end{array}$ & $\begin{array}{l}\text { Leadership } \\
\text { Authority }\end{array}$ & $\begin{array}{l}\text { A program director for peer } \\
\text { tutoring with decision-making } \\
\text { authority has been appointed. }\end{array}$ \\
\hline Needs Assessment & $\begin{array}{l}\text { An assessment of peer tutoring } \\
\text { is ongoing in the areas of: } \\
\text { a) student needs. } \\
\text { b) faculty needs. } \\
\text { c) institutional needs. }\end{array}$ & Centralization & $\begin{array}{l}\text { One central office oversees the } \\
\text { implementation, supervision, } \\
\text { and assessment of the peer } \\
\text { tutoring program. }\end{array}$ \\
\hline Master Plan & $\begin{array}{l}\text { A master plan for peer tutoring } \\
\text { has been developed that } \\
\text { outlines: } \\
\text { a) program relevance and } \\
\text { importance. } \\
\text { b) educational objectives. } \\
\text { c) administrative costs. }\end{array}$ & Support & $\begin{array}{l}\text { Peer tutoring administrators and } \\
\text { staff meet regularly with other } \\
\text { campus groups to ensure } \\
\text { support. }\end{array}$ \\
\hline Marketing & $\begin{array}{l}\text { A marketing plan is in place to } \\
\text { promote peer tutoring. }\end{array}$ & Funding & $\begin{array}{l}\text { The peer tutoring program and } \\
\text { staff are a permanent item in the } \\
\text { institutional budget. }\end{array}$ \\
\hline \multicolumn{4}{|l|}{ Faculty } \\
\hline Shared Vision & $\begin{array}{l}\text { There is a shared vision of peer } \\
\text { tutoring among departments. }\end{array}$ & $\begin{array}{l}\text { Staff } \\
\text { Development }\end{array}$ & $\begin{array}{l}\text { Ongoing staff development on } \\
\text { peer tutoring practices is in } \\
\text { place. }\end{array}$ \\
\hline Collaboration & $\begin{array}{l}\text { Faculty and administrators } \\
\text { collaborate on peer tutoring to: } \\
\text { a) plan. } \\
\text { b) implement. } \\
\text { c) decide budget. } \\
\text { d) assess effectiveness. }\end{array}$ & Incentives & $\begin{array}{l}\text { a) Professional incentives to } \\
\text { participate in peer tutoring } \\
\text { programs are available (i.e. } \\
\text { credit towards promotion and } \\
\text { tenure, flexibility in time } \\
\text { teaching). } \\
\text { b) Financial incentives to } \\
\text { participate in peer tutoring } \\
\text { programs are available (i.e. merit } \\
\text { pay, grants for future research, } \\
\text { new computer). }\end{array}$ \\
\hline Communication & $\begin{array}{l}\text { Communication between faculty } \\
\text { and students: } \\
\text { a) encourages student } \\
\text { engagement. } \\
\text { b) supports different teaching } \\
\text { styles. } \\
\text { c) supports different learning } \\
\text { styles. }\end{array}$ & Responsibility & $\begin{array}{l}\text { Peer tutoring practices are } \\
\text { oriented toward developing a } \\
\text { climate in which students' } \\
\text { responsibility and active } \\
\text { participation are promoted. }\end{array}$ \\
\hline
\end{tabular}


Each factor was followed by two Likert scales. On the first scale, respondents rated the level of importance for each factor to the institutionalization to peer tutoring. Responses to the first scale were coded as follows: 1, critical; 2, important, but not critical; 3, of minor importance; and 4, not important. On the second scale, respondents were asked to rate how difficult it is for their institution to implement each factor. Responses to the second scale were coded as follows: 1 , nearly impossible; 2 , very difficult; 3 , of minor difficulty; and 4, not difficult. The survey instrument also contained a demographic section in which respondents identified: their position at the institution (administrator or faculty); their involvement in peer tutoring; and indicate a) whether their institution was private, public, or a public land grant institution; the highest degree awarded by their institution; the enrollment of their institution; and its Carnegie classification.

Pina's sample included distance learning professionals who use electronic communication as part of their job; therefore, he distributed the cover letter and survey instrument electronically through a website. Participants were sent a post card explaining the study, along with directions to access the website. Similarly, since the sample for this study included administrators and faculty, who are interested in and have knowledge about academic tutoring programs, and are involved in their supervision, evaluation, and delivery of services; and who also use electronic communication in their jobs, it was decided to distribute the cover letter and survey electronically through a website. After a mailing list of Region II NASPA members was received, an invitation to participate in the study and a link to the survey was sent to each member electronically via SurveyMonkey. A follow-up email was sent via SurveyMonkey six weeks later to those who had not completed the survey. 
Reliability and validity. Accuracy in measurement is very important in research. The main reason accuracy matters is that a measure that is not reliable cannot be valid ("Reliability of Measurement," n.d.). Reliability refers to the ability of the survey instrument to consistently measure what it proposes to measure (research questions/hypotheses). Reliability is established by the degree to which the survey instrument yields the same results on repeated trials (Kay, 1997). Reliability is assessed by three tests: internal consistency reliability, alternate-form reliability, and test-retest reliability. Internal consistency reliability refers to consistency within the questionnaire; "it is measured by correlating item scores with one another in some fashion, generally using a statistic called a correlation" (Suskie, 1996, p. 55). Test-retest reliability refers to consistency over time and is measured by administering the same questionnaire to the same population to see how consistent their responses are ("Survey Methodology: Reliability and Validity," n.d.). In alternate- form reliability differently worded surveys are used to measure the same characteristic ("Survey Methodology: Reliability and Validity,” n.d.).

It is important to be concerned with a test's reliability for two reasons. First, reliability provides a measure of the extent to which an examinee's score reflects random measurement error.... The second reason to be concerned with reliability is that it is a precursor to test validity. That is, if test scores cannot be assigned consistently, it is impossible to conclude that the scores accurately measure the domain [field] of interest. (Wells \& Wollack, 2003, pp. 2-3)

The most common methods used to test reliability are the Cronbach alpha, and the splithalf reliability coefficient, which provide a measure of the extent to which the items on a questionnaire are consistent (Wells \& Wollack, 2003). Ranging from 00.0-1.00, the "Cronbach alpha is used to estimate the proportion of variance that is...consistent in a set of test scores. For 
example, if the Cronbach alpha ...turns out to be .90 , you can interpret that as meaning that the test is $90 \%$ reliable and...10\% unreliable" (Brown, 2002, p. 17). "In spilt-half, you treat one single test as two tests by dividing the items into two subsets. Reliability is estimated by computing the correlation between the two subsets" (Yu, n.d., para. 3).

The researcher used Cronbach alpha to test the internal consistency reliability of the survey items. It also tested how closely related the items were between groups, faculty and administrators, and across the survey items. Cronbach alpha was selected for the following reasons: a) internal consistency reliability is used to judge the consistency of results across items on the same test (Cherry, 2011), b) "in internal consistency reliability estimation we use our single measurement instrument administered to a group of people on one occasion" (Trochim, 2006b, para. 1), c) Cronbach alpha is a type of internal consistency reliability (Trochim, 2006a), and d) Cronbach alpha is "applicable when questions are small scales in their own right like the Likert scale" and "Cronbach alpha is most often the reliability estimate of choice for survey research" (Brown, 1997, p. 20).

Validity is the extent to which a test measures what it is supposed to measure. There are three basic ways to establish validity (Suskie, 1996):

a) Compare survey results with the results from other methods of data collection.

b) Compare survey results from different groups to see if the differences match what others have found.

c) Have a panel of experts review the survey before it is administered to find out if a) they interpret each item the way it was intended, b) each item is clear and easily understood, c) items have s relationship with the study's topic and goals, and d) the intent behind each item is clear to colleagues 
knowledgeable about the subject.

The next section addresses two popular methods for establishing reliability (pilot tests) and validity (panel of experts).

Pilot studies. Pilot studies are an important step in survey research as they are valuable in "identifying and addressing problems in surveys early in the process" and "give researchers more time to improve the survey instrument....Flaws that are discovered after a survey has been administered usually cannot be compensated for in data analysis, and some study goals simply may not be realized" (Blair, 2011, para. 2). This section addresses two of the most common means used to establish validity and reliability: a) a panel of experts (validity) and b) a pilot test (reliability).

Panel of experts. "To ensure the accuracy of the data collected and the conclusions derived from the findings, it is essential to validate the survey" (Turocy, 2002, p. S-176). To ensure content validity, experts in survey research and in the subject matter must be consulted and their input used in question revision and redesign (Strachota, Schmidt, \& Conceicao, 2006). This helps to ensure that the instrument will be suitable to individuals who administer it, are tested by it, and who will use the results (Turocy, 2002). A review by a panel of experts is the first step in evaluating the survey instrument (Blair, 2011).

Ramirez (2002) recommended including on the panel not just experts in the field of study, but also experts in survey design and analyzing data. For the purpose of this study, a panel of four was selected to include two members who are experts in the area of peer tutoring programs in higher education and are involved in their supervision, evaluation, and delivery of services, one member who is an expert in the institutionalization of programs in higher education, and one member who is an expert in survey design. 
Panel members included Dr. Reagan Curtis, Associate Professor of Technology, Learning and Culture, West Virginia University and expert on survey design; Dr. John. N. Gardner, President of the John N. Gardner Institute for Excellence in Undergraduate Education and Senior Fellow, National Resource Center on the First-Year Experience and Students in Transition, University of South Carolina; Dr. Marie Leichliter, Coordinator of the West Virginia University Honors College Peer Tutoring Program; and Dr. Anthony Pina, Dean of Online Studies, Sullivan University and expert on the institutionalization of programs in higher education.

Panel members were asked to participate via electronic email (See Appendix A). A second email was sent to each participant upon receipt of acceptance (See Appendix B.) which included a) reviewer directions (See Appendix C.) and b) a copy of the first draft of the survey (See Appendix D).

The panel was asked to provide feedback in the following areas (Ramirez, 2002, p. 3):

- Content of questionnaire

- Importance/meaningfulness of question areas to research aims

- Wording and terminology of items

- Comprehensiveness/mutual exclusivity of answer choices

- Respondent identification - titles/roles of best respondent

- Respondent motivation/knowledge/ability to answer questions

- Sensitivity/threat of information request

- Cost/burden to respondent population

- Appropriate incentives and/or fieldwork methods for the population

Recommendations. The panel of experts made the following recommendations to the invitation to participate: a) add rank and contact information for Principle Investigator and 
b) change wording of the phrase West Virginia University's Institutional Review Board acknowledgement to West Virginia University's Institutional Review Board approval.

The panel made the following recommendations to the demographics section:

Question 1: Add "other" as an option. The reason for this was that participants may be trainers or supervisors rather than faculty and/or administrators. Question 2: Change responses to clarify how participants are involved in peer tutoring to better reflect their involvement. The reason for the change was that responses may be similar and, therefore, confusing. Question 3: Change the focus of the question from which types of peer tutoring programs are offered at your institution to where does peer tutoring take place at your institution? This will identify the different types of tutoring (i.e. residential, learning center-based) and the location. Question 5: Eliminate public land-grant institutions and include private for-profit institutions. This will eliminate a very small sector (public land-grant institutions and divide the private sector to include private non-profit and private for-profit. Question 8: Modify the Carnegie Classifications to include all categories.

The panel also made the following recommendations to the survey instrument: a) keep the options for rating the factors to no more than four; this will provide a clearer idea of what the boundaries are for each of the factors and keep participants from gravitating to the middle and b) all of the institutionalization factors were deemed appropriate; however it was recommended that similar factors be combined and wording be changed slightly for clarity.

Pilot test. Reliability is established by "using a pilot test to collect data from...subjects not included in the sample (Radhakrishna, 2007, para. 10). A pilot test is a "small experiment designed to test logistics and gather information prior to a larger study, in order to improve the latter's quality and efficiency.... It can reveal deficiencies in the design of a proposed experiment or procedure and these can then be addressed before time and resources are expended on large 
scale studies" (Altman, Burton, Cuthill, Festing, Hutton, \& Playle, 2006, p. 1). Altman et al. (2006) identified the following factors that are addressed by a pilot test:

- Check that the instructions given to investigators (e.g.... procedures) are comprehensible.

- Check that investigators and technicians are sufficiently skilled in the procedures.

- Check the correct operation of equipment.

- Check the reliability and validity of results.

- Detect a floor or ceiling effect (e.g. if a task is too difficult or too easy there will be skewed results (p. 1).

The survey instrument was revised according to the recommendations of the panel of experts above and an on-line version (See Appendix E) was pilot-tested on June 2, 2011 with 10 professionals representative of the target population to establish reliability. All participants supervise peer-tutoring programs as either an administrator or faculty director of the tutoring program in their academic department. Eight participants completed the demographic section, seven participants completed the survey. There were no recommended changes to the survey.

Table 4 illustrates the following demographic characteristics of survey respondents:

a) Institutional role, b) involvement in peer tutoring, c) location of peer tutoring, d) involvement in the supervision of peer tutoring, e) institutional classification, f) highest degree awarded, g) institutional enrollment, and h) Carnegie Classification. Demographic characteristics are reported by frequency and percentage. 
Table 4

Pilot Study: Demographic Characteristics of Survey Respondents

\begin{tabular}{|c|c|c|c|}
\hline Classification & Role & Frequency & Percent \\
\hline $\begin{array}{l}\text { Institutional Role } \\
\text { (Check all that apply.) }\end{array}$ & $\begin{array}{l}\text { Administrator } \\
\text { Faculty }\end{array}$ & $\begin{array}{l}4 \\
4\end{array}$ & $\begin{array}{l}50 \\
50\end{array}$ \\
\hline $\begin{array}{l}\text { Involvement in Peer Tutoring } \\
\text { (Check all that apply.) }\end{array}$ & $\begin{array}{l}\text { Administrative oversight of peer tutoring/ } \\
\text { Not involved in day-to-day operations } \\
\text { Administrators } \\
\text { Faculty } \\
\text { Directing or coordinating peer tutoring/ } \\
\text { Involved in day-to-day operations } \\
\text { Administrators } \\
\text { Faculty }\end{array}$ & $\begin{array}{l}3 \\
1 \\
\\
2 \\
2 \\
\end{array}$ & $\begin{array}{l}37.5 \\
12.5 \\
\\
25 \\
25 \\
\end{array}$ \\
\hline $\begin{array}{l}\text { Involvement in Peer Tutoring } \\
\text { (Check all that apply.) }\end{array}$ & $\begin{array}{l}\text { Evaluating the peer tutoring program } \\
\text { Administrators } \\
\text { Faculty } \\
\text { Recruiting tutors } \\
\text { Administrators } \\
\text { Faculty } \\
\text { Training tutors } \\
\text { Administrators } \\
\text { Faculty }\end{array}$ & $\begin{array}{l}3 \\
2 \\
2 \\
2 \\
2 \\
3 \\
3\end{array}$ & $\begin{array}{l}37.5 \\
25 \\
25 \\
25 \\
\\
37.5 \\
25\end{array}$ \\
\hline $\begin{array}{l}\text { Location of Peer Tutoring } \\
\text { (Check all that apply.) }\end{array}$ & $\begin{array}{l}\text { Residence Hall } \\
\text { Administrators } \\
\text { Faculty } \\
\text { Tutoring center or other academic center } \\
\text { Administrators } \\
\text { Faculty } \\
\text { Classroom } \\
\text { Administrator } \\
\text { Faculty } \\
\text { Other (Student Union) } \\
\text { Administrators } \\
\text { Faculty }\end{array}$ & $\begin{array}{l}4 \\
2 \\
4 \\
4 \\
1 \\
2 \\
1 \\
0\end{array}$ & $\begin{array}{l}50 \\
25 \\
50 \\
50 \\
12.5 \\
25 \\
12.5 \\
0\end{array}$ \\
\hline $\begin{array}{l}\text { Supervision of Peer Tutoring } \\
\text { (Check all that apply.) }\end{array}$ & $\begin{array}{l}\text { Student Affairs } \\
\text { Administrators } \\
\text { Faculty } \\
\text { Academic Affairs } \\
\text { Administrators } \\
\text { Faculty } \\
\text { Individual Colleges/Departments } \\
\text { Administrators } \\
\text { Faculty } \\
\text { Don't Know } \\
\text { Administrators } \\
\text { Faculty }\end{array}$ & $\begin{array}{l}3 \\
0 \\
3 \\
3 \\
1 \\
\\
0 \\
2 \\
\\
0 \\
2\end{array}$ & $\begin{array}{c}37.5 \\
0 \\
\\
37.5 \\
12.5 \\
0 \\
25 \\
0 \\
0 \\
25\end{array}$ \\
\hline Institutional Classification & $\begin{array}{l}\text { Public } \\
\text { Administrators } \\
\text { Faculty }\end{array}$ & $\begin{array}{l}4 \\
4\end{array}$ & $\begin{array}{l}50 \\
50\end{array}$ \\
\hline
\end{tabular}


Table 4 (Cont.)

Pilot Study: Demographic Characteristics of Survey Respondents

\begin{tabular}{|c|c|c|c|}
\hline Classification & Role & Frequency & Percent \\
\hline $\begin{array}{l}\text { Highest Degree Awarded } \\
\text { (Check all that apply.) }\end{array}$ & $\begin{array}{l}\text { Doctorate } \\
\text { Administrators } \\
\text { Faculty } \\
\text { Professional (e. g. J.D., M.D.) } \\
\text { Administrators } \\
\text { Faculty }\end{array}$ & $\begin{array}{l}1 \\
2 \\
3 \\
2\end{array}$ & $\begin{array}{l}12.5 \\
25 \\
\\
37.5 \\
25\end{array}$ \\
\hline Institutional Enrollment & $\begin{array}{l}\text { Over 20,000 } \\
\text { Administrators } \\
\text { Faculty }\end{array}$ & $\begin{array}{l}4 \\
4\end{array}$ & $\begin{array}{l}50 \\
50\end{array}$ \\
\hline Carnegie Classification & $\begin{array}{l}\text { Research University (High Research) } \\
\text { Administrators } \\
\text { Faculty }\end{array}$ & $\begin{array}{l}4 \\
4 \\
\end{array}$ & $\begin{array}{l}50 \\
50 \\
\end{array}$ \\
\hline
\end{tabular}

Results of the pilot study were grouped by a) institutional role (administrator or faculty)

and b) category (organization/planning and resources/personnel). In the areas of organization and planning, administrators and faculty identified the following factors that facilitate the institutionalization of peer tutoring: a) peer tutoring is compatible with the institution's mission and goals, b) a marketing plan outlining formal policies and procedures has been implemented, and c) assessments have been done to ensure that students' needs and educational goals have been met.

In the areas of resources and personnel, administrators and faculty agreed that it is critical that a) the peer tutoring program and staff must be a permanent part of the institutional budget, b) there must be open communication between faculty and students to support different teaching and learning styles, and c) peer tutoring practices must be oriented toward developing a climate in which students' responsibility and active participation are promoted.

Administrators and faculty identified the following institutional policies as barriers to facilitating peer tutoring programs: a) having one central office to oversee the implementation, supervision, and assessment of the peer tutoring program, b) the lack of professional incentives 
to participate in peer tutoring programs (i.e. credit towards promotion and tenure, flexibility in time teaching), and c) the lack of financial incentives to participate in peer tutoring programs (i.e. merit pay, research grants, new computer).

Data dissemination and collection. The sample for this survey included faculty and administrators in higher education who were involved in the supervision, evaluation, and delivery of peer tutoring services at their institution. A mailing list was received of over 2000 members of NASPA Region II who fit the target population. Research indicated that faculty and administrators often receive requests to participate in survey research; however, they are more likely to complete an emailed or web-based survey ("Surveys and Sampling," 2011). Therefore, it was decided to compose a HTML (Hyper Text Markup Language) version of the survey instrument on SurveyMonkey, as opposed to a paper-based survey. Respondents could access the survey instrument from any internet-accessible computer via a Uniform Resource Locator (URL) or web address and complete the survey using pull-down menus to answer each item. Results were available to the researcher daily on a password-protected website. A research schedule included the following:

Stage 1: Dissertation prospectus was submitted to the dissertation committee for approval in April 2011 and successfully defended in May 2011.

Stage 2: Once the prospectus was successfully defended, approval to conduct the study was solicited from the West Virginia University Institutional Rev1ew Board for the Protection of Human Subjects (IRB). Approval to proceed with the study was received in May 2011.

Stage 3: In May 2011, the survey was sent to a panel of experts for review.

Stage 4: Minor adjustments were made to the survey instrument based on the 
recommendations of the panel of experts and a pilot study was conducted in June 2011.

Stage 5: Potential respondents were sent an email in June 2011, with an invitation to participate in the survey, along with an offer to receive survey results. The information included the website address of the online survey form, a statement of confidentiality, and instructions on how to receive a printed copy of the survey results.

Stage 6: A reminder email was sent out six weeks after the first email to those who had not yet responded.

Stage 7: Data was collected during Summer 2011.

Stage 8: After two months, the survey was closed and data analysis began in September 2011.

"A good rule-of-thumb in evaluating the quality of a survey is that studies with fewer than 1,000 respondents [participants] should result in a response rate of at least $50 \%$. For surveys with more than 1,000 , it is a little safer to accept somewhat lower rates of response" ("Response Rates," 2006, para. 8). Since an entire population cannot be surveyed, the number of people surveyed can create a sampling bias, also known as a sampling error. "Sampling error describes the possible difference between your findings and the true results if you were able to obtain valid responses from everyone" (Suskie, 1996, p. 13). An ideal sampling error is 5\% or less; to achieve a sampling error of $5 \%$ for a population of 2000, you would need a sampling size of 322 (Suskie, 1996).

Data analysis. Mean scores, standard deviations, and item ranking of institutionalization factors were calculated for each of the factors for importance and difficulty of implementation. 
Scores for the importance rating range between 1 (critical) and 4 (not important) and scores for the difficulty of implementation range between 1 (nearly impossible) to 4 (not difficult). Mean scores, standard deviations, and rank were also calculated for each of the following demographic items: a) position (administrators and faculty), b) institutional affiliation (public-for-profit, public non-profit, and private), c) highest degree awarded (associates, bachelors, masters, professional (law, medicine, dentistry), and doctorate), d) institutional size (small, medium, and large institutions) and e) Carnegie classifications (research university, very high research; research university, high research; doctoral research university; master's colleges and universities (small, medium, and large), baccalaureate colleges, and associate's colleges). Compilation of data, statistical analysis, and compilation of tables was done using Statistical Package for Social Sciences (SPSS).

\section{Summary}

From a literature review of factors that contribute to the growth of peer tutoring, barriers to organizational change, and factors that institutionalize programs in higher education, this study identified a) 14 administrative and 12 faculty factors that contribute to the institutionalization of peer tutoring and b) institutional factors that facilitate and form barriers to peer tutoring programs. It also addressed differences in perceptions of these factors between administrators and how they were affected by demographic factors such as department affiliation, enrollment, degrees awarded, and Carnegie classification. The demographics were selected as they represent the categories around which the Carnegie classifications are organized: a) what is taught (degrees awarded and program classifications), b) who are the students (enrollment), and c) function of faculty and staff (department affiliation). 
On completion of the literature review, a questionnaire was developed to be used as a measurement instrument. The factors were ranked on a 4-point Likert scale by a) importance to institutionalization and b) difficulty in implementation. Data was collected via a web-based questionnaire from administrators and faculty members of Region II NASPA institutions, who have an interest in and knowledge about academic tutoring programs, and who are involved in their supervision, evaluation, and delivery of services. Reliability of the survey instrument was established by internal consistency reliability (pilot test) and Cronbach alpha. Validity was established by a panel of experts. Mean scores, standard deviations, and item ranking of institutionalization factors were calculated for each of the factors for importance and difficulty of implementation.

An Analysis of Variance (ANOVA) was used to compare the means between groups to determine which groups differ from each other and how they differ (Plonsky, 2011). The Bonferroni correction, a post-hoc test that is done after the study is completed and other tests have been done, was calculated to determine the significance of the difference. A response rate of 20 percent was expected. Although the initial response rate for this study was 23 percent, many of the surveys returned by faculty were not completed and, therefore, not useable. This brought the response rate of useable surveys to 9 percent. This is consistent with other research on implementing academic support programs (Kezar, 2003; Pina 2005). 


\section{Chapter Four}

\section{Results}

The intent of this study was to identify a) institutional factors that administrators and faculty see as facilitating peer tutoring programs, b) institutional factors that administrators and faculty see as forming barriers to peer tutoring programs, and c) the differences in perceptions of peer tutoring between administrators and faculty. However, there was a low response rate of faculty which resulted in nonresponse error and made the faculty data unusable. Sivo et al. (2006) reported that nonresponse error occurs when the number of respondents from a targeted population who respond differs substantially from those who did not respond, making it difficult to make generalizations from the sample about the entire population. Therefore, just administrative data was reported and faculty data was used for demographic and descriptive purposes only. In addition, a comparison was made of administrators' perceptions based on the following demographic factors: department affiliation, enrollment, highest degree awarded, and Carnegie classification.

This chapter is divided into two sections. Section one, Descriptive Statistics, provides a) the results of Cronbach's alpha and b) descriptive statistics for each demographic and survey item. Section two, Results, discusses the results of data analysis for the three research questions.

\section{Descriptive Statistics}

Results of Cronbach's alpha. Before conducting the data analysis, the reliability of the survey was measured by determining how closely related the set of survey items were as a group. "Different questions that test the same construct should give consistent results. Internal consistency reliability evaluates individual questions in comparison with one another for their ability to give consistently appropriate results" (“Internal Consistency Reliability," n.d., para. 1). 
For example, if a respondent answered one survey item as important, it was expected that they would answer each additional survey item similarly.

The internal consistency reliability of the survey instrument was established by Cronbach's alpha, which is a "coefficient (a number between 0 and 1) that is used to rate the...correlation of the items in a test" ("Cronbach's alpha," n.d., para. 13). The formula for computing Cronbach's alpha is $\alpha=\frac{N \cdot \bar{c}}{(\bar{v}+(N-1) \cdot \bar{c})}$, in which $\mathrm{N}$ represents the number of survey items being measured, $\bar{v}$ equals the average variance for the current sample "and $\bar{c}$ is the average of all covariances between the components across the current sample..." ("Cronbach's alpha," 2011, para. 2). "A reliability coefficient of .70 or higher is considered acceptable in most social science research situations" (“SPSS FAQ: What does Cronbach's Alpha Mean?” n.d., para. 1).

The survey was sent to all members of NASPA, Region II (2201) via SurveyMonkey. Forty-two surveys were undeliverable due to incorrect email addresses, bringing the total number of surveys delivered to 2159 . Seven recipients opted not to participate in the survey. Table 5 illustrates the participant response rate. Demographic statistics are reported by frequency and percentages.

Table 5

Participant Response Rate

\begin{tabular}{|l|c|l|}
\hline \multicolumn{1}{|c|}{ Survey } & Frequency & \multicolumn{1}{c|}{ Percentage } \\
\hline Delivered & 2,159 & 100 \\
\hline Returned by Respondents & 488 & 23 \\
\hline Returned, but not Completed & 296 & 61 (of returned surveys) \\
\hline Returned and Completed & 192 & 9 \\
\hline
\end{tabular}

As indicated by Table 5, 488 participated in the survey, for a response rate of 23 percent. However, upon review of the responses it was discovered that 296 (61 percent) of the 488 
respondents had not answered most of the survey items, which made them unusable in the data analysis. Therefore, only completed surveys were used and all responses from incomplete surveys were deleted, bringing the number of useable surveys to 192 and the response rate of useable surveys to nine percent. The response rate of this study is comparable to similar studies using a population of administrators and faculty who are members of an organization such as NASPA (Kezar, 2003; Pina, 2005). Kezar (2003) conducted a quantitative study on barriers to collaboration in implementing programs in higher education. His population consisted of a sample of 260 student affairs senior administrators from a base of 3500 members of NASPA, for a response rate of 7.4 percent.

Twenty-eight factors that influence the institutionalization of peer tutoring were identified from a literature review and three similar factors were combined, after a review by the panel of experts, for a total of 26 survey items. Participants were asked to rate each factor for importance to peer tutoring and difficulty in implementation. Cronbach's alpha was calculated for a) importance factors (factors that contribute to the institutionalization of peer tutoring) and b) difficulty factors (factors that form barriers to peer tutoring). A perfectly correlated survey would yield a Cronbach's alpha score of 1 (“Cronbach's alpha," n.d.). "The stronger the items are inter-related, the more likely the test is consistent" (Yu, n.d., para. 13). Table 6 illustrates Cronbach's alpha for importance factors and difficulty factors for this study. 
Table 6

Cronbach's Alpha for Reliability of Importance Factors and Difficulty Factors

\begin{tabular}{|c|c|c|c|c|c|c|c|}
\hline \multicolumn{4}{|c|}{ Importance factors } & \multicolumn{4}{|c|}{ Difficulty Factors } \\
\hline \multicolumn{2}{|c|}{$\begin{array}{l}\text { Number of } \\
\text { Participants }\end{array}$} & $\begin{array}{l}\begin{array}{l}\text { Number of } \\
\text { Survey Items }\end{array} \\
26\end{array}$ & $\begin{array}{l}\text { Cronbach's } \\
\text { Alpha } \\
\text { (Correlation) } \\
.925\end{array}$ & \multicolumn{2}{|c|}{$\begin{array}{l}\text { Number of } \\
\text { Participants }\end{array}$} & \multirow{2}{*}{\begin{tabular}{|c|}
$\begin{array}{l}\text { Number of } \\
\text { Survey Items }\end{array}$ \\
26
\end{tabular}} & $\begin{array}{l}\begin{array}{l}\text { Cronbach's } \\
\text { Alpha } \\
\text { (Correlation) }\end{array} \\
.913\end{array}$ \\
\hline $\begin{array}{l}\text { Valid } \\
\text { Excluded } \\
\text { Total }\end{array}$ & $\begin{array}{r}192 \\
0 \\
192\end{array}$ & 26 & .925 & $\begin{array}{l}\text { Valid } \\
\text { Excluded } \\
\text { Total }\end{array}$ & $\begin{array}{r}192 \\
0 \\
192 \\
\end{array}$ & & .913 \\
\hline
\end{tabular}

As indicated by Table 6 , there was a significant correlation between both importance factors (.925) and difficulty factors (.913), which shows that there is a strong internal consistency among survey items. This means that a) the survey items are closely related as a group and b) there was a consistency in the responses across survey items.

Descriptive statistics for demographic and survey items. "Descriptive statistics are used to describe the basic features of the data in a study... and...provide simple summaries about the sample [population] and the measures. Together with simple graphics analysis, they form the basis of virtually every quantitative analysis of data" (Trochim, 2006a, para.1).

Data from all participants was first imported into SPSS (Statistical Package for the Social Sciences) by SurveyMonkey Gold, 2011 and converted to a word document for the following reasons: a) it is an effective way to display information (French, 2008) and b) it is consistent with previous documentation of the results of this study. Data were analyzed using descriptive statistics (means, standard deviations, and ranking order). This section provides descriptive statistics of the entire data set of demographic and survey items.

Demographic items. Respondents were asked to answer eight demographic questions to identify a) their role in peer tutoring and b) characteristics about their institution that may influence peer tutoring. The first set of questions related to institutional role (administrator 
versus faculty) and involvement in peer tutoring (administrative oversight of peer tutoring/not involved in day-to-day operation, directing or coordinating peer tutoring/involved in day-to-day operation, evaluating the peer tutoring program, recruiting tutors, training tutors, not involved, or other capacity).

The second set of questions centered on factors that define the institution and may play a role in influencing peer tutoring such as a) the location of peer tutoring, b) supervision of peer tutoring, c) institutional affiliation, d) highest degree awarded, e) enrollment, and f) Carnegie classification. Respondents had the option of checking all responses that apply, adding additional responses), or stating “I don't know." Therefore, data for some questions equaled more than 100 percent. Tables 7-14 report the demographic data for each question.

Position. Table 7 illustrates the position of each of the 192 respondents. Respondents could choose more than one position (administrator and faculty) or add another position, which created two additional categories called "both" and "other." Demographic statistics are reported by frequency and percentage.

Table 7

Question 1: What is your position?

\begin{tabular}{|l|c|c|}
\hline \multicolumn{1}{|c|}{ Position } & Frequency & Percentage \\
\hline Administrator & 167 & 87.0 \\
\hline Faculty & 9 & 4.7 \\
\hline Both & 10 & 5.2 \\
\hline Other & 6 & 3.1 \\
Graduate Assistant (2) & & \\
Counselor/Professional Staff (1) & & \\
Database Researcher (1) & & \\
Residential Life Staff (1) & & \\
V.P. for Student Affairs (1) & 192 & 100 \\
\hline Total & & \\
\hline
\end{tabular}

As indicated in Table 7, the majority of respondents reported their position as administrators. One hundred sixty-seven (87 percent) were administrators, while only 9 (4.7 percent) were 
faculty. Ten (5.2 percent) were identified as both administrators and faculty. Six respondents (3.1 percent) reported their position as a) graduate assistant, b) counselor, c) database researcher, residential life staff, or Vice President for Student Affairs.

Involvement in peer tutoring. Table 8 indicates the level of involvement of peer tutoring among the respondents. Responses were divided into two categories a) respondents who oversee peer tutoring in some capacity and are not involved in the day-to-day operation and b) respondents who are involved in the day-to-day operation of peer tutoring. Demographic statistics are reported by frequency and percentage in descending order.

Table 8

Question 2: How are you involved in peer tutoring on your campus?

\begin{tabular}{|l|c|c|}
\hline Level of Involvement in Peer Tutoring & Frequency & Percentage \\
\hline Involved, but not in the Day-to-Day Operation & \multicolumn{1}{|c|}{} \\
\hline Identified as contact for peer tutoring & 70 & 36.5 \\
\hline Administrative oversight of peer tutoring & 21 & 21.9 \\
\hline Involved in the Day-to-Day Operation & 20 & 10.9 \\
\hline Evaluating the peer tutoring program & 16 & 8.3 \\
\hline Recruiting tutors & 14 & 7.3 \\
\hline Training tutors & 9 & 4.7 \\
\hline Directing or coordinating peer tutoring & & \\
\hline $\begin{array}{l}\text { Other } \\
\text { Refers students to peer tutoring (5) }\end{array}$ & & \\
$\begin{array}{l}\text { Former director of peer tutoring program (1) } \\
\text { Occasionally tutors (1) } \\
\text { Supervises peer groups in alcohol and wellness } \\
\text { education (1) }\end{array}$ & & \\
$\begin{array}{l}\text { Works on academic programs with direct } \\
\text { supervisor of peer tutoring (1) }\end{array}$ & & \\
\hline Total & & \\
\hline
\end{tabular}

As indicated in Table 8, the majority of respondents were not involved in the day-to-day operation of peer tutoring: 70 (36.5 percent) were contacts for peer tutoring, while 42 (21.9 percent) had administrative oversight. These respondents represented a combined total of 112 (58.4 percent). Less than one-half of the respondents reported that they were involved in the day- 
to-day operation of peer tutoring. Twenty-one (10.9 percent) were involved in evaluating peer tutoring, 20 (10.4 percent) recruited tutors, 16 (8.3 percent) trained tutors, and 14 (7.3 percent) directed or coordinated a peer tutoring program. Nine (4.7 percent) of the respondents served in another capacity including a) referring students to peer tutoring, b) occasionally tutoring, and c) former director of peer tutoring. These respondents represented a combined total of 80 (41.6 percent).

Location of peer tutoring programs on campus. Table 9 shows where peer tutoring takes place at each institution of the respondents: a) tutoring center or other academic center, b) residence hall, and c) classroom. Demographic statistics are reported by frequency and percentage in descending order. Respondents could choose more than one peer tutoring location or add an additional location, which caused the frequency to be higher than the number of respondents (192) and the total percentage to be higher than 100 percent.

Table 9

Question 3: Where do peer tutoring programs occur at your institution?

\begin{tabular}{|l|c|c|}
\hline \multicolumn{1}{|c|}{ Location } & Frequency & Percentage \\
\hline Tutoring center/Academic Center & 176 & 91.7 \\
\hline Residence Hall & 72 & 37.5 \\
\hline Classroom & 60 & 31.3 \\
\hline Other & 10 & 5.2 \\
Any Public Place on Campus (3) & & \\
Counseling Office (2) & & \\
On-line (2) & & \\
Fraternities/Sororities (1) & & \\
Off-Campus, such as at Starbuck's or a Book Store (1) & & \\
Student Athletic Training Center (1) & & \\
\hline
\end{tabular}

As indicated in Table 9, most peer tutoring occurred outside the classroom. One hundred seventy-six (91.7 percent) of the tutoring sessions occurred at a tutoring center or other academic center and 72 (37.5 percent) occurred in a residence hall. Ten respondents (5.2 percent) 
identified the following locations: a) any public place on campus, counseling office, on-line, at a fraternity or sorority, at Starbuck's or a book store, and at a student athletic training center.

Supervision of peer tutoring. Table 10 illustrates which institutional unit supervises peer tutoring. Demographic statistics are reported by frequency and percentage in descending order. Respondents could check more than one response (Academic Affairs or Student Affairs). Respondents also had the option to report that they didn't know which department supervised peer tutoring at their institution or add another department, which produced a number of responses for question four to be higher than the sample of 192 and a total percentage higher than 100 percent.

Table 10

Question 4: Which unit supervises peer tutoring at your institution?

\begin{tabular}{|l|c|c|}
\hline \multicolumn{1}{|c|}{ Unit } & $\begin{array}{c}\text { Number of Institutions } \\
\text { Supervised by Unit }\end{array}$ & Percentage \\
\hline Academic Affairs & 123 & 64.0 \\
\hline Student Affairs & 91 & 47.4 \\
\hline Don't Know & 14 & 7.3 \\
\hline Other & 7 & \\
Academic Support Center (1) & & \\
Both Academic and Student Affairs (1) & & \\
Counseling (1) & & \\
Faculty Who Teach the Course (1) & & \\
Multicultural Programs (1) & & \\
Student Affairs Supervisors Peer Mentors/ & & \\
Academic Affairs Supervises Peer Tutors (1) & & \\
Student Life/Academic Advising (1) & & \\
\hline
\end{tabular}

As indicated in Table 10, the majority (123 or 64 percent) reported that peer tutoring at their institution was supervised by Academic affairs. The second most frequent department was Student Affairs (91 or 47.4 percent). Fourteen respondents (7.3 percent) reported that they didn't know, and 7 (3.6 percent) reported an assortment of units that included a) multicultural programs, b) counseling, and c) academic advising. 
Institutional affiliation. Table 11 reports respondents' institutional affiliation, which falls into three categories: a) private, b) public non-profit and c) public for-profit. Demographic statistics are reported by frequency and percentage in descending order.

Table 11

Question 5: Is your institution public or private?

\begin{tabular}{|l|c|c|}
\hline \multicolumn{1}{|c|}{ Institutional Affiliation } & Frequency & Percentage \\
\hline $\begin{array}{l}\text { Public } \\
\text { Non-profit (85) }\end{array}$ & 96 & 50 \\
For-profit (11) & & \\
\hline Private & 94 & 49 \\
\hline Omitted & 2 & 1 \\
\hline Total & 192 & 100 \\
\hline
\end{tabular}

As indicated in Table 11, the majority of institutions were public (96 or 50 percent). Within the public institutions, 85 were public non-profit and 11 were public-for-profit. Ninety-four (49 percent) of the institutions fell in the private sector.

Degree awarded. Table 12 illustrates the highest degree awarded by the institutions. Respondents could select from one of the following five categories: a) Associates, b) Bachelors, c) Masters, d) Doctorate, and e) Professional. Demographic statistics are reported by frequency and percentage in descending order.

Table 12

Question 6: What is the highest degree awarded by your institution?

\begin{tabular}{|l|c|c|}
\hline \multicolumn{1}{|c|}{ Degree Awarded } & Frequency & Percent \\
\hline Doctorate & 80 & 41.7 \\
\hline Masters & 36 & 18.8 \\
\hline Professional (e.g. J.D., M.D., D.D.S.) & 35 & 18.2 \\
\hline Associates & 23 & 12.0 \\
\hline Bachelors & 16 & 8.3 \\
\hline Omitted & 2 & 1.0 \\
\hline Total & 192 & 100 \\
\hline
\end{tabular}

As indicated in Table 12, the highest degree awarded by the majority of institutions was the 
doctorate ( 80 or 41.7 percent). The masters was the highest degree awarded at 36 institutions (18.8 percent), followed by professional ( 35 or 18.2 percent). At 23 (12 percent) of the institutions, the associates was the highest degree awarded. The bachelors was the highest degree awarded at 16 (8.2 percent) of the institutions.

Enrollment. Table 13 reports the enrollment of the institutions. Respondents could select from one of the following five categories: a) less than 1000 students, b) 1001-5000 students, c) 5001-10,000 students, d) 10,001-20,000 students, or e) more than 20,000 students. Demographic statistics are reported by frequency and percentage in descending order. Table 13

Question 7: What is the enrollment at your institution?

\begin{tabular}{|l|c|c|}
\hline \multicolumn{1}{|c|}{ Size } & Frequency & Percent \\
\hline $1001-5000$ & 69 & 36.3 \\
\hline $10,001-20,000$ & 41 & 21.6 \\
\hline $5001-10,000$ & 39 & 20.5 \\
\hline More than 20,000 & 38 & 20.0 \\
\hline Less than 1000 & 3 & 1.6 \\
\hline Total & 192 & 100 \\
\hline
\end{tabular}

As indicated in Table 13, enrollment at the majority of institutions fell in the 1001-5000 range (69 or 36.3 percent). Forty-one (21.6 percent) of the institutions fell in the 5001-10,000 range, while 39 (20.5 percent) were in the 5001-10,000 range. At 38 (20 percent) of the institutions, enrollment was over 20,000. Three institutions (1.6 percent) had an enrollment of less than 1000 students.

Carnegie classification. Table 14 illustrates the Carnegie classifications of the institutions. Respondents could choose from the following eight categories: a) research university, very high research; b) research university, high research; c) doctoral research university; d) masters colleges and universities, larger programs; e) masters colleges and universities, medium programs; f) masters colleges and universities, smaller programs; 
g) baccalaureate colleges, all subtypes; and h) associates colleges, all subtypes. Demographic statistics are reported by frequency and percentage in descending order.

Table 14

Question 8: Which Carnegie classification best describes your institution?

\begin{tabular}{|l|c|c|}
\hline \multicolumn{1}{|c|}{ Carnegie Classification } & Frequency & Percent \\
\hline Research University (Very High Research) & 29 & 15.2 \\
\hline Masters Colleges and Universities (Medium Programs) & 28 & 14.7 \\
\hline Baccalaureate Colleges (All Subtypes) & 25 & 13.1 \\
\hline Associates Colleges (All Subtypes) & 24 & 12.6 \\
\hline Research University (High Research) & 24 & 12.6 \\
\hline Doctoral Research University & 23 & 12.0 \\
\hline Masters Colleges and Universities (Smaller Programs) & 22 & 11.5 \\
\hline Masters Colleges and Universities (Larger Programs) & 16 & 8.4 \\
\hline Total & 192 & 100 \\
\hline
\end{tabular}

As Table 14 indicates, there was an even distribution of institutions among the Carnegie classifications. Twenty-nine (15.2 percent) of the institutions were research universities with very high research and 28 (14.7 percent) were masters colleges and universities with medium programs. Twenty-five (13.1 percent) of the institutions were baccalaureate colleges, while 24 (12.6 percent) were associate degree colleges and 24 (12.6 percent) were research universities with high research. There were 23 (12 percent) doctoral research universities and 22 masters colleges and universities with smaller programs. Sixteen (8.4 percent) of the institutions were masters colleges and universities with larger programs.

Survey Items. Using a 4-point Likert scale, respondents were asked to rate twenty-six survey items for a) their importance to the institutionalization to peer tutoring and b) their difficulty of implementation. Responses on the first scale (importance) were coded as follows: 1, critical; 2, important but not critical; 3, of minor importance; and 4, not important. Responses for the second scale (difficulty) were coded as follows: 1 nearly impossible; 2 , very difficult; 3 , of 
minor difficulty; and 4, not difficult. Descriptive statistics (standard deviations and means) were calculated for each survey item. Due to the low response rate of faculty, it was difficult to make generalizations from the sample about the entire population. Therefore, just administrative data was reported and faculty data was used for demographic and descriptive purposes only.

Administrative factors. Twelve administrative factors that influence the institutionalization of programs in higher education were identified from a literature review of administrative, faculty, and student factors that contribute to the growth of peer tutoring, barriers to organizational change, and factors that institutionalize programs in higher education. The first six factors (institutional mission and goals, policies and procedures, needs assessment, evaluation, master plan, and marketing) involve the planning of institutional programs and the last six factors (organization, visibility, centralization, leadership authority, support, and funding) involve the organization of institutional programs. At least one survey item relating to peer tutoring was developed for each factor for a total of 14 survey items. Table 15 illustrates the relationship between each factor and the corresponding survey item(s). 
Table 15

Administrative Factors and Corresponding Survey Items

\begin{tabular}{|l|l|}
\hline Administrative Factors & \multicolumn{1}{|c|}{ Survey Items } \\
\hline Planning Factors & Peer tutoring is compatible with the institution's mission and goals. \\
\hline $\begin{array}{l}\text { Institutional Mission and } \\
\text { Goals }\end{array}$ & Formal policies and procedures for peer tutoring have been implemented. \\
\hline Policies and Procedures & $\begin{array}{l}\text { Assessments are done to determine student needs in the area of peer } \\
\text { tutoring. } \\
\text { Assessments are done to determine faculty needs for implementing peer } \\
\text { tutoring. } \\
\text { Assessments are done to determine institutional needs for implementing peer } \\
\text { tutoring. }\end{array}$ \\
\hline Evaluation & $\begin{array}{l}\text { Regular evaluations of the peer tutoring program are done to ensure that } \\
\text { educational goals are met. }\end{array}$ \\
\hline Master Plan & $\begin{array}{l}\text { A master plan outlining the relevance, importance, objectives, and costs of } \\
\text { peer tutoring has been developed. }\end{array}$ \\
\hline Marketing & A marketing plan is in place to promote peer tutoring. \\
\hline Organizational Factors & $\begin{array}{l}\text { Peer tutoring is a campus-wide function and not part of a specific school, } \\
\text { department, or academic discipline. }\end{array}$ \\
\hline Organization & Peer tutoring is visible on campus. \\
\hline Visibility & $\begin{array}{l}\text { One central office oversees the implementation, supervision, and assessment } \\
\text { of the peer tutoring program }\end{array}$ \\
\hline Centralization & $\begin{array}{l}\text { A program director for peer tutoring with decision-making authority has been } \\
\text { appointed. }\end{array}$ \\
\hline Leadership Authority & $\begin{array}{l}\text { Peer tutoring administrators and staff meet regularly with other campus groups } \\
\text { to ensure support. }\end{array}$ \\
\hline Support & $\begin{array}{l}\text { The peer tutoring program and staff are a permanent item in the institutional } \\
\text { budget. }\end{array}$ \\
\hline Funding & \multicolumn{2}{|l|}{ and } \\
\hline
\end{tabular}

The mean and standard deviation were calculated for each of the 14 survey items above for importance to peer tutoring and for difficulty in implementation, and reported in Tables 1619. The mean represents the average of the importance (or difficulty) ratings for each survey item (factor) and is based on a 4-point Likert scale, with 1 being the most important and 4 being the least important for importance factors and 1 being the most difficult and 4 being the least difficult for difficulty factors.

The standard deviation measures how much the individual importance (or difficulty) ratings of the respondents vary from the mean, or average, for the entire group. The formula for 
computing the standard deviation is $s=\sqrt{\frac{\sum(X-M)^{2}}{n-1}}$ where $\Sigma=$ sum of, $X=$ individual score, $M=$ mean or average score, and $\mathrm{N}=$ the number of scores or sample size ("Formula: Standard Deviation," n.d.). Once the mean and standard deviation are calculated, the range of importance or difficulty ratings can be calculated by subtracting the standard deviation from the mean to find the low end of the range, and adding the standard deviation to the mean to find the high end of the range ("Standard Deviation, What Does it Mean?," 2011). For example, if a factor has a mean of 2.10 and a standard deviation of .92 , the range of responses one standard deviation from the mean would fall between 1.18 and 3.02.

Planning. Table 16 shows the mean, standard deviation, and rank order for importance for the eight administrative factors for planning. The factors are ranked in order of importance by mean, with the lowest mean indicating the most important. Several factors had the same mean but a different standard deviation. This means that the factors were considered equally important; however, the distance of individual scores from the mean differed. For example, a smaller standard deviation means that the individual responses are closer to the mean, while a larger standard deviation means that the individual responses are scattered farther from the mean (Field, 2005). Therefore, the factors that had the same mean but different standard deviations are ranked in importance by the lower standard deviation, which means that individual responses were closer to the mean. 
Table 16

Mean Scores for Importance of the Administrative Factors for Planning

\begin{tabular}{|l|c|c|c|}
\hline \multicolumn{1}{|c|}{ Factor } & \multicolumn{3}{|c|}{$\begin{array}{c}\text { Administrator } \\
\text { (n=167) }\end{array}$} \\
\cline { 3 - 4 } & Mean & S.D. & Rank \\
\hline Planning Factors & 1.42 & .62 & 1 \\
Evaluation & 1.59 & .80 & 2 \\
Mission and Goals & 1.66 & .61 & 3 \\
Policies and Procedures & 1.76 & .81 & 4 \\
Needs Assessment - Institutional & 1.82 & .79 & 5 \\
Master Plan & 1.82 & .94 & 6 \\
Marketing & 2.02 & .90 & 7 \\
Needs Assessment - Faculty & 2.10 & .92 & 8 \\
\hline
\end{tabular}

As illustrated in Table 16, the planning factor considered most important by administrators was Evaluation with a mean of 1.42 and a standard deviation of .62. Evaluation refers to an assessment of peer tutoring to make sure the needs of the students (educational goals) are met. A mean of 1.42 indicates that on average administrators felt that it was critical that regular evaluations of the peer tutoring program are done to ensure that educational goals are met. Administrators ranked Needs Assessment - Students second in importance with a mean of 1.59 and a standard deviation of .80. Needs Assessment - Students determines student needs in the area of peer tutoring. A mean of 1.59 shows that on average administrators believed it was from important, but not critical to critical that assessments are done to determine student needs in the area of peer tutoring.

Administrators ranked Mission and Goals third in importance with a mean of 1.66 and a standard deviation of .61. Mission and Goals refers to the importance that the mission and goals 
of peer tutoring are compatible with the institution's mission and goals. A mean of 1.66 indicates that on average administrators thought it was from important, but not critical to critical that the mission and goals of peer tutoring are compatible with the institution's mission and goals. Administrators ranked Policies and Procedures fourth in importance with a mean of 1.76 and a standard deviation of .81. Policies and Procedures refer to the implementation of formal policies and procedures of peer tutoring. A mean of 1.76 shows that on average administrators felt that it was important, but not critical that formal policies and procedures for peer tutoring are implemented.

Administrators ranked Needs Assessment - Institutional fifth in importance with a mean of 1.82 and a standard deviation of .79. Needs Assessment - Institutional determines institutional needs for implementing peer tutoring. A mean of 1.82 indicates that on average administrators thought it was important, but not critical that assessments are done to determine institutional needs for implementing peer tutoring. Administrators ranked Master Plan sixth in importance with a mean of 1.82 and a standard deviation of .94. A master plan outlines the relevance, importance, objectives and costs of peer tutoring. A mean of 1.82 shows that on average administrators felt it was important, but not critical that a master plan outlining the relevance, importance, objectives, and costs of peer tutoring has been developed.

Administrators ranked Marketing seventh in importance with a mean of 2.02 and a standard deviation of .90. Marketing refers to the development of a plan to promote peer tutoring. A mean of 2.02 indicates that on average administrators thought it was important, but not critical that a marketing plan is in place to promote peer tutoring. Administrators ranked Needs Assessment - Faculty last (eighth) in importance with a mean of 2.10 and a standard deviation of .92. Needs Assessment - Faculty determines faculty needs for implementing peer 
tutoring. A mean of 2.10 shows that on average administrators believed it was important, but not critical that assessments are done to determine faculty needs for implementing peer tutoring. It is interesting to note that administrators ranked the two planning factors that directly relate to students - Evaluation and Needs Assessment - Students - as the two most important factors.

Table 17 shows the mean, standard deviation, and rank order for the difficulty in implementation of the eight administrative factors for planning. The factors are ranked in order of difficulty by mean, with the lowest mean indicating the most difficulty.

Table 17

Mean Scores for Difficulty in Implementation of the Administrative Factors for Planning

\begin{tabular}{|l|c|c|c|}
\hline \multirow{2}{*}{ Factor } & \multicolumn{3}{c|}{$\begin{array}{c}\text { Administrator } \\
\text { (n=167) }\end{array}$} \\
\cline { 2 - 4 } & Mean & S.D. & Rank \\
\hline Planning Factors & 2.55 & .88 & 1 \\
Needs Assessment - Faculty & 2.75 & .77 & 2 \\
Needs Assessment - Institutional & 2.81 & .82 & 3 \\
Master Plan & 2.89 & .74 & 4 \\
Needs Assessment - Students & 3.05 & .77 & 5 \\
Marketing & 3.06 & .70 & 6 \\
Evaluation & 3.10 & .71 & 7 \\
Policies and Procedures & 3.22 & .62 & 8 \\
Mission and Goals & &
\end{tabular}

As indicated in Table 17, the planning factor ranked most difficult to implement by administrators was Needs Assessment - Faculty with a mean of 2.55 and a standard deviation of .88. A mean of 2.55 indicates that although Needs Assessment - Faculty was ranked most difficult to implement, on average administrators believed that it would be between of minor difficulty and very difficult to conduct an assessment of faculty needs for implementing peer 
tutoring. Administrators ranked Needs Assessment - Institutional second in difficulty of implementation with a mean of 2.75 and a standard deviation of .77. This means that on average administrators felt that it would be of minor difficulty to conduct an assessment to determine institutional needs for implementing peer tutoring.

Administrators ranked Master Plan third in difficulty of implementation with a mean of 2.81 and a standard deviation of .82 . This indicates that on average administrators thought it would be of minor difficulty to develop and implement a master plan outlining the relevance, importance, objectives, and costs of peer tutoring. Administrators ranked Needs Assessment Students fourth in difficulty of implementation with a mean of 2.89 and a standard deviation of .74. A mean of 2.89 shows that on average administrators believed it would be of minor difficulty to conduct an assessment to determine student needs in the area of peer tutoring.

Administrators ranked Marketing fifth in difficulty of implementation with a mean of 3.05 and a standard deviation of .77. This shows that on average administrators felt it would be of minor difficulty to implement a marketing plan to promote peer tutoring. Administrators ranked Evaluation sixth in difficulty of implementation with a mean of 3.06 and a standard deviation of .70. A mean of 3.06 indicates that on average administrators thought it would be of minor difficulty to conduct regular evaluations of the peer tutoring program to ensure that educational goals are met.

Administrators ranked Policies and Procedures seventh in difficulty of implementation with a mean of 3.10 and a standard deviation of .71 . This means that on average administrators believed that it would be of minor difficulty to implement formal policies and procedures for peer tutoring. Administrators ranked Mission and Goals as the least difficult to implement (eighth) with a mean of 3.22 and a standard deviation of .62. A mean of 3.22 indicates that on 
average administrators felt that it would be of minor difficulty to implement a mission and goals for peer tutoring that are compatible with the institution's mission and goals. It is interesting to note that the factor that was ranked most important by administrators was also ranked as the least difficult factor to implement.

Organization. Table 18 shows the mean, standard deviation, and rank order of importance for the six administrative factors for organization. The factors are ranked in order of importance by mean, with the lowest mean indicating the most importance.

Table 18

Mean Scores for Importance of the Administrative Factors for Organization

\begin{tabular}{|l|c|c|c|}
\hline \multirow{2}{*}{ Factor } & \multicolumn{3}{|c|}{$\begin{array}{c}\text { Administrator } \\
\text { (n=167) }\end{array}$} \\
\cline { 2 - 4 } & Mean & S.D. & Rank \\
\hline Organizational & & & \\
Factors & 1.03 & .82 & 1 \\
Centralization & 1.60 & .80 & 2 \\
Visibility & 1.61 & .88 & 3 \\
Funding & 1.82 & .96 & 4 \\
Leadership Authority & & .87 & 5 \\
Support & 2.04 & .05 & 6 \\
Organization & 2.14 & 1.05 \\
\hline
\end{tabular}

As shown in Table 18, the organizational factor that was considered most important by administrators was Centralization with a mean of 1.03 and a standard deviation of .82 .

Centralization means that one office oversees the implementation, supervision, and assessment of peer tutoring. A mean of 1.03 indicates that on average administrators felt it was critical that one central office oversees the implementation, supervision, and assessment of peer tutoring. Administrators ranked Visibility second in importance with a mean of 1.60 and a standard deviation of .80. Visibility refers to the importance that peer tutoring is visible on campus. A 
mean of 1.60 shows that on average administrators believed it was between important, but not critical and critical that peer tutoring is visible on campus.

Administrators ranked Funding third in importance with a mean of 1.61 and a standard deviation of .88. Funding refers to the fact that it is important that the peer tutoring program and staff are a permanent item in the institutional budget. A mean of 1.61 indicates that on average administrators thought it was between important, but not critical and critical that the peer tutoring program and staff are a permanent item in the institutional budget. Administrators ranked Leadership Authority fourth in importance with a mean of 1.82 and a standard deviation of .96. Leadership Authority refers to the appointment of a program director for peer tutoring with decision-making authority. A mean of 1.82 shows that on average administrators felt it was important, but not critical that a program director for peer tutoring be appointed with decisionmaking authority.

Administrators ranked Support as fifth in importance with a mean of 2.04 and a standard deviation of .87. Support refers to the meeting of peer tutoring administrators and staff with other campus groups to ensure support. A mean of 2.04 shows that on average administrators believed that it was important, but not critical that peer tutoring administrators and staff meet with other campus groups to ensure support. Administrators ranked Organization least important (sixth) with a mean of 2.14 and a standard deviation of 1.05. Organization refers to how peer tutoring is organized and the importance that peer tutoring is a campus-wide function and not part of a specific school, department, or academic discipline. A mean of 2.14 indicates that on average administrators felt that it was important, but not critical that peer tutoring is a campus-wide function rather than a part of a specific school, department, or academic discipline. 
Table 19 shows the mean, standard deviation, and rank order for the difficulty in implementation of the six administrative factors for organization. The factors are ranked in order of difficulty by mean, with the highest mean indicating the most difficulty. Several factors had the same mean but a different standard deviation. This means that the factors were considered equally important; however, the distance of individual scores from the mean differed. For example, a smaller standard deviation means that the individual responses are closer to the mean, while a larger standard deviation means that the individual responses are scattered farther from the mean (Field, 2005). Therefore, the factors that had the same mean but different standard deviations are ranked in importance by the lower standard deviation, which means that individual responses were closer to the mean.

Table 19

Mean Scores for Difficulty in Implementation of the Administrative Factors for Organization

\begin{tabular}{|l|r|r|c|}
\hline \multirow{2}{*}{ Factor } & \multicolumn{3}{|c|}{$\begin{array}{l}\text { Administrator } \\
(\mathrm{n}=167)\end{array}$} \\
\cline { 2 - 4 } & Mean & S.D. & Rank \\
\hline Organizational & & & \\
Factors & 2.80 & .91 & 1 \\
\hline Support & 2.82 & 1.00 & 2 \\
Centralization & 2.83 & .91 & 3 \\
Funding & 2.83 & .98 & 4 \\
Organization & 2.94 & .82 & 5 \\
Visibility & 3.05 & .94 & 6 \\
Leadership Authority & &
\end{tabular}

As indicated in Table 19, the organizational factor ranked most difficult to implement by administrators was Support with a mean of 2.80 and a standard deviation of .91 . A mean of 2.80 indicates that on average administrators believed that it would be of minor difficulty for peer tutoring administrators and staff to meet regularly with other campus groups to ensure support. 
Administrators ranked Centralization second in difficulty of implementation with a mean of 2.82 and a standard deviation of 1.00. A mean of 2.82 shows that on average administrators thought it would be of minor difficulty for one central office to oversee the implementation, supervision, and assessment of the peer tutoring program.

Administrators ranked Funding third in difficulty of implementation with a mean of 2.83 and a standard deviation of .91. A mean of 2.83 indicates that on average administrators felt it would be of minor difficulty for peer tutoring to be considered a permanent item in the institution's budget. Administrators ranked Organization fourth in difficulty of implementation with a mean of 2.83 and a standard deviation of .98 . A mean of 2.83 shows that on average administrators thought it would be of minor difficulty for peer tutoring to be considered a campus-wide function and not part of a specific school, department, or academic discipline.

Administrators ranked Visibility fifth in difficulty of implementation with a mean of 2.94 and a standard deviation of .82. A mean of 2.94 shows that on average administrators thought that it would be of minor difficulty to make peer tutoring visible to everyone on campus. Administrators ranked Leadership Authority as the least difficult factor (sixth) with a mean of 3.05 and a standard deviation of .94. A mean of 3.05 indicates that on average administrators believed it would be of minor difficulty for a director of peer tutoring to be appointed who had decision-making authority.

It is interesting to note that although they were ranked in different order of difficulty and importance, all of the organizational factors rated as important by administrators were rated of minor difficulty to implement.

Faculty factors. Six faculty factors that influence the institutionalization of programs in higher education were identified from a literature review of administrative, faculty, and student 
factors that contribute to the growth of peer tutoring, barriers to organizational change, and factors that institutionalize programs in higher education. The first four factors (shared vision, collaboration, staff development, and incentives) involve collaboration between faculty and administrators. The last two factors (communication and responsibility) involve faculty/student interaction. At least one survey item relating to peer tutoring was developed for each factor for a total of 12 survey items. Table 20 illustrates the relationship between each factor and the corresponding survey item(s).

Table 20

Faculty Factors and Corresponding Survey Items

\begin{tabular}{|l|l|}
\hline Faculty Factors & \multicolumn{1}{c|}{ Survey Items } \\
\hline Shared Vision & There is a shared vision of peer tutoring among departments. \\
\hline Collaboration & $\begin{array}{l}\text { Faculty and administrators collaborate on peer tutoring to plan programs. } \\
\text { Faculty and administrators collaborate on peer tutoring to implement } \\
\text { programs. } \\
\text { Faculty and administrators collaborate on peer tutoring to decide the program } \\
\text { budget. } \\
\text { Faculty and administrators collaborate on peer tutoring to access program } \\
\text { effectiveness. }\end{array}$ \\
\hline Staff Development & Ongoing staff development on peer tutoring best practices is in place. \\
\hline Incentives & $\begin{array}{l}\text { Professional incentives to participate in peer tutoring programs are available } \\
\text { (i.e. credit towards promotion and tenure, flexibility in time teaching). } \\
\text { Financial incentives to participate in peer tutoring are available (i.e. merit pay, } \\
\text { grants for future research, new computer). }\end{array}$ \\
\hline Communication & $\begin{array}{l}\text { Communication between faculty and students encourages student } \\
\text { engagement. } \\
\text { Communication between faculty and students supports different teaching } \\
\text { styles. } \\
\text { Communication between faculty and students supports different learning } \\
\text { styles. }\end{array}$ \\
\hline Responsibility & $\begin{array}{l}\text { Peer tutoring practices are oriented toward developing a climate in which } \\
\text { students' responsibility and active participation are promoted. }\end{array}$ \\
\hline
\end{tabular}

The mean and standard deviation were calculated for each of the 12 survey items above for importance to peer tutoring and for difficulty in implementation, and reported in Tables 21 and 22. The mean represents the average of the importance (or difficulty) ratings for each survey item (factor) and is based on a 4-point Likert scale, with 1 being the most important and 4 being 
the least important for importance factors and 1 being the most difficult and 4 being the least difficult for difficulty factors.

Table 21 illustrates the mean, standard deviation, and rank order of responses for importance for the six faculty factors. At least one survey item relating to peer tutoring was developed for each factor for a total of 12 survey items. The factors are ranked in order of importance by mean, with the lowest mean indicating the most importance. Several factors had the same mean but a different standard deviation. This means that the factors were considered equally important; however, the distance of individual scores from the mean differed. For example, a smaller standard deviation means that the individual responses are closer to the mean, while a larger standard deviation means that the individual responses are scattered farther from the mean (Field, 2005). Therefore, the factors that had the same mean but different standard deviations are ranked in importance by the lower standard deviation, which means that individual responses were closer to the mean. 
Table 21

Mean Scores for Importance of Faculty Factors

\begin{tabular}{|l|r|r|c|}
\hline Factor & \multicolumn{3}{|l|}{$\begin{array}{l}\text { Administrator } \\
(\mathrm{n}=167)\end{array}$} \\
\cline { 2 - 4 } & \multicolumn{1}{|c|}{ Mean } & \multicolumn{1}{|c|}{ S.D. } & Rank \\
\hline Responsibility & 1.41 & .65 & 1 \\
Communication - Encourage Student Engagement & 1.41 & .68 & 2 \\
Communication - Support Different Teaching Styles & 1.53 & .73 & 3 \\
Communication - Support Different Learning Styles & 1.53 & .75 & 4 \\
Staff Development & 1.80 & .86 & 5 \\
Shared Vision & 1.99 & .86 & 6 \\
Collaboration - Plan Programs & 2.01 & .83 & 7 \\
Collaboration - Implement Programs & 2.02 & .83 & 8 \\
Collaboration - Access Program Effectiveness & 2.04 & .93 & 9 \\
Incentives - Professional & 2.59 & 1.08 & 10 \\
Collaboration - Decide Budget & 2.63 & 1.01 & 11 \\
Incentives - Financial & 2.65 & 1.05 & 12 \\
\hline
\end{tabular}

As indicated in Table 21, the factor considered most important by administrators was Responsibility with a mean of 1.41 and a standard deviation of .65. Responsibility refers to students' responsibility and how peer tutoring practices are oriented toward developing a climate in which students' responsibility and active participation are promoted. A mean of 1.41 indicates that on average administrators felt that it was critical that peer tutoring practices are oriented toward developing a climate in which students' responsibility and active participation are promoted. Administrators ranked Communication - Encourage Student Engagement second in importance with a mean of 1.41 and a standard deviation of .68. Communication - Encourage Student Engagement refers to how communication between faculty and students encourages 
student engagement. A mean of 1.41 shows that on average administrators believed that it was critical that faculty communicate with students to encourage student engagement.

Administrators ranked Communication - Support Different Teaching Styles third in importance with a mean of 1.53 and a standard deviation of .73. Communication - Support Different Teaching Styles refers to how communication between faculty and students supports different teaching styles. A mean of 1.53 indicates that on average administrators thought it was between critical and important, but not critical that communication between faculty and students supports different teaching styles. Administrators ranked Communication - Support Different Learning Styles fourth in importance with a mean of 1.53 and a standard deviation of .75. Communication - Support Different Learning Styles refers to how communication between faculty and students supports different learning styles. A mean of 1.53 illustrates that on average administrators believed that it was between critical and important, but not critical that communication between faculty and students supports different learning styles.

Administrators ranked Staff Development fifth in importance with a mean of 1.80 and a standard deviation of .86. Staff Development refers to the importance that ongoing staff development on peer tutoring best practices is in place. A mean of 1.80 indicates that on average administrators felt it was important, but not critical that ongoing staff development in best practices of peer tutoring is in place. Administrators ranked Shared Vision sixth in importance with a mean of 1.99 and a standard deviation of .86 . Shared Vision refers to the idea that there must be a shared vision of peer tutoring among departments. A mean of 1.99 shows that on average administrators believed that it was important, but not critical that there is a shared vision among departments. 
Administrators ranked Collaboration - Plan Programs seventh in importance with a mean of 2.01 and a standard deviation of .83. Collaboration - Plan Programs refers to the importance of administrators and faculty collaborating to plan peer tutoring programs. A mean of 2.01 indicates that on average administrators felt that it was important, but not critical that administrators and faculty meet to plan peer tutoring programs. Administrators ranked Collaboration - Implement Programs eighth in importance with a mean of 2.02 and a standard deviation of .83. Collaboration - Implement Programs refers to how faculty and administrators collaborate on peer tutoring to implement programs. A mean of 2.02 shows that on average administrators thought that it was important, but not critical, that faculty and administrators meet to decide how to implement peer tutoring programs.

Administrators ranked Collaboration - Access Program Effectiveness ninth in importance with a mean of 2.04 and a standard deviation of .93. Collaboration - Access Program Effectiveness refers to the collaboration of administrators and faculty to access and determine the effectiveness of peer tutoring programs. A mean of 2.04 indicates that on average administrators felt that it was important, but not critical, that administrators and faculty meet to access and determine the effectiveness of peer tutoring programs. Administrators ranked Incentives Professional tenth in importance with a mean of 2.59 and a standard deviation of 1.08. Incentives - Professional refers to the professional incentives faculty receive to participate in peer tutoring such as credit towards promotion and tenure and flexibility in time teaching. A mean of 2.59 illustrates that on average administrators believed that it was between important, but not critical and of minor importance that professional incentives be in place for faculty to participate in peer tutoring.

Administrators ranked Collaboration - Decide Budget eleventh in importance with a 
mean of 2.63 and a standard deviation of 1.01. Collaboration - Decide Budget refers to the importance of the collaboration of faculty and administrators to decide the peer tutoring budget. A mean of 2.63 indicates that on average administrators thought it was between important, but not critical and of minor importance that faculty and administrators jointly decide on the peer tutoring budget. Administrators ranked Incentives - Financial as the least important factor (twelfth) with a mean of 2.65 and a standard deviation of 1.05. Incentives - Financial refers to financial incentives faculty receive to participate in peer tutoring such as merit pay, grants for future research, or a new computer. A mean of 2.65 indicates that on average administrators felt that it was between important, but not critical and of minor importance that financial incentives be in place for faculty to participate in peer tutoring.

Table 22 shows the mean, standard deviation, and rank order for the difficulty in implementation of the six faculty factors. At least one survey item relating to peer tutoring was developed for each factor for a total of 12 survey items. The factors are ranked in order of difficulty by mean, with the lowest mean indicating the most difficulty. 
Table 22

Mean Scores for Difficulty in Implementation of Faculty Factors

\begin{tabular}{|l|l|c|c|}
\hline Factor & \multicolumn{3}{|l|}{$\begin{array}{l}\text { Administrator } \\
(\mathrm{n}=167)\end{array}$} \\
\cline { 2 - 5 } & Mean & S.D. & Rank \\
\hline Incentives - Professional & 2.08 & .92 & 1 \\
Incentives - Financial & 2.14 & .99 & 2 \\
Shared Vision & 2.26 & .92 & 3 \\
Collaboration - Decide Budget & 2.30 & 1.00 & 4 \\
Collaboration - Plan Programs & 2.31 & .86 & 5 \\
Collaboration - Implement Programs & 2.32 & .87 & 6 \\
Collaboration - Access Program Effectiveness & 2.38 & .85 & 7 \\
Communication - Support Different Learning Styles & 2.56 & .79 & 8 \\
Communication - Support Teaching Styles & 2.59 & .80 & 9 \\
Responsibility & 2.68 & .69 & 10 \\
Staff Development & 2.78 & .82 & 11 \\
Communication - Encourage Student Engagement & 2.87 & .74 & 12 \\
\hline
\end{tabular}

As indicated in Table 22, the faculty factor ranked most difficult to implement by administrators was Incentives - Professional with a mean of 2.08 and a standard deviation of .92 . A mean of 2.08 indicates that on average administrators felt that it would be very difficult to implement professional incentives for faculty to participate in peer tutoring programs, such as credit towards promotion and tenure and flexibility in time teaching. It is interesting to note that administrators also ranked Incentives - Professional as one of the least important factors (tenth out of twelve). Administrators ranked Incentives - Financial second in difficulty of implementation with a mean of 2.14 and a standard deviation of .99 A mean of 2.14 shows that on average administrators believed that it would be very difficult to implement financial incentives for faculty to participate 
in peer tutoring such as merit pay, grants for future research, or a new computer. It is interesting to note that while administrators ranked Incentives - Financial as one of the most difficult factors to implement (second), they also ranked Incentives - Financial as the least important factor.

Administrators ranked Shared Vision third in difficulty of implementation with a mean of 2.26 and a standard deviation of .92. A mean of 2.26 indicates that on average administrators felt that it would be very difficult to implement a shared vision of peer tutoring among departments. It is interesting to note that administrators ranked Shared Vision sixth (out of 12) in importance. Administrators ranked Collaboration - Decide Budget fourth in difficulty of implementation with a mean of 2.30 and a standard deviation of 1 . A mean of 2.30 shows that on average administrators believed it would be very difficult for faculty and administrators to collaborate on peer tutoring to decide the program budget. It is interesting to note that administrators ranked Collaboration - Decide Budget in the top four factors for difficulty and the bottom four factors for importance.

Administrators ranked Collaboration - Plan Programs fifth in difficulty of implementation with a mean of 2.31 and a standard deviation of .86. A mean of 2.31 indicates that on average administrators thought it would be very difficult for administrators and faculty to collaborate on peer tutoring to plan programs. It is interesting to note that administrators ranked Collaboration - Plan Programs mid-range for both importance and difficulty. Administrators ranked Collaboration - Implement Programs sixth in difficulty of implementation with a mean of 2.32 and a standard deviation of .87. A mean of 2.32 illustrates that on average administrators believed it would be very difficult for administrators and faculty to collaborate on peer tutoring to implement programs. It is interesting to note that administrators ranked Collaboration Implement Programs mid-range for both importance and difficulty. 
Administrators ranked Collaboration - Access Program Effectiveness seventh in difficulty of implementation with a mean of 2.38 and a standard deviation of .85. A mean of 2.38 indicates that on average administrators felt it would be very difficult for administrators and faculty to collaborate on peer tutoring to access and evaluate the effectiveness of peer tutoring programs. It is interesting to note that administrators ranked Collaboration - Access Program Effectiveness similarly in both importance (ninth out of twelve) and difficulty (seventh out of twelve). Administrators ranked Communication - Support Different Learning Styles eighth in difficulty of implementation with a mean of 2.56 and a standard deviation of .79. A mean of 2.56 shows that on average administrators thought it would be between very difficult and of minor difficulty to implement communication between faculty and students that would support different learning styles. It is interesting to note that administrators ranked Communication Support Different Learning Styles in the top third for importance and near the lower third (eighth out of twelve) for difficulty.

Administrators ranked Communication - Support Different Teaching Styles ninth in difficulty of implementation with a mean of 2.59 and a standard deviation of .80 . A mean of 2.59 indicates that on average administrators thought it would be between very difficult and of minor difficulty to implement communication between faculty and students to support different teaching styles. It is interesting to note that administrators ranked Communication - Support Different Teaching Styles as one of the least difficult factors to implement (ninth out of twelve) and one of the most important (fourth out of twelve). Administrators ranked Responsibility tenth in difficulty of implementation with a mean of 2.68 and a standard deviation of .69. A mean of 2.76 shows that on average administrators thought that it would be between very difficult and of minor difficulty to implement peer tutoring practices which are oriented toward developing a 
climate in which students' responsibility and active participation are promoted. It is interesting to note that although administrators ranked Responsibility as one of the least difficult factors to implement (tenth out of twelve), it was ranked as one of the most important (second).

Administrators ranked Staff Development eleventh in difficulty of implementation with a mean of 2.78 and a standard deviation of .82 . A mean of 2.78 indicates that on average administrators felt that it would be of minor difficulty to implement ongoing staff development on peer tutoring best practices. It is interesting to note that administrators ranked Staff Development in the middle of the importance factors (eighth in importance), yet at the bottom (eleventh out if twelve) for difficulty of implementation. The factor administrators ranked least difficult to implement was Communication - Encourage Student Engagement with a mean of 2.87 and a standard deviation of .74 . A mean of 2.87 shows that on average administrators believed that it would be of minor difficulty for communication between faculty and students to encourage student engagement. It is interesting to note that the factor faculty ranked as the least difficult to implement was also ranked as the most important factor.

It is interesting to note that, the factors administrators ranked as the most difficult to implement (Incentives - Financial and Incentives - Professional) were ranked as the least important factors. Similarly, the factor administrators ranked as least difficult to implement (Communication - Encourage Student Engagement) they also ranked as the most important factor.

Demographic responses of other groups. Respondents included administrators, faculty, both (administrators and faculty), and other. Although there were not enough respondents to generalize data for each group to the entire population, a comparison of the groups can be made. Tables 23-28 illustrate how the responses of the other groups compare to administrative 
responses for importance and difficulty factors. Data is reported by descriptive statistics (mean and standard deviation). The factors are ranked in order of importance by mean, with the lowest mean indicating the most importance/difficulty.

Table 23

Comparison of Mean Scores for Importance of the Administrative Factors for Planning

\begin{tabular}{|c|c|c|c|c|c|c|c|c|c|c|c|c|}
\hline \multirow[t]{2}{*}{ Factor } & \multicolumn{3}{|c|}{$\begin{array}{l}\text { Administrator } \\
(\mathrm{n}=167)\end{array}$} & \multicolumn{3}{|c|}{$\begin{array}{c}\text { Faculty } \\
(n=9)\end{array}$} & \multicolumn{3}{|c|}{$\begin{array}{l}\text { Both } \\
(n=10)\end{array}$} & \multicolumn{3}{|c|}{$\begin{array}{l}\text { Other } \\
(n=6)\end{array}$} \\
\hline & Mean & S.D. & Rank & Mean & S.D. & Rank & Mean & S.D. & Rank & Mean & S.D. & Rank \\
\hline $\begin{array}{l}\text { Planning } \\
\text { Factors }\end{array}$ & & & & & & & & & & & & \\
\hline $\begin{array}{l}\text { Needs } \\
\text { Assessment - } \\
\text { Faculty }\end{array}$ & 2.10 & .92 & 8 & 2.33 & .70 & 6 & 2.10 & .99 & 7 & 2.00 & 1.26 & 6 \\
\hline Marketing & 2.02 & .90 & 7 & 2.22 & 1.20 & 5 & 2.00 & .94 & 6 & 2.00 & 1.26 & 6 \\
\hline $\begin{array}{l}\text { Needs } \\
\text { Assessment - } \\
\text { Institutional }\end{array}$ & 1.82 & .79 & 6 & 2.44 & .73 & 7 & 1.80 & .92 & 5 & 1.83 & .75 & 5 \\
\hline Master Plan & 1.82 & .94 & 5 & 2.00 & 94 & 4 & 2.10 & 1.20 & 8 & 1.83 & .75 & 5 \\
\hline $\begin{array}{l}\text { Policies and } \\
\text { Procedures }\end{array}$ & 1.76 & .81 & 4 & 1.89 & .78 & 3 & 1.70 & .67 & 4 & 1.67 & .82 & 2 \\
\hline $\begin{array}{l}\text { Mission and } \\
\text { Goals }\end{array}$ & 1.66 & .61 & 3 & 1.89 & .60 & 2 & 1.70 & .48 & 3 & 1.50 & .84 & 1 \\
\hline $\begin{array}{l}\text { Needs } \\
\text { Assessment - } \\
\text { Students }\end{array}$ & 1.59 & .80 & 2 & 1.89 & .78 & 3 & 1.40 & .52 & 2 & 1.67 & 1.66 & 3 \\
\hline Evaluation & 1.42 & .62 & 1 & 1.78 & 1.09 & 1 & 1.30 & .48 & 1 & 1.67 & 1.67 & 4 \\
\hline
\end{tabular}

As indicated in Table 23, rank order for importance of the administrative factors for planning was consistent across groups, with the exception of Master Plan, which was ranked least important (eighth) by respondents who were both an administrator and faculty and fourth or fifth by the other groups. However, responses on average for all groups fell within the critical (1) to important, but not critical (2) range for each factor. 
Table 24

Comparison of Mean Scores for Difficulty in Implementation of the Administrative Factors for Planning

\begin{tabular}{|c|c|c|c|c|c|c|c|c|c|c|c|c|}
\hline \multirow[t]{2}{*}{ Factor } & \multicolumn{3}{|c|}{$\begin{array}{l}\text { Administrator } \\
(\mathrm{n}=167)\end{array}$} & \multicolumn{3}{|c|}{$\begin{array}{l}\text { Faculty } \\
(\mathrm{n}=9)\end{array}$} & \multicolumn{3}{|c|}{$\begin{array}{c}\text { Both } \\
(n=10)\end{array}$} & \multicolumn{3}{|c|}{$\begin{array}{l}\text { Other } \\
(\mathrm{n}=6)\end{array}$} \\
\hline & Mean & S.D. & Rank & Mean & S.D. & Rank & Mean & S.D. & Rank & Mean & S.D. & Rank \\
\hline $\begin{array}{l}\text { Planning } \\
\text { Factors }\end{array}$ & & & & & & & & & & & & \\
\hline $\begin{array}{l}\text { Mission and } \\
\text { Goals }\end{array}$ & 3.22 & .62 & 8 & 3.10 & 1.05 & 6 & 2.90 & .88 & 7 & 3.00 & 1.09 & 2 \\
\hline $\begin{array}{l}\text { Policies and } \\
\text { Procedures }\end{array}$ & 3.10 & .71 & 7 & 3.10 & 1.05 & 6 & 2.60 & 1.07 & 5 & 3.50 & .55 & 7 \\
\hline Evaluation & 3.06 & .70 & 6 & 3.22 & .67 & 7 & 2.40 & .84 & 4 & 3.33 & .52 & 6 \\
\hline Marketing & 3.05 & .77 & 5 & 2.89 & 1.05 & 3 & 2.60 & 1.07 & 5 & 3.17 & .55 & 4 \\
\hline $\begin{array}{l}\text { Needs } \\
\text { Assessment - } \\
\text { Students }\end{array}$ & 2.89 & .74 & 4 & 3.10 & .78 & 5 & 2.70 & .67 & 6 & 3.20 & .75 & 5 \\
\hline Master Plan & 2.81 & .82 & 3 & 2.89 & .60 & 2 & 2.00 & .94 & 1 & 3.17 & .75 & 3 \\
\hline $\begin{array}{l}\text { Needs } \\
\text { Assessment - } \\
\text { Institutional }\end{array}$ & 2.75 & .77 & 2 & 3.00 & 1.00 & 4 & 2.30 & .67 & 3 & 3.00 & .63 & 1 \\
\hline $\begin{array}{l}\text { Needs } \\
\text { Assessment - } \\
\text { Faculty }\end{array}$ & 2.55 & .88 & 1 & 2.78 & .97 & 1 & 2.20 & .92 & 2 & 3.00 & .63 & 1 \\
\hline
\end{tabular}

As indicated in Table 24, rank order for difficulty in implementation of the administrative factors for planning was consistent across groups, with the exception of Mission and Goals. Each group ranked Mission and Goals as one of the least difficult factors to implement except respondents who held positions other than administrator or faculty, who ranked Mission and Goals second in difficulty of implementation. Responses for all groups on average fell between the very difficult (2) to of minor difficulty (3) range for each factor, with the exception of respondents who held positions other than administrator or faculty, who rated every factor "of minor difficulty." 
Table 25

Comparison of Mean Scores for Importance of the Administrative Factors for Organization

\begin{tabular}{|c|c|c|c|c|c|c|c|c|c|c|c|c|}
\hline \multirow[t]{2}{*}{ Factor } & \multicolumn{3}{|c|}{$\begin{array}{l}\text { Administrator } \\
\quad(n=167)\end{array}$} & \multicolumn{3}{|c|}{$\begin{array}{l}\text { Faculty } \\
(\mathrm{n}=9)\end{array}$} & \multicolumn{3}{|c|}{$\begin{array}{l}\text { Both } \\
(n=10)\end{array}$} & \multicolumn{3}{|c|}{$\begin{array}{l}\text { Other } \\
(\mathrm{n}=6)\end{array}$} \\
\hline & Mean & S.D. & Rank & Mean & S.D. & Rank & Mean & S.D. & Rank & Mean & S.D. & Rank \\
\hline $\begin{array}{l}\text { Organizational } \\
\text { Factors }\end{array}$ & & & & & & & & & & & & \\
\hline Organization & 2.14 & 1.05 & 6 & 1.67 & .71 & 2 & 1.90 & .71 & 4 & 1.83 & .75 & 3 \\
\hline Support & 2.04 & .87 & 5 & 2.00 & .87 & 5 & 1.70 & .95 & 3 & 2.00 & .89 & 4 \\
\hline $\begin{array}{l}\text { Leadership } \\
\text { Authority }\end{array}$ & 1.82 & .96 & 4 & 2.11 & 1.05 & 6 & 2.10 & .99 & 5 & 1.83 & .75 & 3 \\
\hline Funding & 1.61 & .88 & 3 & 1.55 & .53 & 1 & 1.60 & 1.07 & 2 & 1.33 & .82 & 1 \\
\hline Visibility & 1.60 & .80 & 2 & 1.78 & .67 & 3 & 1.50 & .97 & 1 & 1.33 & .82 & 1 \\
\hline Centralization & 1.03 & .82 & 1 & 1.78 & .97 & 4 & 2.30 & 1.33 & 6 & 1.34 & .75 & 2 \\
\hline
\end{tabular}

As indicated in Table 25, the rank order for importance of the administrative factors for organization was not consistent across groups. However, responses for all groups on average fell within the critical (1) to important, but not critical (2) range for each factor. 
Table 26

Comparison of Mean Scores for Difficulty in Implementation of the Administrative Factors for Organization

\begin{tabular}{|c|c|c|c|c|c|c|c|c|c|c|c|c|}
\hline \multirow[t]{2}{*}{ Factor } & \multicolumn{3}{|c|}{$\begin{array}{l}\text { Administrator } \\
(\mathrm{n}=167)\end{array}$} & \multicolumn{3}{|c|}{$\begin{array}{l}\text { Faculty } \\
(n=9)\end{array}$} & \multicolumn{3}{|c|}{$\begin{array}{l}\text { Both } \\
(n=10)\end{array}$} & \multicolumn{3}{|l|}{$\begin{array}{l}\text { Other } \\
(n=6)\end{array}$} \\
\hline & Mean & S.D. & Rank & Mean & S.D. & Rank & Mean & S.D. & Rank & Mean & S.D. & Rank \\
\hline $\begin{array}{l}\text { Organizational } \\
\text { Factors }\end{array}$ & & & & & & & & & & & & \\
\hline $\begin{array}{l}\text { Leadership } \\
\text { Authority }\end{array}$ & 3.05 & .94 & 6 & 3.00 & 1.12 & 5 & 2.80 & 2.80 & 5 & 2.83 & .98 & 4 \\
\hline Visibility & 2.94 & .82 & 5 & 2.78 & .97 & 3 & 2.60 & 2.60 & 3 & 2.91 & .82 & 5 \\
\hline Funding & 2.83 & .91 & 4 & 2.78 & .83 & 2 & 2.60 & 2.60 & 4 & 2.83 & .75 & 3 \\
\hline Organization & 2.83 & .98 & 3 & 3.22 & 1.09 & 6 & 2.30 & 2.30 & 2 & 2.83 & .75 & 3 \\
\hline Centralization & 2.82 & 1.00 & 2 & 2.67 & 1.22 & 1 & 2.80 & 2.80 & 6 & 2.80 & 1.13 & 2 \\
\hline Support & 2.80 & .91 & 1 & 2.89 & 1.05 & 4 & 2.10 & 2.10 & 1 & 2.67 & 1.03 & 1 \\
\hline
\end{tabular}

As indicated in Table 26, rank order for difficulty in implementation of the administrative factors for organization were most similar among administrators and respondents who held positions other than administrators and faculty. The two factors that were ranked significantly different were Centralization, which was ranked first or second by all groups except respondents who were both an administrator and faculty, who ranked Centralization as the least difficult to implement (sixth); and Organization, which was ranked second or third by all groups except faculty, who ranked Organization as the least difficult to implement (sixth). Responses for all groups averaged in the of minor difficulty range (3) for each factor, with the exception of respondents who served as both an administrator and faculty, whose responses fell in the very difficult (2) to of minor difficulty range. 
Table 27

Comparison of Mean Scores for Importance for Faculty Factors

\begin{tabular}{|c|c|c|c|c|c|c|c|c|c|c|c|c|}
\hline \multirow[t]{2}{*}{ Factor } & \multicolumn{3}{|c|}{$\begin{array}{l}\text { Administrator } \\
(\mathrm{n}=167)\end{array}$} & \multicolumn{3}{|c|}{$\begin{array}{l}\text { Faculty } \\
(\mathrm{n}=9)\end{array}$} & \multicolumn{3}{|c|}{$\begin{array}{l}\text { Both } \\
(\mathrm{n}=10)\end{array}$} & \multicolumn{3}{|l|}{$\begin{array}{l}\text { Other } \\
(\mathrm{n}=6)\end{array}$} \\
\hline & Mean & S.D. & Rank & Mean & S.D. & Rank & Mean & S.D. & Rank & Mean & S.D. & Rank \\
\hline $\begin{array}{l}\text { Incentives - } \\
\text { Financial }\end{array}$ & 2.65 & 1.05 & 12 & 2.11 & .93 & 8 & 2.30 & 1.25 & 7 & 2.50 & 1.08 & 10 \\
\hline $\begin{array}{l}\text { Collaboration - } \\
\text { Decide Budget }\end{array}$ & 2.63 & 1.01 & 11 & 2.00 & 1.00 & 5 & 3.10 & 1.10 & 11 & 2.00 & 1.26 & 7 \\
\hline $\begin{array}{l}\text { Incentives - } \\
\text { Professional }\end{array}$ & 2.59 & 1.08 & 10 & 2.22 & .97 & 10 & 2.50 & 1.08 & 10 & 2.33 & 1.03 & 9 \\
\hline $\begin{array}{l}\text { Collaboration - } \\
\text { Access Program } \\
\text { Effectiveness }\end{array}$ & 2.04 & .93 & 9 & 2.11 & .60 & 6 & 2.50 & .97 & 9 & 1.83 & .98 & 4 \\
\hline $\begin{array}{l}\text { Collaboration - } \\
\text { Implement } \\
\text { Programs }\end{array}$ & 2.02 & .83 & 8 & 2.22 & .83 & 9 & 2.30 & 1.16 & 8 & 1.83 & 1.33 & 5 \\
\hline $\begin{array}{l}\text { Collaboration - } \\
\text { Plan Programs }\end{array}$ & 2.01 & .83 & 7 & 2.11 & .78 & 7 & 2.20 & 1.03 & 6 & 2.00 & 1.26 & 7 \\
\hline Shared Vision & 1.99 & .86 & 6 & 2.00 & .71 & 4 & 2.00 & .82 & 4 & 1.67 & .82 & 3 \\
\hline $\begin{array}{l}\text { Staff } \\
\text { Development }\end{array}$ & 1.80 & .86 & 5 & 2.33 & .87 & 11 & 2.10 & .74 & 5 & 2.17 & 1.33 & 8 \\
\hline $\begin{array}{l}\text { Communication- } \\
\text { Support } \\
\text { Different } \\
\text { Teaching Styles }\end{array}$ & 1.53 & .73 & 4 & 1.89 & .78 & 3 & 1.50 & .71 & 3 & 1.83 & .98 & 4 \\
\hline $\begin{array}{l}\text { Communication- } \\
\text { Support } \\
\text { Different } \\
\text { Learning Styles }\end{array}$ & 1.53 & .75 & 3 & 1.55 & .73 & 1 & 1.40 & .70 & 2 & 2.00 & 1.09 & 6 \\
\hline Responsibility & 1.41 & .65 & 2 & 1.55 & .73 & 1 & 1.40 & .70 & 2 & 1.33 & .82 & 1 \\
\hline $\begin{array}{l}\text { Communication- } \\
\text { Encourage } \\
\text { Student } \\
\text { Engagement }\end{array}$ & 1.41 & .68 & 1 & 1.67 & .71 & 2 & 1.20 & .42 & 1 & 1.50 & .84 & 2 \\
\hline
\end{tabular}


As indicated in table 27, the rank order for importance for faculty factors was not consistent among groups. However, responses for all groups fell within the critical (1) to important, but not critical (2) range for each factor except for respondents who served as both an administrator and faculty, whose responses fell between critical (1) and of minor importance (3). 
Table 28

Comparison of Mean Scores for Difficulty in Implementation for Faculty Factors

\begin{tabular}{|c|c|c|c|c|c|c|c|c|c|c|c|c|}
\hline \multirow[t]{2}{*}{ Factor } & \multicolumn{3}{|c|}{$\begin{array}{l}\text { Administrator } \\
(\mathrm{n}=167)\end{array}$} & \multicolumn{3}{|c|}{$\begin{array}{l}\text { Faculty } \\
(\mathrm{n}=9)\end{array}$} & \multicolumn{3}{|c|}{$\begin{array}{l}\text { Both } \\
(n=10)\end{array}$} & \multicolumn{3}{|l|}{$\begin{array}{l}\text { Other } \\
(\mathrm{n}=6)\end{array}$} \\
\hline & Mean & S.D. & Rank & Mean & S.D. & Rank & Mean & S.D. & Rank & Mean & S.D. & Rank \\
\hline $\begin{array}{l}\text { Communication- } \\
\text { Encourage } \\
\text { Student } \\
\text { Engagement }\end{array}$ & 2.87 & .74 & 12 & 2.67 & .71 & 5 & 2.20 & .92 & 7 & 3.17 & .98 & 7 \\
\hline $\begin{array}{l}\text { Staff } \\
\text { Development }\end{array}$ & 2.78 & .82 & 11 & 3.00 & .71 & 11 & 2.30 & .82 & 8 & 2.67 & 1.03 & 5 \\
\hline Responsibility & 2.68 & .69 & 10 & 2.78 & .83 & 8 & 2.50 & .85 & 10 & 2.50 & .55 & 3 \\
\hline $\begin{array}{l}\text { Communication- } \\
\text { Support } \\
\text { Different } \\
\text { Teaching Styles }\end{array}$ & 2.59 & .80 & 9 & 2.67 & .87 & 6 & 2.20 & .92 & 7 & 2.33 & .82 & 1 \\
\hline $\begin{array}{l}\text { Communication- } \\
\text { Support } \\
\text { Different } \\
\text { Learning Styles }\end{array}$ & 2.56 & .79 & 8 & 2.67 & .87 & 7 & 2.20 & .92 & 7 & 2.50 & .84 & 4 \\
\hline $\begin{array}{l}\text { Collaboration- } \\
\text { Access Program } \\
\text { Effectiveness }\end{array}$ & 2.38 & .85 & 7 & 2.56 & .88 & 4 & 1.90 & .87 & 5 & 2.50 & .84 & 4 \\
\hline $\begin{array}{l}\text { Collaboration- } \\
\text { Implement } \\
\text { Programs }\end{array}$ & 2.32 & .87 & 6 & 2.78 & .83 & 8 & 1.90 & .74 & 4 & 2.83 & .98 & 6 \\
\hline $\begin{array}{l}\text { Collaboration- } \\
\text { Plan Programs }\end{array}$ & 2.31 & .86 & 5 & 2.78 & .97 & 9 & 1.80 & .92 & 2 & 2.67 & 1.03 & 5 \\
\hline $\begin{array}{l}\text { Collaboration- } \\
\text { Decide Budget }\end{array}$ & 2.30 & 1.00 & 4 & 2.78 & 1.09 & 10 & 2.00 & 1.05 & 6 & 2.67 & 1.03 & 5 \\
\hline Shared Vision & 2.26 & .92 & 3 & 2.33 & 1.00 & 3 & 2.40 & .70 & 9 & 2.83 & .98 & 6 \\
\hline $\begin{array}{l}\text { Incentives- } \\
\text { Financial }\end{array}$ & 2.14 & .99 & 2 & 2.11 & .93 & 1 & 1.80 & 1.13 & 3 & 2.33 & 1.21 & 2 \\
\hline $\begin{array}{l}\text { Incentives - } \\
\text { Professional }\end{array}$ & 2.08 & .92 & 1 & 2.33 & .87 & 2 & 1.70 & .95 & 1 & 2.83 & .98 & 6 \\
\hline
\end{tabular}


As indicated in Table 28, the rank order for difficulty in implementation for faculty factors was not consistent among groups. However, responses for all groups on average fell within the very difficult (2) to of minor difficulty (3) range for each factor.

It is interesting to note that there was a trend among responses from administrators, respondents who served as both administrators and faculty, and respondents who held positions other than administrators and faculty: factors that were ranked more important tended to be ranked less difficult to implement. Similarly, factors that were ranked less important tended to be ranked more difficult to implement.

\section{Results}

Data analysis of research questions. The survey was originally sent to administrators and faculty with the intent of comparing the differences in perceptions of peer tutoring between administrators and faculty. However, due to a low response rate from faculty, only responses from administrators were used. Therefore, the focus of research for all three questions changed from administrators and faculty to administrators. In addition, question three was changed from differences in perceptions of peer tutoring between administrators and faculty to differences in perceptions of peer tutoring among administrators based on the following demographics: department affiliation, enrollment, highest degree awarded, and Carnegie classification.

Respondents were asked to rate 26 survey items for a) their importance to the institutionalization to peer tutoring and b) their difficulty of implementation. Responses on the first scale (importance) were coded as follows: 1, critical; 2, important, but not critical; 3, of minor importance; and 4, not important. Responses on the second scale (difficulty) were coded as follows: 1 , nearly impossible; 2 , very difficult; 3 , of minor difficulty; and 4, not difficult. The mean, standard deviation, and rank order were calculated for each of the 26 survey items for 
importance to peer tutoring and for difficulty in implementation, and used in determining the answers to the following three research questions:

Question One: What institutional factors facilitate peer tutoring programs in Region II NASPA institutions, according to administrators who are members of Region II?

Question Two: What factors are barriers to peer tutoring programs in Region II NASPA institutions, according to administrators who are members of Region II?

Question Three: What are the differences in perceptions of these factors among administrators based on the following demographic factors: department affiliation, enrollment, highest degree awarded, and Carnegie classification?

Research question one. Question one addressed which institutional factors facilitate peer tutoring programs in Region II NASPA institutions, according to administrators who are members of Region II. The factors were divided into two groups, administrative factors and faculty factors. Administrative factors were divided into two categories: planning and organization. Although the faculty factors were grouped together, the first four factors (shared vision, collaboration, staff development, and incentives) involve collaboration between faculty and administrators and the last two factors (communication and responsibility) involve faculty/student interaction.

Responses on the importance scale of 1-1.5 (critical) and 1.51-2.5 (important, but not critical) were used to identify institutional factors that facilitate peer tutoring programs in Region II NASPA institutions. Table 29 illustrates the mean scores and ranking of administrative and faculty factors that facilitate peer tutoring programs in Region II NASPA institutions. Factors are listed by category and ranked in order of importance both within each category and across categories. Several factors have the same mean, but are ranked differently. This is because they 
also had a lower standard deviation, which makes the response closer to the mean. Therefore, factors with a lower standard deviation were ranked higher.

Table 29

Mean Scores and Ranking of Administrative and Faculty Factors that Facilitate Peer Tutoring Programs in Region II NASPA Institutions

\begin{tabular}{|c|c|c|c|c|c|c|c|}
\hline $\begin{array}{l}\text { Administrative } \\
\text { Factors }\end{array}$ & Mean & $\begin{array}{c}\text { Rank } \\
\text { Within } \\
\text { Categories } \\
\end{array}$ & $\begin{array}{c}\text { Rank } \\
\text { Across } \\
\text { Categories } \\
\end{array}$ & Faculty Factors & Mean & $\begin{array}{c}\text { Rank } \\
\text { Within } \\
\text { Categories }\end{array}$ & $\begin{array}{c}\text { Rank } \\
\text { Across } \\
\text { Categories }\end{array}$ \\
\hline $\begin{array}{l}\text { Planning } \\
\text { Factors }\end{array}$ & & & & $\begin{array}{l}\text { Administrator/Faculty } \\
\text { Collaborative Factors }\end{array}$ & & & \\
\hline Evaluation & 1.42 & 1 & 4 & Staff Development & 1.80 & 1 & 12 \\
\hline $\begin{array}{l}\text { Needs } \\
\text { Assessment - } \\
\text { Students }\end{array}$ & 1.59 & 2 & 7 & $\begin{array}{l}\text { Collaboration - } \\
\text { Plan Programs }\end{array}$ & $\begin{array}{l}1.99 \\
2.01\end{array}$ & $\begin{array}{l}2 \\
3\end{array}$ & $\begin{array}{l}16 \\
17\end{array}$ \\
\hline $\begin{array}{l}\text { Mission and } \\
\text { Goals }\end{array}$ & 1.66 & 3 & 10 & $\begin{array}{l}\text { Collaboration - } \\
\text { Implement Programs }\end{array}$ & 2.02 & 4 & 18 \\
\hline $\begin{array}{l}\text { Policies and } \\
\text { Procedures }\end{array}$ & 1.76 & 4 & 11 & $\begin{array}{l}\text { Collaboration - } \\
\text { Access Program } \\
\text { Effectiveness }\end{array}$ & 2.04 & 5 & 20 \\
\hline $\begin{array}{l}\text { Needs } \\
\text { Assessment - } \\
\text { Institutional }\end{array}$ & 1.82 & 5 & 13 & & & & \\
\hline Master Plan & 1.82 & 6 & 14 & & & & \\
\hline Marketing & 2.02 & 7 & 19 & & & & \\
\hline $\begin{array}{l}\text { Needs } \\
\text { Assessment - } \\
\text { Faculty }\end{array}$ & 2.10 & 8 & 22 & & & & \\
\hline $\begin{array}{l}\text { Organizational } \\
\text { Factors }\end{array}$ & & & & $\begin{array}{l}\text { Student/Faculty } \\
\text { Interactive Factors }\end{array}$ & & & \\
\hline Centralization & 1.03 & 1 & 1 & Responsibility & 1.41 & 1 & 2 \\
\hline Visibility & 1.60 & 2 & 8 & $\begin{array}{l}\text { Communication - } \\
\text { Encourage Student }\end{array}$ & 1.41 & 2 & 3 \\
\hline Funding & 1.61 & 3 & 9 & Engagement & & & \\
\hline $\begin{array}{l}\text { Leadership } \\
\text { Authority }\end{array}$ & 1.82 & 4 & 15 & $\begin{array}{l}\text { Communication - } \\
\text { Support Different } \\
\text { Teaching Styles }\end{array}$ & 1.53 & 3 & 5 \\
\hline $\begin{array}{l}\text { Support } \\
\text { Organization }\end{array}$ & $\begin{array}{l}2.04 \\
2.14\end{array}$ & $\begin{array}{l}5 \\
6\end{array}$ & $\begin{array}{l}21 \\
23\end{array}$ & $\begin{array}{l}\text { Communication - } \\
\text { Support Different } \\
\text { Learning Styles } \\
\end{array}$ & 1.53 & 4 & 6 \\
\hline
\end{tabular}


As illustrated in Table 29, administrators in Region II NASPA institutions identified 23 factors (out of 26 total factors) that facilitate peer tutoring, fourteen administrative factors and nine faculty factors. Four factors were identified as critical: a) Centralization, b) Responsibility, c) Communication - Encourage Student Engagement, and d) Evaluation. The remaining factors were identified as important, but not critical. The top ten factors included: a) Centralization, b) Responsibility, c) Communication - Encourage Student Engagement, and d) Evaluation, e) Communication - Support Different Teaching Styles, f) Communication - Support Different Learning Styles, g) Needs Assessment - Students, h) Visibility, i) Funding, and j) Mission and Goals. The student/faculty interactive factors were among the top six factors. Three factors not identified as facilitating peer tutoring were Collaboration - Decide Budget, Incentives = Financial, and Incentives - Professional. The following factors are presented within the two major categories.

\section{Administrative factors for planning.}

Evaluation. The planning factor considered most important by administrators was Evaluation with a mean of 1.42. However, Evaluation was ranked fourth across categories and refers to an assessment of peer tutoring to make sure the needs of the students (educational goals) are met. This means that on average administrators felt that it was critical that regular evaluations of the peer tutoring program are done to ensure that educational goals are met.

Needs Assessment - students. Administrators ranked Needs Assessment - Students second in importance with a mean of 1.59. Needs Assessment - Students ranked seventh across categories and determines student needs in the area of peer tutoring. A mean of 1.59 shows that on average administrators believed it was important, but not critical to critical that assessments are done to determine student needs in the area of peer tutoring. 
Mission and goals. Administrators ranked Mission and Goals third in importance with a mean of 1.66. However Mission and Goals ranked tenth across categories and refers to the importance that the mission and goals of peer tutoring are compatible with the institution's mission and goals. A mean of 1.66 indicates that on average administrators thought it was important, but not critical to critical that the mission and goals of peer tutoring are compatible with the institution's mission and goals.

Policies and procedures. Administrators ranked Policies and Procedures fourth in importance with a mean of 1.76. Policies and Procedures ranked eleventh across categories and refer to the implementation of formal policies and procedures of peer tutoring. A mean of 1.76 shows that on average administrators felt that it was important, but not critical that formal policies and procedures for peer tutoring are implemented.

Needs Assessment - institutional. Administrators ranked Needs Assessment Institutional fifth in importance with a mean of 1.82. However Needs Assessment - Institutional ranked thirteenth across categories and determines institutional needs for implementing peer tutoring. A mean of 1.82 indicates that on average administrators thought it was important, but not critical that assessments are done to determine institutional needs for implementing peer tutoring.

Master plan. Administrators ranked Master Plan sixth in importance with a mean of 1.82 . Master plan ranked fourteenth across categories and outlines the relevance, importance, objectives and costs of peer tutoring. A mean of 1.82 shows that on average administrators felt it was important, but not critical that a master plan outlining the relevance, importance, objectives, and costs of peer tutoring has been developed. 
Marketing. Administrators ranked Marketing seventh in importance with a mean of 2.02. However Marketing ranked nineteenth across categories and refers to the development of a plan to promote peer tutoring. A mean of 2.02 indicates that on average administrators thought it was important, but not critical that a marketing plan is in place to promote peer tutoring.

Needs Assessment-faculty. Administrators ranked Needs Assessment - Faculty last (eighth) in importance with a mean of 2.10. Similarly, Needs Assessment - Faculty ranked twenty-second (out of twenty-three) and determines faculty needs for implementing peer tutoring. A mean of 2.10 shows that on average administrators believed it was important, but not critical that assessments are done to determine faculty needs for implementing peer tutoring.

Administrative factors for organization.

Centralization. The organizational factor that was considered most important by administrators and most important across categories was Centralization with a mean of 1.03 . Centralization means that one office oversees the implementation, supervision, and assessment of peer tutoring. A mean of 1.03 indicates that on average administrators felt it was critical that one central office oversees the implementation, supervision, and assessment of peer tutoring.

Visibility. Administrators ranked Visibility second in importance with a mean of 1.60. However Visibility ranked eighth across categories and refers to the importance that peer tutoring is visible on campus. A mean of 1.60 shows that on average administrators believed it was important, but not critical to critical that peer tutoring is visible on campus.

Funding. Administrators ranked Funding third in importance with a mean of 1.61. Funding ranked ninth across categories and refers to the fact that it is important that the peer tutoring program and staff are a permanent item in the institutional budget. A mean of 1.61 indicates that on average administrators thought it was important, but not critical to critical that the peer tutoring program and staff are a permanent item in the institutional budget. 
Leadership. Administrators ranked Leadership Authority fourth in importance with a mean of 1.82. However Leadership Authority ranked fifteenth across categories and refers to the appointment of a program director for peer tutoring with decision-making authority. A mean of 1.82 shows that on average administrators felt it was important, but not critical that a program director for peer tutoring be appointed with decision-making authority.

Support. Administrators ranked Support as fifth in importance with a mean of 2.04. Support ranked near the bottom across categories (twenty-one out of twenty-three) and refers to the meeting of peer tutoring administrators and staff with other campus groups to ensure support. A mean of 2.04 shows that on average administrators believed that it was important, but not critical that peer tutoring administrators and staff meet with other campus groups to ensure support.

Organization. Administrators ranked Organization sixth in importance with a mean of 2.14. Organization ranked last in importance (twenty-third) across categories and refers to how peer tutoring is organized and peer tutoring is a campus-wide function and not part of a specific school, department, or academic discipline. A mean of 2.14 indicates that on average administrators felt that it was important, but not critical that peer tutoring is a campus-wide function rather than a part of a specific school, department, or academic discipline.

\section{Faculty factors for administrator and faculty collaboration.}

Staff development. Administrators ranked Staff Development first in importance with a mean of 1.80. However Staff Development ranked twelfth across categories and refers to the importance that ongoing staff development on peer tutoring best practices is in place. A mean of 1.80 indicates that on average administrators felt it was important, but not critical that ongoing staff development in best practices of peer tutoring is in place. 
Shared vision. Administrators ranked Shared Vision second in importance with a mean of 1.99. Shared Vision ranked sixteenth across categories and refers to the idea that there must be a shared vision of peer tutoring among departments. A mean of 1.99 shows that on average administrators believed that it was important, but not critical that there is a shared vision among departments.

Collaboration - plan programs. Administrators ranked Collaboration - Plan Programs third in importance with a mean of 2.01. However Collaboration - Plan Programs ranked seventeenth across categories and refers to the importance of administrators and faculty collaborating to plan peer tutoring programs. A mean of 2.01 indicates that on average administrators felt that it was important, but not critical that administrators and faculty meet to plan peer tutoring programs. Collaboration - implement programs. Administrators ranked Collaboration - Implement Programs fourth in importance with a mean of 2.02. Collaboration - Implement Programs also ranked eighteenth across categories and refers to how faculty and administrators collaborate on peer tutoring to implement programs. A mean of 2.02 shows that on average administrators thought that it was important, but not critical that faculty and administrators meet to decide how to implement peer tutoring programs.

Collaboration - access program effectiveness. Administrators ranked Collaboration Access Program Effectiveness fifth in importance with a mean of 2.04. However Collaboration Access Program Effectiveness ranked twentieth in importance across categories and refers to the collaboration of administrators and faculty to access and determine the effectiveness of peer tutoring programs. A mean of 2.04 indicates that on average administrators felt that it was important, but not critical, that administrators and faculty meet to access and determine the effectiveness of peer tutoring programs. 


\section{Faculty factors for faculty/student interaction.}

Responsibility. The factor considered most important by administrators and ranked second by administrators across categories was Responsibility with a mean of 1.41 . Responsibility refers to students' responsibility and how peer tutoring practices are oriented toward developing a climate in which students' responsibility and active participation are promoted. A mean of 1.41 indicates that on average administrators felt that it was critical that peer tutoring practices are oriented toward developing a climate in which students' responsibility and active participation are promoted.

Communication - encourage student engagement. Administrators ranked Communication - Encourage Student Engagement second in importance with a mean of 1.41. CommunicationEncourage Student Engagement also ranked third in importance across categories and refers to how communication between faculty and students encourages student engagement. A mean of 1.41 shows that on average administrators believed that it was critical that faculty communicate with students to encourage student engagement.

\section{Communication - support different teaching styles. Administrators ranked}

Communication - Support Different Teaching Styles third in importance with a mean of 1.53. Communication - Support Different Teaching Styles ranked fifth in importance across categories and refers to how communication between faculty and students supports different teaching styles. A mean of 1.53 indicates that on average administrators thought it was important, but not critical that communication to critical that communication between faculty and students supports different teaching styles.

Communication - support different learning styles. Administrators ranked Communication - Support Different Learning Styles fourth in importance with a mean of 1.53. 
Communication - Support Different Learning Styles also ranked sixth in importance across categories and refers to how communication between faculty and students supports different learning styles. A mean of 1.53 illustrates that on average administrators believed that it was between critical and important, but not critical that communication between faculty and students supports different learning styles.

Research question two. Question two addresses which factors are barriers to peer tutoring programs in Region II NASPA institutions, according to administrators who are members of Region II. The factors were divided into two groups, administrative factors and faculty factors. Administrative factors were divided into two categories: planning and organization. Although the faculty factors were grouped together, the first four factors (shared vision, collaboration, staff development, and incentives) involve collaboration between faculty and administrators and the last two factors (communication and responsibility) involve faculty/student interaction.

Barriers were calculated by averaging the means for each factor on the difficulty scale. Responses of 1-1.5 (nearly impossible) or 1.51-2.5 (very difficult) were used to identify institutional factors that form barriers to peer tutoring programs in Region II NASPA institutions. Factors that had an average mean of 2.51-2.59 were identified as potential barriers. Table 30 illustrates the mean scores and ranking of administrative and faculty factors that were barriers to peer tutoring programs in Region II NASPA institutions. Although the factors are listed by category, they are ranked in order of importance across categories. 
Table 30

Mean Scores and Ranking of Administrative and Faculty Factors that Form Barriers to Peer Tutoring Programs in Region II NASPA Institutions

\begin{tabular}{|c|c|c|c|c|c|}
\hline $\begin{array}{l}\text { Administrative } \\
\text { Factors }\end{array}$ & Mean & Rank & Faculty Factors & Mean & Rank \\
\hline Planning Factors & \multirow{8}{*}{2.55} & \multirow{8}{*}{8} & Administrator/Faculty Collaborative Factors & & \\
\hline \multirow{7}{*}{$\begin{array}{l}\text { Needs Assessment - } \\
\text { Faculty }\end{array}$} & & & Incentives - Professional & 2.08 & 1 \\
\hline & & & Incentives - Financial & 2.14 & 2 \\
\hline & & & Shared Vision & 2.26 & 3 \\
\hline & & & Collaboration - Decide Budget & 2.30 & 4 \\
\hline & & & Collaboration - Plan Programs & 2.31 & 5 \\
\hline & & & Collaboration - Implement Programs & 2.32 & 6 \\
\hline & & & Collaboration - Access Program Effectiveness & 2.38 & 7 \\
\hline \multirow{3}{*}{$\begin{array}{l}\text { Organizational } \\
\text { Factors }\end{array}$} & & & Student/Faculty Interactive Factors & & \\
\hline & & & Communication - Support Different Learning Styles & 2.56 & 9 \\
\hline & & & Communication - Support Different Teaching Styles & 2.59 & 10 \\
\hline
\end{tabular}

As indicated in Table 30, administrators in Region II NASPA institutions identified ten, out of twenty-six total factors, that were barriers to peer tutoring: one administrative factor and nine faculty factors. Administrators identified the top five barriers as follows: a) Incentives Professional, b) Incentives - Financial, c) Shared Vision, d) Collaboration - Decide Budget, and e) Collaboration - Plan Programs. Several factors had means slightly above mid-range for response 2, very difficult, which identified them as potential barriers. These factors include a) Needs Assessment - Faculty, b) Communication - Support Different Learning Styles, and c) Communication - Support different teaching styles. The following factors are presented within the two major categories. 


\section{Administrative factors for planning.}

Needs assessment - faculty. Although administrators identified Needs Assessment -

Faculty as a factor that facilitates peer tutoring with an importance mean of 2.10 , it was also identified as a potential barrier to peer tutoring with a difficulty mean of 2.55. Needs Assessment - Faculty determines faculty needs for implementing peer tutoring. Administrators ranked Needs Assessment - Faculty as the most difficult planning factor. However, a difficulty mean of 2.55 indicates that on average administrators believed that it would be between minor difficulty and very difficult to conduct an assessment of faculty needs for implementing peer tutoring.

Administrative factors for organization. There were no organizational factors identified as barriers to peer tutoring programs in Region II NASPA institutions, according to administrators who are members of Region II.

Faculty factors for administrator and faculty collaboration.

Incentives - professional. Administrators ranked Incentives - Professional most difficult with a mean of 2.08. Incentives - Professional refers to professional incentives to participate in peer tutoring programs that are available to faculty (i.e. credit towards promotion and tenure, flexibility in time teaching). A mean of 2.08 indicates that on average administrators felt that it would be very difficult to provide professional incentives, such as credit towards promotion and tenure or flexibility in time teaching, for faculty to participate in peer tutoring programs.

Incentives - financial. Administrators ranked Incentives - Financial second in difficulty with a mean of 2.14. Incentives - Financial refers to financial incentives to participate in peer tutoring that are available to faculty (i.e. merit pay, grants for future research, new computer).A mean of 2.14 shows that on average administrators believed that it would be very difficult to 
provide financial incentives, such as merit pay, grants for future research, or a new computer, for faculty to participate in peer tutoring.

Shared vision. Although administrators identified Shared Vision as a factor that facilitates peer tutoring with an importance mean of 1.99, administrators also identified Shared Vision as a barrier to peer tutoring and ranked it third in difficulty with a mean of 1.99. Shared Vision refers to the idea that there must be a shared vision of peer tutoring among departments. A difficulty mean of 1.99 shows that on average administrators believed that it would be very difficult for there to be a shared vision of peer tutoring among departments.

Collaboration - decide budget. Administrators ranked Collaboration - Decide Budget fourth in difficulty with a mean of 2.30. Collaboration - Decide Budget refers to the collaboration of faculty and administrators to decide the peer tutoring budget. A mean of 2.30 shows that on average administrators believed it would be very difficult for faculty and administrators to collaborate on peer tutoring to decide the program budget.

Collaboration - plan programs. Although administrators identified Collaboration - Plan Programs as a factor that facilitates peer tutoring with an importance mean of 2.01, administrators also identified Collaboration - Plan Programs as a barrier to peer tutoring and ranked it fifth in difficulty with a mean of 2.31. Collaboration - Plan Programs refers to the importance of administrators and faculty collaboration to plan peer tutoring programs. A mean of 2.31 indicates that on average administrators thought it would be very difficult for administrators and faculty to collaborate on peer tutoring to plan programs.

Collaboration - implement programs. While administrators identified Collaboration Implement Programs as a factor that facilitates peer tutoring with an importance mean of 2.02, administrators also identified Collaboration - Implement programs as a barrier to peer tutoring 
and ranked it sixth in difficulty with a mean of 2.32. Collaboration - Implement Programs refers to how faculty and administrators collaborate on peer tutoring to implement programs. A mean of 2.32 illustrates that on average administrators believed it would be very difficult for administrators and faculty to collaborate on peer tutoring to implement programs.

Collaboration - access program effectiveness. Collaboration - Access program effectiveness was also identified as both a factor that facilitates peer tutoring and a barrier to peer tutoring. Administrators ranked it seventh in difficulty with a mean of 2.38. Collaboration Access Program Effectiveness refers to the collaboration of administrators and faculty to access and determine the effectiveness of peer tutoring programs. A mean of 2.38 indicates that on average administrators felt it would be very difficult for administrators and faculty to collaborate on peer tutoring to access and evaluate the effectiveness of peer tutoring programs. It is interesting to note that administrators also ranked Collaboration - Access Program Effectiveness ninth in order of importance with a mean of 2.04. This shows that on average administrators felt that it was important, but not critical, that administrators and faculty meet to access and determine the effectiveness of peer tutoring programs.

\section{Faculty factors for faculty/student interaction.}

Communication - support different learning styles. While administrators identified Communication - Support Different Learning Styles as a factor that facilitates peer tutoring with an importance mean of 1.53 , it was also identified as a potential barrier to peer tutoring and ranked ninth in difficulty with a mean of 2.56. Communication - Support Different Learning Styles refers to how communication between faculty and students supports different learning styles. A mean of 2.56 shows that on average administrators thought it would be between minor 
difficulty and very difficult for communication between faculty and students to support different learning styles.

Communication - support different teaching styles. Administrators ranked Communication - Support Different Teaching Styles tenth in difficulty and identified Communication - Support Different Teaching Styles as both a factor that facilitates peer tutoring with an importance mean of 1.53 , and as a potential barrier to peer tutoring with a difficulty mean of 2.59. Communication - Support Different Teaching Styles refers to how communication between faculty and students supports different teaching styles. A mean of 2.59 indicates that on average administrators thought it would be between minor difficulty and very difficult for communication between faculty and students to support different teaching styles.

Research question three. Question three discusses the differences in perceptions among administrators of the administrative and faculty factors that a) facilitate peer tutoring and b) form barriers to peer tutoring based on the following demographic factors: department affiliation (Academic Affairs, Student Affairs, or both), enrollment (less than 5000, 5,000 - 10,000, 10,001 -20,000, or over 20,000), highest degree awarded (associates, bachelors, doctorate, or professional), and Carnegie classification (research university, very high research; research university, high research; doctoral research university; master's colleges and universities, larger programs; master's colleges and universities, medium programs; master's colleges and universities, smaller programs; baccalaureate colleges, all subtypes; or associate's colleges, all subtypes) .

The mean, standard deviation, and rank were calculated for each survey item for each of the demographic factors. In addition, further testing was conducted using SPSS (Statistical Package for the Social Sciences) to determine the difference between groups. An analysis of 
variance (ANOVA), a test that compares group means by analyzing comparisons of variance estimates, was done in order to determine which groups differ from each other and how they differ (Plonsky, 2011). "The analysis of variance...is the most widely used method of statistical analysis of quantitative data. It calculates the probability that differences among the observed means could simply be due to chance" (The ANOVA," n.d., para. 1).

A post-hoc test was also calculated to determine the significance of the difference. The Bonferroni correction, a statistical test "that allows many comparison statements to be made (or confidence intervals to be constructed) while still assuring an overall confidence coefficient is maintained" ("Bonferroni's method," n.d., para. 1), was used. This test commonly is used with ANOVA when the researcher has selected a finite set of comparisons in advance ("Bonferroni's method," n.d.).

\section{Differences in perception of administrative factors.}

Factors that facilitate peer tutoring - department affiliation. Table 31 shows the mean scores for differences in perception among administrators of administrative factors that facilitate peer tutoring based on the following department affiliation: Student Affairs, Academic Affairs, and both Student Affairs and Academic Affairs. Responses on the importance scale of 1-1.5 (critical) and 1.51-2.5 (important, but not critical) were used to identify institutional factors that facilitate peer tutoring programs. Although 167 respondents identified themselves as administrators, 14 respondents identified themselves as "in another department." For reporting purposes, only responses from administrators in Academic Affairs or Student Affairs were used, bringing the total respondents to 153 . 
Table 31

Mean Scores for Differences in Perception of Administrative Factors that Facilitate Peer Tutoring Based on Department Affiliation

\begin{tabular}{|c|c|c|c|c|}
\hline Factor & \multicolumn{4}{|c|}{ Department Affiliation } \\
\hline & $\begin{array}{l}\text { Student } \\
\text { Affairs } \\
n=47\end{array}$ & $\begin{array}{c}\text { Academic } \\
\text { Affairs } \\
n=74\end{array}$ & $\begin{array}{l}\text { Both } \\
n=32\end{array}$ & $\begin{array}{l}\text { Total } \\
\text { Average } \\
n=153\end{array}$ \\
\hline $\begin{array}{l}\text { 1. Peer tutoring is compatible with the institution's } \\
\text { mission and goals. }\end{array}$ & 1.77 & 1.55 & 1.69 & 1.65 \\
\hline $\begin{array}{l}\text { 2. Formal policies and procedures for peer tutoring } \\
\text { have been implemented. }\end{array}$ & 1.55 & 1.66 & 2.06 & 1.71 \\
\hline $\begin{array}{l}\text { 3. Assessments are done to determine student needs } \\
\text { in the area of peer tutoring. }\end{array}$ & 1.68 & 1.54 & 1.56 & 1.59 \\
\hline $\begin{array}{l}\text { 4. Assessments are done to determine faculty needs } \\
\text { for implementing peer tutoring. }\end{array}$ & 2.23 & 2.01 & 2.13 & 2.10 \\
\hline $\begin{array}{l}\text { 5. Assessments are done to determine institutional } \\
\text { needs for implementing peer tutoring. }\end{array}$ & 1.89 & 1.69 & 1.94 & 1.80 \\
\hline $\begin{array}{l}\text { 6. Regular evaluations of the peer tutoring program } \\
\text { are done to ensure that educational goals are met. }\end{array}$ & 1.47 & 1.32 & 1.47 & 1.40 \\
\hline $\begin{array}{l}\text { 7. A master plan outlining relevance, importance, } \\
\text { objectives, and costs of peer tutoring has been developed. }\end{array}$ & 1.91 & 1.81 & 1.78 & 1.84 \\
\hline 8. A marketing plan is in place to promote peer tutoring. & 2.09 & 1.99 & 2.00 & 2.02 \\
\hline $\begin{array}{l}\text { 9. Peer tutoring is a campus-wide function and not part } \\
\text { of a specific school, department, or academic discipline. }\end{array}$ & 2.15 & 1.99 & 2.31 & 2.10 \\
\hline 10. Peer tutoring is visible on campus. & 1.70 & 1.57 & 1.50 & 1.59 \\
\hline $\begin{array}{l}\text { 11. One central office oversees the implementation, } \\
\text { supervision, and assessment of the peer tutoring program. }\end{array}$ & 1.94 & 1.55 & 2.76 & 1.93 \\
\hline $\begin{array}{l}\text { 12. A program director for peer tutoring with decision- } \\
\text { making authority has been appointed. }\end{array}$ & 1.77 & 1.64 & 2.15 & 1.78 \\
\hline $\begin{array}{l}\text { 13. Peer tutoring administrators and staff meet } \\
\text { regularly with other campus groups to ensure support. }\end{array}$ & 2.09 & 1.95 & 2.16 & 2.03 \\
\hline $\begin{array}{l}\text { 14. The peer tutoring program and staff are a permanent } \\
\text { part of the institutional budget. }\end{array}$ & 1.64 & 1.43 & 1.84 & 1.58 \\
\hline
\end{tabular}


As indicated in Table 31, on average all administrative factors were perceived by administrators to facilitate peer tutoring and there were minimal differences in perceptions among administrators based on department affiliation. The mean fell within the same range for each factor for each department affiliation, with the exception of the following two factors:

a) Centralization. A mean of 1.93 indicates that on average administrators across departments ( $\mathrm{n}=153)$ felt that it was important, but not critical that one central office oversees the implementation, supervision, and assessment of peer tutoring. While administrators in Student Affairs ( $n=47)$, and Academic Affairs $(n=74)$ agreed, with means of 1.94 and 1.55 respectively, administrators who were affiliated with both Student Affairs and Academic Affairs ( $\mathrm{n}=32$, mean $=2.76$ ) believed that it was of minor importance for one central office to oversee the implementation, supervision, and assessment of peer tutoring.

b) Funding. A mean of 1.58 indicates that administrators across departments $(\mathrm{n}=153)$ believed it was important, but not critical that the peer tutoring program and staff are a permanent part of the institutional budget. While administrators in Student Affairs ( $\mathrm{n}=47)$ and administrators who are affiliated with both Student Affairs and Academic Affairs $(\mathrm{n}=32)$ agreed, with means of 1.64 and 1.84 respectively, administrators in Academic Affairs ( $\mathrm{n}=74$, mean=1.43) felt it was critical that there be permanent funding for peer tutoring.

Factors that facilitate peer tutoring - enrollment. Table 32 shows the mean scores for differences in perception among administrators of administrative factors that facilitate peer tutoring based on the following enrollment: a) less than 5000, b) 5,000-10,000, c) 10,00120,000 , or d) over 20,000. Responses on the importance scale of 1-1.5 (critical) and 1.51-2.5 (important, but not critical) were used to identify institutional factors that facilitate peer tutoring 
programs. Although 167 respondents identified themselves as administrators, one respondent didn't select a response, bringing the total respondents to 166 .

Table 32

Mean Scores for Differences in Perception of Administrative Factors that Facilitate Peer Tutoring Based on Enrollment

\begin{tabular}{|c|c|c|c|c|}
\hline Enrollment & \multicolumn{4}{|c|}{ Factor } \\
\hline \multirow[b]{2}{*}{$\begin{array}{l}\text { Less than } \\
5,000(n=65)\end{array}$} & $\begin{array}{l}\text { 1. Peer tutoring is } \\
\text { compatible with } \\
\text { the institution's } \\
\text { mission and goals. }\end{array}$ & $\begin{array}{l}\text { 2. Formal policies and } \\
\text { procedures for peer } \\
\text { tutoring have been } \\
\text { implemented. }\end{array}$ & $\begin{array}{l}\text { 3. Assessments are } \\
\text { done to determine } \\
\text { student needs in the } \\
\text { area of peer tutoring. }\end{array}$ & $\begin{array}{l}\text { 4. Assessments are } \\
\text { done to determine } \\
\text { faculty needs for } \\
\text { implementing peer } \\
\text { tutoring. }\end{array}$ \\
\hline & 1.57 & 1.75 & 1.54 & 2.10 \\
\hline $\begin{array}{l}5,000-10,000 \\
(\mathrm{n}=32)\end{array}$ & 1.66 & 1.31 & 1.47 & 2.00 \\
\hline $\begin{array}{l}10,001-20,000 \\
(\mathrm{n}=35)\end{array}$ & 1.77 & 1.94 & 1.77 & 2.31 \\
\hline $\begin{array}{l}\text { Over } 20,000 \\
(\mathrm{n}=34)\end{array}$ & 1.74 & 1.97 & 1.62 & 1.94 \\
\hline $\begin{array}{l}\text { Total Average } \\
(n=166)\end{array}$ & 1.66 & 1.75 & 1.59 & 2.10 \\
\hline & $\begin{array}{l}\text { 5. Assessments are } \\
\text { done to determine } \\
\text { institutional needs } \\
\text { for implementing } \\
\text { peer tutoring. }\end{array}$ & $\begin{array}{l}\text { 6. Regular evaluations } \\
\text { of the peer tutoring } \\
\text { program are done } \\
\text { to ensure that educa- } \\
\text { tional goals are met. }\end{array}$ & $\begin{array}{l}\text { 7. A master plan } \\
\text { outlining relevance, } \\
\text { importance, } \\
\text { objectives, and costs } \\
\text { of peer tutoring has } \\
\text { been developed. }\end{array}$ & $\begin{array}{l}\text { 8. A marketing plan } \\
\text { is in place to } \\
\text { promote peer } \\
\text { tutoring. }\end{array}$ \\
\hline $\begin{array}{l}\text { Less than } 5,000 \\
(\mathrm{n}=65)\end{array}$ & 1.83 & 1.38 & 1.92 & 2.17 \\
\hline $\begin{array}{l}5,000-10,000 \\
(\mathrm{n}=32)\end{array}$ & 1.53 & 1.31 & 1.59 & 1.81 \\
\hline $\begin{array}{l}10,001-20,000 \\
(\mathrm{n}=35)\end{array}$ & 2.11 & 1.60 & 2.03 & 2.17 \\
\hline $\begin{array}{l}\text { Over } 20,000 \\
(n=34)\end{array}$ & 1.76 & 1.38 & 1.68 & 1.79 \\
\hline $\begin{array}{l}\text { Total Average } \\
(\mathrm{n}=166)\end{array}$ & 1.82 & 1.42 & 1.83 & 2.02 \\
\hline
\end{tabular}


Table 32 (Cont.)

Mean Scores for Differences in Perception of Administrative Factors that Facilitate Peer Tutoring Based on Enrollment

\begin{tabular}{|c|c|c|c|c|}
\hline Enrollment & \multicolumn{4}{|c|}{ Factor } \\
\hline & $\begin{array}{l}\text { 9. Peer tutoring is a } \\
\text { campus-wide } \\
\text { function and not } \\
\text { part of a specific } \\
\text { school, department, } \\
\text { or academic } \\
\text { discipline. }\end{array}$ & $\begin{array}{l}10 . \text { Peer tutoring is } \\
\text { visible on campus. }\end{array}$ & $\begin{array}{l}\text { 11. One central office } \\
\text { oversees the } \\
\text { implementation, } \\
\text { supervision, and } \\
\text { assessment of the } \\
\text { peer tutoring } \\
\text { program. }\end{array}$ & $\begin{array}{l}\text { 12. A program } \\
\text { director for peer } \\
\text { tutoring with } \\
\text { decision- } \\
\text { making authority } \\
\text { has been appointed. }\end{array}$ \\
\hline $\begin{array}{l}\text { Less than } 5,000 \\
(\mathrm{n}=65)\end{array}$ & 2.06 & 1.65 & 1.74 & 1.66 \\
\hline $\begin{array}{l}5,000-10,000 \\
(\mathrm{n}=32)\end{array}$ & 2.09 & 1.34 & 1.75 & 1.78 \\
\hline $\begin{array}{l}10,001-20,000 \\
(n=35)\end{array}$ & 2.20 & 1.83 & 2.26 & 1.86 \\
\hline $\begin{array}{l}\text { Over } 20,000 \\
(n=34)\end{array}$ & 2.32 & 1.53 & 2.29 & 2.06 \\
\hline Total Average & 2.15 & 1.60 & 1.96 & 1.81 \\
\hline & $\begin{array}{l}\text { 13. Peer tutoring } \\
\text { administrators and } \\
\text { staff meet } \\
\text { regularly with other } \\
\text { campus groups to } \\
\text { ensure support. }\end{array}$ & $\begin{array}{l}\text { 14. The peer } \\
\text { tutoring program } \\
\text { and staff are a } \\
\text { permanent part of } \\
\text { the institutional } \\
\text { budget. }\end{array}$ & & \\
\hline $\begin{array}{l}\text { Less than } 5,000 \\
(\mathrm{n}=65)\end{array}$ & 2.03 & 1.54 & & \\
\hline $\begin{array}{l}5,000-10,000 \\
(n=32)\end{array}$ & 1.91 & 1.28 & & \\
\hline $\begin{array}{l}10,001-20,000 \\
(n=35)\end{array}$ & 2.20 & 2.03 & & \\
\hline $\begin{array}{l}\text { Over } 20,000 \\
(n=34)\end{array}$ & 2.00 & 1.65 & & \\
\hline $\begin{array}{l}\text { Total Average } \\
(\mathrm{n}=166)\end{array}$ & 2.03 & 1.61 & & \\
\hline
\end{tabular}


As indicated in Table 32, on average all fourteen administrative factors were perceived by administrators to facilitate peer tutoring and there were minimal differences in perceptions among administrators based on institutional enrollment. The mean fell within the same range for each factor for each level of enrollment, with the exception of the following four factors:

a) Policies and Procedures. A mean of 1.75 indicates that on average administrators, regardless of institutional enrollment $(\mathrm{n}=166)$, thought it was important, but not critical that formal policies and procedures for peer tutoring are in place. However, administrators at institutions with enrollment between 5,000 and 10,000 students ( $\mathrm{n}=32)$ differed from the other groups in their perception of the importance of the implementation of formal policies and procedures, with a mean of 1.31 . This shows that administrators at institutions with an enrollment between 5,000 and 10,000 believed it was critical that formal policies and procedures for peer tutoring are in place.

b) Evaluation. A mean of 1.42 indicates that on average administrators $(n=166)$ believed it was critical that regular evaluations of the peer tutoring program are done to ensure that educational goals are met. However, administrators from institutions with an enrollment of $10,001-20,000(\mathrm{n}=35)$ differed from the other groups in their perception of evaluations, with a mean of 1.60. This shows that administrators at institutions with an enrollment of 10,001-20,000 thought it was important, but not critical that regular evaluations of the peer tutoring program are done to ensure that educational goals are met.

c) Visibility. A mean of 1.60 indicates that on average administrators $(n=166)$ believed it was important, but not critical that peer tutoring is visible on campus. However, administrators at institutions with enrollment between 5,000 and 10,000 students $(\mathrm{n}=32)$ differed in their belief, 
with a mean of 1.34. This shows that administrators at institutions with enrollment between 5,000 and 10,000 students $(n=32)$ felt that it was critical that peer tutoring is visible on campus.

d) Funding. A mean of 1.61 indicates that on average administrators $(n=166)$ felt it was important, but not critical that the peer tutoring program and staff are a permanent part of the institutional budget. Once again administrators at institutions with enrollment between 5,000 and 10,000 students $(n=32)$ differed in their view from the other groups, with a mean of 1.28 . This shows that administrators at institutions with enrollment between 5,000 and 10,000 students believed it was critical that the peer tutoring program and staff are a permanent part of the institutional budget.

Factors that facilitate peer tutoring - highest degree awarded. Table 33 shows the mean scores for differences in perception of administrative factors that facilitate peer tutoring based on the following degrees awarded: a) associates, b) bachelors, c) masters, d) doctorate, and e) professional. An average mean for the total respondents was also computed for each factor. Responses on the importance scale of 1-1.5 (critical) and 1.51-2.5 (important, but not critical) were used to identify institutional factors that facilitate peer tutoring programs. Although 167 respondents identified themselves as administrators, one respondent didn't select a response, bringing the total respondents to 166 . 
Table 33

Mean Scores for Differences in Perception of Administrative Factors that Facilitate Peer Tutoring Based on Highest Degree Awarded

\begin{tabular}{|c|c|c|c|c|}
\hline Degree & \multicolumn{4}{|c|}{ Factor } \\
\hline & $\begin{array}{l}\text { 1. Peer tutoring is } \\
\text { compatible with the } \\
\text { institution's } \\
\text { mission and goals. }\end{array}$ & $\begin{array}{l}\text { 2. Formal policies and } \\
\text { procedures for peer } \\
\text { tutoring have been } \\
\text { implemented. }\end{array}$ & $\begin{array}{l}\text { 3. Assessments are } \\
\text { done to determine } \\
\text { student needs in the } \\
\text { area of peer } \\
\text { tutoring. }\end{array}$ & $\begin{array}{l}\text { 4. Assessments are } \\
\text { done to determine } \\
\text { faculty needs for } \\
\text { implementing peer } \\
\text { tutoring. }\end{array}$ \\
\hline $\begin{array}{l}\text { Associates } \\
(\mathrm{n}=19)\end{array}$ & 1.68 & 1.79 & 1.79 & 2.47 \\
\hline $\begin{array}{l}\text { Bachelors } \\
(\mathrm{n}=15)\end{array}$ & 1.53 & 1.67 & 1.27 & 1.93 \\
\hline $\begin{array}{l}\text { Masters } \\
(\mathrm{n}=33)\end{array}$ & 1.60 & 1.64 & 1.70 & 2.03 \\
\hline $\begin{array}{l}\text { Doctorate } \\
(\mathrm{n}=69)\end{array}$ & 1.70 & 1.74 & 1.52 & 2.06 \\
\hline $\begin{array}{l}\text { Professional } \\
\text { (30) }\end{array}$ & 1.73 & 1.93 & 1.67 & 2.10 \\
\hline Total Average & 1.67 & 1.75 & 1.59 & 2.10 \\
\hline & $\begin{array}{l}\text { 5. Assessments are } \\
\text { done to determine } \\
\text { institutional needs } \\
\text { for implementing } \\
\text { peer tutoring. }\end{array}$ & $\begin{array}{l}\text { 6. Regular evaluations } \\
\text { of the peer tutoring } \\
\text { program are done to } \\
\text { ensure that educa- } \\
\text { tional goals are met. }\end{array}$ & $\begin{array}{l}\text { 7. A master plan } \\
\text { outlining relevance, } \\
\text { importance, } \\
\text { objectives, and } \\
\text { costs of peer } \\
\text { tutoring has been } \\
\text { developed. }\end{array}$ & $\begin{array}{l}\text { 8. A marketing plan } \\
\text { is in place to } \\
\text { promote peer } \\
\text { tutoring. }\end{array}$ \\
\hline $\begin{array}{l}\text { Associates } \\
(\mathrm{n}=19)\end{array}$ & 2.00 & 1.68 & 2.05 & 2.32 \\
\hline $\begin{array}{l}\text { Bachelors } \\
(\mathrm{n}=15)\end{array}$ & 1.67 & 1.27 & 1.93 & 2.07 \\
\hline $\begin{array}{l}\text { Masters } \\
(\mathrm{n}=33)\end{array}$ & 1.81 & 1.30 & 1.73 & 2.00 \\
\hline $\begin{array}{l}\text { Doctorate } \\
(\mathrm{n}=69)\end{array}$ & 1.77 & 1.42 & 1.77 & 1.99 \\
\hline $\begin{array}{l}\text { Professional } \\
\text { (30) }\end{array}$ & 1.90 & 1.47 & 1.90 & 1.97 \\
\hline $\begin{array}{l}\text { Total Average } \\
(\mathrm{n}=166)\end{array}$ & 1.82 & 1.42 & 1.83 & 2.03 \\
\hline
\end{tabular}


Table 33 (Cont.)

Mean Scores for Differences in Perception of Administrative Factors that Facilitate Peer Tutoring Based on Highest Degree Awarded

\begin{tabular}{|c|c|c|c|c|}
\hline Degree & \multicolumn{4}{|c|}{ Factor } \\
\hline & $\begin{array}{l}\text { 9. Peer tutoring is a } \\
\text { campus-wide } \\
\text { function and not } \\
\text { part of a specific } \\
\text { school, department, } \\
\text { or academic } \\
\text { discipline. }\end{array}$ & $\begin{array}{l}\text { 10. Peer tutoring is } \\
\text { visible on campus. }\end{array}$ & $\begin{array}{l}\text { 11. One central office } \\
\text { oversees the } \\
\text { implementation, } \\
\text { supervision, and } \\
\text { assessment of the } \\
\text { peer tutoring } \\
\text { program. }\end{array}$ & $\begin{array}{l}\text { 12. A program } \\
\text { director for peer } \\
\text { tutoring with } \\
\text { decision- } \\
\text { making authority } \\
\text { has been appointed. }\end{array}$ \\
\hline $\begin{array}{l}\text { Associates } \\
(\mathrm{n}=19)\end{array}$ & 2.32 & 1.84 & 2.21 & 2.16 \\
\hline $\begin{array}{l}\text { Bachelors } \\
(\mathrm{n}=15)\end{array}$ & 2.00 & 1.13 & 1.73 & 1.60 \\
\hline $\begin{array}{l}\text { Masters } \\
(\mathrm{n}=33)\end{array}$ & 2.12 & 1.58 & 1.58 & 1.52 \\
\hline $\begin{array}{l}\text { Doctorate } \\
(\mathrm{n}=69)\end{array}$ & 2.12 & 1.59 & 1.96 & 1.80 \\
\hline $\begin{array}{l}\text { Professional } \\
(30)\end{array}$ & 2.23 & 1.73 & 2.33 & 2.03 \\
\hline Total Average & 2.15 & 1.60 & 1.96 & 1.81 \\
\hline & $\begin{array}{l}\text { 13. Peer tutoring } \\
\text { administrators } \\
\text { and staff meet } \\
\text { regularly with other } \\
\text { campus groups to } \\
\text { ensure support. }\end{array}$ & $\begin{array}{l}\text { 14. The peer } \\
\text { tutoring program } \\
\text { and staff are a } \\
\text { permanent part of } \\
\text { the institutional } \\
\text { budget. }\end{array}$ & & \\
\hline $\begin{array}{l}\text { Associates } \\
(\mathrm{n}=19)\end{array}$ & 2.47 & 1.79 & & \\
\hline $\begin{array}{l}\text { Bachelors } \\
(\mathrm{n}=15)\end{array}$ & 2.07 & 1.60 & & \\
\hline $\begin{array}{l}\text { Masters } \\
(\mathrm{n}=33)\end{array}$ & 1.76 & 1.45 & & \\
\hline $\begin{array}{l}\text { Doctorate } \\
(\mathrm{n}=69)\end{array}$ & 2.01 & 1.52 & & \\
\hline $\begin{array}{l}\text { Professional } \\
\text { (30) }\end{array}$ & 2.10 & 1.90 & & \\
\hline $\begin{array}{l}\text { Total Average } \\
(\mathrm{n}=166)\end{array}$ & 2.04 & 1.61 & & \\
\hline
\end{tabular}


As indicated in Table 33, on average all fourteen administrative factors were perceived to facilitate peer tutoring and there were minimal differences in perceptions among administrators based on the highest degree awarded. The mean fell within the same range for each factor for each degree, with the exception of the following four factors:

a) Needs Assessment - Students. A mean of 1.59 indicates that on average administrators, regardless of degrees awarded $(n=166)$, thought it was important, but not critical that assessments be done to determine student needs in the area of peer tutoring. However, administrators from institutions that award bachelor degrees $(\mathrm{n}=15)$ differed from the other groups in their perception of evaluations, with a mean of 1.27 . This shows that administrators from institutions that award bachelor degrees thought it was critical that assessments be done to determine student needs in the area of peer tutoring.

b) Evaluation. A mean of 1.42 indicates that on average administrators $(n=166)$ believed it was critical that regular evaluations of the peer tutoring program are done to ensure that educational goals are met. However, administrators from associates colleges $(n=19$, mean $=1.68)$ felt it was important, but not critical that regular evaluations of the peer tutoring program are done to ensure that educational goals are met.

c) Visibility. A mean of 1.60 indicates that on average administrators $(n=166)$ felt it was important, but not critical that peer tutoring is visible on campus. However, administrators from institutions that award bachelor degrees $(n=15$, mean $=1.13)$ believed that it was critical that peer tutoring is visible on campus.

d) Funding. A mean of 1.61 shows that on average administrators $(n=166)$ thought it was important, but not critical that the peer tutoring program and staff should be a permanent part of the institutional budget. However, administrators from masters colleges and universities $(n=33$, 
mean=1.45) felt it was critical that the peer tutoring program and staff should be a permanent part of the institutional budget.

Factors that facilitate peer tutoring - Carnegie classification. Table 34 shows the mean scores for differences in perception of administrative factors that facilitate peer tutoring based on the following Carnegie classifications: a) research university, b) very high research;

c) research university, high research; d) doctoral research university; e) masters colleges and universities, larger programs; f) masters colleges and universities, medium programs; g) masters colleges and universities, smaller programs; h) baccalaureate colleges; and i) associates colleges. An average mean for the total respondents was also computed for each factor. Responses on the importance scale of 1-1.5 (critical) and 1.51-2.5 (important, but not critical) were used to identify institutional factors that facilitate peer tutoring programs. 
Table 34

Mean Scores for Differences in Perception of Administrative Factors that Facilitate Peer Tutoring Based on Carnegie Classification

\begin{tabular}{|c|c|c|c|c|}
\hline \multirow{2}{*}{$\begin{array}{c}\text { Carnegie } \\
\text { Classification }\end{array}$} & \multicolumn{4}{|c|}{ Factor } \\
\hline & $\begin{array}{l}\text { 1. Peer tutoring } \\
\text { is compatible } \\
\text { with the } \\
\text { institution's } \\
\text { mission and } \\
\text { goals. }\end{array}$ & $\begin{array}{l}\text { 2. Formal policies } \\
\text { and procedures for } \\
\text { peer tutoring have } \\
\text { been implemented. }\end{array}$ & $\begin{array}{l}\text { 3. Assessments are } \\
\text { done to determine } \\
\text { student needs in the } \\
\text { area of peer tutoring. }\end{array}$ & $\begin{array}{l}\text { 4. Assessments are } \\
\text { done to determine } \\
\text { faculty needs for } \\
\text { implementing peer } \\
\text { tutoring. }\end{array}$ \\
\hline $\begin{array}{l}\text { Research University, } \\
\text { Very High Research } \\
(\mathrm{n}=26)\end{array}$ & 1.77 & 2.30 & 1.96 & 2.23 \\
\hline $\begin{array}{l}\text { Research University, } \\
\text { High Research }(n=20)\end{array}$ & 1.75 & 1.60 & 1.40 & 2.00 \\
\hline $\begin{array}{l}\text { Doctoral Research } \\
\text { University }(n=20)\end{array}$ & 1.60 & 1.80 & 1.50 & 2.05 \\
\hline $\begin{array}{l}\text { Masters Colleges and } \\
\text { Universities, Larger } \\
\text { Programs }(n=14)\end{array}$ & 1.64 & 2.07 & 1.64 & 2.21 \\
\hline $\begin{array}{l}\text { Masters Colleges and } \\
\text { Universities, Medium } \\
\text { Programs }(n=25)\end{array}$ & 1.64 & 1.20 & 1.40 & 1.88 \\
\hline $\begin{array}{l}\text { Masters Colleges and } \\
\text { Universities, Smaller } \\
\text { Programs }(n=20)\end{array}$ & 1.55 & 1.70 & 1.70 & 2.30 \\
\hline $\begin{array}{l}\text { Baccalaureate } \\
\text { Colleges }(n=22)\end{array}$ & 1.68 & 1.73 & 1.36 & 1.82 \\
\hline $\begin{array}{l}\text { Associates Colleges } \\
(\mathrm{n}=20)\end{array}$ & 1.65 & 1.75 & 1.75 & 2.40 \\
\hline $\begin{array}{l}\text { Total Average } \\
(\mathrm{n}=167)\end{array}$ & 1.66 & 1.76 & 1.59 & 2,10 \\
\hline
\end{tabular}


Table 34 (Cont.)

Mean Scores for Differences in Perception of Administrative Factors that Facilitate Peer Tutoring Based on Carnegie Classification

\begin{tabular}{|c|c|c|c|c|}
\hline Carnegie & \multicolumn{4}{|c|}{ Factor } \\
\hline & $\begin{array}{l}\text { 5. Assessments } \\
\text { are done to } \\
\text { determine } \\
\text { institutional } \\
\text { needs for } \\
\text { implementing } \\
\text { peer tutoring. }\end{array}$ & $\begin{array}{l}\text { 6. Regular evaluations } \\
\text { of the peer tutoring } \\
\text { program are done to } \\
\text { ensure that educa- } \\
\text { tional goals are met. }\end{array}$ & $\begin{array}{l}\text { 7. A master plan } \\
\text { outlining relevance, } \\
\text { importance, } \\
\text { objectives, and } \\
\text { costs of peer } \\
\text { tutoring has been } \\
\text { developed. }\end{array}$ & $\begin{array}{l}\text { 8. A marketing plan } \\
\text { is in place to } \\
\text { promote peer } \\
\text { tutoring. }\end{array}$ \\
\hline $\begin{array}{l}\text { Research University, } \\
\text { Very High Research } \\
(\mathrm{n}=26)\end{array}$ & 2.04 & 1.42 & 1.81 & 1.92 \\
\hline $\begin{array}{l}\text { Research University, } \\
\text { High Research }(\mathrm{n}=20)\end{array}$ & 1.80 & 1.45 & 1.55 & 2.05 \\
\hline $\begin{array}{l}\text { Doctoral Research } \\
\text { University }(n=20)\end{array}$ & 1.75 & 1.40 & 1.95 & 1.80 \\
\hline $\begin{array}{l}\text { Masters Colleges and } \\
\text { Universities, Larger } \\
\text { Programs }(n=14)\end{array}$ & 1.71 & 1.50 & 1.93 & 2.07 \\
\hline $\begin{array}{l}\text { Masters Colleges and } \\
\text { Universities, Medium } \\
\text { Programs }(n=25)\end{array}$ & 1.72 & 1.36 & 1.60 & 1.88 \\
\hline $\begin{array}{l}\text { Masters Colleges and } \\
\text { Universities, Smaller } \\
\text { Programs }(n=20)\end{array}$ & 1.80 & 1.30 & 1.95 & 2.15 \\
\hline $\begin{array}{l}\text { Baccalaureate } \\
\text { Colleges }(n=22)\end{array}$ & 1.73 & 1.32 & 1.91 & 2.09 \\
\hline $\begin{array}{l}\text { Associates Colleges } \\
(\mathrm{n}=20)\end{array}$ & 1.95 & 1.65 & 2.00 & 2,30 \\
\hline $\begin{array}{l}\text { Total Average } \\
(\mathrm{n}=167)\end{array}$ & 1.82 & 1.42 & 1.83 & 2.02 \\
\hline
\end{tabular}


Table 34 (Cont.)

Mean Scores for Differences in Perception of Administrative Factors that Facilitate Peer Tutoring Based on Carnegie Classification

\begin{tabular}{|c|c|c|c|c|}
\hline Carnegie & \multicolumn{4}{|c|}{ Factor } \\
\hline & $\begin{array}{l}\text { 9. Peer tutoring is } \\
\text { a campus-wide } \\
\text { function and not } \\
\text { part of a specific } \\
\text { school, } \\
\text { department, or } \\
\text { academic } \\
\text { discipline. }\end{array}$ & $\begin{array}{l}\text { 10. Peer tutoring } \\
\text { is visible on } \\
\text { campus. }\end{array}$ & $\begin{array}{l}\text { 11. One central office } \\
\text { oversees the } \\
\text { implementation, } \\
\text { supervision, and } \\
\text { assessment of the peer } \\
\text { tutoring program. }\end{array}$ & $\begin{array}{l}\text { 12. A program } \\
\text { director for peer } \\
\text { tutoring with } \\
\text { decision- } \\
\text { making authority } \\
\text { has been appointed. }\end{array}$ \\
\hline $\begin{array}{l}\text { Research University, } \\
\text { Very High Research } \\
(\mathrm{n}=26)\end{array}$ & 2.54 & 1.65 & 2.65 & 2.27 \\
\hline $\begin{array}{l}\text { Research University, } \\
\text { High Research }(\mathrm{n}=20)\end{array}$ & 1.90 & 1.55 & 2.00 & 2.00 \\
\hline $\begin{array}{l}\text { Doctoral Research } \\
\text { University }(n=20)\end{array}$ & 2.10 & 1.60 & 1.95 & 1.90 \\
\hline $\begin{array}{l}\text { Masters Colleges and } \\
\text { Universities, Larger } \\
\text { Programs }(n=14)\end{array}$ & 2.43 & 1.71 & 1.86 & 1.64 \\
\hline $\begin{array}{l}\text { Masters Colleges and } \\
\text { Universities, Medium } \\
\text { Programs }(n=25)\end{array}$ & 1.88 & 1.32 & 1.56 & 1.32 \\
\hline $\begin{array}{l}\text { Masters Colleges and } \\
\text { Universities, Smaller } \\
\text { Programs }(n=20)\end{array}$ & 2.05 & 2.00 & 1.75 & 1.70 \\
\hline $\begin{array}{l}\text { Baccalaureate } \\
\text { Colleges }(n=22)\end{array}$ & 2.00 & 1.23 & 1.68 & 1.59 \\
\hline $\begin{array}{l}\text { Associates Colleges } \\
(\mathrm{n}=20)\end{array}$ & 2.30 & 1.85 & 2.15 & 2.10 \\
\hline $\begin{array}{l}\text { Total Average } \\
(\mathrm{n}=167)\end{array}$ & 2.14 & 1.60 & 1.96 & 1.82 \\
\hline
\end{tabular}


Table 34 (Cont.)

Mean Scores for Differences in Perception of Administrative Factors that Facilitate Peer Tutoring Based on Carnegie Classification

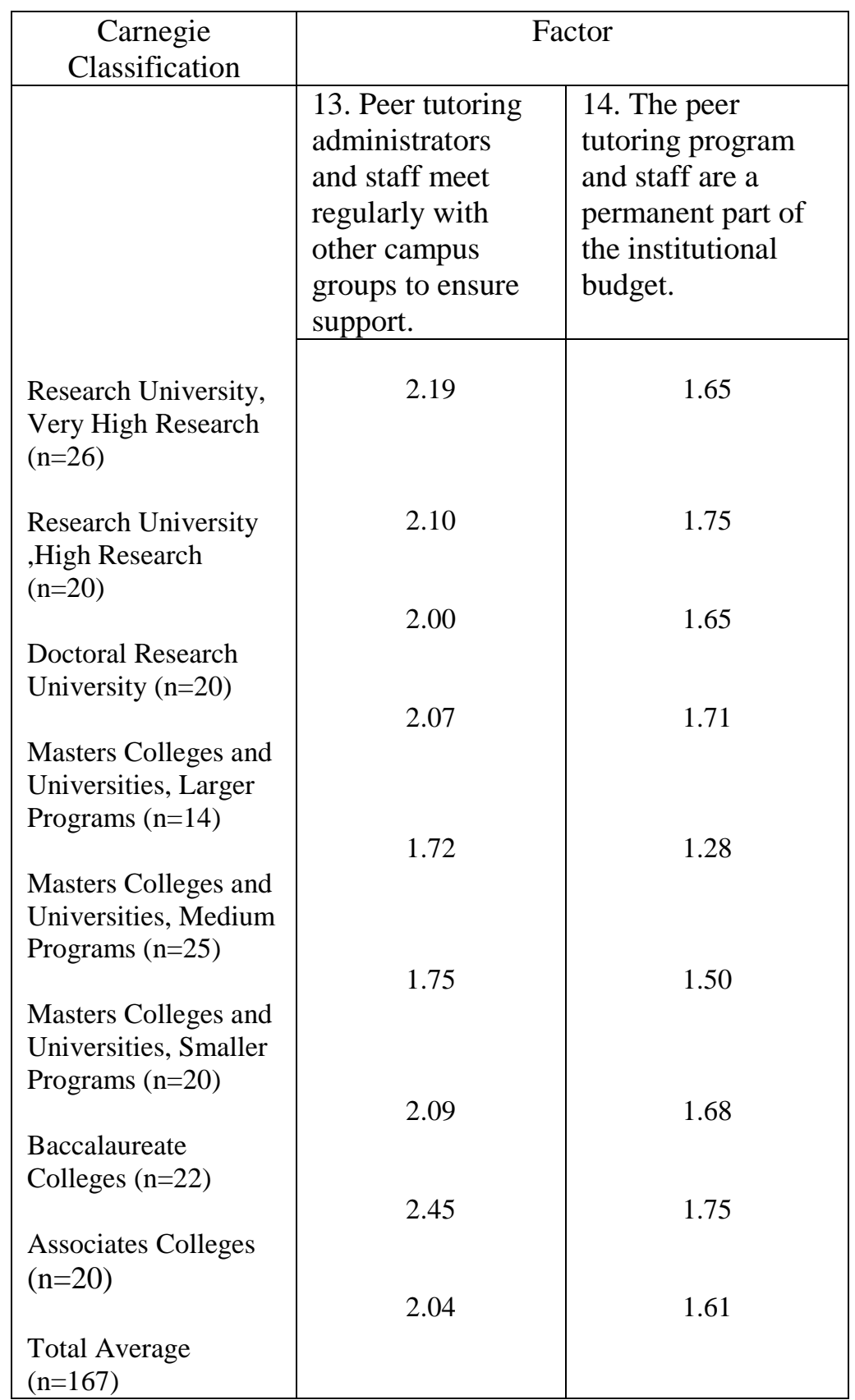

As indicated in table 34, on average all fourteen administrative factors were perceived to facilitate peer tutoring and there were minimal differences in perceptions among administrators 
based on Carnegie classifications. The mean fell within the same range for each factor for each degree, with the exception of the following six factors:

a) Policies and Procedures: A mean of 1.76 indicates that on average administrators $(n=167)$ believed that it was important, but not critical that formal policies and procedures for peer tutoring are in place. However, administrators from masters colleges and universities, medium programs $(n=25$, mean=1.20) felt that having formal policies and procedures for peer tutoring in place was critical.

b) Needs Assessment - Students: A mean of 1.59 shows that on average administrators $(n=167)$ thought it was important, but not critical that assessments are done to determine student needs in the area of peer tutoring. However, administrators from research universities; high research $(n=20$, mean $=1.40)$, masters colleges and universities, medium programs $(n=25$, mean $=1.40)$; and baccalaureate colleges $(n=22$, mean $=1.36)$ believed that assessments to determine student needs in peer tutoring were critical.

c) Evaluations. A mean of 1.42 indicates that on average administrators $(n=167)$ thought regular evaluations to ensure educational goals are being met were critical. However, administrators at associates colleges $(n=20$, mean $=1.65)$ believed regular evaluations to ensure educational goals are being met were important, but not critical.

d) Visibility. A mean of 1.60 shows that on average administrators $(n=167)$ believed it was important, but not critical that peer tutoring is visible on campus. However, administrators at masters colleges and universities, medium programs $(n=25$, mean=1.32) and baccalaureate colleges $(n=22$, mean $=1.23)$ felt it was critical for peer tutoring to be visible on campus.

e) Leadership Authority. A mean of 1.82 shows that on average administrators $(n=167)$ believed it was important, but not critical that a program director for peer tutoring with decision- 
making authority be appointed. However, administrators at masters colleges and universities, medium programs $(n=25$, mean $=1.32)$ thought it was critical to appoint a program director for peer tutoring with decision-making authority.

f) Funding. A mean of 1.61 indicates that on average administrators $(n=167)$ felt it was important, but not critical that the peer tutoring program and staff are a permanent part of the institutional budget. However, administrators at masters colleges and universities, medium programs $(n=25$, mean $=1.28)$ believed it was critical that peer tutoring programs and staff are a permanent part of the institutional budget.

Factors that form barriers to peer tutoring - department affiliation. Table 35 illustrates the differences in perception among administrators of administrative factors that form barriers to peer tutoring based on the following department affiliation: Student Affairs, Academic Affairs, and both Student Affairs and Academic Affairs. Responses on the difficulty scale of 1-1.5 (nearly impossible) and 1.51-2.5 (very difficult) were used to identify institutional factors that form barriers to peer tutoring. Factors that had an average mean of 2.51-2.59 were identified as potential barriers. Although 167 respondents identified themselves as administrators, 14 respondents identified themselves as "in another department." For reporting purposes, only responses from administrators in Academic Affairs or Student Affairs were used, bringing the total respondents to 153 . 
Table 35

Mean Scores for Differences in Perception of Administrative Factors that Form Barriers to Peer Tutoring Based on Department Affiliation

\begin{tabular}{|c|c|c|c|c|}
\hline Factor & \multicolumn{4}{|c|}{ Department Affiliation } \\
\hline & $\begin{array}{l}\text { Student } \\
\text { Affairs } \\
n=47\end{array}$ & $\begin{array}{c}\text { Academic } \\
\text { Affairs } \\
n=74\end{array}$ & $\begin{array}{l}\text { Both } \\
n=32\end{array}$ & $\begin{array}{l}\text { Total } \\
\text { Average } \\
n=153\end{array}$ \\
\hline $\begin{array}{l}\text { 1. Peer tutoring is compatible with the institution's } \\
\text { mission and goals. }\end{array}$ & 3.26 & 3.22 & 3.25 & 3.24 \\
\hline $\begin{array}{l}\text { 2. Formal policies and procedures for peer tutoring } \\
\text { have been implemented. }\end{array}$ & 3.15 & 3.04 & 2.91 & 3.05 \\
\hline $\begin{array}{l}\text { 3. Assessments are done to determine student needs } \\
\text { in the area of peer tutoring. }\end{array}$ & 2.81 & 2.92 & 2.88 & 2.88 \\
\hline $\begin{array}{l}\text { 4. Assessments are done to determine faculty needs } \\
\text { for implementing peer tutoring. }\end{array}$ & 2.49 & 2.54 & 2.63 & 2.55 \\
\hline $\begin{array}{l}\text { 5. Assessments are done to determine institutional needs } \\
\text { for implementing peer tutoring. }\end{array}$ & 2.72 & 2.70 & 2.75 & 2.72 \\
\hline $\begin{array}{l}\text { 6. Regular evaluations of the peer tutoring program } \\
\text { are done to ensure that educational goals are met. }\end{array}$ & 3.09 & 3.04 & 2.94 & 3.03 \\
\hline $\begin{array}{l}\text { 7. A master plan outlining relevance, importance, } \\
\text { objectives, and costs of peer tutoring has been developed. }\end{array}$ & 2.89 & 2.77 & 2.72 & 2.80 \\
\hline 8. A marketing plan is in place to promote peer tutoring. & 3.04 & 3.04 & 3.09 & 3.05 \\
\hline $\begin{array}{l}\text { 9. Peer tutoring is a campus-wide function and not part } \\
\text { of a specific school, department, or academic discipline. }\end{array}$ & 2.70 & 3.03 & 2.66 & 2.85 \\
\hline 10. Peer tutoring is visible on campus. & 2.87 & 2.97 & 3.03 & 2.95 \\
\hline $\begin{array}{l}\text { 11. One central office oversees the implementation, } \\
\text { supervision, and assessment of the peer tutoring program. }\end{array}$ & 2.89 & 3.04 & 2.25 & 2.83 \\
\hline $\begin{array}{l}\text { 12. A program director for peer tutoring with decision- } \\
\text { making authority has been appointed. }\end{array}$ & 3.28 & 3.18 & 2.59 & 3.09 \\
\hline $\begin{array}{l}\text { 13. Peer tutoring administrators and staff meet } \\
\text { regularly with other campus groups to ensure support. }\end{array}$ & 2.89 & 2.89 & 2.78 & 2.87 \\
\hline $\begin{array}{l}\text { 14. The peer tutoring program and staff are a permanent } \\
\text { part of the institutional budget. }\end{array}$ & 2.87 & 3.07 & 2.47 & 2.88 \\
\hline
\end{tabular}


As indicated in Table 35, on average no administrative factors were perceived by administrators as barriers to peer tutoring and there were minimal differences in perceptions among administrators based on department affiliation. Although the mean fell within the same range for most factors, there were a few exceptions. In addition, one factor had a mean slightly above midrange for response 2, very difficult, which identified it as a potential barrier to peer tutoring. These exceptions are explained below.

a) Needs Assessment - Faculty. Although administrators identified Needs Assessment Faculty as a factor that facilitates peer tutoring, it was also identified as a potential barrier to peer tutoring, with an average mean of 2.55. This indicates that on average administrators $(n=153)$ believed that it would be between of minor difficulty and very difficult to conduct an assessment of faculty needs for implementing peer tutoring. It is interesting to note that administrators who are in Student Affairs ( $n=47$, mean=2.49) felt that it would be very difficult to conduct an assessment of faculty needs for implementing peer tutoring, while administrators in Academic Affairs $(n=74$, mean=2.54) and administrators who are in both Student Affairs and Academic Affairs ( $n=32$, mean=2.63) thought it would be between of minor difficulty and very difficult.

b) Centralization. On average administrators $(n=153)$ did not identify Centralization as a barrier to peer tutoring, with an average mean 2.83. A mean of 2.83 indicates that on average administrators felt that it would be of minor difficulty for one central office to implement, supervise, and assess peer tutoring. However, administrators who are in both Student Affairs and Academic Affairs $(n=32$, mean=2.25) believed it would be very difficult for one central office to implement, supervise, and assess peer tutoring.

Factors that form barriers to peer tutoring - enrollment. Table 36 illustrates the differences in perception among administrators of administrative factors that form barriers to 
peer tutoring based on the following enrollment: less than 5000, 5,000-10,000, 10,001 20,000 , or over 20,000 . Responses on the difficulty scale of 1-1.5 (nearly impossible) and 1.512.5 (very difficult) were used to identify institutional factors that form barriers to peer tutoring. Factors that had a mean slightly above mid-range for response 2, very difficult, were identified as a potential barrier to peer tutoring. Although 167 respondents identified themselves as administrators, one respondent didn't select a response, bringing the total respondents to 166 . 
Table 36

Mean Scores for Differences in Perception of Administrative Factors that Form Barriers to Peer Tutoring Based on Enrollment

\begin{tabular}{|c|c|c|c|c|}
\hline Enrollment & \multicolumn{4}{|c|}{ Factor } \\
\hline & $\begin{array}{l}\text { 1. Peer tutoring is } \\
\text { compatible with the } \\
\text { institution's } \\
\text { mission and goals. }\end{array}$ & $\begin{array}{l}\text { 2. Formal policies and } \\
\text { procedures for peer } \\
\text { tutoring have been } \\
\text { implemented. }\end{array}$ & $\begin{array}{l}\text { 3. Assessments are } \\
\text { done to determine } \\
\text { student needs in the } \\
\text { area of peer } \\
\text { tutoring. }\end{array}$ & $\begin{array}{l}\text { 4. Assessments are } \\
\text { done to determine } \\
\text { faculty needs for } \\
\text { implementing peer } \\
\text { tutoring. }\end{array}$ \\
\hline $\begin{array}{l}\text { Less than } 5,000 \\
(\mathrm{n}=65)\end{array}$ & 3.34 & 3.12 & 2.94 & 2.65 \\
\hline $\begin{array}{l}5,000-10,000 \\
(n=32)\end{array}$ & 3.38 & 3.22 & 2.84 & 2.47 \\
\hline $\begin{array}{l}10,001-20,000 \\
(n=35)\end{array}$ & 3.20 & 2.94 & 2.94 & 2.57 \\
\hline $\begin{array}{l}\text { Over } 20,000 \\
(\mathrm{n}=34)\end{array}$ & 2.88 & 2.94 & 2.79 & 2.44 \\
\hline $\begin{array}{l}\text { Total Average } \\
(\mathrm{n}=166)\end{array}$ & 3.22 & 3.07 & 2.89 & 2.55 \\
\hline & $\begin{array}{l}\text { 5. Assessments are } \\
\text { done to determine } \\
\text { institutional needs } \\
\text { for implementing } \\
\text { peer tutoring. }\end{array}$ & $\begin{array}{l}\text { 6. Regular evaluations } \\
\text { of the peer tutoring } \\
\text { program are done to } \\
\text { ensure that educa- } \\
\text { tional goals are met. }\end{array}$ & $\begin{array}{l}\text { 7. A master plan } \\
\text { outlining relevance, } \\
\text { importance, } \\
\text { objectives, and } \\
\text { costs of peer } \\
\text { tutoring has been } \\
\text { developed. }\end{array}$ & $\begin{array}{l}\text { 8. A marketing plan } \\
\text { is in place to } \\
\text { promote peer } \\
\text { tutoring. }\end{array}$ \\
\hline $\begin{array}{l}\text { Less than } 5,000 \\
(\mathrm{n}=65)\end{array}$ & 2.86 & 2.98 & 2.86 & 3.22 \\
\hline $\begin{array}{l}5,000-10,000 \\
(\mathrm{n}=32)\end{array}$ & 2.81 & 3.00 & 2.84 & 2.94 \\
\hline $\begin{array}{l}10,001-20,000 \\
(n=35)\end{array}$ & 2.74 & 3.17 & 2.86 & 2.94 \\
\hline $\begin{array}{l}\text { Over } 20,000 \\
(n=34)\end{array}$ & 2.47 & 3.03 & 2.62 & 2.97 \\
\hline $\begin{array}{l}\text { Total Average } \\
(\mathrm{n}=166)\end{array}$ & 2.75 & 3.04 & 2.81 & 3.05 \\
\hline
\end{tabular}


Table 36 (Cont.)

Mean Scores for Differences in Perception of Administrative Factors that Form Barriers to Peer Tutoring Based on Enrollment

\begin{tabular}{|c|c|c|c|c|}
\hline Enrollment & \multicolumn{4}{|c|}{ Factor } \\
\hline & $\begin{array}{l}\text { 9. Peer tutoring is a } \\
\text { campus-wide } \\
\text { function and not } \\
\text { part of a specific } \\
\text { school, department, } \\
\text { or academic } \\
\text { discipline. }\end{array}$ & $\begin{array}{l}\text { 10. Peer tutoring is } \\
\text { visible on campus. }\end{array}$ & $\begin{array}{l}\text { 11. One central office } \\
\text { oversees the } \\
\text { implementation, } \\
\text { supervision, and } \\
\text { assessment of the } \\
\text { peer tutoring } \\
\text { program. }\end{array}$ & $\begin{array}{l}\text { 12. A program } \\
\text { director for peer } \\
\text { tutoring with } \\
\text { decision- } \\
\text { making authority } \\
\text { has been appointed. }\end{array}$ \\
\hline $\begin{array}{l}\text { Less than } 5,000 \\
(\mathrm{n}=65)\end{array}$ & 3.09 & 3.14 & 3.12 & 3.35 \\
\hline $\begin{array}{l}5,000-10,000 \\
(n=32)\end{array}$ & 2.94 & 3.00 & 3.19 & 3.16 \\
\hline $\begin{array}{l}10,001-20,000 \\
(n=35)\end{array}$ & 2.54 & 2.83 & 2.63 & 2.86 \\
\hline $\begin{array}{l}\text { Over } 20,000 \\
(n=34)\end{array}$ & 2.53 & 2.59 & 2.15 & 2.62 \\
\hline $\begin{array}{l}\text { Total Average } \\
(\mathrm{n}=166)\end{array}$ & 2.83 & 2.93 & 2.83 & 3.06 \\
\hline & $\begin{array}{l}\text { 13. Peer tutoring } \\
\text { administrators and } \\
\text { staff meet } \\
\text { regularly with other } \\
\text { campus groups to } \\
\text { ensure support. }\end{array}$ & $\begin{array}{l}\text { 14. The peer } \\
\text { tutoring program } \\
\text { and staff are a } \\
\text { permanent part of } \\
\text { the institutional } \\
\text { budget. }\end{array}$ & & \\
\hline $\begin{array}{l}\text { Less than } 5,000 \\
(\mathrm{n}=65)\end{array}$ & 2.92 & 3.09 & & \\
\hline $\begin{array}{l}5,000-10,000 \\
(n=32)\end{array}$ & 2.84 & 2.91 & & \\
\hline $\begin{array}{l}10,001-20,000 \\
(n=35)\end{array}$ & 2.83 & 2.51 & & \\
\hline $\begin{array}{l}\text { Over } 20,000 \\
(n=34)\end{array}$ & 2.53 & 2.59 & & \\
\hline $\begin{array}{l}\text { Total Average } \\
(\mathrm{n}=166)\end{array}$ & 2.81 & 2.83 & & \\
\hline
\end{tabular}


As indicated in Table 36, on average no administrative factors were perceived by administrators as barriers to peer tutoring and there were minimal differences in perceptions among administrators based on enrollment. Although the mean fell within the same range for most factors, there were a few exceptions. In addition, one factor had a mean slightly above mid-range for response 2, very difficult, which identified it as a potential barrier to peer tutoring. These exceptions are explained below.

Needs Assessment - Faculty. Although administrators identified Needs Assessment Faculty as a factor that facilitates peer tutoring, it was also identified as a potential barrier to peer tutoring with an average mean of 2.55 . This indicates that on average $(n=166)$ administrators believed it would be between minor difficulty and very difficult to assess faculty needs to implement peer tutoring. It is interesting to note that there were also differences in perceptions of Needs Assessment - Faculty between groups. Administrators at institutions with enrollments of less than 5,000 $(n=65$, mean=2.65 $)$ and 10,000-20,000 $(n=35$, mean=2.47) believed that Needs Assessment - Faculty was not a barrier to peer tutoring, while administrators at institutions with enrollments of 5,000 to $10,000(n=32 m$ mean-2.47) and over 20,000 $(n=34$, mean=2.44) felt that it was a barrier to peer tutoring.

Centralization. A mean of 2.83 indicates that on average administrators (n-166) believed it would be of minor difficulty for one central office to implement, supervise, and assess peer tutoring. However, administrators from institutions with an enrollment of over 20,000 ( $n=34$, mean=2.15) felt it would be very difficult for one central office to oversee peer tutoring.

Factors that form barriers to peer tutoring - highest degrees awarded. Table 37 shows mean scores for differences in perception of administrative factors that form barriers to peer tutoring based on the following degrees awarded: a) associates, b) bachelors, c) masters, 
d) doctorate, and e) professional. An average mean for the total respondents was also computed for each factor. Responses on the difficulty scale of 1-1.5 (nearly impossible) and 1.51-2.5, very difficult were used to identify institutional factors that facilitate peer tutoring programs. Factors that had an average mean of 2.51-2.59 were identified as potential barriers. Although 167 respondents identified themselves as administrators, one respondent didn't select a response, bringing the total respondents to 166. 
Table 37

Mean Scores for Differences in Perception of Administrative Factors that Form Barriers to Peer Tutoring Based on Highest Degree Awarded

\begin{tabular}{|c|c|c|c|c|}
\hline Degree & \multicolumn{4}{|c|}{ Factor } \\
\hline & $\begin{array}{l}\text { 1. Peer tutoring is } \\
\text { compatible with the } \\
\text { institution's } \\
\text { mission and goals. }\end{array}$ & $\begin{array}{l}\text { 2. Formal policies and } \\
\text { procedures for peer } \\
\text { tutoring have been } \\
\text { implemented. }\end{array}$ & $\begin{array}{l}\text { 3. Assessments are } \\
\text { done to determine } \\
\text { student needs in the } \\
\text { area of peer } \\
\text { tutoring. }\end{array}$ & $\begin{array}{l}\text { 4. Assessments are } \\
\text { done to determine } \\
\text { faculty needs for } \\
\text { implementing peer } \\
\text { tutoring. }\end{array}$ \\
\hline $\begin{array}{l}\text { Associates } \\
(\mathrm{n}=19)\end{array}$ & 3.21 & 3.05 & 3.11 & 2.89 \\
\hline $\begin{array}{l}\text { Bachelors } \\
(\mathrm{n}=15)\end{array}$ & 3.47 & 3.00 & 3.07 & 2.47 \\
\hline $\begin{array}{l}\text { Masters } \\
(\mathrm{n}=33)\end{array}$ & 3.24 & 3,24 & 2.82 & 2.52 \\
\hline $\begin{array}{l}\text { Doctorate } \\
(n=69)\end{array}$ & 3.13 & 3.03 & 2.93 & 2.55 \\
\hline $\begin{array}{l}\text { Professional } \\
\text { (30) }\end{array}$ & 3.27 & 2.93 & 2.60 & 2.37 \\
\hline Total Average & 3.22 & 3.05 & 2.88 & 2.54 \\
\hline & $\begin{array}{l}\text { 5. Assessments are } \\
\text { done to determine } \\
\text { institutional needs } \\
\text { for implementing } \\
\text { peer tutoring. }\end{array}$ & $\begin{array}{l}\text { 6. Regular evaluations } \\
\text { of the peer tutoring } \\
\text { program are done to } \\
\text { ensure that educa- } \\
\text { tional goals are met. }\end{array}$ & $\begin{array}{l}\text { 7. A master plan } \\
\text { outlining relevance, } \\
\text { importance, } \\
\text { objectives, and } \\
\text { costs of peer } \\
\text { tutoring has been } \\
\text { developed. }\end{array}$ & $\begin{array}{l}\text { 8. A marketing plan } \\
\text { is in place to } \\
\text { promote peer } \\
\text { tutoring. }\end{array}$ \\
\hline $\begin{array}{l}\text { Associates } \\
(\mathrm{n}=19)\end{array}$ & 2.68 & 3.21 & 2.74 & 3.05 \\
\hline $\begin{array}{l}\text { Bachelors } \\
(\mathrm{n}=15)\end{array}$ & 2.93 & 2.80 & 2.53 & 3.00 \\
\hline $\begin{array}{l}\text { Masters } \\
(\mathrm{n}=33)\end{array}$ & 2.64 & 3.09 & 3.00 & 2.97 \\
\hline $\begin{array}{l}\text { Doctorate } \\
(\mathrm{n}=69)\end{array}$ & 2.72 & 3.03 & 2.86 & 3.14 \\
\hline $\begin{array}{l}\text { Professional } \\
\text { (30) }\end{array}$ & 2.83 & 2.97 & 2.67 & 2.93 \\
\hline $\begin{array}{l}\text { Total Average } \\
(\mathrm{n}=166)\end{array}$ & 2.74 & 3.03 & 2.81 & 3.05 \\
\hline
\end{tabular}


Table 37 (Cont.)

Mean Scores for Differences in Perception of Administrative Factors that Form Barriers to Peer Tutoring Based on Highest Degree Offered

\begin{tabular}{|c|c|c|c|c|}
\hline Degree & \multicolumn{4}{|c|}{ Factor } \\
\hline & $\begin{array}{l}\text { 9. Peer tutoring is a } \\
\text { campus-wide } \\
\text { function and not } \\
\text { part of a specific } \\
\text { school, department, } \\
\text { or academic } \\
\text { discipline. }\end{array}$ & $\begin{array}{l}10 . \text { Peer tutoring is } \\
\text { visible on campus. }\end{array}$ & $\begin{array}{l}\text { 11. One central } \\
\text { office oversees the } \\
\text { implementation, } \\
\text { supervision, and } \\
\text { assessment of the } \\
\text { peer tutoring } \\
\text { program. }\end{array}$ & $\begin{array}{l}\text { 12. A program } \\
\text { director for peer } \\
\text { tutoring with } \\
\text { decision-making } \\
\text { authority has been } \\
\text { appointed. }\end{array}$ \\
\hline $\begin{array}{l}\text { Associates } \\
(\mathrm{n}=19)\end{array}$ & 3.16 & 3.05 & 3.00 & 2.89 \\
\hline $\begin{array}{l}\text { Bachelors } \\
(\mathrm{n}=15)\end{array}$ & 3.20 & 3.07 & 3.13 & 3.27 \\
\hline $\begin{array}{l}\text { Masters } \\
(\mathrm{n}=33)\end{array}$ & 2.88 & 3.00 & 3.21 & 3.27 \\
\hline $\begin{array}{l}\text { Doctorate } \\
(\mathrm{n}=69)\end{array}$ & 2.84 & 2.99 & 2.72 & 3.04 \\
\hline $\begin{array}{l}\text { Professional } \\
(30)\end{array}$ & 2.33 & 2.60 & 2.33 & 2.77 \\
\hline Total Average & 2.83 & 2.93 & 2.82 & 3.04 \\
\hline & $\begin{array}{l}\text { 13. Peer tutoring } \\
\text { administrators } \\
\text { and staff meet } \\
\text { regularly with other } \\
\text { campus groups to } \\
\text { ensure support. }\end{array}$ & $\begin{array}{l}\text { 14. The peer } \\
\text { tutoring program } \\
\text { and staff are a } \\
\text { permanent part of } \\
\text { the institutional } \\
\text { budget. }\end{array}$ & & \\
\hline $\begin{array}{l}\text { Associates } \\
(n=19)\end{array}$ & 2.68 & 2.58 & & \\
\hline $\begin{array}{l}\text { Bachelors } \\
(\mathrm{n}=15)\end{array}$ & 2.80 & 3.07 & & \\
\hline $\begin{array}{l}\text { Masters } \\
(\mathrm{n}=33)\end{array}$ & 2.91 & 2.94 & & \\
\hline $\begin{array}{l}\text { Doctorate } \\
(n=69)\end{array}$ & 2.87 & 2.90 & & \\
\hline $\begin{array}{l}\text { Professional } \\
(30)\end{array}$ & 2.60 & 2.60 & & \\
\hline $\begin{array}{l}\text { Total Average } \\
(\mathrm{n}=166)\end{array}$ & 2.80 & 2.83 & & \\
\hline
\end{tabular}

As indicated in Table 37, on average no administrative factors were perceived by administrators as barriers to peer tutoring and there were minimal differences in perceptions among 
administrators based on the highest degree awarded. Although the mean fell within the same range for most factors, there were a few exceptions. In addition, one factor had a mean slightly above mid-range for response 2, very difficult, which identified it as a potential barrier to peer tutoring. These exceptions are explained below.

Needs Assessment - Faculty. Although administrators identified Needs Assessment Faculty as a factor that facilitates peer tutoring, it was also identified as a potential barrier to peer tutoring with an average mean of 2.54 . This indicates that on average $(n=166)$ administrators believed it would be between minor difficulty and very difficult to assess faculty needs for implementing peer tutoring. There were also differences in perceptions of Needs Assessment Faculty between groups. Administrators at institutions that award associates $(n=19$, mean=2.89), masters $(n=33$, mean=2.52), and doctoral $(n=69$, mean=2.55) degrees agreed that Needs Assessment - Faculty was not a barrier to peer tutoring, while administrators at institutions that confer bachelors $(n=15$, mean=2.47) and professional $(n=30$, mean=2.37) degrees believed that it was a barrier to peer tutoring.

Centralization. A mean of 2.82 indicates that on average administrators believed it would be of minor difficulty for one central office to implement, supervise, and assess peer tutoring. However, administrators from institutions that award professional degrees $(n=30)$ felt it would be very difficult for one central office to oversee peer tutoring.

Factors that form barriers to peer tutoring - Carnegie Classification. Table 38 shows mean scores for differences in perception of administrative factors that form barriers to peer tutoring based on the following Carnegie classifications: a) research university, very high research; b) research university, high research; c) doctoral research university; d) masters colleges and universities, larger programs; e) masters colleges and universities, medium 
programs; f) masters colleges and universities, smaller programs; g) baccalaureate colleges; and h) associates colleges. Responses on the difficulty scale of 1-1.5 nearly impossible and 1.51-2.5 (very difficult) were used to identify institutional factors that form barriers to peer tutoring. An average mean for the total respondents was also computed for each factor.

Table 38

Mean Scores for Differences in Perception of Administrative Factors that Form Barriers to Peer Tutoring Based on Carnegie Classification

\begin{tabular}{|c|c|c|c|c|}
\hline Carnegie & \multicolumn{4}{|c|}{ Factor } \\
\hline & $\begin{array}{l}\text { 1. Peer tutoring } \\
\text { is compatible } \\
\text { with the } \\
\text { institution's } \\
\text { mission and } \\
\text { goals. }\end{array}$ & $\begin{array}{l}\text { 2. Formal policies } \\
\text { and procedures for } \\
\text { peer tutoring have } \\
\text { been implemented. }\end{array}$ & $\begin{array}{l}\text { 3. Assessments are } \\
\text { done to determine } \\
\text { student needs in the } \\
\text { area of peer tutoring. }\end{array}$ & $\begin{array}{l}\text { 4. Assessments are } \\
\text { done to determine } \\
\text { faculty needs for } \\
\text { implementing peer } \\
\text { tutoring. }\end{array}$ \\
\hline $\begin{array}{l}\text { Research University, } \\
\text { Very High Research } \\
(\mathrm{n}=26)\end{array}$ & 3.12 & 3.04 & 2.73 & 2.62 \\
\hline $\begin{array}{l}\text { Research University, } \\
\text { High Research }(n=20)\end{array}$ & 3.05 & 2.85 & 2.85 & 2.25 \\
\hline $\begin{array}{l}\text { Doctoral Research } \\
\text { University }(n=20)\end{array}$ & 3.10 & 3.15 & 2.85 & 2.40 \\
\hline $\begin{array}{l}\text { Masters Colleges and } \\
\text { Universities, Larger } \\
\text { Programs }(n=14)\end{array}$ & 3.43 & 3.14 & 2.93 & 2.71 \\
\hline $\begin{array}{l}\text { Masters Colleges and } \\
\text { Universities, Medium } \\
\text { Programs }(n=25)\end{array}$ & 3.32 & 3.28 & 2.88 & 2.60 \\
\hline $\begin{array}{l}\text { Masters Colleges and } \\
\text { Universities, Smaller } \\
\text { Programs }(n=20)\end{array}$ & 3.15 & 2.90 & 2.80 & 2.50 \\
\hline $\begin{array}{l}\text { Baccalaureate } \\
\text { Colleges }(n=22)\end{array}$ & 3.45 & 3.05 & 3.05 & 2.50 \\
\hline $\begin{array}{l}\text { Associates Colleges } \\
(\mathrm{n}=20)\end{array}$ & 3.20 & 3.05 & 3.05 & 2.85 \\
\hline $\begin{array}{l}\text { Total Average } \\
(\mathrm{n}=167)\end{array}$ & 3.22 & 3.06 & 2.89 & 2.55 \\
\hline
\end{tabular}


Table 38 (Cont.)

Mean Scores for Differences in Perception of Administrative Factors that Form barriers to Peer Tutoring Based on Carnegie Classification

\begin{tabular}{|c|c|c|c|c|}
\hline Carnegie & \multicolumn{4}{|c|}{ Factor } \\
\hline & $\begin{array}{l}\text { 5. Assessments } \\
\text { are done to } \\
\text { determine } \\
\text { institutional } \\
\text { needs for } \\
\text { implementing } \\
\text { peer tutoring. }\end{array}$ & $\begin{array}{l}\text { 6. Regular evaluations } \\
\text { of the peer tutoring } \\
\text { program are done to } \\
\text { ensure that educa- } \\
\text { tional goals are met. }\end{array}$ & $\begin{array}{l}\text { 7. A master plan } \\
\text { outlining relevance, } \\
\text { importance, } \\
\text { objectives, and } \\
\text { costs of peer } \\
\text { tutoring has been } \\
\text { developed. }\end{array}$ & $\begin{array}{l}\text { 8. A marketing plan } \\
\text { is in place to } \\
\text { promote peer } \\
\text { tutoring. }\end{array}$ \\
\hline $\begin{array}{l}\text { Research University, } \\
\text { Very High Research } \\
(\mathrm{n}=26)\end{array}$ & 2.62 & 2.92 & 2.65 & 3.12 \\
\hline $\begin{array}{l}\text { Research University, } \\
\text { High Research }(n=20)\end{array}$ & 2.70 & 3.20 & 2.90 & 3.30 \\
\hline $\begin{array}{l}\text { Doctoral Research } \\
\text { University }(n=20)\end{array}$ & 2.80 & 3.20 & 2.85 & 3.15 \\
\hline $\begin{array}{l}\text { Masters Colleges and } \\
\text { Universities, Larger } \\
\text { Programs }(n=14)\end{array}$ & 2.79 & 2.93 & 3.00 & 2,64 \\
\hline $\begin{array}{l}\text { Masters Colleges and } \\
\text { Universities, Medium } \\
\text { Programs }(n=25)\end{array}$ & 2.92 & 3.08 & 3.12 & 2.96 \\
\hline $\begin{array}{l}\text { Masters Colleges and } \\
\text { Universities, Smaller } \\
\text { Programs }(n=20)\end{array}$ & 2.60 & 2.95 & 2.60 & 2.95 \\
\hline $\begin{array}{l}\text { Baccalaureate } \\
\text { Colleges }(n=22)\end{array}$ & 2.86 & 2.86 & 2.68 & 3.09 \\
\hline $\begin{array}{l}\text { Associates Colleges } \\
(\mathrm{n}=20)\end{array}$ & 2.70 & 3.15 & 2.70 & 3.10 \\
\hline $\begin{array}{l}\text { Total Average } \\
(\mathrm{n}=167)\end{array}$ & 2.75 & 3.04 & 3.81 & 3.05 \\
\hline
\end{tabular}


Table 38 (Cont.)

Mean Scores for Differences in Perception of Administrative Factors that Form Barriers to Peer Tutoring Based on Carnegie Classification

\begin{tabular}{|c|c|c|c|c|}
\hline Carnegie & \multicolumn{4}{|c|}{ Factor } \\
\hline & $\begin{array}{l}\text { 9. Peer tutoring } \\
\text { is a campus- } \\
\text { wide function } \\
\text { and not part of } \\
\text { a specific } \\
\text { school, } \\
\text { department, or } \\
\text { academic } \\
\text { discipline. }\end{array}$ & $\begin{array}{l}10 . \text { Peer tutoring is } \\
\text { visible on campus. }\end{array}$ & $\begin{array}{l}\text { 11. One central office } \\
\text { oversees the } \\
\text { implementation, } \\
\text { supervision, and } \\
\text { assessment of the } \\
\text { peer tutoring } \\
\text { program. }\end{array}$ & $\begin{array}{l}\text { 12. A program } \\
\text { director for peer } \\
\text { tutoring with } \\
\text { decision-making } \\
\text { authority has been } \\
\text { appointed. }\end{array}$ \\
\hline $\begin{array}{l}\text { Research University, } \\
\text { Very High Research } \\
(\mathrm{n}=26)\end{array}$ & 2.38 & 2.73 & 2.23 & 2.88 \\
\hline $\begin{array}{l}\text { Research University, } \\
\text { High Research }(n=20)\end{array}$ & 2.60 & 2.10 & 2.45 & 2.65 \\
\hline $\begin{array}{l}\text { Doctoral Research } \\
\text { University }(n=20)\end{array}$ & 3.00 & 2.85 & 2.95 & 2.85 \\
\hline $\begin{array}{l}\text { Masters Colleges and } \\
\text { Universities, Larger } \\
\text { Programs }(n=14)\end{array}$ & 2.86 & 2.71 & 2.86 & 3.29 \\
\hline $\begin{array}{l}\text { Masters Colleges and } \\
\text { Universities, Medium } \\
\text { Programs }(n=25)\end{array}$ & 2.84 & 3.12 & 3.08 & 3.36 \\
\hline $\begin{array}{l}\text { Masters Colleges and } \\
\text { Universities, Smaller } \\
\text { Programs }(n=20)\end{array}$ & 2.70 & 2.95 & 3.05 & 3.40 \\
\hline $\begin{array}{l}\text { Baccalaureate } \\
\text { Colleges }(n=22)\end{array}$ & 3.27 & 2.91 & 3.00 & 3.05 \\
\hline $\begin{array}{l}\text { Associates Colleges } \\
(\mathrm{n}=20)\end{array}$ & 3.10 & 3.10 & 3.05 & 2.95 \\
\hline $\begin{array}{l}\text { Total Average } \\
(\mathrm{n}=167)\end{array}$ & 2.83 & 2.94 & 2.82 & 3.05 \\
\hline
\end{tabular}


Table 38 (Cont.)

Mean Scores for Differences in Perception of Administrative Factors that Form Barriers to Peer Tutoring Based on Carnegie Classification

\begin{tabular}{|c|c|c|}
\hline Carnegie & \multicolumn{2}{|c|}{ Factor } \\
\hline & $\begin{array}{l}\text { 13. Peer tutoring } \\
\text { administrators } \\
\text { and staff meet } \\
\text { regularly with } \\
\text { other campus } \\
\text { groups to ensure } \\
\text { support. }\end{array}$ & $\begin{array}{l}\text { 14. The peer } \\
\text { tutoring program } \\
\text { and staff are a } \\
\text { permanent part of } \\
\text { the institutional } \\
\text { budget. }\end{array}$ \\
\hline $\begin{array}{l}\text { Research University, } \\
\text { Very High Research } \\
(\mathrm{n}=26)\end{array}$ & 2.85 & 2.73 \\
\hline $\begin{array}{l}\text { Research University, } \\
\text { High Research }(n=20)\end{array}$ & 2.65 & 2.75 \\
\hline $\begin{array}{l}\text { Doctoral Research } \\
\text { University }(n=20)\end{array}$ & 2.80 & 2.70 \\
\hline $\begin{array}{l}\text { Masters Colleges and } \\
\text { Universities, Larger } \\
\text { Programs }(n=14)\end{array}$ & 2.79 & 2.76 \\
\hline $\begin{array}{l}\text { Masters Colleges and } \\
\text { Universities, Medium } \\
\text { Programs }(n=25)\end{array}$ & 2.72 & 3.00 \\
\hline $\begin{array}{l}\text { Masters Colleges and } \\
\text { Universities, Smaller } \\
\text { Programs }(n=20)\end{array}$ & 3.05 & 3.15 \\
\hline $\begin{array}{l}\text { Baccalaureate } \\
\text { Colleges }(n=22)\end{array}$ & 2.91 & 2.91 \\
\hline $\begin{array}{l}\text { Associates Colleges } \\
(\mathrm{n}=20)\end{array}$ & 2.65 & 2.60 \\
\hline $\begin{array}{l}\text { Total Average } \\
(\mathrm{n}=167)\end{array}$ & 2.80 & 2.84 \\
\hline
\end{tabular}

As indicated in Table 38, on average no administrative factors were perceived by administrators as barriers to peer tutoring and there were minimal differences in perceptions among administrators based on Carnegie classifications. Although the mean fell within the same range 
for most factors, there were a few exceptions. In addition, one factor had a mean slightly above mid-range for response 2, very difficult, which identified it as a potential barrier to peer tutoring. These exceptions are explained below.

Needs Assessment - Faculty. Although administrators identified Needs Assessment Faculty as a factor that facilitates peer tutoring, it was also identified as a potential barrier to peer tutoring with an average mean of 2.55 . This indicates that on average $(n=167)$ administrators believed it would be between minor difficulty and very difficult to assess faculty needs for implementing peer tutoring. There were also differences in perceptions of Needs Assessment Faculty between groups. While administrators at research universities, high research $(n=20$, mean $=2.25)$ and doctoral research universities $(n=20$, mean $=2.40)$ believed Needs Assessment Faculty was a barrier to peer tutoring, administrators in the other categories felt that Needs Assessment - Faculty was not barrier to peer tutoring.

\section{Differences in perception of faculty factors.}

Factors that facilitate peer tutoring - department affiliation. Table 39 shows the mean scores for differences in perception among administrators of faculty factors that facilitate peer tutoring based on the following department affiliation: Student Affairs, Academic Affairs, and both Student Affairs and Academic Affairs. Responses on the importance scale of 1-1.5 (critical) and 1.51-2.5 (important, but not critical) were used to identify institutional factors that facilitate peer tutoring programs. Although 167 respondents identified themselves as administrators, 14 respondents identified themselves as in an academic department. For reporting purposes, only responses from administrators in Academic Affairs or Student Affairs were used, bringing the total respondents to 153 . 
Table 39

Mean Scores for Differences in Perception of Faculty Factors that Facilitate Peer Tutoring Based on Department Affiliation

\begin{tabular}{|c|c|c|c|c|}
\hline Factor & \multicolumn{4}{|c|}{ Department Affiliation } \\
\hline & $\begin{array}{r}\text { Student } \\
\text { Affairs } \\
\mathrm{n}=47\end{array}$ & $\begin{array}{l}\text { Academic } \\
\text { Affairs } \\
\quad \mathrm{n}=74\end{array}$ & $\begin{array}{l}\text { Both } \\
\mathrm{n}=32\end{array}$ & $\begin{array}{l}\text { Total } \\
\text { Average } \\
\mathrm{n}=153\end{array}$ \\
\hline $\begin{array}{l}\text { 1. There is a shared vision of peer tutoring among } \\
\text { departments. }\end{array}$ & 1.89 & 1.95 & 2.13 & 1.97 \\
\hline $\begin{array}{l}\text { 2. Faculty and administrators collaborate on peer tutoring } \\
\text { to plan programs. }\end{array}$ & 2.06 & 1.99 & 2.00 & 2.01 \\
\hline $\begin{array}{l}\text { 3. Faculty and administrators collaborate on peer tutoring } \\
\text { to implement programs. }\end{array}$ & 2.11 & 1.96 & 2.03 & 2.02 \\
\hline $\begin{array}{l}\text { 4. Faculty and administrators collaborate on peer tutoring to } \\
\text { decide the program budget. }\end{array}$ & 2.70 & 2.53 & 2.63 & 2.60 \\
\hline $\begin{array}{l}\text { 5. Faculty and administrators collaborate on peer tutoring to } \\
\text { access program effectiveness. }\end{array}$ & 2.19 & 1.95 & 2.03 & 2.04 \\
\hline $\begin{array}{l}\text { 6. Ongoing staff development on peer tutoring best practices } \\
\text { is in place. }\end{array}$ & 1.72 & 1.73 & 1.97 & 1.78 \\
\hline $\begin{array}{l}\text { 7. Professional incentives to participate in peer tutoring } \\
\text { programs are available (i.e. credit towards promotion and } \\
\text { tenure, flexibility in time teaching). }\end{array}$ & 2.62 & 2.57 & 2.63 & 2.59 \\
\hline $\begin{array}{l}\text { 8. Financial incentives to participate in peer tutoring are } \\
\text { available (i.e. merit pay, grants for future research, new } \\
\text { computer). }\end{array}$ & 2.47 & 2.72 & 2.66 & 2.63 \\
\hline $\begin{array}{l}\text { 9. Communication between faculty and students encourages } \\
\text { student engagement. }\end{array}$ & 1.38 & 1.36 & 1.50 & 1.40 \\
\hline $\begin{array}{l}\text { 10. Communication between faculty and students supports } \\
\text { different teaching styles. }\end{array}$ & 1.70 & 1.50 & 1.34 & 1.53 \\
\hline $\begin{array}{l}\text { 11. Communication between faculty and students supports } \\
\text { different learning styles. }\end{array}$ & 1.72 & 1.50 & 1.31 & 1.53 \\
\hline $\begin{array}{l}\text { 12. Peer tutoring practices are oriented toward developing a } \\
\text { climate in which students' responsibility and active } \\
\text { participation are promoted. }\end{array}$ & 1.38 & 1.31 & 1.56 & 1.39 \\
\hline
\end{tabular}


As shown in Table 39, there were minimal differences in perceptions among groups based on department affiliation. Administrators identified nine factors as facilitators to peer tutoring based on department affiliation: Staff Development, Shared Vision, Collaboration - Plan Programs, Collaboration - Implement Programs, Collaboration - Assess Program Effectiveness, Communication - Encourage Student Engagement, Communication - Support Different Teaching Styles, Communication - Support Different Learning Styles, and Responsibility. Administrators also identified three factors as barriers to peer tutoring based on department affiliation: Collaboration - Decide Program Budget, Incentives - Professional, and Incentives Financial. The mean fell within the same range for each factor for each department affiliation, with the exception of the following factors:

a) Communication - Support Different Teaching Styles. A mean of 1.53 indicates that on average administrators across groups $(n=153)$ believed it was important, but not critical that communication between faculty and students supports different teaching styles, while administrators in both Academic Affairs and Student Affairs ( $\mathrm{n}=32$, mean=1.34) felt communication between faculty and students to support different teaching styles was critical.

b) Communication - Support Different Learning Styles. A mean of 1.53 shows that on average administrators across groups $(n=153)$ thought it was important, but not critical that communication between faculty and students supports different learning styles; however, administrators in both Academic Affairs and Student Affairs $(\mathrm{n}=32$, mean=1.31) believed that communication between faculty students to support different learning styles was critical.

c) Responsibility. A mean of 1.39 indicates that on average administrators across groups $(n=153)$ felt it was critical that peer tutoring practices are oriented towards developing a climate in which students' responsibility and active participation are promoted. However, administrators 
in both Academic Affairs and Student Affairs ( $\mathrm{n}=32$, mean=1.56) believed it was important, but not critical that peer tutoring practices are oriented towards developing a climate in which students' responsibility and active participation are promoted.

Factors that facilitate peer tutoring - enrollment. Table 40 illustrates the differences in perception among administrators of faculty factors that facilitate peer tutoring based on the following enrollment: less than 5000, 5,000 - 10,000, 10,001 - 20,000, or over 20,000. Responses on the importance scale of 1-1.5 (critical) and 1.51-2.5 (important, but not critical) were used to identify institutional factors that facilitate peer tutoring. Although 167 respondents identified themselves as administrators, one respondent didn't select a response, bringing the total respondents to 166 . 
Table 40

Mean Scores for Differences in Perception of Faculty Factors that Facilitate Peer Tutoring Based on Enrollment

\begin{tabular}{|c|c|c|c|c|}
\hline Enrollment & \multicolumn{4}{|c|}{ Factor } \\
\hline & $\begin{array}{l}\text { 1. There is a shared } \\
\text { vision of peer } \\
\text { tutoring among } \\
\text { departments. }\end{array}$ & $\begin{array}{l}\text { 2. Faculty and } \\
\text { administrators } \\
\text { collaborate on peer } \\
\text { tutoring to plan } \\
\text { programs. }\end{array}$ & $\begin{array}{l}\text { 3. Faculty and } \\
\text { administrators } \\
\text { collaborate on peer } \\
\text { tutoring to implement } \\
\text { programs. }\end{array}$ & $\begin{array}{l}\text { 4. Faculty and } \\
\text { administrators } \\
\text { collaborate on peer } \\
\text { tutoring to decide } \\
\text { the program budget. }\end{array}$ \\
\hline $\begin{array}{l}\text { Less than } 5,000 \\
(\mathrm{n}=65)\end{array}$ & 1.91 & 2.03 & 1.94 & 2.78 \\
\hline $\begin{array}{l}5,000-10,000 \\
(n=32)\end{array}$ & 2.16 & 2.03 & 2.25 & 2.66 \\
\hline $\begin{array}{l}10,001-20,000 \\
(n=35)\end{array}$ & 2.03 & 1.97 & 1.97 & 2.43 \\
\hline $\begin{array}{l}\text { Over } 20,000 \\
(n=34)\end{array}$ & 1.94 & 1.97 & 2.03 & 2.53 \\
\hline $\begin{array}{l}\text { Total Average } \\
(\mathrm{n}=166)\end{array}$ & 1.99 & 2.01 & 2.02 & 2.63 \\
\hline & $\begin{array}{l}\text { 5. Faculty and } \\
\text { administrators } \\
\text { collaborate on peer } \\
\text { tutoring to access } \\
\text { program } \\
\text { effectiveness. }\end{array}$ & $\begin{array}{l}\text { 6. Ongoing staff } \\
\text { development on } \\
\text { peer tutoring best } \\
\text { practices is in } \\
\text { place. }\end{array}$ & $\begin{array}{l}\text { 7. Professional } \\
\text { incentives to } \\
\text { participate in peer } \\
\text { tutoring programs are } \\
\text { available (i.e. credit } \\
\text { towards promotion } \\
\text { and tenure, flexibility } \\
\text { in time teaching). }\end{array}$ & $\begin{array}{l}\text { 8. Financial } \\
\text { incentives to } \\
\text { participate in peer } \\
\text { tutoring are } \\
\text { available (i.e. merit } \\
\text { pay, grants for } \\
\text { future research, new } \\
\text { computer). }\end{array}$ \\
\hline $\begin{array}{l}\text { Less than } 5,000 \\
(\mathrm{n}=65)\end{array}$ & 2.02 & 1.75 & 2.80 & 2.77 \\
\hline $\begin{array}{l}5,000-10,000 \\
(n=32)\end{array}$ & 2.31 & 1.66 & 2.34 & 2.50 \\
\hline $\begin{array}{l}10,001-20,000 \\
(n=35)\end{array}$ & 1.91 & 1.91 & 2.60 & 2.49 \\
\hline $\begin{array}{l}\text { Over } 20,000 \\
(n=34)\end{array}$ & 1.97 & 1.85 & 2.35 & 2.71 \\
\hline $\begin{array}{l}\text { Total Average } \\
(n=166)\end{array}$ & 2.04 & 1.79 & 2.58 & 2.64 \\
\hline
\end{tabular}


Table 40 (Cont.)

Mean Scores for Differences in Perception of Faculty Factors that Facilitate Peer Tutoring Based on Enrollment

\begin{tabular}{|c|c|c|c|c|}
\hline Enrollment & \multicolumn{4}{|c|}{ Factor } \\
\hline & $\begin{array}{l}\text { 9. Communication } \\
\text { between faculty } \\
\text { and students } \\
\text { encourages student } \\
\text { engagement. }\end{array}$ & $\begin{array}{l}\text { 10. Communication } \\
\text { between faculty and } \\
\text { students supports } \\
\text { different teaching } \\
\text { styles. }\end{array}$ & $\begin{array}{l}\text { 11. Communication } \\
\text { between faculty and } \\
\text { students supports } \\
\text { different learning } \\
\text { styles }\end{array}$ & $\begin{array}{l}\text { 12. Peer tutoring } \\
\text { practices are } \\
\text { oriented toward } \\
\text { developing a } \\
\text { climate in which } \\
\text { students' } \\
\text { responsibility and } \\
\text { active participation } \\
\text { are promoted. }\end{array}$ \\
\hline $\begin{array}{l}\text { Less than } 5,000 \\
(\mathrm{n}=65)\end{array}$ & 1.26 & 1.49 & 1.49 & 1.35 \\
\hline $\begin{array}{l}5,000-10,000 \\
(\mathrm{n}=32)\end{array}$ & 1.56 & 1.69 & 1.75 & 1.41 \\
\hline $\begin{array}{l}10,001-20,000 \\
(\mathrm{n}=35)\end{array}$ & 1.43 & 1.54 & 1.51 & 1.40 \\
\hline $\begin{array}{l}\text { Over } 20,000 \\
(\mathrm{n}=34)\end{array}$ & 1.53 & 1.44 & 1.41 & 1.50 \\
\hline $\begin{array}{l}\text { Total Average } \\
(\mathrm{n}=166)\end{array}$ & 1.41 & 1.53 & 1.53 & 1.40 \\
\hline
\end{tabular}

As indicated in Table 40, there were minimal differences in perceptions among groups based on enrollment. Administrators identified nine factors as facilitators to peer tutoring based on enrollment: a) Staff Development, b) Shared Vision, c) Collaboration - Plan Programs, d) Collaboration - Implement Programs, e) Collaboration - Assess Program Effectiveness, f) Communication - Encourage Student Engagement, h) Communication - Support Different Teaching Styles, h) Communication - Support Different Learning Styles, and i) Responsibility. Administrators also identified three factors as barriers to peer tutoring based on enrollment: 
a) Collaboration - Decide Program Budget, b) Incentives - Professional, and c) Incentives Financial. The mean fell within the same range for each factor for each level of enrollment with the exception of the following factors:

a) Collaboration - Decide Program Budget. A mean of 2.63 indicates that on average administrators ( $\mathrm{n}=166)$ felt that it was of minor importance for administrators and faculty to collaborate to decide the peer tutoring budget. However, administrators at institutions with an enrollment of 10,001-20,000 $(n=35$, mean $=2.43)$ believed it was important, but not critical that administrators and faculty meet to decide the peer tutoring budget.

b) Incentives - Professional. A mean of 2.56 shows that on average administrators $(n=166)$ believed it was of minor importance that professional incentives to participate in peer tutoring programs are available (i.e. credit towards promotion and tenure, flexibility in time teaching). However, administrators at institutions with an enrollment of 5,000-10,000 $(n=32$, mean $=2.34)$ and over 20,000 $(n=34$, mean=2.35) believed it was very important that professional incentives to participate in peer tutoring programs are available (i.e. credit towards promotion and tenure, flexibility in time teaching).

c) Incentives - Financial. A mean of 2.64 indicates that on average administrators $(n=166)$ felt it was of minor importance that financial incentives to participate in peer tutoring are available (i.e. merit pay, grants for future research, new computer). However, administrators at institutions with an enrollment of 10.001-20,000 $(n=35$, mean=2.49) believed financial incentives were important, but not critical.

d) Communication - Encourages Student Engagement. A mean of 1.41 shows that on average administrators $(n=166)$ believed it was critical that communication between faculty and students encourage student engagement. However, administrators at institutions with an 
enrollment of 5,000-10,000 $(n=32$, mean=1.56) and over 20,000 $(n=34$, mean=1.53) felt it was important, but not critical that communication between faculty and students encourages student engagement.

e) Communication - Supports Different Teaching Styles. A mean of 1.53 indicates that on average administrators $(n=166)$ thought it was important, but not critical that communication between faculty and students supports different teaching styles. However, administrators at institutions with an enrollment of less than 5,000 $(n=65$, mean=1.49) and over 20,000 (n-34, mean=1.44) felt it was critical that communication between faculty and students supports different teaching styles.

f) Communication - Support Different Learning Styles. A mean of 1.53 shows that on average administrators $(\mathrm{n}=166)$ thought it was important, but not critical that communication between faculty and students supports different learning styles. However, administrators at institutions with an enrollment of less than 5,000 $(n=65$, mean=1.49) and over 20,000 (n-34. Mean=1.41) felt it was critical that communication between faculty and students support different learning styles.

Factors that facilitate peer tutoring - highest degree awarded. Table 41 illustrates the differences in perception among administrators of faculty factors that facilitate peer tutoring based on the following degrees awarded: a) associates, b) bachelors, c) masters, d) doctorate, and e) professional. An average mean for the total respondents was also computed for each factor. Responses on the importance scale of 1-1.5 (critical) and 1.51-2.5 (important, but not critical) were used to identify institutional factors that facilitate peer tutoring. Although 167 respondents identified themselves as administrators, one respondent didn't select a response, bringing the total respondents to 166 . 
Table 41

Mean Scores for Differences in Perception of Faculty Factors that Facilitate Peer Tutoring Based on Highest Degree Awarded

\begin{tabular}{|c|c|c|c|c|}
\hline Degree & \multicolumn{4}{|c|}{ Factor } \\
\hline \multirow{7}{*}{$\begin{array}{l}\text { Associates } \\
(\mathrm{n}=19) \\
\text { Bachelors } \\
(\mathrm{n}=15) \\
\text { Masters } \\
(\mathrm{n}=33) \\
\text { Doctorate } \\
(\mathrm{n}=69) \\
\text { Professional } \\
(30) \\
\text { Total Average } \\
(\mathrm{n}=166)\end{array}$} & $\begin{array}{l}\text { 1. There is a shared } \\
\text { vision of peer } \\
\text { tutoring among } \\
\text { departments. }\end{array}$ & $\begin{array}{l}\text { 2. Faculty and } \\
\text { administrators } \\
\text { collaborate on peer } \\
\text { tutoring to plan } \\
\text { programs. }\end{array}$ & $\begin{array}{l}\text { 3. Faculty and } \\
\text { administrators } \\
\text { collaborate on peer } \\
\text { tutoring to implement } \\
\text { programs. }\end{array}$ & $\begin{array}{l}\text { 4. Faculty and } \\
\text { administrators } \\
\text { collaborate on peer } \\
\text { tutoring to decide } \\
\text { the program } \\
\text { budget. }\end{array}$ \\
\hline & 2.32 & 2.00 & 2.05 & 2.78 \\
\hline & 2.00 & 1.80 & 1.80 & 2.40 \\
\hline & 1.88 & 1.82 & 1.70 & 2.55 \\
\hline & 1.93 & 2.14 & 2,17 & 2.59 \\
\hline & 2.03 & 2.03 & 2.10 & 2.77 \\
\hline & 1.99 & 2.01 & 2.02 & 2.62 \\
\hline & $\begin{array}{l}\text { 5. Faculty and } \\
\text { administrators } \\
\text { collaborate on peer } \\
\text { tutoring to access } \\
\text { program } \\
\text { effectiveness. }\end{array}$ & $\begin{array}{l}\text { 6. Ongoing staff } \\
\text { development on peer } \\
\text { tutoring best } \\
\text { practices is in place. }\end{array}$ & $\begin{array}{l}\text { 7. Professional } \\
\text { incentives to } \\
\text { participate in peer } \\
\text { tutoring programs are } \\
\text { available (i.e. credit } \\
\text { towards promotion } \\
\text { and tenure, flexibility } \\
\text { in time teaching). }\end{array}$ & $\begin{array}{l}\text { 8. Financial } \\
\text { incentives to } \\
\text { participate in peer } \\
\text { tutoring are } \\
\text { available (i.e. merit } \\
\text { pay, grants for } \\
\text { future research, } \\
\text { new computer). }\end{array}$ \\
\hline $\begin{array}{l}\text { Associates } \\
(n=19)\end{array}$ & 2.21 & 2.16 & 2.58 & 2.84 \\
\hline $\begin{array}{l}\text { Bachelors } \\
(\mathrm{n}=15)\end{array}$ & 1.87 & 1.80 & 2.33 & 2.33 \\
\hline $\begin{array}{l}\text { Masters } \\
(\mathrm{n}=33)\end{array}$ & 1.85 & 1.48 & 2.45 & 2.48 \\
\hline $\begin{array}{l}\text { Doctorate } \\
(\mathrm{n}=69)\end{array}$ & 2.17 & 1.81 & 2.61 & 2.67 \\
\hline $\begin{array}{l}\text { Professional } \\
\text { (30) }\end{array}$ & 1.87 & 1.83 & 2.77 & 2.83 \\
\hline $\begin{array}{l}\text { Total Average } \\
(n=166)\end{array}$ & 2.03 & 1.79 & 2.58 & 2.65 \\
\hline
\end{tabular}


Table 41 (Cont.)

Mean Scores for Differences in Perception of Faculty Factors that Facilitate Peer Tutoring Based on Highest Degree Awarded

\begin{tabular}{|c|c|c|c|c|}
\hline Degree & \multicolumn{4}{|c|}{ Factor } \\
\hline & $\begin{array}{l}\text { 9. Communication } \\
\text { between faculty } \\
\text { and students } \\
\text { encourages student } \\
\text { engagement. }\end{array}$ & $\begin{array}{l}\text { 10. Communication } \\
\text { between faculty and } \\
\text { students supports } \\
\text { different teaching } \\
\text { styles. }\end{array}$ & $\begin{array}{l}\text { 11. Communication } \\
\text { between faculty and } \\
\text { students supports } \\
\text { different learning } \\
\text { styles }\end{array}$ & $\begin{array}{l}\text { 12. Peer tutoring } \\
\text { practices are } \\
\text { oriented toward } \\
\text { developing a } \\
\text { climate in which } \\
\text { students' } \\
\text { responsibility and } \\
\text { active participation } \\
\text { are promoted. }\end{array}$ \\
\hline $\begin{array}{l}\text { Associates } \\
(\mathrm{n}=19)\end{array}$ & 1.63 & 1.68 & 1.68 & 1.53 \\
\hline $\begin{array}{l}\text { Bachelors } \\
(\mathrm{n}=15)\end{array}$ & 1.20 & 1.33 & 1.33 & 1.27 \\
\hline $\begin{array}{l}\text { Masters } \\
(\mathrm{n}=33)\end{array}$ & 1.33 & 1.55 & 1.52 & 1.36 \\
\hline $\begin{array}{l}\text { Doctorate } \\
(\mathrm{n}=69)\end{array}$ & 1.38 & 1.55 & 1.58 & 1.41 \\
\hline $\begin{array}{l}\text { Professional } \\
\text { (30) }\end{array}$ & 1.53 & 1.47 & 1.43 & 1.47 \\
\hline $\begin{array}{l}\text { Total Average } \\
(\mathrm{n}=166)\end{array}$ & 1.41 & 1.53 & 1.53 & 1.41 \\
\hline
\end{tabular}

As indicated in Table 41, administrators identified seven factors that facilitate peer tutoring based on the highest degree offered: a) Shared Vision, b) Collaboration - Plan Programs,

c) Collaboration - Implement Programs, d) Collaboration - Access Program Effectiveness,

e) Staff Development, f) Communication - Encourages Student Engagement, and

g) Responsibility. Administrators also identified five barriers to peer tutoring based on the highest degree offered: a) Collaboration - Decide Program Budget, b) Incentives - Professional, c) Incentives - Financial, d) Communication - Supports Different Teaching Styles, and

e) Communication - Supports Different Learning Styles. Although the means were within the same range for most groups, there were slight differences between groups for the following factors: 
a) Collaborate - Decide Program Budget. A mean of 2.62 indicates that on average administrators $(n=166)$ believed it was of minor importance that faculty and administrators collaborate on peer tutoring to decide the program budget. However, administrators at bachelors institutions $(n=15$, mean $=2.40)$ felt it was important, but not critical.

b) Staff Development. A mean of 1.79 shows that on average administrators $(n=166)$ thought it was important, but not critical that ongoing staff development on peer tutoring best practices was in place, while administrators at masters colleges and universities $(n=33$, mean=1.48) believed ongoing staff development on peer tutoring best practices was critical.

c) Incentives - Professional. A mean of 2.58 shows that on average administrators $(n=166)$ believed that the availability of professional incentives to participate in peer tutoring programs (i.e. credit towards promotion and tenure, flexibility in time teaching) were of minor importance, while administrators from bachelors institutions $(\mathrm{n}=15$, mean=2.33) and masters colleges and universities $(n-33$, mean $=2.45)$ thought it was critical that professional incentives to participate in peer tutoring programs were available.

d) Incentives - Financial. A mean of 2.65 indicates that on average administrators $(n=166)$ felt that the availability of financial incentives to participate in peer tutoring are available (i.e. merit pay, grants for future research, new computer) was of minor importance. However, administrators from bachelors institutions $(n=15$, mean=2.33) and masters colleges and universities $(n-33$, mean=2.48) thought it was important, but not critical that financial incentives to participate in peer tutoring programs were available.

e) Communication - Encourages Student Engagement. A mean of 1.44 shows that on average administrators $(n=166)$ believed that it was critical that communication between faculty and students encourages student engagement. However associates institutions $(n=19$, 
mean=1.63) and institutions that award professional degrees (i.e. JD, MD, DDS) $(n=30$, mean=1.53) felt it was important, but not critical.

f) Communication - Supports Different Teaching Styles. A mean of 1.53 indicates that on average administrators $(n=166)$ administrators felt it was important, but not critical that Communication between faculty and students supports different teaching styles. However, bachelors institutions $(n=15$, mean=1.33) and professional institutions $(n=30)$ felt it was critical.

g) Communication - Supports Different Learning Styles, A mean of 1.53 shows that on average administrators $(n=166)$ believed that it was important, but not critical that communication between faculty and students supports different learning styles. However, bachelors institutions $(n=15$, mean $=1.33)$ and professional institutions $(n=30$, mean=1.43) felt it was critical.

h) Responsibility. A mean of 1.41 indicates that on average administrators felt it was critical that peer tutoring practices are oriented toward developing a climate in which students' responsibility and active participation are promoted. However, bachelors institutions $(\mathrm{n}=15$, mean=1.53) felt it was important, but not critical that peer tutoring practices are oriented toward developing a climate in which students' responsibility and active participation are promoted.

Factors that facilitate peer tutoring - Carnegie classification. Table 42 illustrates the differences in perception among administrators of faculty factors that facilitate peer tutoring based on the following Carnegie classifications: a) research university, very high research; b) research university, high research; c) doctoral research university; d) masters colleges and universities, larger programs; e) masters colleges and universities, medium programs; f) masters colleges and universities, smaller programs; g) baccalaureate colleges; and h) associates colleges. An average mean for the total respondents was also computed for each factor. Responses on the 
importance scale of 1-1.5 (critical) and 1.51-2.5 (important, but not critical) were used to identify institutional factors that facilitate peer tutoring.

Table 42

Mean Scores for Differences in Perception of faculty Factors Facilitate Peer Tutoring Based on Carnegie Classification

\begin{tabular}{|c|c|c|c|c|}
\hline Carnegie & \multicolumn{4}{|c|}{ Factor } \\
\hline & $\begin{array}{l}\text { 1. There is a } \\
\text { shared vision } \\
\text { of peer tutoring } \\
\text { among } \\
\text { departments. } \\
\end{array}$ & $\begin{array}{l}\text { 2. Faculty and } \\
\text { administrators } \\
\text { collaborate on } \\
\text { peer tutoring to } \\
\text { plan programs. }\end{array}$ & $\begin{array}{l}\text { 3. Faculty and } \\
\text { administrators } \\
\text { collaborate on peer } \\
\text { tutoring to implement } \\
\text { programs. }\end{array}$ & $\begin{array}{l}\text { 4. Faculty and } \\
\text { administrators } \\
\text { collaborate on peer } \\
\text { tutoring to decide the } \\
\text { program budget. }\end{array}$ \\
\hline $\begin{array}{l}\text { Research University, } \\
\text { Very High Research } \\
(\mathrm{n}=26)\end{array}$ & 2.12 & 2.12 & 2.12 & 2.77 \\
\hline $\begin{array}{l}\text { Research University, } \\
\text { High Research }(n=20)\end{array}$ & 1.95 & 2.00 & 2.00 & 2.50 \\
\hline $\begin{array}{l}\text { Doctoral Research } \\
\text { University }(n=20)\end{array}$ & 2.05 & 2.25 & 2.40 & 2.80 \\
\hline $\begin{array}{l}\text { Masters Colleges and } \\
\text { Universities, Larger } \\
\text { Programs }(n=14)\end{array}$ & 1.79 & 1.79 & 2.07 & 2.50 \\
\hline $\begin{array}{l}\text { Masters Colleges and } \\
\text { Universities, Medium } \\
\text { Programs }(n=25)\end{array}$ & 1.72 & 2.08 & 1.96 & 2.56 \\
\hline $\begin{array}{l}\text { Masters Colleges and } \\
\text { Universities, Smaller } \\
\text { Programs }(n=20)\end{array}$ & 1.90 & 1.95 & 1.85 & 2.60 \\
\hline $\begin{array}{l}\text { Baccalaureate Colleges } \\
(n=22)\end{array}$ & 2.05 & 1.86 & 1.77 & 2.50 \\
\hline $\begin{array}{l}\text { Associates Colleges } \\
(\mathrm{n}=20)\end{array}$ & 2.30 & 1.95 & 2.05 & 2,75 \\
\hline $\begin{array}{l}\text { Total Average } \\
(\mathrm{n}=167)\end{array}$ & 1.99 & 2.01 & 2.02 & 2.63 \\
\hline
\end{tabular}


Table 42 (Cont.)

Mean Scores for Differences in Perception of Faculty Factors that Facilitate Peer Tutoring Based on Carnegie Classification

\begin{tabular}{|c|c|c|c|c|}
\hline Carnegie & \multicolumn{4}{|c|}{ Factor } \\
\hline & $\begin{array}{l}\text { 5. Faculty and } \\
\text { administrators } \\
\text { collaborate on } \\
\text { peer tutoring to } \\
\text { access program } \\
\text { effectiveness. }\end{array}$ & $\begin{array}{l}\text { 6. Ongoing } \\
\text { staff } \\
\text { development } \\
\text { on peer } \\
\text { tutoring best } \\
\text { practices is in } \\
\text { place. }\end{array}$ & $\begin{array}{l}\text { 7. Professional } \\
\text { incentives to } \\
\text { participate in peer } \\
\text { tutoring programs are } \\
\text { available (i.e. credit } \\
\text { towards promotion } \\
\text { and tenure, flexibility } \\
\text { in time teaching). }\end{array}$ & $\begin{array}{l}\text { 8. Financial incentives } \\
\text { to participate in peer } \\
\text { tutoring are available } \\
\text { (i.e. merit pay, grants } \\
\text { for future research, new } \\
\text { computer). }\end{array}$ \\
\hline $\begin{array}{l}\text { Research University, } \\
\text { Very High Research } \\
(\mathrm{n}=26)\end{array}$ & 2.30 & 2.04 & 2.58 & 2.69 \\
\hline $\begin{array}{l}\text { Research University, } \\
\text { High Research }(n=20)\end{array}$ & 1.90 & 1.85 & 2.80 & 2.80 \\
\hline $\begin{array}{l}\text { Doctoral Research } \\
\text { University }(n=20)\end{array}$ & 2.15 & 1.80 & 2.70 & 2.95 \\
\hline $\begin{array}{l}\text { Masters Colleges and } \\
\text { Universities, Larger } \\
\text { Programs }(n=14)\end{array}$ & 1.71 & 1.71 & 2.71 & 2.36 \\
\hline $\begin{array}{l}\text { Masters Colleges and } \\
\text { Universities, Medium } \\
\text { Programs }(n=25)\end{array}$ & 2.08 & 1.48 & 2.28 & 2.32 \\
\hline $\begin{array}{l}\text { Masters Colleges and } \\
\text { Universities, Smaller } \\
\text { Programs }(n=20)\end{array}$ & 1.85 & 1.45 & 2.75 & 2.80 \\
\hline $\begin{array}{l}\text { Baccalaureate } \\
\text { Colleges }(n=22)\end{array}$ & 2.00 & 1.95 & 2.45 & 2.50 \\
\hline $\begin{array}{l}\text { Associates Colleges } \\
(\mathrm{n}=20)\end{array}$ & 2.15 & 2.10 & 2.55 & 2,80 \\
\hline $\begin{array}{l}\text { Total Average } \\
(\mathrm{n}=167)\end{array}$ & 2.05 & 1.80 & 2.59 & 2.65 \\
\hline
\end{tabular}


Table 42 (Cont.)

Mean Scores for Differences in Perception of Faculty Factors that Facilitate Peer Tutoring Based on Carnegie Classification

\begin{tabular}{|c|c|c|c|c|}
\hline Carnegie & \multicolumn{4}{|c|}{ Factor } \\
\hline & $\begin{array}{l}\text { 9. Communication } \\
\text { between faculty } \\
\text { and students } \\
\text { encourages } \\
\text { student } \\
\text { engagement. }\end{array}$ & $\begin{array}{l}\text { 10. Communication } \\
\text { between faculty } \\
\text { and students } \\
\text { supports different } \\
\text { teaching styles. }\end{array}$ & $\begin{array}{l}\text { 11. Communication } \\
\text { between faculty } \\
\text { and students } \\
\text { supports different } \\
\text { learning styles }\end{array}$ & $\begin{array}{l}\text { 12. Peer tutoring } \\
\text { practices are } \\
\text { oriented toward } \\
\text { developing a climate } \\
\text { in which students' } \\
\text { responsibility and } \\
\text { active participation } \\
\text { are promoted. }\end{array}$ \\
\hline $\begin{array}{l}\text { Research } \\
\text { University, Very } \\
\text { High Research } \\
(\mathrm{n}=26)\end{array}$ & 1.58 & 1.62 & 1.58 & 1.73 \\
\hline $\begin{array}{l}\text { Research University, } \\
\text { High Research } \\
(\mathrm{n}=20)\end{array}$ & 1.55 & 1.55 & 1.50 & 1.40 \\
\hline $\begin{array}{l}\text { Doctoral Research } \\
\text { University }(n=20)\end{array}$ & 1.20 & 1.65 & 1.55 & 1.25 \\
\hline $\begin{array}{l}\text { Masters Colleges } \\
\text { and Universities, } \\
\text { Larger Programs } \\
(\mathrm{n}=14)\end{array}$ & 1.57 & 1.57 & 1.50 & 1.29 \\
\hline $\begin{array}{l}\text { Masters Colleges } \\
\text { and Universities, } \\
\text { Medium Programs } \\
(\mathrm{n}=25)\end{array}$ & 1.24 & 1.36 & 1.44 & 1.28 \\
\hline $\begin{array}{l}\text { Masters Colleges } \\
\text { and Universities, } \\
\text { Smaller Programs } \\
(\mathrm{n}=20)\end{array}$ & 1.35 & 1.40 & 1.60 & 1.35 \\
\hline $\begin{array}{l}\text { Baccalaureate } \\
\text { Colleges }(n=22)\end{array}$ & 1.23 & 1.46 & 1.41 & 1.36 \\
\hline $\begin{array}{l}\text { Associates Colleges } \\
(\mathrm{n}=20)\end{array}$ & 1.60 & 1.65 & 1.65 & 1.50 \\
\hline $\begin{array}{l}\text { Total Average } \\
(\mathrm{n}=167)\end{array}$ & 1.41 & 1.53 & 1.53 & 1.41 \\
\hline
\end{tabular}


As indicated in Table 42, administrators identified seven factors that facilitate peer tutoring based on Carnegie classification: a) Shared Vision, b) Collaboration - Plan Programs, c) Collaboration - Implement Programs, d) Collaboration - Access Program Effectiveness,

e) Staff Development, f) Communication - Encourages Student Engagement, and

g) Responsibility. Administrators also identified five barriers to peer tutoring based on Carnegie classification: a) Collaboration - Decide Program Budget, b) Incentives - Professional, c) Incentives - Financial, d) Communication - Supports Different Teaching Styles, and e) Communication - Supports Different Learning Styles. Although the means were within the same range for most groups, there were slight differences between groups for the following factors:

a) Staff Development. A mean of 1.80 indicates that on average administrators $(n=167)$ believed it was important, but not critical that ongoing staff development on peer tutoring best practices was in place. However, administrators at masters colleges and universities, medium programs $(n=25$, mean $=1.48)$ and masters colleges and universities, smaller programs $(\mathrm{n}=20$, mean=1.45) thought it was critical.

b) Incentives - Professional. A mean of 2.59 shows that on average administrators $(n=167)$ felt it was of minor importance that professional incentives to participate in peer tutoring programs are available (i.e. credit towards promotion and tenure, flexibility in time teaching). However, administrators at masters colleges and universities, medium programs $(\mathrm{n}=25$, mean $=2.28)$ and baccalaureate colleges $(n=22$, mean=2.45) thought it was important, but not critical.

c) Incentives - Financial. A mean of 2.65 indicates that on average administrators $(n=167)$ believed it was of minor importance that financial incentives to participate in peer 
tutoring are available (i.e. merit pay, grants for future research, new computer). However, administrators at masters colleges and universities, larger programs $(n=14$, mean=2.36) and masters colleges and universities, medium programs $(n=25$, mean=2.32) felt it was important, but not critical.

d) Communication - Encourages Student Engagement. A mean of 1.41 shows that on average administrators $(n=167)$ thought it was critical that communication between faculty and students encourages student engagement. However, administrators from research universities, very high research $(n=26$, mean=1.58); research universities, high research $(n=20$, mean=1.55); masters colleges and universities, larger programs $(n=14$, mean=1.57); and associates colleges $(n=20$, mean=1.60) felt it was important, but not critical.

d) Communication - Supports Different Teaching Styles. A mean of 1.53 indicates that on average administrators $(n=167)$ believed it was important, but not critical that communication between faculty and students supports different teaching styles. However, administrators at masters colleges and universities, medium programs $(n=25$, mean=1.36); masters universities and colleges, smaller programs $(n=20$, mean=1.40); and baccalaureate colleges $(n=22$, mean=1.46) thought communication between faculty and students that supports different teaching styles was critical.

e) Communication - Supports Different Learning Styles. A mean of 1.53 shows that on average administrators felt it was important, but not critical that communication between faculty and students supports different learning styles. However, administrators at masters colleges and universities, medium programs $(n=25$, mean=1.44) and baccalaureate colleges $(n=22$, mean=1.41) believed communication between faculty and students that supports different learning styles was critical. 
f) Responsibility. A mean of 1.41 indicates that on average administrators $(n=167)$ believed it was critical that peer tutoring practices are oriented toward developing a climate in which students' responsibility and active participation are promoted. However, administrators at research universities, very high research $(n=36$, mean=1.73) thought developing a climate in which students' responsibility and active participation are promoted was important, but not critical.

Factors that form barriers to peer tutoring - department affiliation. Table 43 shows the mean scores for differences in perception of faculty factors that form barriers to peer tutoring based on the following department affiliation: a) Student Affairs, b Academic Affairs, and c) both Student Affairs and Academic Affairs. Responses on the difficulty scale of 1-1.5 (nearly impossible) and 1.51-2.5 (very difficult) were used to identify institutional factors that form barriers to peer tutoring programs. Although 167 respondents identified themselves as administrators, 14 respondents identified themselves as in an academic department. For reporting purposes, only responses from administrators in Academic Affairs or Student Affairs were used, bringing the total respondents to 153 . 
Table 43

Mean Scores for Differences in Perception of Faculty Factors that Form Barriers to Peer Tutoring Based on Department Affiliation

\begin{tabular}{|c|c|c|c|c|}
\hline Factor & \multicolumn{4}{|c|}{ Department Affiliation } \\
\hline & $\begin{array}{l}\text { Student } \\
\text { Affairs } \\
\mathrm{n}=47\end{array}$ & $\begin{array}{l}\text { Academic } \\
\text { Affairs } \\
\mathrm{n}=74\end{array}$ & $\begin{array}{l}\text { Both } \\
\mathrm{n}=32\end{array}$ & $\begin{array}{l}\text { Total } \\
\text { Average } \\
\mathrm{n}=153\end{array}$ \\
\hline $\begin{array}{l}\text { 1. There is a shared vision of peer tutoring among } \\
\text { departments. }\end{array}$ & 2.34 & 2.35 & 2.03 & 2.28 \\
\hline $\begin{array}{l}\text { 2. Faculty and administrators collaborate on peer tutoring } \\
\text { to plan programs. }\end{array}$ & 2.34 & 2.36 & 2.19 & 2.32 \\
\hline $\begin{array}{l}\text { 3. Faculty and administrators collaborate on peer tutoring } \\
\text { to implement programs. }\end{array}$ & 2.23 & 2.43 & 2.22 & 2.33 \\
\hline $\begin{array}{l}\text { 4. Faculty and administrators collaborate on peer tutoring to } \\
\text { decide the program budget. }\end{array}$ & 2.04 & 2.47 & 2.34 & 2.31 \\
\hline $\begin{array}{l}\text { 5. Faculty and administrators collaborate on peer tutoring to } \\
\text { access program effectiveness. }\end{array}$ & 2.21 & 2.47 & 2.47 & 2.39 \\
\hline $\begin{array}{l}\text { 6. Ongoing staff development on peer tutoring best practices } \\
\text { is in place. }\end{array}$ & 2.83 & 2.81 & 2.66 & 2.78 \\
\hline $\begin{array}{l}\text { 7. Professional incentives to participate in peer tutoring } \\
\text { programs are available (i.e. credit towards promotion and } \\
\text { tenure, flexibility in time teaching). }\end{array}$ & 1.87 & 2.16 & 2.13 & 2.07 \\
\hline $\begin{array}{l}\text { 8. Financial incentives to participate in peer tutoring are } \\
\text { available (i.e. merit pay, grants for future research, new } \\
\text { computer). }\end{array}$ & 1.98 & 2.12 & 2.31 & 2.12 \\
\hline $\begin{array}{l}\text { 9. Communication between faculty and students encourages } \\
\text { student engagement. }\end{array}$ & 2.77 & 2.82 & 3.13 & 2.87 \\
\hline $\begin{array}{l}\text { 10. Communication between faculty and students supports } \\
\text { different teaching styles. }\end{array}$ & 2.49 & 2.59 & 2.81 & 2.61 \\
\hline $\begin{array}{l}\text { 11. Communication between faculty and students supports } \\
\text { different learning styles. }\end{array}$ & 2.49 & 2.51 & 2.81 & 2.57 \\
\hline $\begin{array}{l}\text { 12. Peer tutoring practices are oriented toward developing a } \\
\text { climate in which students' responsibility and active } \\
\text { participation are promoted. }\end{array}$ & 2.62 & 2,64 & 2.94 & 2.69 \\
\hline
\end{tabular}


As indicated in Table 43, there were minimal differences in perceptions between groups of administrators based on department affiliation and the mean fell within the same range for each factor for each department affiliation, with the exception of the following factors:

a) Communication - Supports Different Teaching Styles. A mean of 2.61 indicates that on average administrators $(\mathrm{n}=153)$ believed it was of minor difficulty that communication between faculty and students supports different teaching styles. However, administrators in Student Affairs ( $\mathrm{n}=47$, mean=2.49) felt communication between faculty and students that supports different teaching styles would be very difficult

b) Communication - Supports Different Learning Styles. A mean of 2.57 shows that on average administrators $(n=153)$ thought it would be of minor difficulty for communication between faculty and students to support different learning styles. However, administrators in Student Affairs ( $\mathrm{n}=47$, mean=2.49) felt communication between faculty and students that supports different learning styles would be very difficult.

Factors that form barriers to peer tutoring - enrollment. Table 44 illustrates the mean scores for differences in perception among administrators of administrative factors that form barriers to peer tutoring based on the following enrollment: less than 5000, 5,000-10,000, $10,001-20,000$, or over 20,000. Responses on the difficulty scale of 1-1.5 (nearly impossible) and 1.51-2.5 (very difficult) were used to identify institutional factors that form barriers to peer tutoring. Although 167 respondents identified themselves as administrators, one respondent didn't select a response, bringing the total respondents to 166 . 
Table 44

Mean Scores for Differences in Perception of Faculty Factors that Form Barriers to Peer Tutoring Based on Enrollment

\begin{tabular}{|c|c|c|c|c|}
\hline Enrollment & \multicolumn{4}{|c|}{ Factor } \\
\hline & $\begin{array}{l}\text { 1. There is a shared } \\
\text { vision of peer } \\
\text { tutoring among } \\
\text { departments. }\end{array}$ & $\begin{array}{l}\text { 2. Faculty and } \\
\text { administrators } \\
\text { collaborate on } \\
\text { peer tutoring to } \\
\text { plan programs. }\end{array}$ & $\begin{array}{l}\text { 3. Faculty and } \\
\text { administrators } \\
\text { collaborate on peer } \\
\text { tutoring to implement } \\
\text { programs. }\end{array}$ & $\begin{array}{l}\text { 4. Faculty and } \\
\text { administrators } \\
\text { collaborate on peer } \\
\text { tutoring to decide the } \\
\text { program budget. }\end{array}$ \\
\hline $\begin{array}{l}\text { Less than } 5,000 \\
(\mathrm{n}=65)\end{array}$ & 2.49 & 2.40 & 2.46 & 2.37 \\
\hline $\begin{array}{l}5,000-10,000 \\
(n=32)\end{array}$ & 2.50 & 2.50 & 2.47 & 2.63 \\
\hline $\begin{array}{l}10,001-20,000 \\
(n=35)\end{array}$ & 2.06 & 2.31 & 2.09 & 2.06 \\
\hline $\begin{array}{l}\text { Over } 20,000 \\
(n=34)\end{array}$ & 1.76 & 2.00 & 2.15 & 2.12 \\
\hline \multirow{2}{*}{$\begin{array}{l}\text { Total Average } \\
(\mathrm{n}=166)\end{array}$} & 2.25 & 2.32 & 2.32 & 2.30 \\
\hline & $\begin{array}{l}\text { 5. Faculty and } \\
\text { administrators } \\
\text { collaborate on peer } \\
\text { tutoring to access } \\
\text { program } \\
\text { effectiveness. }\end{array}$ & $\begin{array}{l}\text { 6. Ongoing staff } \\
\text { development on } \\
\text { peer tutoring best } \\
\text { practices is in } \\
\text { place. }\end{array}$ & $\begin{array}{l}\text { 7. Professional } \\
\text { incentives to } \\
\text { participate in peer } \\
\text { tutoring programs are } \\
\text { available (i.e. credit } \\
\text { towards promotion } \\
\text { and tenure, flexibility } \\
\text { in time teaching). }\end{array}$ & $\begin{array}{l}\text { 8. Financial incentives } \\
\text { to participate in peer } \\
\text { tutoring are available } \\
\text { (i.e. merit pay, grants } \\
\text { for future research, } \\
\text { new computer). }\end{array}$ \\
\hline $\begin{array}{l}\text { Less than } 5,000 \\
(\mathrm{n}=65)\end{array}$ & 2.40 & 2.77 & 2.12 & 2.08 \\
\hline $\begin{array}{l}5,000-10,000 \\
(n=32)\end{array}$ & 2.59 & 3.00 & 2.28 & 2.34 \\
\hline $\begin{array}{l}10,001-20,000 \\
(n=35)\end{array}$ & 2.26 & 2.63 & 2.03 & 2.17 \\
\hline $\begin{array}{l}\text { Over } 20,000 \\
(\mathrm{n}=34)\end{array}$ & 2.26 & 2.79 & 1.88 & 2.06 \\
\hline $\begin{array}{l}\text { Total Average } \\
(\mathrm{n}=166)\end{array}$ & 2.38 & 2.79 & 2.08 & 2.14 \\
\hline
\end{tabular}


Table 44 (Cont.)

Mean Scores for Differences in Perception of Faculty Factors that Form Barriers to Peer Tutoring Based on Enrollment

\begin{tabular}{|c|c|c|c|c|}
\hline Enrollment & \multicolumn{4}{|c|}{ Factor } \\
\hline & $\begin{array}{l}\text { 9. Communication } \\
\text { between faculty } \\
\text { and students } \\
\text { encourages student } \\
\text { engagement. }\end{array}$ & $\begin{array}{l}\text { 10. Communication } \\
\text { between faculty and } \\
\text { students supports } \\
\text { different teaching } \\
\text { styles. }\end{array}$ & $\begin{array}{l}\text { 11. Communication } \\
\text { between faculty and } \\
\text { students supports } \\
\text { different learning } \\
\text { styles }\end{array}$ & $\begin{array}{l}\text { 12. Peer tutoring } \\
\text { practices are } \\
\text { oriented toward } \\
\text { developing a } \\
\text { climate in which } \\
\text { students' } \\
\text { responsibility and } \\
\text { active participation } \\
\text { are promoted. }\end{array}$ \\
\hline $\begin{array}{l}\text { Less than } 5,000 \\
(\mathrm{n}=65)\end{array}$ & 3.02 & 2.69 & 2.68 & 2.71 \\
\hline $\begin{array}{l}5,000-10,000 \\
(\mathrm{n}=32)\end{array}$ & 2.81 & 2.53 & 2.53 & 2.75 \\
\hline $\begin{array}{l}10,001-20,000 \\
(\mathrm{n}=35)\end{array}$ & 2.71 & 2.63 & 2.54 & 2.66 \\
\hline $\begin{array}{l}\text { Over } 20,000 \\
(\mathrm{n}=34)\end{array}$ & 2.76 & 2.41 & 2.35 & 2.59 \\
\hline $\begin{array}{l}\text { Total Average } \\
(\mathrm{n}=166)\end{array}$ & 2.86 & 2.59 & 2.55 & 2.68 \\
\hline
\end{tabular}

As indicated in Table 44, there were minimal differences in perceptions between groups of administrators based on enrollment and the mean fell within the same range for each factor for each level of enrollment, with the exception of the following factors:

a) Collaboration - Decide Budget. A mean of 2.30 indicates that on average administrators $(n=166)$ believed it would be very difficult for faculty and administrators to collaborate on peer tutoring to decide the program budget. However, administrators at institutions with an enrollment of 5,000-10,000 $(n=32$, mean=2.63) felt collaboration between faculty and administrators on peer tutoring to decide the program budget would be of minor difficulty. 
b) Collaboration - Access Program Effectiveness. A mean of 2.39 shows that on average administrators ( $\mathrm{n}=167)$ felt it would be very difficult for faculty and administrators to collaborate on peer tutoring to access program effectiveness. However, administrators at institutions with an enrollment of 5,000-10,000 $(\mathrm{n}=32$, mean=2.59) felt collaboration between faculty and administrators on peer tutoring to access program effectiveness would be of minor difficulty.

c) Communication - Supports Different Teaching Styles. A mean of 2.59 indicates that on average administrators ( $\mathrm{n}=167)$ believed it would be of minor difficulty to have communication between faculty and students that supports different teaching styles. However, administrators at institutions with an enrollment of over 20,000 $(n=34$, mean=2.41) felt it would be very difficult to have communication between faculty and students that supports different teaching styles.

d) Communication - Supports Different Learning Styles. A mean of 2.55 shows that on average administrators $(\mathrm{n}=167)$ believed it would be of minor difficulty for communication between faculty and students to support different learning styles. However, administrators at institutions with an enrollment of over 20,000 $(n=34$, mean=2.35) felt it would be very difficult for communication between faculty and students to support different learning styles.

Factors that form barriers to peer tutoring - highest degree awarded. Table 45 shows mean scores for differences in perception of faculty factors that form barriers to peer tutoring based on the following degrees awarded a) associates, b) bachelors, c) masters, d) doctorate, and e) professional. An average mean for the total respondents was also computed for each factor. Responses on the difficulty scale of 1-1.5 (nearly impossible) and 1.51-2.5 (very difficult) were used to identify institutional factors that form barriers to peer tutoring. Although 167 respondents 
identified themselves as administrators, one respondent didn't select a response, bringing the total respondents to 166 .

Table 45

Mean Scores for Differences in Perception of Faculty Factors that Form Barriers to Peer Tutoring Based on Highest Degree Offered

\begin{tabular}{|c|c|c|c|c|}
\hline Degree & \multicolumn{4}{|c|}{ Factor } \\
\hline \multirow{7}{*}{$\begin{array}{l}\begin{array}{l}\text { Associates } \\
(\mathrm{n}=19)\end{array} \\
\text { Bachelors } \\
(\mathrm{n}=15) \\
\text { Masters } \\
(\mathrm{n}=33) \\
\text { Doctorate } \\
(\mathrm{n}=69) \\
\text { Professional } \\
(30) \\
\text { Total Average } \\
(\mathrm{n}=166)\end{array}$} & $\begin{array}{l}\text { 1. There is a shared } \\
\text { vision of peer } \\
\text { tutoring among } \\
\text { departments. }\end{array}$ & $\begin{array}{l}\text { 2. Faculty and } \\
\text { administrators } \\
\text { collaborate on peer } \\
\text { tutoring to plan } \\
\text { programs. }\end{array}$ & $\begin{array}{l}\text { 3. Faculty and } \\
\text { administrators } \\
\text { collaborate on peer } \\
\text { tutoring to implement } \\
\text { programs. }\end{array}$ & $\begin{array}{l}\text { 4. Faculty and } \\
\text { administrators } \\
\text { collaborate on peer } \\
\text { tutoring to decide } \\
\text { the program } \\
\text { budget. }\end{array}$ \\
\hline & 2.42 & 2.42 & 2.37 & 2.42 \\
\hline & 2.13 & 2.40 & 2.40 & 2.40 \\
\hline & 2.46 & 2.30 & 2.27 & 2.24 \\
\hline & 2.26 & 2.32 & 2.35 & 2.33 \\
\hline & 2.00 & 2.17 & 2.20 & 2.17 \\
\hline & 2.26 & 2.31 & 2.31 & 2.30 \\
\hline & $\begin{array}{l}\text { 5. Faculty and } \\
\text { administrators } \\
\text { collaborate on peer } \\
\text { tutoring to access } \\
\text { program } \\
\text { effectiveness. }\end{array}$ & $\begin{array}{l}\text { 6. Ongoing staff } \\
\text { development on peer } \\
\text { tutoring best } \\
\text { practices is in place. }\end{array}$ & $\begin{array}{l}\text { 7. Professional } \\
\text { incentives to } \\
\text { participate in peer } \\
\text { tutoring programs are } \\
\text { available (i.e. credit } \\
\text { towards promotion } \\
\text { and tenure, flexibility } \\
\text { in time teaching). }\end{array}$ & $\begin{array}{l}\text { 8. Financial } \\
\text { incentives to } \\
\text { participate in peer } \\
\text { tutoring are } \\
\text { available (i.e. merit } \\
\text { pay, grants for } \\
\text { future research, } \\
\text { new computer). }\end{array}$ \\
\hline $\begin{array}{l}\text { Associates } \\
(\mathrm{n}=19)\end{array}$ & 2.58 & 2.63 & 2.21 & 2.26 \\
\hline $\begin{array}{l}\text { Bachelors } \\
(\mathrm{n}=15)\end{array}$ & 2.33 & 2.60 & 2.13 & 2.20 \\
\hline $\begin{array}{l}\text { Masters } \\
(n=33)\end{array}$ & 2.30 & 2.88 & 2.03 & 2.09 \\
\hline $\begin{array}{l}\text { Doctorate } \\
(\mathrm{n}=69)\end{array}$ & 2.41 & 2.86 & 2.14 & 2.10 \\
\hline $\begin{array}{l}\text { Professional } \\
\text { (30) }\end{array}$ & 2.27 & 2.73 & 1.90 & 2.20 \\
\hline $\begin{array}{l}\text { Total Average } \\
(\mathrm{n}=166)\end{array}$ & 2.37 & 2.79 & 2.08 & 2.14 \\
\hline
\end{tabular}


Table 45 (Cont.)

Mean Scores for Differences in Perception of Faculty Factors that Form Barriers to Peer Tutoring Based on Highest Degree Offered

\begin{tabular}{|c|c|c|c|c|}
\hline Degree & \multicolumn{4}{|c|}{ Factor } \\
\hline & $\begin{array}{l}\text { 9. Communication } \\
\text { between faculty } \\
\text { and students } \\
\text { encourages student } \\
\text { engagement. }\end{array}$ & $\begin{array}{l}\text { 10. Communication } \\
\text { between faculty and } \\
\text { students supports } \\
\text { different teaching } \\
\text { styles. }\end{array}$ & $\begin{array}{l}\text { 11. Communication } \\
\text { between faculty and } \\
\text { students supports } \\
\text { different learning } \\
\text { styles. }\end{array}$ & $\begin{array}{l}\text { 12. Peer tutoring } \\
\text { practices are } \\
\text { oriented toward } \\
\text { developing a } \\
\text { climate in which } \\
\text { students' } \\
\text { responsibility and } \\
\text { active participation } \\
\text { are promoted. }\end{array}$ \\
\hline $\begin{array}{l}\text { Associates } \\
(\mathrm{n}=19)\end{array}$ & 3.05 & 2.74 & 2.74 & 2.58 \\
\hline $\begin{array}{l}\text { Bachelors } \\
(\mathrm{n}=15)\end{array}$ & 2.67 & 2.60 & 2.60 & 2.80 \\
\hline $\begin{array}{l}\text { Masters } \\
(\mathrm{n}=33)\end{array}$ & 2.88 & 2.61 & 2.64 & 2.61 \\
\hline $\begin{array}{l}\text { Doctorate } \\
(\mathrm{n}=69)\end{array}$ & 2.83 & 2.54 & 2.50 & 2.74 \\
\hline $\begin{array}{l}\text { Professional } \\
\text { (30) }\end{array}$ & 2.90 & 2.57 & 2.43 & 2.60 \\
\hline $\begin{array}{l}\text { Total Average } \\
(\mathrm{n}=166)\end{array}$ & 2.86 & 2.58 & 2.55 & 2.67 \\
\hline
\end{tabular}

As indicated in Table 45, there were minimal differences in perceptions between groups of administrators based on the highest degree awarded and the mean fell within the same range for each factor for each degree awarded, with the exception of the following factors:

a) Collaboration - Access Program Effectiveness. A mean of 2.37 indicates that on average administrators $(\mathrm{n}=166)$ believed faculty and administrator collaboration on peer tutoring to access program effectiveness would be very difficult. However, administrators at associates institutions ( $\mathrm{n}=19$, mean=2.58) felt faculty and administrator collaboration on peer tutoring to access program effectiveness would be of minor difficulty.

b) Communication - Supports Different Learning Styles. A mean of 2.55 shows that on average administrators ( $\mathrm{n}=166$ ) thought it would be of minor difficulty for communication 
between faculty and students to support different learning styles. However, administrators from institutions that award professional degrees (i.e. JD, MD, DDS) $(n=30$, mean=2.43) believed it would be very difficult for communication between faculty and students to support different learning styles.

Factors that form barriers to peer tutoring - Carnegie Classification. Table 46 shows the mean scores for differences in the perception of faculty factors that form barriers to peer tutoring based on the following Carnegie classifications: a) research university, very high research; b) research university, high research; c) doctoral research university; d) masters colleges and universities, larger programs; e) masters colleges and universities, medium programs; f) masters colleges and universities, smaller programs; g) baccalaureate colleges; and h) associates colleges. An average mean for the total respondents was also computed for each factor. Responses on the difficulty scale of 1-1.5 (nearly impossible) and 1.51-2.5 (very difficult) were used to identify institutional factors that facilitate peer tutoring. 
Table 46

Mean Scores for Differences in Perception of Faculty Factors that Form Barriers to Peer Tutoring Based on Carnegie Classification

\begin{tabular}{|c|c|c|c|c|}
\hline \multirow{2}{*}{$\begin{array}{c}\text { Carnegie } \\
\text { Classification } \\
\end{array}$} & \multicolumn{4}{|c|}{ Factor } \\
\hline & $\begin{array}{l}1 . \text { There is a } \\
\text { shared vision of } \\
\text { peer tutoring } \\
\text { among } \\
\text { departments. }\end{array}$ & $\begin{array}{l}\text { 2. Faculty and } \\
\text { administrators } \\
\text { collaborate on peer } \\
\text { tutoring to plan } \\
\text { programs. }\end{array}$ & $\begin{array}{l}\text { 3. Faculty and } \\
\text { administrators } \\
\text { collaborate on peer } \\
\text { tutoring to implement } \\
\text { programs. }\end{array}$ & $\begin{array}{l}\text { 4. Faculty and } \\
\text { administrators } \\
\text { collaborate on peer } \\
\text { tutoring to decide } \\
\text { the program } \\
\text { budget. }\end{array}$ \\
\hline $\begin{array}{l}\text { Research University } \\
\text { Very High Research } \\
(\mathrm{n}=26)\end{array}$ & 1.88 & 2.12 & 2.23 & 2.00 \\
\hline $\begin{array}{l}\text { Research University } \\
\text { High Research }(n=20)\end{array}$ & 2.10 & 2.05 & 2.10 & 2.05 \\
\hline $\begin{array}{l}\text { Doctoral Research } \\
\text { University }(n=20)\end{array}$ & 2.15 & 2.35 & 2.45 & 2.40 \\
\hline $\begin{array}{l}\text { Masters Colleges and } \\
\text { Universities, Larger } \\
\text { Programs }(n=14)\end{array}$ & 2.14 & 2.36 & 2.07 & 2.36 \\
\hline $\begin{array}{l}\text { Masters Colleges and } \\
\text { Universities, Medium } \\
\text { Programs }(\mathrm{n}=25)\end{array}$ & 2.60 & 2.56 & 2.52 & 2.52 \\
\hline $\begin{array}{l}\text { Masters Colleges and } \\
\text { Universities, Smaller } \\
\text { Programs }(n=20)\end{array}$ & 2.35 & 2.15 & 2.15 & 2.15 \\
\hline $\begin{array}{l}\text { Baccalaureate } \\
\text { Colleges }(n=22)\end{array}$ & 2.41 & 2.50 & 2.55 & 2.55 \\
\hline $\begin{array}{l}\text { Associates Colleges } \\
(\mathrm{n}=20)\end{array}$ & 2.40 & 2,40 & 2.35 & 2.40 \\
\hline $\begin{array}{l}\text { Total Average } \\
(\mathrm{n}=167)\end{array}$ & 2.26 & 2.31 & 2.32 & 2.30 \\
\hline
\end{tabular}


Table 46 (Cont.)

Mean Scores for Differences in Perception of Faculty Factors that Form Barriers to Peer Tutoring Based on Carnegie Classification

\begin{tabular}{|c|c|c|c|c|}
\hline Carnegie & \multicolumn{4}{|c|}{ Factor } \\
\hline & $\begin{array}{l}\text { 5. Faculty and } \\
\text { administrators } \\
\text { collaborate on } \\
\text { peer tutoring to } \\
\text { access program } \\
\text { effectiveness. }\end{array}$ & $\begin{array}{l}\text { 6. Ongoing staff } \\
\text { development on } \\
\text { peer tutoring best } \\
\text { practices is in } \\
\text { place. }\end{array}$ & $\begin{array}{l}\text { 7. Professional } \\
\text { incentives to } \\
\text { participate in peer } \\
\text { tutoring programs are } \\
\text { available (i.e. credit } \\
\text { towards promotion } \\
\text { and tenure, flexibility } \\
\text { in time teaching). }\end{array}$ & $\begin{array}{l}\text { 8. Financial } \\
\text { incentives to } \\
\text { participate in peer } \\
\text { tutoring are } \\
\text { available (i.e. merit } \\
\text { pay, grants for } \\
\text { future research, } \\
\text { new computer). }\end{array}$ \\
\hline $\begin{array}{l}\text { Research University, } \\
\text { Very High Research } \\
(\mathrm{n}=26)\end{array}$ & 2.20 & 2.65 & 1.77 & $2 . .00$ \\
\hline $\begin{array}{l}\text { Research University, } \\
\text { High Research }(\mathrm{n}=20)\end{array}$ & 2.25 & 2.85 & 2.00 & 2.30 \\
\hline $\begin{array}{l}\text { Doctoral Research } \\
\text { University }(n=20)\end{array}$ & 2.50 & 3.05 & 2.05 & 1.90 \\
\hline $\begin{array}{l}\text { Masters Colleges and } \\
\text { Universities, Larger } \\
\text { Programs }(n=14)\end{array}$ & 2.29 & 2.43 & 2.43 & 2.00 \\
\hline $\begin{array}{l}\text { Masters Colleges and } \\
\text { Universities, Medium } \\
\text { Programs }(n=25)\end{array}$ & 2.48 & 3.00 & 2.12 & 2.40 \\
\hline $\begin{array}{l}\text { Masters Colleges and } \\
\text { Universities, Smaller } \\
\text { Programs }(n=20)\end{array}$ & 2.30 & 3.05 & 2.05 & 1.95 \\
\hline $\begin{array}{l}\text { Baccalaureate } \\
\text { Colleges }(n=22)\end{array}$ & 2.50 & 2.59 & 2.18 & 2.18 \\
\hline $\begin{array}{l}\text { Associates Colleges } \\
(\mathrm{n}=20)\end{array}$ & 2.50 & 2.55 & 2.20 & 2.30 \\
\hline $\begin{array}{l}\text { Total Average } \\
(\mathrm{n}=167)\end{array}$ & 2.38 & 2.78 & 2.08 & 2.14 \\
\hline
\end{tabular}


Table 46 (Cont.)

Mean Scores for Differences in Perception of Faculty Factors that Form Barriers to Peer Tutoring Based on Carnegie Classification

\begin{tabular}{|c|c|c|c|c|}
\hline Carnegie & \multicolumn{4}{|c|}{ Factor } \\
\hline & $\begin{array}{l}\text { 9. Communication } \\
\text { between faculty } \\
\text { and students } \\
\text { encourages } \\
\text { student } \\
\text { engagement. }\end{array}$ & $\begin{array}{l}\text { 10. Communication } \\
\text { between faculty } \\
\text { and students } \\
\text { supports different } \\
\text { teaching styles. }\end{array}$ & $\begin{array}{l}\text { 11. Communication } \\
\text { between faculty } \\
\text { and students } \\
\text { supports different } \\
\text { learning styles }\end{array}$ & $\begin{array}{l}\text { 12. Peer tutoring } \\
\text { practices are } \\
\text { oriented toward } \\
\text { developing a } \\
\text { climate in which } \\
\text { students' } \\
\text { responsibility and } \\
\text { active participation } \\
\text { are promoted. }\end{array}$ \\
\hline $\begin{array}{l}\text { Research University, } \\
\text { Very High Research } \\
(\mathrm{n}=26)\end{array}$ & 2.88 & 2.50 & 2.38 & 2.65 \\
\hline $\begin{array}{l}\text { Research University, } \\
\text { High Research }(n=20)\end{array}$ & 3.00 & 2.65 & 2.60 & 2.80 \\
\hline $\begin{array}{l}\text { Doctoral Research } \\
\text { University }(n=20)\end{array}$ & 2.65 & 2.35 & 2.40 & 2.65 \\
\hline $\begin{array}{l}\text { Masters Colleges and } \\
\text { Universities, Larger } \\
\text { Programs }(n=14)\end{array}$ & 2.71 & 2.71 & 2.57 & 2.50 \\
\hline $\begin{array}{l}\text { Masters Colleges and } \\
\text { Universities, Medium } \\
\text { Programs }(n=25)\end{array}$ & 3.08 & 2.80 & 2.76 & 2.96 \\
\hline $\begin{array}{l}\text { Masters Colleges and } \\
\text { Universities, Smaller } \\
\text { Programs }(n=20)\end{array}$ & 2,85 & 2.45 & 2.45 & 2.45 \\
\hline $\begin{array}{l}\text { Baccalaureate } \\
\text { Colleges }(n=22)\end{array}$ & 2.68 & 2.59 & 2.59 & 2.77 \\
\hline $\begin{array}{l}\text { Associates Colleges } \\
(\mathrm{n}=20)\end{array}$ & 3.00 & 2.70 & 2.70 & 2.55 \\
\hline $\begin{array}{l}\text { Total Average } \\
(\mathrm{n}=167)\end{array}$ & 2.87 & 2.59 & 2.56 & 2.68 \\
\hline
\end{tabular}

As indicated in Table 46, there were differences between groups of administrators for eight of the twelve faculty factors based on Carnegie classification. The group with the most differences 
in perceptions (four) was masters colleges and universities, medium programs $(n=25)$ followed by masters universities and colleges, smaller programs $(n=20)$ with three differences in perceptions. The differences are as follows:

a) Shared Vision. A mean of 2.26 indicates that on average administrators $(n=167)$ felt it would be very difficult to have a shared vision of peer tutoring among departments, while administrators from masters colleges and universities, medium program $(n=25$, mean $=2.60)$ believed a shared vision of peer tutoring among departments would be of minor difficulty.

b) Collaboration - Plan Programs. A mean of 2.31 shows that on average administrators $(n=167)$ thought it would be very difficult for faculty and administrators to collaborate on peer tutoring to plan programs, while administrators from masters colleges and universities, medium program $(n=25$, mean=2.56) felt it would be of minor difficulty.

c) Collaboration - Implement Programs. A mean of 2.32 indicates that on average administrators $(n=167)$ believed it would be very difficult for faculty and administrators to collaborate on peer tutoring to implement programs, while administrators from masters colleges and universities, medium program $(n=25$, mean=2.52) and baccalaureate colleges $(n=22$, mean=2.55) felt it would be of minor difficulty.

d) Collaboration - Decide Program Budget. A mean of 2.30 shows that on average administrators $(n=167)$ thought it would be very difficult for faculty and administrators to collaborate on peer tutoring to decide the program budget, while administrators from masters colleges and universities, medium program $(n=25$, mean=2.52) and baccalaureate colleges $(n=22$, mean $=2.55)$ felt it would be of minor difficulty.

e) Staff Development. A mean of on 2.78 indicates that on average administrators $(n=167)$ believed that it would be of minor difficulty to provide ongoing staff development on 
peer tutoring best practices, while administrators at masters colleges and universities, larger programs $9 \mathrm{n}=14$, mean $=2.43$ ) thought it would be very difficult.

f) Communication - Supports Different Teaching Styles. A mean of 2.59 shows that on average administrators $(n=167)$ thought it would be of minor difficulty for communication between faculty and students to support different teaching styles. However, administrators from doctoral research universities $(n=20$, mean=2.35) and masters colleges and universities, smaller programs $(n=20$, mean $=2.45)$ believed it would be very difficult for communication between faculty and students to support different teaching styles.

g) Communication -Supports Different Learning Styles. A mean of 2.56 indicates that on average administrators $(n=167)$ thought communication between faculty and students that supports different learning styles would be of minor difficulty. However, administrators from research universities, very high research $(n=26$, mean=2.38); doctoral research universities $(n=20$, mean $=2.40)$; and masters colleges and universities, smaller programs $(n=20$, mean=2.45) felt it would be very difficult.

h) Responsibility. A mean of 2.68 shows that on average administrators believed it would be of minor difficulty to have peer tutoring practices that are oriented towards developing a climate in which students' responsibility and active participation are promoted. However, administrators at masters colleges and universities, smaller programs $(n=20$, mean=2.45) felt it would be very difficult to develop a climate in which students' responsibility and active participation are promoted. 


\section{Findings}

\section{Factors that facilitate peer tutoring.}

Department affiliation. A one-way between groups analysis of variance (ANOVA) was conducted to compare the differences of the means for all factors that facilitate peer tutoring based on the following department affiliations: a) Academic Affairs, b) Student Affairs, and c) both (administrators who are in both Academic Affairs and Student Affairs). Table 47 illustrates the findings of the ANOVA. The probability that there was a significant difference in perception between groups was set at $\mathrm{p}<.05$, which "indicates the probability of getting a mean difference between the groups is as high as what is observed by chance. The lower the p-value, the more significant the difference between the groups" (Statistical Analysis (1-way ANOVA)," 2003, p. 4).

Table 47

One-way ANOVA for Differences in Perception of Administrative Factors that Facilitate Peer Tutoring Based on Department Affiliation

\begin{tabular}{|ll|r|r|r|r|r|}
\hline $\begin{array}{l}\text { Demographic Category } \\
\text { (Dependent Variable) }\end{array}$ & $\begin{array}{c}\text { Sum of } \\
\text { Squares }\end{array}$ & df & $\begin{array}{c}\text { Mean } \\
\text { Square }\end{array}$ & $F$ & \multicolumn{1}{c|}{$\begin{array}{c}\text { Sig. } \\
(\mathrm{p})\end{array}$} \\
\hline Department Affiliation & Between Groups & .786 & 2 & .393 & 1.558 & .214 \\
& $\begin{array}{l}\text { Within Groups } \\
\text { Total }\end{array}$ & 37.853 & 150 & .252 & & \\
\hline
\end{tabular}

As indicated in Table 47, there was not a significant difference in the perception of factors that facilitate peer tutoring between groups based on department affiliation at the $\mathrm{p}<.05$ level $[F(2$, $150)=1.558, \mathrm{p}=.214]$

A post hoc test, the Bonferroni correction, also confirmed the results of the ANOVA. Table 48 illustrates the findings of the Bonferroni correction. The probability that there was a significant difference in perception between groups was set at $\mathrm{p}<.05$. 
Table 48

Bonferroni Correction for Differences in Perception of Administrative Factors that Facilitate Peer Tutoring Based on Department Affiliation

\begin{tabular}{|lll|r|r|r|}
\hline $\begin{array}{l}\text { Dependent } \\
\text { Variable }\end{array}$ & (I) Affiliation & (J) Affiliation & $\begin{array}{c}\text { Mean } \\
\text { Difference } \\
(\mathrm{I}-\mathrm{J})\end{array}$ & \multicolumn{1}{c|}{$\begin{array}{c}\text { Std. } \\
\text { Error }\end{array}$} & \multicolumn{1}{c|}{$\begin{array}{c}\text { Sig. } \\
(\mathrm{p})\end{array}$} \\
\hline $\begin{array}{l}\text { Importance } \\
\text { Mean }\end{array}$ & Student Affairs & Academic Affairs & .118 & .094 & .627 \\
& & $\begin{array}{l}\text { Both Academic and } \\
\text { Student Affairs }\end{array}$ & -.051 & .115 & 1.000 \\
\cline { 2 - 6 } & Academic Affairs & Student Affairs & -.118 & .094 & .627 \\
& Both Academic and & -.169 & .106 & .340 \\
& Student Affairs & & .051 & .115 & 1.000 \\
& Both Academic and & Student Affairs & .169 & .106 & .340 \\
\hline
\end{tabular}

As illustrated in Table 48, there was not a significant difference in the perception of factors that facilitate peer tutoring between groups based on department affiliation.

Enrollment. A one-way between groups analysis of variance (ANOVA) was conducted to compare the differences of the means for all factors that facilitate peer tutoring based on the following enrollment: a) less than 5000, b) 5,000 - 10,000, c) 10,001 - 20,000, or d) over 20,000. Table 49 illustrates the findings of the ANOVA. The probability that there was a significant difference in perception between groups was set at $\mathrm{p}<.05$.

Table 49

One-way ANOVA for Differences in Perception of Administrative Factors that Facilitate Peer Tutoring Based on Enrollment

\begin{tabular}{|ll|r|r|r|r|c|}
\hline $\begin{array}{l}\text { Demographic Category } \\
\text { (Dependent Variable) }\end{array}$ & $\begin{array}{c}\text { Sum of } \\
\text { Squares }\end{array}$ & df & $\begin{array}{c}\text { Mean } \\
\text { Square }\end{array}$ & $F$ & \multicolumn{1}{c|}{$\begin{array}{c}\text { Sig. } \\
(\mathrm{p})\end{array}$} \\
\hline Enrollment & Between Groups & .450 & 3 & .150 & .582 & .628 \\
& $\begin{array}{l}\text { Within Groups } \\
\text { Total }\end{array}$ & 41.737 & 162 & .258 & & \\
\hline
\end{tabular}


As indicated in Table 49, there was not a significant difference in the perception of factors that facilitate peer tutoring between groups based on enrollment at the $\mathrm{p}<.05$ level $[F(3,162)=$ $.582, \mathrm{p}=.628]$

A post hoc test, the Bonferroni correction, also confirmed the results of the ANOVA. Table 50 illustrates the findings of the Bonferroni correction. The probability that there was a significant difference in perception between groups was set at $\mathrm{p}<.05$.

Table 50

Bonferroni Correction for Differences in Perception of Administrative Factors that Facilitate Peer Tutoring Based on Enrollment

\begin{tabular}{|c|c|c|c|c|c|c|}
\hline Position & $\begin{array}{l}\text { Dependent } \\
\text { Variable }\end{array}$ & (I) Enrollment & $(\mathrm{J})$ Enrollment & $\begin{array}{c}\text { Mean } \\
\text { Difference } \\
(\mathrm{I}-\mathrm{J})\end{array}$ & $\begin{array}{l}\text { Std. } \\
\text { Error }\end{array}$ & $\begin{array}{l}\text { Sig. } \\
\text { (p) }\end{array}$ \\
\hline & \multirow{12}{*}{ Importance Mean } & \multirow[t]{3}{*}{ Under 5,000 } & $5,000-10,000$ & .054 & .110 & 1.000 \\
\hline & & & $10,001-20,000$ & -.105 & .106 & 1.000 \\
\hline & & & Over 20,000 & -.016 & .107 & 1.000 \\
\hline & & \multirow[t]{3}{*}{$5,000-10,000$} & Under 5,000 & -.054 & .110 & 1.000 \\
\hline & & & $10,001-20,000$ & -.159 & .124 & 1.000 \\
\hline & & & Over 20,000 & -.070 & .125 & 1.000 \\
\hline & & \multirow[t]{3}{*}{$10,001-20,000$} & Under 5,000 & .105 & .106 & 1.000 \\
\hline & & & $5,000-10,000$ & .159 & .124 & 1.000 \\
\hline & & & Over 20,000 & .089 & .122 & 1.000 \\
\hline & & \multirow[t]{3}{*}{ Over 20,000} & Under 5,000 & .016 & .107 & 1.000 \\
\hline & & & $5,000-10,000$ & .070 & .125 & 1.000 \\
\hline & & & $10,001-20,000$ & -.089 & .122 & 1.000 \\
\hline
\end{tabular}

As illustrated in Table 50, there was not a significant difference in the perception of factors that facilitate peer tutoring between groups based on enrollment.

Highest degree awarded. A one-way between groups analysis of variance (ANOVA) was conducted to compare the differences of the means for all factors that facilitate peer tutoring based on the following degrees awarded: a) associates, b) bachelors, c) masters, d) doctorate, and 
e) professional. Table 51 illustrates the findings of the ANOVA. The probability that there was a significant difference in perception between groups was set at $\mathrm{p}<.05$.

Table 51

One-way ANOVA for Differences in Perception of Administrative Factors that Facilitate Peer Tutoring Based on Highest Degree Awarded

\begin{tabular}{|ll|r|r|r|r|r|}
\hline $\begin{array}{l}\text { Demographic Category } \\
\text { (Dependent Variable) }\end{array}$ & $\begin{array}{c}\text { Sum of } \\
\text { Squares }\end{array}$ & df & $\begin{array}{c}\text { Mean } \\
\text { Square }\end{array}$ & $F$ & \multicolumn{1}{c|}{$\begin{array}{c}\text { Sig. } \\
(\mathrm{p})\end{array}$} \\
\hline Degrees Awarded & Between Groups & 1.790 & 4 & .447 & 1.783 & .135 \\
& Within Groups & 40.398 & 161 & .251 & & \\
& Total & 42.187 & 165 & & & \\
\hline
\end{tabular}

As indicated in Table 51, there was not a significant difference in the perception of factors that facilitate peer tutoring between groups based on degrees awarded at the $\mathrm{p}<.05$ level $[\mathrm{F}(4,161)$ $=1.783, \mathrm{p}=.135]$.

A post hoc test, the Bonferroni correction, also confirmed the results of the ANOVA. Table 52 illustrates the findings of the Bonferroni correction. The probability that there was a significant difference in perception between groups was set at $\mathrm{p}<.05$. 
Table 52

Bonferroni Correction for Differences in Perception of Administrative Factors that Facilitate Peer Tutoring Based on Highest Degree Awarded

\begin{tabular}{|c|c|c|c|c|c|}
\hline $\begin{array}{l}\text { Dependent } \\
\text { Variable }\end{array}$ & (I) Degree Awarded & $\begin{array}{l}(\mathrm{J}) \text { Degree } \\
\text { Awarded }\end{array}$ & $\begin{array}{c}\text { Mean } \\
\text { Difference } \\
(\mathrm{I}-\mathrm{J})\end{array}$ & $\begin{array}{l}\text { Std. } \\
\text { Error }\end{array}$ & $\begin{array}{l}\text { Sig. } \\
(\mathrm{p})\end{array}$ \\
\hline \multirow{20}{*}{$\begin{array}{l}\text { Importance } \\
\text { Mean }\end{array}$} & \multirow[t]{4}{*}{ Associates } & Bachelors & .351 & .173 & .443 \\
\hline & & Masters & .318 & .144 & .290 \\
\hline & & Doctorate & .195 & .130 & 1.0002 \\
\hline & & $\begin{array}{l}\text { Professional (e.g. } \\
\text { JD, MD, DDS) }\end{array}$ & .112 & .147 & 1.000 \\
\hline & \multirow[t]{4}{*}{ Bachelors } & Associates & -.351 & .173 & .443 \\
\hline & & Masters & -.033 & .156 & 1.000 \\
\hline & & Doctorate & -.155 & .143 & 1.000 \\
\hline & & $\begin{array}{l}\text { Professional (e.g. } \\
\text { JD, MD, DDS) }\end{array}$ & -.238 & .158 & 1.000 \\
\hline & \multirow[t]{4}{*}{ Masters } & Associates & -.318 & .144 & .290 \\
\hline & & Bachelors & .033 & .156 & 1.000 \\
\hline & & Doctorate & -.122 & .106 & 1.000 \\
\hline & & $\begin{array}{l}\text { Professional(e.g. } \\
\text { JD, MD, DDS) }\end{array}$ & -.206 & .126 & 1.000 \\
\hline & \multirow[t]{4}{*}{ Doctorate } & Associates & -.195 & .130 & 1.000 \\
\hline & & Bachelors & .155 & .143 & 1.000 \\
\hline & & Masters & .122 & .106 & 1.000 \\
\hline & & $\begin{array}{l}\text { Professional (e.g. } \\
\text { JD, MD, DDS) }\end{array}$ & -.083 & .110 & 1.000 \\
\hline & \multirow{4}{*}{$\begin{array}{l}\text { Professional } \\
\text { (e.g. JD, MD, DDS) }\end{array}$} & Associates & -.112 & .147 & 1.000 \\
\hline & & Bachelors & .238 & .158 & 1.000 \\
\hline & & Masters & .206 & .126 & 1.000 \\
\hline & & $\begin{array}{l}\text { Doctorate (e.g. } \\
\text { JD, MD, DDS) }\end{array}$ & .083 & .110 & 1.000 \\
\hline
\end{tabular}

As illustrated in Table 52, there was not a significant difference in the perception of factors that facilitate peer tutoring between groups based on degrees awarded. 
Carnegie classification. A one-way between groups analysis of variance (ANOVA) was conducted to compare the differences of the means for all factors that facilitate peer tutoring based on the following Carnegie classifications: a) research university, b) very high research; c) research university, high research; d) doctoral research university; e) masters colleges and universities, larger programs; f) masters colleges and universities, medium programs; g) masters colleges and universities, smaller programs; h) baccalaureate colleges; and i) associates colleges. Table 53 illustrates the findings of the ANOVA. The probability that there was a significant difference in perception between groups was set at $\mathrm{p}<.05$.

Table 53

One-way ANOVA for Differences in Perception of Administrative Factors that Facilitate Peer Tutoring Based on Carnegie Classification.

\begin{tabular}{|ll|r|r|r|r|c|}
\hline $\begin{array}{l}\text { Demographic Category } \\
\text { (Dependent Variable) }\end{array}$ & $\begin{array}{c}\text { Sum of } \\
\text { Squares }\end{array}$ & df & $\begin{array}{c}\text { Mean } \\
\text { Square }\end{array}$ & $F$ & \multicolumn{1}{c|}{$\begin{array}{c}\text { Sig. } \\
(\mathrm{p})\end{array}$} \\
\hline Carnegie Classification Between Groups & 2.685 & 7 & .384 & 1.540 & .157 \\
& $\begin{array}{r}\text { Within Groups } \\
\text { Total }\end{array}$ & $\begin{array}{r}39.598 \\
42.283\end{array}$ & 159 & .249 & & \\
\hline
\end{tabular}

As indicated in Table 53, there was not a significant difference in the perception of factors that facilitate peer tutoring between groups based on Carnegie classification at the $\mathrm{p}<.05$ level [F ( 7 , $159)=1.540, \mathrm{p}=.157]$.

A post hoc test, the Bonferroni correction, also confirmed the results of the ANOVA. Table 54 illustrates the findings of the Bonferroni correction. The probability that there was a significant difference in perception between groups was set at $\mathrm{p}<.05$. 
Table 54

Bonferroni Correction for Differences in Perception of Administrative Factors that Facilitate Peer Tutoring Based on Carnegie Classification

\begin{tabular}{|c|c|c|c|c|c|}
\hline $\begin{array}{l}\text { Dependent } \\
\text { Variable }\end{array}$ & $\begin{array}{l}\text { (I) Carnegie } \\
\text { Classification }\end{array}$ & $\begin{array}{l}\text { (J) Carnegie } \\
\text { Classification }\end{array}$ & $\begin{array}{c}\text { Mean } \\
\text { Difference } \\
(\mathrm{I}-\mathrm{J}) \\
\end{array}$ & $\begin{array}{l}\text { Std. } \\
\text { Error }\end{array}$ & $\begin{array}{l}\text { Sig. } \\
(\mathrm{p})\end{array}$ \\
\hline \multirow[t]{14}{*}{$\begin{array}{l}\text { Importance } \\
\text { Mean }\end{array}$} & \multirow[t]{7}{*}{$\begin{array}{l}\text { Research University } \\
\text { (Very High Research) }\end{array}$} & $\begin{array}{l}\text { Research University } \\
\text { (High Research) }\end{array}$ & .191 & .148 & 1.000 \\
\hline & & $\begin{array}{l}\text { Doctoral Research } \\
\text { University }\end{array}$ & .148 & .148 & 1.000 \\
\hline & & $\begin{array}{l}\text { Masters Colleges and } \\
\text { Universities (Larger } \\
\text { Programs) }\end{array}$ & .187 & .165 & 1.000 \\
\hline & & $\begin{array}{l}\text { Masters Colleges and } \\
\text { Universities (Medium } \\
\text { Programs) }\end{array}$ & .388 & .140 & .172 \\
\hline & & $\begin{array}{l}\text { Masters Colleges and } \\
\text { Universities (Smaller } \\
\text { Programs) }\end{array}$ & .215 & .148 & 1.000 \\
\hline & & Baccalaureate Colleges & .277 & .145 & 1.000 \\
\hline & & Associates Colleges & .021 & .148 & 1.000 \\
\hline & \multirow[t]{7}{*}{$\begin{array}{l}\text { Research University } \\
\text { (High Research) }\end{array}$} & $\begin{array}{l}\text { Research University } \\
\text { (Very High Research) }\end{array}$ & -.190 & .148 & 1.000 \\
\hline & & $\begin{array}{l}\text { Doctoral Research } \\
\text { University }\end{array}$ & -.042 & .158 & 1.000 \\
\hline & & $\begin{array}{l}\text { Masters Colleges and } \\
\text { Universities (Larger } \\
\text { Programs) }\end{array}$ & -.003 & .174 & 1.000 \\
\hline & & $\begin{array}{l}\text { Masters Colleges and } \\
\text { Universities (Medium } \\
\text { Programs) }\end{array}$ & .198 & .150 & 1.000 \\
\hline & & $\begin{array}{l}\text { Masters Colleges and } \\
\text { Universities (Smaller } \\
\text { Programs) }\end{array}$ & .025 & .158 & 1.000 \\
\hline & & Baccalaureate Colleges & .086 & .154 & 1.000 \\
\hline & & Associates Colleges & -.169 & .158 & \\
\hline
\end{tabular}


Table 54 (Cont.)

Bonferroni correction for Differences in Perception of Administrative Factors that Facilitate Peer Tutoring Based on Carnegie Classification

\begin{tabular}{|c|c|c|c|c|c|}
\hline $\begin{array}{l}\text { Dependent } \\
\text { Variable }\end{array}$ & $\begin{array}{l}\text { (I) Carnegie } \\
\text { Classification }\end{array}$ & $\begin{array}{l}\text { (J) Carnegie } \\
\text { Classification }\end{array}$ & $\begin{array}{c}\text { Mean } \\
\text { Difference } \\
(\mathrm{I}-\mathrm{J}) \\
\end{array}$ & $\begin{array}{l}\text { Std. } \\
\text { Error }\end{array}$ & $\begin{array}{l}\text { Sig. } \\
\text { (p) }\end{array}$ \\
\hline \multirow[t]{18}{*}{$\begin{array}{l}\text { Importance } \\
\text { Mean }\end{array}$} & \multirow[t]{7}{*}{$\begin{array}{l}\text { Doctoral Research } \\
\text { University }\end{array}$} & $\begin{array}{l}\text { Research University } \\
\text { (Very High Research) }\end{array}$ & -.148 & .148 & 1.000 \\
\hline & & $\begin{array}{l}\text { Research University } \\
\text { (High Research) }\end{array}$ & .042 & .158 & 1.000 \\
\hline & & $\begin{array}{l}\text { Masters Colleges and } \\
\text { Universities (Larger } \\
\text { Programs) }\end{array}$ & .039 & .174 & 1.000 \\
\hline & & $\begin{array}{l}\text { Masters Colleges and } \\
\text { Universities (Medium } \\
\text { Programs) }\end{array}$ & .240 & .150 & 1.000 \\
\hline & & $\begin{array}{l}\text { Masters Colleges and } \\
\text { Universities (Smaller } \\
\text { Programs) }\end{array}$ & .067 & .158 & 1.000 \\
\hline & & Baccalaureate Colleges & .120 & .154 & 1.000 \\
\hline & & Associates Colleges & -.127 & .158 & 1.000 \\
\hline & \multirow[t]{11}{*}{$\begin{array}{l}\text { Masters Colleges and } \\
\text { Universities (Larger } \\
\text { Programs) }\end{array}$} & $\begin{array}{l}\text { Research University } \\
\text { (Very High Research) }\end{array}$ & -.187 & .165 & 1.000 \\
\hline & & $\begin{array}{l}\text { Research University } \\
\text { (High Research) }\end{array}$ & .003 & .174 & 1.000 \\
\hline & & $\begin{array}{l}\text { Doctoral Research } \\
\text { University }\end{array}$ & -.039 & .174 & 1.000 \\
\hline & & Masters Colleges and & .201 & .167 & 1.000 \\
\hline & & Universities (Medium & & & \\
\hline & & Programs) & & & \\
\hline & & Masters Colleges and & .028 & .174 & 1.000 \\
\hline & & Universities (Smaller & & & \\
\hline & & Programs) & & & \\
\hline & & Baccalaureate Colleges & .090 & .171 & 1.000 \\
\hline & & Associates Colleges & -.166 & .174 & 1.000 \\
\hline
\end{tabular}


Table 54 (Cont.)

Bonferroni correction for Differences in Perception of Administrative Factors that Facilitate Peer Tutoring Based on Carnegie Classification

\begin{tabular}{|c|c|c|c|c|c|}
\hline $\begin{array}{l}\text { Dependent } \\
\text { Variable }\end{array}$ & $\begin{array}{l}\text { (I) Carnegie } \\
\text { Classification }\end{array}$ & $\begin{array}{l}\text { (J) Carnegie } \\
\text { Classification }\end{array}$ & $\begin{array}{c}\text { Mean } \\
\text { Difference } \\
(\mathrm{I}-\mathrm{J}) \\
\end{array}$ & $\begin{array}{l}\text { Std. } \\
\text { Error }\end{array}$ & $\begin{array}{l}\text { Sig. } \\
\text { (p) }\end{array}$ \\
\hline \multirow[t]{24}{*}{$\begin{array}{l}\text { Importance } \\
\text { Mean }\end{array}$} & \multirow{12}{*}{$\begin{array}{l}\text { Masters Colleges and } \\
\text { Universities (Medium } \\
\text { Programs) }\end{array}$} & $\begin{array}{l}\text { Research University } \\
\text { (Very High Research) }\end{array}$ & -.388 & .140 & .172 \\
\hline & & $\begin{array}{l}\text { Research University } \\
\text { (High Research) }\end{array}$ & -.198 & .150 & 1.000 \\
\hline & & Doctoral Research & -.240 & .150 & 1.000 \\
\hline & & University & & & \\
\hline & & Masters Colleges and & -.201 & .167 & 1.000 \\
\hline & & Universities (Larger & & & \\
\hline & & Programs) & & & \\
\hline & & Masters Colleges and & -.173 & .150 & 1.000 \\
\hline & & Universities (Smaller & & & \\
\hline & & Programs) & & & \\
\hline & & Baccalaureate Colleges & -.111 & .146 & 1.000 \\
\hline & & Associates Colleges & -.367 & .150 & .429 \\
\hline & \multirow[t]{12}{*}{$\begin{array}{l}\text { Masters Colleges and } \\
\text { Universities (Smaller } \\
\text { Programs) }\end{array}$} & $\begin{array}{l}\text { Research University } \\
\text { (Very High Research) }\end{array}$ & -.216 & .148 & 1.000 \\
\hline & & $\begin{array}{l}\text { Research University } \\
\text { (High Research) }\end{array}$ & -.025 & .158 & 1.000 \\
\hline & & Doctoral Research & -.067 & .158 & 1.000 \\
\hline & & University & & & \\
\hline & & Masters Colleges and & -.028 & .174 & 1.000 \\
\hline & & Universities (Larger & & & \\
\hline & & Programs) & & & \\
\hline & & Masters Colleges and & .173 & .150 & 1.000 \\
\hline & & Universities (Medium & & & \\
\hline & & Programs) & & & \\
\hline & & Baccalaureate Colleges & .061 & .154 & 1.000 \\
\hline & & Associates Colleges & -.194 & .158 & 1.000 \\
\hline
\end{tabular}


Table 54 (Cont.)

Bonferroni correction for Differences in Perception of Administrative Factors that Facilitate Peer Tutoring Based on Carnegie Classification

\begin{tabular}{|c|c|c|c|c|c|}
\hline $\begin{array}{l}\text { Dependent } \\
\text { Variable }\end{array}$ & $\begin{array}{l}\text { (I) Carnegie } \\
\text { Classification }\end{array}$ & $\begin{array}{l}\text { (J) Carnegie } \\
\text { Classification }\end{array}$ & $\begin{array}{c}\text { Mean } \\
\text { Difference } \\
(\mathrm{I}-\mathrm{J}) \\
\end{array}$ & $\begin{array}{l}\text { Std. } \\
\text { Error }\end{array}$ & $\begin{array}{l}\text { Sig. } \\
\text { (p) }\end{array}$ \\
\hline \multirow[t]{14}{*}{$\begin{array}{l}\text { Importance } \\
\text { Mean }\end{array}$} & \multirow[t]{7}{*}{ Baccalaureate Colleges } & $\begin{array}{l}\text { Research University } \\
\text { (Very High Research) }\end{array}$ & -.277 & .145 & 1.000 \\
\hline & & $\begin{array}{l}\text { Research University } \\
\text { (High Research) }\end{array}$ & -.086 & .154 & 1.000 \\
\hline & & $\begin{array}{l}\text { Doctoral Research } \\
\text { University }\end{array}$ & -.129 & .154 & 1.000 \\
\hline & & $\begin{array}{l}\text { Masters Colleges and } \\
\text { Universities (Larger } \\
\text { Programs) }\end{array}$ & -.090 & .171 & 1.000 \\
\hline & & $\begin{array}{l}\text { Masters Colleges and } \\
\text { Universities (Medium } \\
\text { Programs) }\end{array}$ & .111 & .146 & 1.000 \\
\hline & & $\begin{array}{l}\text { Masters Colleges and } \\
\text { Universities (Smaller } \\
\text { Programs) }\end{array}$ & -.061 & .154 & 1.000 \\
\hline & & Associates Colleges & -.256 & .154 & 1.000 \\
\hline & \multirow[t]{7}{*}{ Associates Colleges } & $\begin{array}{l}\text { Research University } \\
\text { (Very High Research) }\end{array}$ & -.021 & .148 & 1.000 \\
\hline & & $\begin{array}{l}\text { Research University } \\
\text { (High Research) }\end{array}$ & .169 & .158 & 1.000 \\
\hline & & $\begin{array}{l}\text { Doctoral Research } \\
\text { University }\end{array}$ & .127 & .158 & 1.000 \\
\hline & & $\begin{array}{l}\text { Masters Colleges and } \\
\text { Universities (Larger } \\
\text { Programs) }\end{array}$ & .166 & .174 & 1.000 \\
\hline & & $\begin{array}{l}\text { Masters Colleges and } \\
\text { Universities (Medium } \\
\text { Programs) }\end{array}$ & .367 & .150 & .429 \\
\hline & & $\begin{array}{l}\text { Masters Colleges and } \\
\text { Universities (Smaller } \\
\text { Programs) }\end{array}$ & .194 & .158 & 1.000 \\
\hline & & Baccalaureate Colleges & .256 & .154 & 1.000 \\
\hline
\end{tabular}


As illustrated in Table 54, there was not a significant difference in the perception of factors that facilitate peer tutoring between groups based on Carnegie classification.

\section{Factors that form barriers to peer tutoring.}

Department affiliation. A one-way between groups analysis of variance (ANOVA) was conducted to compare the differences of the means for all factors that form barriers to peer tutoring based on the following department affiliations: a) Academic Affairs, b) Student Affairs, and c) both (administrators who are in both Academic Affairs and Student Affairs). Table 55 illustrates the findings of the ANOVA. The probability that there was a significant difference in perception between groups was set at $\mathrm{p}<.05$, which "indicates the probability of getting a mean difference between the groups is as high as what is observed by chance. The lower the p-value, the more significant the difference between the groups" (Statistical Analysis (1-way ANOVA)," 2003, p. 4).

Table 55

One-way ANOVA for Differences in Perception of Administrative Factors that Form Barriers to Peer Tutoring Based on Department Affiliation

\begin{tabular}{|ll|r|r|r|r|c|}
\hline $\begin{array}{l}\text { Demographic Category } \\
\text { (Dependent Variable) }\end{array}$ & $\begin{array}{c}\text { Sum of } \\
\text { Squares }\end{array}$ & df & $\begin{array}{c}\text { Mean } \\
\text { Square }\end{array}$ & $F$ & \multicolumn{1}{c|}{$\begin{array}{c}\text { Sig. } \\
(\mathrm{p})\end{array}$} \\
\hline Department Affiliation & Between Groups & .254 & 2 & .127 & .618 & .540 \\
& $\begin{array}{l}\text { Within Groups } \\
\text { Total }\end{array}$ & 30.777 & 150 & .205 & & \\
\hline
\end{tabular}

As indicated in Table 55, there was not a significant difference in the perception of factors that

form barriers to peer tutoring between groups based on department affiliation at the $\mathrm{p}<.05$ level $[\mathrm{F}(2,150)=.618, \mathrm{p}=.540]$

A post hoc test, the Bonferroni correction, also confirmed the results of the ANOVA.

Table 56 illustrates the findings of the Bonferroni correction. The probability that there was a significant difference in perception between groups was set at $\mathrm{p}<.05$. 
Table 56

Bonferroni Correction for Differences in Perception of Administrative Factors that Form Barriers to Peer Tutoring Based on Department Affiliation

\begin{tabular}{|c|c|c|c|c|c|}
\hline $\begin{array}{l}\text { Dependent } \\
\text { Variable }\end{array}$ & (I) Affiliation & (J) Affiliation & $\begin{array}{c}\text { Mean } \\
\text { Difference } \\
(\mathrm{I}-\mathrm{J})\end{array}$ & $\begin{array}{l}\text { Std. } \\
\text { Error }\end{array}$ & $\begin{array}{l}\text { Sig. } \\
\text { (p) }\end{array}$ \\
\hline \multirow{6}{*}{$\begin{array}{l}\text { Difficulty } \\
\text { Mean }\end{array}$} & \multirow[t]{2}{*}{ Student Affairs } & Academic Affairs & -.078 & .084 & 1.000 \\
\hline & & $\begin{array}{l}\text { Both Academic and } \\
\text { Student Affairs }\end{array}$ & .008 & .104 & 1.000 \\
\hline & \multirow[t]{2}{*}{ Academic Affairs } & Student Affairs & .078 & .084 & 1.000 \\
\hline & & $\begin{array}{l}\text { Both Academic and } \\
\text { Student Affairs }\end{array}$ & .086 & .096 & 1.000 \\
\hline & \multirow{2}{*}{$\begin{array}{l}\text { Both Academic and } \\
\text { Student Affairs }\end{array}$} & Student Affairs & -.008 & .104 & 1.000 \\
\hline & & Academic Affairs & -.086 & .096 & 1.000 \\
\hline
\end{tabular}

As indicated in Table 56, there was not a significant difference in the perception of factors that form barriers to peer tutoring between groups based on department affiliation.

Enrollment. A one-way between groups analysis of variance (ANOVA) was conducted to compare the differences of the means for all factors that form barriers to peer tutoring based on the following enrollment: a) less than 5000, b) 5,000-10,000, c) 10,001-20,000, or d) over 20,000. Table 57 illustrates the findings of the ANOVA. The probability that there was a significant difference in perception between groups was set at $\mathrm{p}<.05$.

Table 57

One-way ANOVA for Differences in Perception of Administrative Factors that Form Barriers to Peer Tutoring Based on Enrollment

\begin{tabular}{|ll|r|r|r|r|c|}
\hline $\begin{array}{l}\text { Demographic Category } \\
\text { (Dependent Variable) }\end{array}$ & $\begin{array}{c}\text { Sum of } \\
\text { Squares }\end{array}$ & df & $\begin{array}{c}\text { Mean } \\
\text { Square }\end{array}$ & $F$ & \multicolumn{1}{c|}{$\begin{array}{c}\text { Sig. } \\
(\mathrm{p})\end{array}$} \\
\hline Enrollment & Between Groups & 2.992 & 3 & .997 & 5.448 & .001 \\
& Within Groups & 29.656 & 162 & .183 & & \\
& Total & 32.647 & 165 & & & \\
\hline
\end{tabular}


As indicated in Table 57, there was a significant difference in the perception of factors that form barriers to peer tutoring between groups based on enrollment at the $\mathrm{p}<.05$ level $[F(3,162)=$ $5.448, \mathrm{p}=.001]$.

A post hoc test, the Bonferroni correction, also confirmed the results of the ANOVA.

Table 58 illustrates the findings of the Bonferroni correction. The probability that there was a significant difference in perception between groups was set at $\mathrm{p}<.05$.

Table 58

Bonferroni Correction for Differences in Perception of Administrative Factors that Form Barriers to Peer Tutoring Based on Enrollment

\begin{tabular}{|lll|r|r|r|}
\hline $\begin{array}{l}\text { Dependent } \\
\text { Variable }\end{array}$ & (I) Enrollment & (J) Enrollment & $\begin{array}{c}\text { Mean } \\
\text { Difference } \\
\text { (I-J) }\end{array}$ & \multicolumn{1}{c|}{$\begin{array}{c}\text { Std. } \\
\text { Error }\end{array}$} & \multicolumn{1}{c|}{$\begin{array}{c}\text { Sig. } \\
\text { (p) }\end{array}$} \\
\hline Difficulty Mean & Under 5,000 & $5,000-10,000$ & .016 & .092 & 1.000 \\
& & $10,001-20,000$ & .199 & .090 & .170 \\
& & Over 20,000 & .330 & .091 & .002 \\
\cline { 2 - 6 } & $5,000-10,000$ & Under 5,000 & -.016 & .092 & 1.000 \\
& & $10,001-20,000$ & .183 & .105 & .495 \\
& & Over 20,000 & .314 & .105 & .020 \\
\cline { 2 - 6 } & & Under 5,000 & -.199 & .090 & .170 \\
& & $5,000-10,000$ & -.183 & .105 & .495 \\
& & Over 20,000 & .132 & .103 & 1.000 \\
\cline { 2 - 6 } & Over 20,000 & Under 5,000 & -.330 & .091 & .002 \\
& & $5,000-10,000$ & -.314 & .105 & .020 \\
& & $10,001-20,000$ & -.132 & .103 & 1.000 \\
\hline
\end{tabular}

As indicated in Table 58, there was a significant difference based on enrollment between the following groups: a) over 20,000 and under 5,000 ( $\mathrm{p}=.002)$ and $\mathrm{b}$ ) over 20,000 and 5,000$10,000(\mathrm{p}=.020)$.

Highest degree awarded. A one-way between groups analysis of variance (ANOVA) was conducted to compare the differences of the means for all factors that form barriers to peer 
tutoring based on the following degrees awarded: a) associates, b) bachelors, c) masters, d) doctorate, and e) professional. Table 59 illustrates the findings of the ANOVA. The probability that there was a significant difference in perception between groups was set at $\mathrm{p}<.05$.

Table 59

One-way ANOVA for Differences in Perception of Administrative Factors that Form Barriers to Peer Tutoring Based on Highest Degree Awarded

\begin{tabular}{|ll|r|r|r|r|c|}
\hline $\begin{array}{l}\text { Demographic Category } \\
\text { (Dependent Variable) }\end{array}$ & $\begin{array}{c}\text { Sum of } \\
\text { Squares }\end{array}$ & df & $\begin{array}{c}\text { Mean } \\
\text { Square }\end{array}$ & $F$ & \multicolumn{1}{c|}{$\begin{array}{c}\text { Sig. } \\
(\mathrm{p})\end{array}$} \\
\hline Degrees Awarded & Between Groups & .889 & 4 & .222 & 1.137 & 1.137 \\
& Within Groups & 31.445 & 161 & .195 & & \\
& Total & 32.333 & 165 & & & \\
\hline
\end{tabular}

As indicated in Table 59, there was a not significant difference in the perception of factors that form barriers to peer tutoring between groups based on the highest degree awarded at the $\mathrm{p}<.05$ level $[\mathrm{F}(4,161)=1.137, \mathrm{p}=1.137]$.

A post hoc test, the Bonferroni correction, also confirmed the results of the ANOVA. Table 60 illustrates the findings of the Bonferroni correction. The probability that there was a significant difference in perception between groups was set at $\mathrm{p}<.05$. 
Table 60

Bonferroni Correction for Differences in Perception of Administrative Factors that Form Barriers to Peer Tutoring Based on Degrees Awarded

\begin{tabular}{|c|c|c|c|c|c|}
\hline $\begin{array}{l}\text { Dependent } \\
\text { Variable }\end{array}$ & (I) Degree Awarded & $\begin{array}{l}(\mathrm{J}) \text { Degree } \\
\text { Awarded }\end{array}$ & $\begin{array}{c}\text { Mean } \\
\text { Difference } \\
(\mathrm{I}-\mathrm{J})\end{array}$ & $\begin{array}{l}\text { Std. } \\
\text { Error }\end{array}$ & $\begin{array}{l}\text { Sig. } \\
(\mathrm{p})\end{array}$ \\
\hline \multirow{20}{*}{$\begin{array}{l}\text { Difficulty } \\
\text { Mean }\end{array}$} & \multirow[t]{4}{*}{ Associates } & Bachelors & .026 & .153 & 1.000 \\
\hline & & Masters & .027 & .127 & 1.000 \\
\hline & & Doctorate & .062 & .115 & 1.000 \\
\hline & & $\begin{array}{l}\text { Professional (e.g. } \\
\text { JD, MD, DDS) }\end{array}$ & .223 & .130 & .869 \\
\hline & \multirow[t]{4}{*}{ Bachelors } & Associates & -.026 & .153 & 1.000 \\
\hline & & Masters & .001 & .138 & 1.000 \\
\hline & & Doctorate & .037 & .126 & 1.000 \\
\hline & & $\begin{array}{l}\text { Professional (e.g. } \\
\text { JD, MD, DDS) }\end{array}$ & .197 & .140 & 1.000 \\
\hline & \multirow[t]{4}{*}{ Masters } & Associates & -.027 & .127 & 1.000 \\
\hline & & Bachelors & -.001 & .138 & 1.000 \\
\hline & & Doctorate & .035 & .094 & 1.000 \\
\hline & & $\begin{array}{l}\text { Professional(e.g. } \\
\text { JD, MD, DDS) }\end{array}$ & .196 & .111 & .806 \\
\hline & \multirow[t]{4}{*}{ Doctorate } & Associates & -.062 & .115 & 1.000 \\
\hline & & Bachelors & -.037 & .126 & 1.000 \\
\hline & & Masters & -.035 & .094 & 1.000 \\
\hline & & $\begin{array}{l}\text { Professional (e.g. } \\
\text { JD, MD, DDS) }\end{array}$ & .161 & .097 & .980 \\
\hline & \multirow{4}{*}{$\begin{array}{l}\text { Professional } \\
\text { (e.g. JD, MD, DDS) }\end{array}$} & Associates & -.223 & .130 & 869 \\
\hline & & Bachelors & -.197 & .140 & 1.000 \\
\hline & & Masters & -.196 & .111 & .806 \\
\hline & & Doctorate & -.161 & .097 & .980 \\
\hline
\end{tabular}

As illustrated in Table 60, there was not a significant difference in the perception of factors that form barriers to peer tutoring between groups based on degrees awarded.

Carnegie classification. A one-way between groups analysis of variance (ANOVA) was conducted to compare the differences of the means for all factors that form barriers to peer 
tutoring based on the following Carnegie classifications: a) research university, b) very high research; c) research university, high research; d) doctoral research university; e) masters colleges and universities, larger programs; f) masters colleges and universities, medium programs; g) masters colleges and universities, smaller programs; h) baccalaureate colleges; and i) associates colleges. Table 61 illustrates the findings of the ANOVA. The probability that there was a significant difference in perception between groups was set at $\mathrm{p}<.05$.

Table 61

One-way ANOVA for Differences in Perception of Administrative Factors that Form Barriers to Peer Tutoring Based on Carnegie Classification.

\begin{tabular}{|c|c|c|c|c|c|}
\hline $\begin{array}{l}\text { Demographic Category } \\
\text { (Dependent Variable) }\end{array}$ & $\begin{array}{l}\text { Sum of } \\
\text { Squares }\end{array}$ & $\mathrm{df}$ & $\begin{array}{l}\text { Mean } \\
\text { Square }\end{array}$ & $F$ & $\begin{array}{l}\text { Sig. } \\
\text { (p) }\end{array}$ \\
\hline $\begin{array}{c}\text { Carnegie Classification } \text { Between Groups } \\
\text { Within Groups } \\
\text { Total }\end{array}$ & $\begin{array}{r}1.566 \\
31.164 \\
32.721\end{array}$ & $\begin{array}{r}7 \\
159 \\
166\end{array}$ & $\begin{array}{l}.222 \\
.196\end{array}$ & 1.133 & .345 \\
\hline
\end{tabular}

As indicated in Table 61, there was not a significant difference between groups for the average mean based on Carnegie Classification at the $\mathrm{p}<.05$ level $[\mathrm{F}(7,159)=1.133, \mathrm{p}=.345]$.

A post hoc test, the Bonferroni correction, also confirmed the results of the ANOVA. Table 62 illustrates the findings of the Bonferroni correction. The probability that there was a significant difference in perception between groups was set at $\mathrm{p}<.05$. 
Table 62

Bonferroni Correction for Differences in Perception of Administrative Factors that Form Barriers to Peer Tutoring Based on Carnegie Classification

\begin{tabular}{|c|c|c|c|c|c|}
\hline $\begin{array}{l}\text { Dependent } \\
\text { Variable }\end{array}$ & $\begin{array}{l}\text { (I) Carnegie } \\
\text { Classification }\end{array}$ & $\begin{array}{l}\text { (J) Carnegie } \\
\text { Classification }\end{array}$ & $\begin{array}{c}\text { Mean } \\
\text { Difference } \\
(\mathrm{I}-\mathrm{J})\end{array}$ & $\begin{array}{l}\text { Std. } \\
\text { Error }\end{array}$ & $\begin{array}{l}\text { Sig. } \\
\text { (p) }\end{array}$ \\
\hline \multirow[t]{14}{*}{$\begin{array}{l}\text { Difficulty } \\
\text { Mean }\end{array}$} & \multirow[t]{7}{*}{$\begin{array}{l}\text { Research University } \\
\text { (Very High Research) }\end{array}$} & $\begin{array}{l}\text { Research University } \\
\text { (High Research) }\end{array}$ & -.083 & .132 & 1.000 \\
\hline & & $\begin{array}{l}\text { Doctoral Research } \\
\text { University }\end{array}$ & -.141 & .132 & 1.000 \\
\hline & & $\begin{array}{l}\text { Masters Colleges and } \\
\text { Universities (Larger } \\
\text { Programs) }\end{array}$ & -.139 & .147 & 1,000 \\
\hline & & $\begin{array}{l}\text { Masters Colleges and } \\
\text { Universities (Medium } \\
\text { Programs) }\end{array}$ & -.315 & .124 & .336 \\
\hline & & $\begin{array}{l}\text { Masters Colleges and } \\
\text { Universities (Smaller } \\
\text { Programs) }\end{array}$ & -.124 & .132 & 1.000 \\
\hline & & Baccalaureate Colleges & -.223 & .128 & 1.000 \\
\hline & & Associates Colleges & -.208 & .132 & 1.000 \\
\hline & \multirow[t]{7}{*}{$\begin{array}{l}\text { Research University } \\
\text { (High Research) }\end{array}$} & $\begin{array}{l}\text { Research University } \\
\text { (Very High Research) }\end{array}$ & .083 & .132 & 1.000 \\
\hline & & $\begin{array}{l}\text { Doctoral Research } \\
\text { University }\end{array}$ & -.058 & .140 & 1.000 \\
\hline & & $\begin{array}{l}\text { Masters Colleges and } \\
\text { Universities (Larger } \\
\text { Programs) }\end{array}$ & -.056 & .154 & 1.000 \\
\hline & & $\begin{array}{l}\text { Masters Colleges and } \\
\text { Universities (Medium } \\
\text { Programs) }\end{array}$ & -232 & .131 & 1.000 \\
\hline & & $\begin{array}{l}\text { Masters Colleges and } \\
\text { Universities (Smaller } \\
\text { Programs) }\end{array}$ & -.040 & .140 & 1.000 \\
\hline & & Baccalaureate Colleges & -.140 & .138 & 1.000 \\
\hline & & Associates Colleges & -.125 & .140 & 1.000 \\
\hline
\end{tabular}


Table 62 (Cont.)

Bonferroni correction for Differences in Perception of Administrative Factors that Form Barriers to Peer Tutoring Based on Carnegie Classification

\begin{tabular}{|c|c|c|c|c|c|}
\hline $\begin{array}{l}\text { Dependent } \\
\text { Variable }\end{array}$ & $\begin{array}{l}\text { (I) Carnegie } \\
\text { Classification }\end{array}$ & $\begin{array}{l}\text { (J) Carnegie } \\
\text { Classification } \\
\end{array}$ & $\begin{array}{c}\text { Mean } \\
\text { Difference } \\
(\mathrm{I}-\mathrm{J})\end{array}$ & $\begin{array}{l}\text { Std. } \\
\text { Error }\end{array}$ & $\begin{array}{l}\text { Sig. } \\
(\mathrm{p})\end{array}$ \\
\hline \multirow[t]{14}{*}{$\begin{array}{l}\text { Difficulty } \\
\text { Mean }\end{array}$} & \multirow[t]{7}{*}{$\begin{array}{l}\text { Doctoral Research } \\
\text { University }\end{array}$} & $\begin{array}{l}\text { Research University } \\
\text { (Very High Research) }\end{array}$ & .141 & .132 & 1.000 \\
\hline & & $\begin{array}{l}\text { Research University } \\
\text { (High Research) }\end{array}$ & .058 & .140 & 1.000 \\
\hline & & $\begin{array}{l}\text { Masters Colleges and } \\
\text { Universities (Larger } \\
\text { Programs) }\end{array}$ & .002 & .154 & 1.000 \\
\hline & & $\begin{array}{l}\text { Masters Colleges and } \\
\text { Universities (Medium } \\
\text { Programs) }\end{array}$ & -.174 & .133 & 1.000 \\
\hline & & $\begin{array}{l}\text { Masters Colleges and } \\
\text { Universities (Smaller } \\
\text { Programs) }\end{array}$ & .017 & .140 & 1,000 \\
\hline & & Baccalaureate Colleges & -.082 & .137 & 1.000 \\
\hline & & Associates Colleges & -.067 & .140 & 1.000 \\
\hline & \multirow[t]{7}{*}{$\begin{array}{l}\text { Masters Colleges and } \\
\text { Universities (Larger } \\
\text { Programs) }\end{array}$} & $\begin{array}{l}\text { Research University } \\
\text { (Very High Research) }\end{array}$ & .139 & .147 & 1.000 \\
\hline & & $\begin{array}{l}\text { Research University } \\
\text { (High Research) }\end{array}$ & .056 & .154 & 1.000 \\
\hline & & $\begin{array}{l}\text { Doctoral Research } \\
\text { University }\end{array}$ & -.002 & .154 & 1.000 \\
\hline & & $\begin{array}{l}\text { Masters Colleges and } \\
\text { Universities (Medium } \\
\text { Programs) }\end{array}$ & -.176 & .148 & 1.000 \\
\hline & & $\begin{array}{l}\text { Masters Colleges and } \\
\text { Universities (Smaller } \\
\text { Programs) }\end{array}$ & .015 & .154 & 1.000 \\
\hline & & Baccalaureate Colleges & -.084 & .151 & 1.000 \\
\hline & & Associates Colleges & -.069 & .154 & 1.000 \\
\hline
\end{tabular}


Table 62 (Cont.)

Bonferroni correction for Differences in Perception of Administrative Factors that Form Barriers to Peer Tutoring Based on Carnegie Classification

\begin{tabular}{|c|c|c|c|c|c|}
\hline $\begin{array}{l}\text { Dependent } \\
\text { Variable }\end{array}$ & $\begin{array}{l}\text { (I) Carnegie } \\
\text { Classification }\end{array}$ & $\begin{array}{l}\text { (J) Carnegie } \\
\text { Classification }\end{array}$ & $\begin{array}{c}\text { Mean } \\
\text { Difference } \\
(\mathrm{I}-\mathrm{J}) \\
\end{array}$ & $\begin{array}{l}\text { Std. } \\
\text { Error }\end{array}$ & $\begin{array}{l}\text { Sig. } \\
\text { (p) }\end{array}$ \\
\hline \multirow[t]{23}{*}{$\begin{array}{l}\text { Difficulty } \\
\text { Mean }\end{array}$} & \multirow{11}{*}{$\begin{array}{l}\text { Masters Colleges and } \\
\text { Universities (Medium } \\
\text { Programs) }\end{array}$} & $\begin{array}{l}\text { Research University } \\
\text { (Very Hioh Research) }\end{array}$ & .315 & .124 & .336 \\
\hline & & $\begin{array}{l}\text { Research University } \\
\text { (High Research) }\end{array}$ & .233 & .133 & 1.000 \\
\hline & & $\begin{array}{l}\text { Doctoral Research } \\
\text { University }\end{array}$ & .174 & .133 & 1.000 \\
\hline & & Masters Colleges and & .176 & .148 & 1.000 \\
\hline & & Universities (Larger & & & \\
\hline & & Programs) & & & \\
\hline & & Masters Colleges and & .192 & .133 & 1.000 \\
\hline & & Universities (Smaller & & & \\
\hline & & Programs) & & & \\
\hline & & Baccalaureate Colleges & .092 & .129 & 1.000 \\
\hline & & Associates Colleges & .107 & .133 & 1.000 \\
\hline & \multirow{12}{*}{$\begin{array}{l}\text { Masters Colleges and } \\
\text { Universities (Smaller } \\
\text { Programs) }\end{array}$} & $\begin{array}{l}\text { Research University } \\
\text { (Very High Research) }\end{array}$ & .124 & .132 & 1.000 \\
\hline & & $\begin{array}{l}\text { Research University } \\
\text { (High Research) }\end{array}$ & .040 & .140 & 1.000 \\
\hline & & Doctoral Research & -.017 & .140 & 1.000 \\
\hline & & University & & & \\
\hline & & Masters Colleges and & -.015 & .154 & 1.000 \\
\hline & & Universities (Larger & & & \\
\hline & & Programs) & & & \\
\hline & & Masters Colleges and & -.192 & .133 & 1.000 \\
\hline & & Universities (Medium & & & \\
\hline & & Programs) & & & \\
\hline & & Baccalaureate Colleges & -.099 & .137 & 1.000 \\
\hline & & Associates Colleges & .085 & .140 & 1.000 \\
\hline
\end{tabular}


Table 62 (Cont.)

Bonferroni correction for Differences in Perception of Administrative Factors that Form Barriers to Peer Tutoring Based on Carnegie Classification

\begin{tabular}{|c|c|c|c|c|c|}
\hline $\begin{array}{l}\text { Dependent } \\
\text { Variable }\end{array}$ & $\begin{array}{l}\text { (I) Carnegie } \\
\text { Classification }\end{array}$ & $\begin{array}{l}\text { (J) Carnegie } \\
\text { Classification }\end{array}$ & $\begin{array}{c}\text { Mean } \\
\text { Difference } \\
(\mathrm{I}-\mathrm{J})\end{array}$ & $\begin{array}{l}\text { Std. } \\
\text { Error }\end{array}$ & $\begin{array}{l}\text { Sig. } \\
\text { (p) }\end{array}$ \\
\hline \multirow[t]{13}{*}{$\begin{array}{l}\text { Difficulty } \\
\text { Mean }\end{array}$} & \multirow[t]{6}{*}{ Baccalaureate Colleges } & $\begin{array}{l}\text { Research University } \\
\text { (Very High Research) }\end{array}$ & .223 & .128 & 1.000 \\
\hline & & $\begin{array}{l}\text { Research University } \\
\text { (High Research) }\end{array}$ & .140 & .137 & 1.000 \\
\hline & & $\begin{array}{l}\text { Doctoral Research } \\
\text { University }\end{array}$ & .082 & .137 & 1.000 \\
\hline & & $\begin{array}{l}\text { Masters Colleges and } \\
\text { Universities (Larger } \\
\text { Programs) }\end{array}$ & .084 & .151 & 1.000 \\
\hline & & $\begin{array}{l}\text { Masters Colleges and } \\
\text { Universities (Medium } \\
\text { Programs) }\end{array}$ & -.092 & .129 & 1.000 \\
\hline & & $\begin{array}{l}\text { Masters Colleges and } \\
\text { Universities (Smaller } \\
\text { Programs) } \\
\text { Associates Colleges }\end{array}$ & .014 & .137 & $\begin{array}{r}1.000 \\
1.000 \\
\end{array}$ \\
\hline & \multirow[t]{7}{*}{ Associates Colleges } & $\begin{array}{l}\text { Research University } \\
\text { (Very High Research) }\end{array}$ & .208 & .132 & 1.000 \\
\hline & & $\begin{array}{l}\text { Research University } \\
\text { (High Research) }\end{array}$ & .125 & .140 & 1.000 \\
\hline & & $\begin{array}{l}\text { Doctoral Research } \\
\text { University }\end{array}$ & .067 & .140 & 1.000 \\
\hline & & $\begin{array}{l}\text { Masters Colleges and } \\
\text { Universities (Larger } \\
\text { Programs) }\end{array}$ & .069 & .154 & 1.000 \\
\hline & & $\begin{array}{l}\text { Masters Colleges and } \\
\text { Universities (Medium } \\
\text { Programs) }\end{array}$ & -.107 & .133 & .429 \\
\hline & & $\begin{array}{l}\text { Masters Colleges and } \\
\text { Universities (Smaller } \\
\text { Programs) }\end{array}$ & .085 & .140 & 1.000 \\
\hline & & Baccalaureate Colleges & -.014 & .137 & 1.000 \\
\hline
\end{tabular}


As illustrated in Table 62, there was not a significant difference in the perception of factors that form barriers to peer tutoring between groups based on Carnegie classification.

\section{Related Findings}

Factors that are both facilitators and barriers to peer tutoring. Administrators identified several administrative and faculty factors that were both facilitators and barriers to peer tutoring. Responses on the importance scale of 1-1.5 (critical) and 1.51-2.5 (important, but not critical) were used to identify institutional factors that were facilitators to peer tutoring programs in Region II NASPA institutions. Responses on the difficulty scale of 1-1.5 (nearly impossible) and 1.5-2.5 (very difficult) were used to identify institutional factors that were barriers to peer tutoring programs in Region II NASPA institutions. Table 63 shows administrative and faculty factors that were both factors that facilitate peer tutoring and factors that were barriers to peer tutoring. 
Table 63

Mean Scores for Faculty and Administrative Factors that Facilitate and Form Barriers to Peer Tutoring Programs in Region II NASPA Institutions

\begin{tabular}{|c|c|c|c|c|c|}
\hline Administrative & \multicolumn{2}{|c|}{ Mean } & \multirow{2}{*}{$\begin{array}{l}\text { Faculty Factors } \\
\text { Administrator/Faculty } \\
\text { Collaborative Factors }\end{array}$} & \multicolumn{2}{|c|}{ Mean } \\
\hline $\begin{array}{l}\text { Planning } \\
\text { Factors }\end{array}$ & $\begin{array}{l}\text { Facilitate } \\
\text { Peer } \\
\text { Tutoring }\end{array}$ & $\begin{array}{l}\text { Form Barriers } \\
\text { to Peer } \\
\text { Tutoring }\end{array}$ & & $\begin{array}{l}\text { Facilitate } \\
\text { Peer } \\
\text { Tutoring }\end{array}$ & $\begin{array}{l}\text { Form Barriers } \\
\text { to Peer } \\
\text { Tutoring }\end{array}$ \\
\hline $\begin{array}{l}\text { Needs } \\
\text { Assessment - } \\
\text { Faculty }\end{array}$ & 2.10 & 2.55 & $\begin{array}{l}\text { Shared Vision } \\
\text { Collaboration - Plan } \\
\text { Programs } \\
\text { Collaboration - } \\
\text { Implement Programs } \\
\text { Collaboration - } \\
\text { Access Program } \\
\text { Effectiveness }\end{array}$ & $\begin{array}{l}1.99 \\
2.01 \\
2.02 \\
2.04\end{array}$ & $\begin{array}{l}2.26 \\
2.31 \\
2.32 \\
2.38\end{array}$ \\
\hline $\begin{array}{l}\text { Organizational } \\
\text { Factors }\end{array}$ & $\begin{array}{l}\text { Facilitate } \\
\text { Peer } \\
\text { Tutoring }\end{array}$ & $\begin{array}{l}\text { Form Barriers } \\
\text { to Peer } \\
\text { Tutoring }\end{array}$ & $\begin{array}{l}\text { Student/Faculty } \\
\text { Interactive Factors }\end{array}$ & $\begin{array}{l}\text { Facilitate } \\
\text { Peer } \\
\text { Tutoring }\end{array}$ & $\begin{array}{l}\text { Form Barriers } \\
\text { to Peer } \\
\text { Tutoring }\end{array}$ \\
\hline & & & $\begin{array}{l}\text { Communication - } \\
\text { Support Different } \\
\text { Learning Styles } \\
\text { Communication - } \\
\text { Support Different } \\
\text { Teaching Styles }\end{array}$ & 1.53 & 2.56 \\
\hline
\end{tabular}

As indicated in Table 63, administrators identified six out of twenty-six factors, that were both facilitators and barriers to peer tutoring: a) Shared Vision, b) Collaboration - Plan Programs

c) Collaboration - Implement Programs, d) Collaboration - Access Program Effectiveness,

e) Communication - Support Different Learning Styles, and f) Communication - Support

Different Teaching Styles). One factor, Needs Assessment - Faculty had a mean that was slightly above mid-range for response 2, very difficult, which identified it as a potential barrier to peer tutoring. 


\section{Chapter Five}

\section{Conclusion}

This chapter is divided into four sections: a) summary, b) findings and conclusions, c) discussion, and d) recommendations for administration, practice, and research.

\section{Summary}

The intent of this study was to identify a) institutional factors that administrators and faculty see as facilitating peer tutoring programs, b) institutional factors that administrators and faculty see as forming barriers to peer tutoring programs, and c) the differences in perceptions of peer tutoring between administrators and faculty. The data were collected through a survey instrument, Administrative and Faculty Factors that Contribute to the Institutionalization of Peer Tutoring in Higher Education, developed specifically for this study and based on the work of Dr. Anthony Pina (2005, 2008a, 2008b), who studied the institutionalization of distance learning programs and factors that institutionalize programs in higher education; and Dr. Vincent Tinto (1997, 2006-7), an expert on both retention and peer tutoring, who identified a gap in the literature on policies and practices in higher education which enable peer tutoring programs to endure and become institutionalized and in so doing, enable schools to be more successful in increasing student GPAs and retaining students.

The survey was sent electronically to 2,159 administrators and faculty, who were members of Region II in the National Association of Student Personnel Administrators (NASPA), with an interest in and knowledge about academic tutoring programs, and who are involved in their supervision, evaluation, and delivery of services. Although 23 percent (488) of the surveys were returned, a large percentage of the surveys returned by faculty (296 or 61 percent) were not completed, resulting in nonresponse error and therefore not useable. Sivo et al. (2006) reported that nonresponse error occurs when the number of respondents from a targeted 
population who respond differs substantially from those who did not respond, making it difficult to make generalizations from the sample about the entire population. Therefore, only administrative data (population 167) were reported and faculty data were used for descriptive purposes only. In addition, the focus of research for all three questions changed from administrators and faculty to administrators.

Question three was changed from differences in perceptions of peer tutoring between administrators and faculty to differences in perceptions of peer tutoring among administrators based on the following demographics: department affiliation (Academic Affairs, Student Affairs, or both), enrollment (less than 5000, 5,000 - 10,000, 10,001 - 20,000, or over 20,000), highest degree awarded (associates, bachelors, doctorate, or professional), and Carnegie classification (research university, very high research; research university, high research; doctoral research university; master's colleges and universities, larger programs; master's colleges and universities, medium programs; master's colleges and universities, smaller programs; baccalaureate colleges, all subtypes; or associate's colleges, all subtypes). Demographics were selected as they represent the categories around which the Carnegie classifications are organized: a) what is taught (degrees awarded and program classifications), b) who are the students (enrollment), and c) function of faculty and staff (department affiliation).

Twenty-eight factors that influence the institutionalization of peer tutoring were identified from a literature review and three similar factors were combined, after a review by the panel of experts, for a total of 26 survey items. Participants were asked to rate each factor for importance to peer tutoring (1, critical; 2, important, but not critical; 3, of minor importance, and 4, not important) and difficulty in implementation (1, nearly impossible; 2 , very difficult; 3 , of minor difficulty, and 4, not difficult). Cronbach's alpha was calculated for a) importance factors 
(factors that contribute to the institutionalization of peer tutoring) and b) difficulty factors (factors that form barriers to peer tutoring). A perfectly correlated survey would yield a Cronbach's alpha score of 1 (“Cronbach's alpha,” n.d.). Cronbach’s alpha for this study was .925 for importance factors and .913 for difficulty factors. This indicated that that a) the survey items are closely related as a group and b) there was a consistency in the responses across survey items.

The first part of the survey included eight demographic questions which identified a) the respondents' role in peer tutoring and b) characteristics about their institution that may influence peer tutoring. The first set of questions related to institutional role (administrator versus faculty) and involvement in peer tutoring (administrative oversight of peer tutoring/not involved in dayto-day operation, directing or coordinating peer tutoring/involved in day-to-day operation, evaluating the peer tutoring program, recruiting tutors, training tutors, not involved, or other capacity).

The second set of questions centered on factors that define the institution and may play a role in influencing peer tutoring such as a) the location of peer tutoring, b) supervision of peer tutoring, c) institutional affiliation, d) degrees awarded, e) enrollment, and f) Carnegie classification. Respondents had the option of checking all responses that apply, adding additional responses), or stating “I don't know." Therefore, data for some questions equaled more than 100 percent. The next section identifies the sample and reports the findings of the demographic questions using descriptive statistics.

\section{Demographic findings.}

Question one: What is your position? The sample included 192 respondents: 167 (87 
percent) were administrators, 9 (4.7 percent) were faculty, 10 (5.2 percent) were both administrators and faculty, and 6 (3.1 percent) held other positions (e.g. graduate assistant (GA), counselor/advisor, database researcher, residential life staff, and vice president for Student Affairs).

Question two: How are you involved in peer tutoring on your campus? The majority of respondents (58.4 percent) were not involved in the day-to-day operation of peer tutoring: 70 (36.5 percent) were contacts for peer tutoring, while 42 (21.9 percent) had administrative oversight. Less than one-half of the respondents (41.6 percent) reported that they were involved in the day-to-day operation of peer tutoring. Twenty-one (10.9 percent) were involved in evaluating peer tutoring, 20 (10.4 percent) recruited tutors, 16 (8.3 percent) trained tutors, and 14 (7.3 percent) directed or coordinated a peer tutoring program. Nine (4.7 percent) of the respondents served in another capacity including a) referring students to peer tutoring, b) occasionally tutoring, and c) former director of peer tutoring.

Question three: Where do peer tutoring programs occur at your institution? Most peer tutoring occurred outside the classroom: 176 (91.7 percent) of the tutoring sessions occurred at a tutoring center or other academic center and 72 (37.5 percent) tutoring sessions occurred in a residence hall. Ten respondents ( 5.2 percent) identified the following locations: a) any public place on campus, counseling office, on-line, at a fraternity or sorority, at Starbuck's or a book store, and at a student athletic training center.

Question four: Which unit supervises peer tutoring at your institution? The majority (123 or 64 percent) reported that peer tutoring at their institution was supervised by Academic Affairs, while 91 (47.4 percent) reported that peer tutoring was supervised by Student Affairs. Fourteen respondents ( 7.3 percent) reported that they didn't know, and 7 (3.6 percent) reported 
an assortment of units that included a) multicultural programs, b) counseling, and c) academic advising.

Question five: Is your institution public or private? The majority of institutions were public (96 or 50 percent). Within the public institutions, 85 were public non-profit and 11 were public-for-profit. Ninety-four (49 percent) of the institutions were in the private sector.

Question six: What is the highest degree awarded by your institution? The highest degree awarded by the majority of institutions was the doctorate ( 80 or 41.7 percent). The masters was the highest degree awarded at 36 institutions (18.8 percent), followed by professional (35 or 18.2 percent), associates (23 or 12 percent), and bachelors (16 or 8.2 percent).

Question seven: What is the enrollment at your institution? Enrollment at the majority of institutions fell in the 1001-5000 range (69 or 36.3 percent). Forty-one (21.6 percent) of the institutions fell in the 5001-10,000 range, while 39 (20.5 percent) were in the 5001-10,000 range. At 38 (20 percent) of the institutions, enrollment was over 20,000 and three institutions (1.6 percent) had an enrollment of less than 1000 students.

Question eight: Which Carnegie classification best describes your institution? Twentynine (15.2 percent) of the institutions were research universities with very high research and 28 (14.7 percent) were masters colleges and universities with medium programs. Twenty-five (13.1 percent) of the institutions were baccalaureate colleges, while 24 (12.6 percent) were associate degree colleges and 24 (12.6 percent) were research universities with high research. There were 23 (12 percent) doctoral research universities and 22 masters colleges and universities with smaller programs. Sixteen (8.4 percent) of the institutions were masters colleges and universities with larger programs. 


\section{Findings and Conclusions}

This section addresses the findings and conclusions for the following three research questions:

a) What institutional factors facilitate peer tutoring programs in Region II NASPA institutions, according to administrators who are members of Region II?

b) What institutional factors are barriers to peer tutoring programs in Region II NASPA institutions, according to administrators who are members of Region II?

c) What are the differences in perceptions of peer tutoring among administrators based on the following demographics: department affiliation (e.g. Academic Affairs, Student Affairs), enrollment, highest degree offered, and Carnegie classification?

Research question one. Question one addressed institutional factors that facilitate peer tutoring programs in Region II NASPA institutions, according to administrators who are members of Region II. Administrators identified twenty-three, out of twenty-six factors, that facilitate peer tutoring: fourteen administrative factors and nine faculty factors. Table 64 identifies factors that facilitate peer tutoring, which are listed by category (administrative or faculty) and in order of importance. Descriptive statics were also reported. Several factors have the same mean but were ranked differently. A higher rank indicates the standard deviation was closer to the mean. 
Table 64

Factors that Facilitate Peer Tutoring Programs in Region II NASPA Institutions

\begin{tabular}{|c|c|c|c|c|c|}
\hline Rank & Category & Factor & Description & Mean & $\begin{array}{l}\text { Explanation } \\
\text { of Mean }\end{array}$ \\
\hline 1. & Administrative & Centralization & $\begin{array}{l}\text { One central office oversees the } \\
\text { implementation, supervision, and } \\
\text { assessment of the peer tutoring } \\
\text { program. }\end{array}$ & 1.03 & Critical \\
\hline 2. & Faculty & Responsibility & $\begin{array}{l}\text { Peer tutoring practices are oriented } \\
\text { toward developing a climate in } \\
\text { which students' responsibility and } \\
\text { active participation are promoted. }\end{array}$ & 1.41 & Critical \\
\hline 3. & Faculty & $\begin{array}{l}\text { Communication - } \\
\text { Encourage Student } \\
\text { Engagement }\end{array}$ & $\begin{array}{l}\text { Communication between faculty } \\
\text { and students encourages student } \\
\text { engagement. }\end{array}$ & 1.41 & Critical \\
\hline 4. & Administrative & Evaluation & $\begin{array}{l}\text { Regular evaluations of the peer } \\
\text { tutoring program are done to ensure } \\
\text { that educational goals are met. }\end{array}$ & 1.42 & Critical \\
\hline 5. & Faculty & $\begin{array}{l}\text { Communication - } \\
\text { Support Different } \\
\text { Teaching Styles }\end{array}$ & $\begin{array}{l}\text { Communication between faculty } \\
\text { and students supports different } \\
\text { teaching styles. }\end{array}$ & 1.53 & $\begin{array}{l}\text { Important, } \\
\text { but not } \\
\text { critical }\end{array}$ \\
\hline 6. & Faculty & $\begin{array}{l}\text { Communication - } \\
\text { Support Different } \\
\text { Learning Styles } \\
\end{array}$ & $\begin{array}{l}\text { Communication between faculty } \\
\text { and students supports different } \\
\text { learning styles. }\end{array}$ & 1.53 & $\begin{array}{l}\text { Important, } \\
\text { but not } \\
\text { critical }\end{array}$ \\
\hline 7. & Administrative & $\begin{array}{l}\text { Needs Assessment } \\
\text { - Students }\end{array}$ & $\begin{array}{l}\text { Assessments are done to determine } \\
\text { student needs in the area of peer } \\
\text { tutoring. }\end{array}$ & 1.59 & $\begin{array}{l}\text { Important, } \\
\text { but not } \\
\text { critical }\end{array}$ \\
\hline 8. & Administrative & Visibility & Peer tutoring is visible on campus. & 1.60 & $\begin{array}{l}\text { Important, } \\
\text { but not } \\
\text { critical }\end{array}$ \\
\hline 9. & Administrative & Funding & $\begin{array}{l}\text { The peer tutoring program and staff } \\
\text { are a permanent } \\
\text { part of the institutional budget. }\end{array}$ & 1.61 & $\begin{array}{l}\text { Important, } \\
\text { but not } \\
\text { critical }\end{array}$ \\
\hline 10. & Administrative & Mission and Goals & $\begin{array}{l}\text { Peer tutoring is compatible with the } \\
\text { institution's mission and goals. }\end{array}$ & 1.66 & $\begin{array}{l}\text { Important, } \\
\text { but not } \\
\text { critical }\end{array}$ \\
\hline
\end{tabular}


Table 64 (Cont.)

Factors that Facilitate Peer Tutoring Programs in Region II NASPA Institutions

\begin{tabular}{|c|c|c|c|c|c|}
\hline Rank & Category & Factor & Description & Mean & $\begin{array}{l}\text { Explanation } \\
\text { of Mean }\end{array}$ \\
\hline 11. & Administrative & $\begin{array}{l}\text { Policies and } \\
\text { Procedures }\end{array}$ & $\begin{array}{l}\text { Formal policies and procedures } \\
\text { for peer tutoring } \\
\text { have been implemented. }\end{array}$ & 1.76 & $\begin{array}{l}\text { Important, } \\
\text { but not } \\
\text { critical }\end{array}$ \\
\hline 12. & Faculty & Staff Development & $\begin{array}{l}\text { Ongoing staff development on } \\
\text { peer tutoring best practices is in } \\
\text { place. }\end{array}$ & 1.80 & $\begin{array}{l}\text { Important, } \\
\text { but not } \\
\text { critical }\end{array}$ \\
\hline 13. & Administrative & $\begin{array}{l}\text { Needs Assessment - } \\
\text { Institutional }\end{array}$ & $\begin{array}{l}\text { Assessments are done to } \\
\text { determine institutional } \\
\text { needs for implementing peer } \\
\text { tutoring. }\end{array}$ & 1.82 & $\begin{array}{l}\text { Important, } \\
\text { but not } \\
\text { critical }\end{array}$ \\
\hline 14. & Administrative & Master Plan & $\begin{array}{l}\text { A master plan outlining } \\
\text { relevance, importance, } \\
\text { objectives, and costs of peer } \\
\text { tutoring has been developed. }\end{array}$ & 1.82 & $\begin{array}{l}\text { Important, } \\
\text { but not } \\
\text { critical }\end{array}$ \\
\hline 15. & Administrative & $\begin{array}{l}\text { Leadership } \\
\text { Authority }\end{array}$ & $\begin{array}{l}\text { A program director for peer } \\
\text { tutoring with decision- } \\
\text { making authority has been } \\
\text { appointed. }\end{array}$ & 1.82 & $\begin{array}{l}\text { Important, } \\
\text { but not } \\
\text { critical }\end{array}$ \\
\hline 16. & Faculty & Shared Vision & $\begin{array}{l}\text { There is a shared vision of peer } \\
\text { tutoring among departments. }\end{array}$ & 1.99 & $\begin{array}{l}\text { Important, } \\
\text { but not } \\
\text { critical }\end{array}$ \\
\hline 17. & Faculty & $\begin{array}{l}\text { Collaboration - Plan } \\
\text { Programs }\end{array}$ & $\begin{array}{l}\text { Faculty and administrators } \\
\text { collaborate on peer tutoring to } \\
\text { plan programs. }\end{array}$ & 2.01 & $\begin{array}{l}\text { Important, } \\
\text { but not } \\
\text { critical }\end{array}$ \\
\hline 18. & Faculty & $\begin{array}{l}\text { Collaboration - } \\
\text { Implement Programs }\end{array}$ & $\begin{array}{l}\text { Faculty and administrators } \\
\text { collaborate on peer tutoring to } \\
\text { implement programs. }\end{array}$ & 2.02 & $\begin{array}{l}\text { Important, } \\
\text { but not } \\
\text { critical }\end{array}$ \\
\hline 19. & Administrative & Marketing & $\begin{array}{l}\text { A marketing plan is in place to } \\
\text { promote peer tutoring. }\end{array}$ & 2.02 & $\begin{array}{l}\text { Important, } \\
\text { but not } \\
\text { critical }\end{array}$ \\
\hline 20. & Faculty & $\begin{array}{l}\text { Collaboration - } \\
\text { Access Program } \\
\text { Effectiveness }\end{array}$ & $\begin{array}{l}\text { Faculty and administrators } \\
\text { collaborate on peer tutoring to } \\
\text { access program effectiveness. }\end{array}$ & 2.04 & $\begin{array}{l}\text { Important, } \\
\text { but not } \\
\text { critical }\end{array}$ \\
\hline 21. & Administrative & Support & $\begin{array}{l}\text { Peer tutoring administrators and } \\
\text { staff meet regularly with other } \\
\text { campus groups to ensure support. }\end{array}$ & 2.04 & $\begin{array}{l}\text { Important, } \\
\text { but not } \\
\text { critical }\end{array}$ \\
\hline 22. & Administrative & $\begin{array}{l}\text { Needs Assessment - } \\
\text { Faculty }\end{array}$ & $\begin{array}{l}\text { Assessments are done to } \\
\text { determine faculty needs } \\
\text { for implementing peer tutoring. }\end{array}$ & 2.10 & $\begin{array}{l}\text { Important, } \\
\text { but not } \\
\text { critical }\end{array}$ \\
\hline 23. & Administrative & Organization & $\begin{array}{l}\text { Peer tutoring is a campus-wide } \\
\text { function and not part } \\
\text { of a specific school, department, } \\
\text { or academic discipline. }\end{array}$ & 2.14 & $\begin{array}{l}\text { Important, } \\
\text { but not } \\
\text { critical }\end{array}$ \\
\hline
\end{tabular}


As indicated in Table 64, four factors were ranked critical: a) Centralization, b) Responsibility, c) Communication - Encourage Student Engagement, and d) Evaluation. The remaining nineteen factors were ranked important, but not critical. Administrators identified the top ten factors that facilitate peer tutoring as follows: a) Centralization, b) Responsibility, c) Communication Encourage Student Engagement, d) Evaluation, e) Communication - Support Different Teaching Styles, f) Communication - Support Different Learning Styles, g) Needs Assessment - Students, h) Visibility, i) Funding, and j) Mission and Goals. Furthermore, administrators identified the four student/faculty interactive factors among the most important factors. The following conclusions can be drawn from Table 64:

- Administrators in Region II NASPA institutions believe student/faculty interaction facilitates peer tutoring.

- Administrators in Region II NASPA institutions believe administrator/faculty collaboration facilitates peer tutoring.

- Administrators in Region II NASPA institutions believe centralization of the implementation, supervision, and assessment of peer tutoring facilitates peer tutoring.

- Administrators in Region II NASPA Institutions believe regular evaluations of the peer tutoring program that are done to ensure that educational goals are met facilitates peer tutoring.

Research question two. Question two addressed institutional factors that form barriers to peer tutoring programs in Region II NASPA institutions, according to administrators who are members of Region II. Administrators identified ten out of twenty-six total factors that form barriers to peer tutoring: one administrative factor and nine faculty factors. Out of the ten factors, three had means slightly above mid-range for response 2 , very difficult, which identified them as 
potential barriers. Table 65 identifies these factors, which are listed by category (administrative or faculty) and in order of importance across categories.

Table 65

Factors that Form Barriers to Peer Tutoring Programs in Region II NASPA Institutions

\begin{tabular}{|c|c|c|c|c|c|}
\hline Rank & Category & Factor & Description & Mean & $\begin{array}{l}\text { Explanation } \\
\text { of Mean }\end{array}$ \\
\hline 1. & Faculty & $\begin{array}{l}\text { Incentives - } \\
\text { Professional }\end{array}$ & $\begin{array}{l}\text { Professional incentives to } \\
\text { participate in peer tutoring } \\
\text { programs are available (i.e. } \\
\text { credit towards promotion and } \\
\text { tenure, flexibility in time } \\
\text { teaching). }\end{array}$ & 2.08 & $\begin{array}{l}\text { Very } \\
\text { Difficult }\end{array}$ \\
\hline 2. & Faculty & Incentives - Financial & $\begin{array}{l}\text { Financial incentives to } \\
\text { participate in peer tutoring are } \\
\text { available (i.e. merit pay, } \\
\text { grants for future research, } \\
\text { new computer). }\end{array}$ & 2.14 & $\begin{array}{l}\text { Very } \\
\text { Difficult }\end{array}$ \\
\hline 3. & Faculty & Shared Vision & $\begin{array}{l}\text { There is a shared vision of } \\
\text { peer tutoring among } \\
\text { departments. }\end{array}$ & 2.26 & $\begin{array}{l}\text { Very } \\
\text { Difficult }\end{array}$ \\
\hline 4. & Faculty & $\begin{array}{l}\text { Collaboration - Decide } \\
\text { Budget }\end{array}$ & $\begin{array}{l}\text { Faculty and administrators } \\
\text { collaborate on peer tutoring to } \\
\text { decide the program budget. }\end{array}$ & 2.30 & $\begin{array}{l}\text { Very } \\
\text { Difficult }\end{array}$ \\
\hline 5. & Faculty & $\begin{array}{l}\text { Collaboration - Plan } \\
\text { Programs }\end{array}$ & $\begin{array}{l}\text { Faculty and administrators } \\
\text { collaborate on peer tutoring to } \\
\text { plan programs. }\end{array}$ & 2.31 & $\begin{array}{l}\text { Very } \\
\text { Difficult }\end{array}$ \\
\hline 6. & Faculty & $\begin{array}{l}\text { Collaboration - } \\
\text { Implement Programs }\end{array}$ & $\begin{array}{l}\text { Faculty and administrators } \\
\text { collaborate on peer tutoring to } \\
\text { implement programs. }\end{array}$ & 2.31 & $\begin{array}{l}\text { Very } \\
\text { Difficult }\end{array}$ \\
\hline 7. & Faculty & $\begin{array}{l}\text { Collaboration - Access } \\
\text { Program Effectiveness }\end{array}$ & $\begin{array}{l}\text { Faculty and administrators } \\
\text { collaborate on peer tutoring to } \\
\text { access program effectiveness. }\end{array}$ & 2.38 & $\begin{array}{l}\text { Very } \\
\text { Difficult }\end{array}$ \\
\hline 8. & Administrative & $\begin{array}{l}\text { Needs Assessment - } \\
\text { Faculty }\end{array}$ & $\begin{array}{l}\text { Assessments are done to } \\
\text { determine } \\
\text { faculty needs for } \\
\text { implementing peer tutoring }\end{array}$ & 2.55 & $\begin{array}{l}\text { Close to } \\
\text { very } \\
\text { difficult }\end{array}$ \\
\hline 9. & Faculty & $\begin{array}{l}\text { Communication - } \\
\text { Support Different } \\
\text { Learning Styles } \\
\end{array}$ & $\begin{array}{l}\text { Communication between } \\
\text { faculty and students supports } \\
\text { different teaching styles. }\end{array}$ & 2.56 & $\begin{array}{l}\text { Close to } \\
\text { very } \\
\text { difficult }\end{array}$ \\
\hline 10. & Faculty & $\begin{array}{l}\text { Communication - } \\
\text { Support Different } \\
\text { Teaching Styles }\end{array}$ & $\begin{array}{l}\text { Communication between } \\
\text { faculty and students supports } \\
\text { different learning styles. }\end{array}$ & 2.59 & $\begin{array}{l}\text { Close to } \\
\text { very } \\
\text { difficult }\end{array}$ \\
\hline
\end{tabular}


As indicated in table 65, nine out of the ten factors relate to faculty. The top two factors involve faculty incentives for participating in the oversight of peer tutoring, while the next five factors involve collaboration with administrators. Three factors had means lightly above mid-range for response 2, very difficult, and were identified as potential barriers. Two of the potential barriers relate to communication between faculty and students. While the third potential barrier was identified as an administrative barrier, it also relates to faculty and recognizes the difficulty of performing assessments to determine faculty needs for implementing peer tutoring. The following conclusions can be drawn from Table 65:

- Administrators in region II NASPA institutions believe faculty are barriers to peer tutoring in higher education.

- Administrators in Region II NASPA believe that assessing faculty needs to implement peer tutoring is a potential barrier to peer tutoring.

Research question three. Research question three addressed differences in perceptions of a) factors that facilitate peer tutoring and b) factors that form barriers to peer tutoring among administrators in Region II NASPA institutions based on the following demographics: department affiliation (Academic Affairs, Student Affairs, or both), enrollment (less than 5000, $5,000-10,000,10,001-20,000$, or over 20,000), highest degree awarded (associates, bachelors, doctorate, or professional), and Carnegie classification (research university, very high research; research university, high research; doctoral research university; master's colleges and universities, larger programs; master's colleges and universities, medium programs; master's colleges and universities, smaller programs; baccalaureate colleges, all subtypes; or associate's colleges, all subtypes).

Differences in perception of factors that facilitate peer tutoring. Testing was conducted using SPSS (Statistical Package for the Social Sciences) to determine the difference in the 
perception of factors that facilitate peer tutoring between groups. An analysis of variance (ANOVA), a test that compares group means by analyzing comparisons of variance estimates, was done in order to determine which groups differ from each other and how they differ (Plonsky, 2011). An average mean across all 26 factors was used to compare groups. Table 66 summarizes the differences in the perception of factors that facilitate peer tutoring between groups based on ANOVA for the following dependent variables: a) department affiliation, b) enrollment, c) highest degree awarded, and d) Carnegie classification. The probability that there was a significant difference in perception between groups was set at $\mathrm{p}<.05$.

Table 66

Differences in the Perception of Factors that Facilitate Peer Tutoring Based on ANOVA

\begin{tabular}{|ll|r|r|r|r|r|}
\hline $\begin{array}{l}\text { Demographic Category } \\
\text { (Dependent Variables) }\end{array}$ & $\begin{array}{c}\text { Sum of } \\
\text { Squares }\end{array}$ & df & $\begin{array}{c}\text { Mean } \\
\text { Square }\end{array}$ & $F$ & $\begin{array}{c}\text { Sig. } \\
(\mathrm{p})\end{array}$ \\
\hline Department Affiliation & Between Groups & .786 & 2 & .393 & 1.558 & .214 \\
& Within Groups & 37.853 & 150 & .252 & & \\
& Total & 38.639 & 152 & & & \\
\hline Enrollment & Between Groups & .450 & 3 & .150 & .582 & .628 \\
& Within Groups & 41.737 & 162 & .258 & & \\
& Total & 42.187 & 165 & & & \\
\hline Degrees Awarded & Between Groups & 1.790 & 4 & .447 & 1.783 & .135 \\
& Within Groups & 40.398 & 161 & .251 & & \\
& Total & 42.187 & 165 & & & \\
\hline Carnegie Classification & Between Groups & 2.685 & 7 & .384 & 1.540 & .157 \\
& Within Groups & 39.598 & 159 & .249 & & \\
& Total & 42.283 & 166 & & & \\
\hline
\end{tabular}

As indicated in Table 66, there were no significant differences in the perceptions of factors that facilitate peer tutoring between groups for any of the demographic factors at $\mathrm{p}<.05$ level.

In addition, a post-hoc test, the Bonferroni correction, was also calculated to determine the significance of the difference. This test is commonly used with ANOVA when there is a predetermined number of outcomes in advance ("Bonferroni's method," n.d.). Table 67 shows the differences in the perception of factors that facilitate peer tutoring based on the Bonferroni 
correction for the following demographics: a) department affiliation, b) enrollment, c) highest degree awarded, and d) Carnegie classification. The probability that there was a significant difference in perception between groups was set at $\mathrm{p}<.05$.

Table 67

Differences in Perception of Factors that Facilitate Peer Tutoring Based on the Bonferroni Correction

\begin{tabular}{|c|c|c|c|c|c|}
\hline $\begin{array}{l}\text { Dependent } \\
\text { Variable }\end{array}$ & (I) Dept. Affiliation & (J) Dept. Affiliation & \begin{tabular}{|c} 
Mean \\
Differenc \\
e (I-J)
\end{tabular} & $\begin{array}{l}\text { Std. } \\
\text { Error }\end{array}$ & $\begin{array}{l}\text { Sig. } \\
\text { (p) }\end{array}$ \\
\hline \multirow{6}{*}{$\begin{array}{l}\text { Importance } \\
\text { Mean }\end{array}$} & \multirow[t]{2}{*}{ Student Affairs } & Academic Affairs & .118 & .094 & .627 \\
\hline & & $\begin{array}{l}\text { Both Academic and } \\
\text { Student Affairs }\end{array}$ & -.051 & .115 & 1.000 \\
\hline & \multirow[t]{2}{*}{ Academic Affairs } & Student Affairs & -.118 & .094 & .627 \\
\hline & & $\begin{array}{l}\text { Both Academic and } \\
\text { Student Affairs }\end{array}$ & -.169 & .106 & .340 \\
\hline & \multirow{2}{*}{$\begin{array}{l}\text { Both Academic and } \\
\text { Student Affairs }\end{array}$} & Student Affairs & .051 & .115 & 1.000 \\
\hline & & Academic Affairs & .169 & 106 & .340 \\
\hline $\begin{array}{l}\text { Dependent } \\
\text { Variable }\end{array}$ & (I) Enrollment & (J) Enrollment & $\begin{array}{c}\text { Mean } \\
\text { Difference } \\
\text { (I-J) }\end{array}$ & $\begin{array}{l}\text { Std. } \\
\text { Error }\end{array}$ & $\begin{array}{r}\text { Sig. } \\
\text { (p) }\end{array}$ \\
\hline \multirow{12}{*}{$\begin{array}{l}\text { Importance } \\
\text { Mean }\end{array}$} & \multirow[t]{3}{*}{ Under 5,000 } & $5,000-10,000$ & .054 & .110 & 1.000 \\
\hline & & $10,001-20,000$ & -.105 & .106 & 1.000 \\
\hline & & Over 20,000 & -.016 & .107 & 1.000 \\
\hline & \multirow[t]{3}{*}{$5,000-10,000$} & Under 5,000 & -.054 & .110 & 1.000 \\
\hline & & $10,001-20,000$ & -.159 & .124 & 1.000 \\
\hline & & Over 20,000 & -.070 & .125 & 1.000 \\
\hline & \multirow[t]{3}{*}{$10,001-20,000$} & Under 5,000 & .105 & 106 & 1.000 \\
\hline & & $5,000-10,000$ & .159 & .124 & 1.000 \\
\hline & & Over 20,000 & .089 & .122 & 1.000 \\
\hline & \multirow[t]{3}{*}{ Over 20,000} & Under 5,000 & .016 & .107 & 1.000 \\
\hline & & $5,000-10,000$ & .070 & .125 & 1.000 \\
\hline & & $10,001-20,000$ & -.089 & .122 & 1.000 \\
\hline
\end{tabular}


Table 67 (Cont.)

Differences in Perception of Factors that Facilitate Peer Tutoring Based on the Bonferroni Correction

\begin{tabular}{|c|c|c|c|c|c|}
\hline $\begin{array}{l}\text { Dependent } \\
\text { Variable }\end{array}$ & (I) Degree Awarded & (J) Degree Awarded & $\begin{array}{c}\text { Mean } \\
\text { Differenc } \\
\text { e (I-J) }\end{array}$ & $\begin{array}{l}\text { Std. } \\
\text { Error }\end{array}$ & $\begin{array}{l}\text { Sig. } \\
\text { (p) }\end{array}$ \\
\hline \multirow{20}{*}{$\begin{array}{l}\text { Importance } \\
\text { Mean }\end{array}$} & \multirow[t]{4}{*}{ Associates } & Bachelors & .351 & .173 & .443 \\
\hline & & Masters & .318 & .144 & .290 \\
\hline & & Doctorate & .195 & .130 & 1.0002 \\
\hline & & $\begin{array}{l}\text { Professional (e.g. JD, MD, } \\
\text { DDS) }\end{array}$ & .112 & .147 & 1.000 \\
\hline & \multirow[t]{4}{*}{ Bachelors } & Associates & -.351 & 173 & .443 \\
\hline & & Masters & -.033 & .156 & 1.000 \\
\hline & & Doctorate & -.155 & .143 & 1.000 \\
\hline & & $\begin{array}{l}\text { Professional (e.g. } \\
\text { JD, MD, DDS) }\end{array}$ & -.238 & .158 & 1.000 \\
\hline & \multirow[t]{4}{*}{ Masters } & Associates & -.318 & .144 & .290 \\
\hline & & Bachelors & .033 & 156 & 1.000 \\
\hline & & Doctorate & -.122 & 106 & 1.000 \\
\hline & & $\begin{array}{l}\text { Professional(e.g. JD, MD, } \\
\text { DDS) }\end{array}$ & -.206 & .126 & 1.000 \\
\hline & \multirow[t]{4}{*}{ Doctorate } & Associates & -.195 & .130 & 1.000 \\
\hline & & Bachelors & .155 & .143 & 1.000 \\
\hline & & Masters & .122 & 106 & 1.000 \\
\hline & & $\begin{array}{l}\text { Professional (e.g. JD, MD, } \\
\text { DDS) }\end{array}$ & -.083 & .110 & 1.000 \\
\hline & \multirow{4}{*}{$\begin{array}{l}\text { Professional } \\
\text { (e.g. JD, MD, DDS) }\end{array}$} & Associates & -.112 & 147 & 1.000 \\
\hline & & Bachelors & .238 & 158 & 1.000 \\
\hline & & Masters & .206 & .126 & 1.000 \\
\hline & & Doctorate & .083 & .110 & 1.000 \\
\hline
\end{tabular}


Table 67 (Cont.)

Differences in Perception of Factors that Facilitate Peer Tutoring Based on the Bonferroni Correction

\begin{tabular}{|c|c|c|c|c|c|}
\hline $\begin{array}{l}\text { Dependent } \\
\text { Variable }\end{array}$ & $\begin{array}{l}\text { (I) Carnegie } \\
\text { Classification }\end{array}$ & $\begin{array}{l}\text { (J) Carnegie } \\
\text { Classification }\end{array}$ & $\begin{array}{c}\text { Mean } \\
\text { Difference } \\
(\mathrm{I}-\mathrm{J})\end{array}$ & $\begin{array}{l}\text { Std. } \\
\text { Error }\end{array}$ & $\begin{array}{l}\text { Sig. } \\
(p)\end{array}$ \\
\hline \multirow[t]{14}{*}{$\begin{array}{l}\text { Importance } \\
\text { Mean }\end{array}$} & $\begin{array}{l}\text { Research University } \\
\text { (Very High Research) }\end{array}$ & $\begin{array}{l}\text { Research University } \\
\text { (High Research) }\end{array}$ & .191 & .148 & 1.000 \\
\hline & & Doctoral Research University & .148 & .148 & 1.000 \\
\hline & & $\begin{array}{l}\text { Masters Colleges and Universities } \\
\text { (Larger Programs) }\end{array}$ & .187 & .165 & 1.000 \\
\hline & & $\begin{array}{l}\text { Masters Colleges and Universities } \\
\text { (Medium Programs) }\end{array}$ & .388 & .140 & .172 \\
\hline & & $\begin{array}{l}\text { Masters Colleges and Universities } \\
\text { (Smaller Programs) }\end{array}$ & .215 & .148 & 1.000 \\
\hline & & Baccalaureate Colleges & .277 & .145 & 1.000 \\
\hline & & Associates Colleges & .021 & .148 & 1.000 \\
\hline & $\begin{array}{l}\text { Research University } \\
\text { (High Research) }\end{array}$ & $\begin{array}{l}\text { Research University } \\
\text { (Very High Research) }\end{array}$ & -.190 & .148 & 1.000 \\
\hline & & Doctoral Research University & -.042 & .158 & 1.000 \\
\hline & & $\begin{array}{l}\text { Masters Colleges and Universities } \\
\text { (Larger Programs) }\end{array}$ & -.003 & .174 & 1.000 \\
\hline & & $\begin{array}{l}\text { Masters Colleges and Universities } \\
\text { (Medium Programs) }\end{array}$ & .198 & .150 & 1.000 \\
\hline & & $\begin{array}{l}\text { Masters Colleges and Universities } \\
\text { (Smaller Programs) }\end{array}$ & .025 & .158 & 1.000 \\
\hline & & Baccalaureate Colleges & .086 & .154 & 1.000 \\
\hline & & Associates Colleges & -.169 & .158 & 1.000 \\
\hline
\end{tabular}


Table 67 (Cont.)

Differences in Perception of Factors that Facilitate Peer Tutoring Based on the Bonferroni Correction

\begin{tabular}{|c|c|c|c|c|c|}
\hline $\begin{array}{l}\text { Dependent } \\
\text { Variable }\end{array}$ & $\begin{array}{l}\text { (I) Carnegie } \\
\text { Classification }\end{array}$ & $\begin{array}{l}\text { (J) Carnegie } \\
\text { Classification }\end{array}$ & $\begin{array}{c}\text { Mean } \\
\text { Difference } \\
(\mathrm{I}-\mathrm{J})\end{array}$ & $\begin{array}{c}\text { Std. } \\
\text { Error }\end{array}$ & $\begin{array}{l}\text { Sig. } \\
(\mathrm{p})\end{array}$ \\
\hline \multirow[t]{14}{*}{$\begin{array}{l}\text { Importance } \\
\text { Mean }\end{array}$} & $\begin{array}{l}\text { Doctoral Research } \\
\text { University }\end{array}$ & $\begin{array}{l}\text { Research University } \\
\text { (Very High Research) }\end{array}$ & -.148 & .148 & 1.000 \\
\hline & & $\begin{array}{l}\text { Research University } \\
\text { (High Research) }\end{array}$ & .042 & .158 & 1.000 \\
\hline & & $\begin{array}{l}\text { Masters Colleges and Universities } \\
\text { (Larger Programs) }\end{array}$ & .039 & .174 & 1.000 \\
\hline & & $\begin{array}{l}\text { Masters Colleges and Universities } \\
\text { (Medium Programs) }\end{array}$ & .240 & .150 & 1.000 \\
\hline & & $\begin{array}{l}\text { Masters Colleges and Universities } \\
\text { (Smaller Programs) }\end{array}$ & .067 & .158 & 1.000 \\
\hline & & Baccalaureate Colleges & .120 & .154 & 1.000 \\
\hline & & Associates Colleges & -.127 & 158 & 1.000 \\
\hline & $\begin{array}{l}\text { Masters Colleges } \\
\text { and Universities } \\
\text { (Larger Programs) }\end{array}$ & $\begin{array}{l}\text { Research University } \\
\text { (Very High Research) }\end{array}$ & -.187 & .165 & 1.000 \\
\hline & & $\begin{array}{l}\text { Research University } \\
\text { (High Research) }\end{array}$ & .003 & .174 & 1.000 \\
\hline & & Doctoral Research University & -.039 & .174 & 1.000 \\
\hline & & $\begin{array}{l}\text { Masters Colleges and Universities } \\
\text { (Medium Programs) }\end{array}$ & .201 & .167 & 1.000 \\
\hline & & $\begin{array}{l}\text { Masters Colleges and Universities } \\
\text { (Smaller Programs) }\end{array}$ & .028 & .174 & 1.000 \\
\hline & & Baccalaureate Colleges & .090 & .171 & 1.000 \\
\hline & & Associates Colleges & -.166 & .174 & 1.000 \\
\hline
\end{tabular}


Table 67 (Cont.)

Differences in Perception of Factors that Facilitate Peer Tutoring Based on the Bonferroni Correction

\begin{tabular}{|c|c|c|c|c|c|}
\hline $\begin{array}{l}\text { Dependent } \\
\text { Variable }\end{array}$ & $\begin{array}{l}\text { (I) Carnegie } \\
\text { Classification }\end{array}$ & $\begin{array}{l}\text { (J) Carnegie } \\
\text { Classification }\end{array}$ & $\begin{array}{c}\text { Mean } \\
\text { Difference } \\
(\mathrm{I}-\mathrm{J})\end{array}$ & $\begin{array}{c}\text { Std. } \\
\text { Error }\end{array}$ & $\begin{array}{l}\text { Sig. } \\
(\mathrm{p})\end{array}$ \\
\hline \multirow[t]{14}{*}{$\begin{array}{l}\text { Importance } \\
\text { Mean }\end{array}$} & $\begin{array}{l}\text { Masters Colleges } \\
\text { and Universities } \\
\text { (Medium Programs) }\end{array}$ & $\begin{array}{l}\text { Research University } \\
\text { (Very High Research) }\end{array}$ & -.388 & .140 & .172 \\
\hline & & $\begin{array}{l}\text { Research University } \\
\text { (High Research) }\end{array}$ & -.198 & .150 & 1.000 \\
\hline & & Doctoral Research University & -.240 & .150 & 1.000 \\
\hline & & $\begin{array}{l}\text { Masters Colleges and Universities } \\
\text { (Larger Programs) }\end{array}$ & -.201 & .167 & 1.000 \\
\hline & & $\begin{array}{l}\text { Masters Colleges and Universities } \\
\text { (Smaller Programs) }\end{array}$ & -.173 & .150 & 1.000 \\
\hline & & Baccalaureate Colleges & -.111 & .146 & 1.000 \\
\hline & & Associates Colleges & -.367 & .150 & .429 \\
\hline & $\begin{array}{l}\text { Masters Colleges } \\
\text { and Universities } \\
\text { (Smaller Programs) }\end{array}$ & $\begin{array}{l}\text { Research University } \\
\text { (Very High Research) }\end{array}$ & -.216 & .148 & 1.000 \\
\hline & & $\begin{array}{l}\text { Research University } \\
\text { (High Research) }\end{array}$ & -.025 & .158 & 1.000 \\
\hline & & Doctoral Research University & -.067 & .158 & 1.000 \\
\hline & & $\begin{array}{l}\text { Masters Colleges and Universities } \\
\text { (Larger Programs) }\end{array}$ & -.028 & .174 & 1.000 \\
\hline & & $\begin{array}{l}\text { Masters Colleges and Universities } \\
\text { (Medium Programs) }\end{array}$ & .173 & .150 & 1.000 \\
\hline & & Baccalaureate Colleges & .061 & .154 & 1.000 \\
\hline & & Associates Colleges & -.194 & .158 & 1.000 \\
\hline
\end{tabular}


Table 67 (Cont.)

Differences in Perception of Factors that Facilitate Peer Tutoring Based on the Bonferroni Correction

\begin{tabular}{|c|c|c|c|c|c|}
\hline $\begin{array}{l}\text { Dependent } \\
\text { Variable }\end{array}$ & $\begin{array}{l}\text { (I) Carnegie } \\
\text { Classification }\end{array}$ & $\begin{array}{l}\text { (J) Carnegie } \\
\text { Classification }\end{array}$ & $\begin{array}{c}\text { Mean } \\
\text { Difference } \\
(\mathrm{I}-\mathrm{J})\end{array}$ & $\begin{array}{l}\text { Std. } \\
\text { Error }\end{array}$ & $\begin{array}{l}\text { Sig. } \\
\text { (p) }\end{array}$ \\
\hline \multirow[t]{14}{*}{$\begin{array}{l}\text { Importance } \\
\text { Mean }\end{array}$} & $\begin{array}{l}\text { Baccalaureate } \\
\text { Colleges }\end{array}$ & $\begin{array}{l}\text { Research University } \\
\text { (Very High Research) }\end{array}$ & -.277 & .145 & 1.000 \\
\hline & & $\begin{array}{l}\text { Research University } \\
\text { (High Research) }\end{array}$ & -.086 & .154 & 1.000 \\
\hline & & Doctoral Research University & -.129 & .154 & 1.000 \\
\hline & & $\begin{array}{l}\text { Masters Colleges and Universities } \\
\text { (Larger Programs) }\end{array}$ & -.090 & .171 & 1.000 \\
\hline & & $\begin{array}{l}\text { Masters Colleges and Universities } \\
\text { (Medium Programs) }\end{array}$ & .111 & .146 & 1.000 \\
\hline & & $\begin{array}{l}\text { Masters Colleges and Universities } \\
\text { (Smaller Programs) }\end{array}$ & -.061 & .154 & 1.000 \\
\hline & & Associates Colleges & -.256 & .154 & 1.000 \\
\hline & Associates Colleges & $\begin{array}{l}\text { Research University } \\
\text { (Very High Research) }\end{array}$ & -.021 & .148 & 1.000 \\
\hline & & $\begin{array}{l}\text { Research University } \\
\text { (High Research) }\end{array}$ & .169 & .158 & 1.000 \\
\hline & & Doctoral Research University & .127 & .158 & 1.000 \\
\hline & & $\begin{array}{l}\text { Masters Colleges and Universities } \\
\text { (Larger Programs) }\end{array}$ & .166 & .174 & 1.000 \\
\hline & & $\begin{array}{l}\text { Masters Colleges and Universities } \\
\text { (Medium Programs) }\end{array}$ & .367 & .150 & .429 \\
\hline & & $\begin{array}{l}\text { Masters Colleges and Universities } \\
\text { (Smaller Programs) }\end{array}$ & .194 & .158 & 1.000 \\
\hline & & Baccalaureate Colleges & .256 & .154 & 1.000 \\
\hline
\end{tabular}


As indicated in Table 67, there were no significant differences in the perceptions of factors that facilitate peer tutoring between groups for any of the demographic factors at $p<.05$ level. The following conclusion can be drawn from Tables 66 and 67:

- Administrators in region II NASPA institutions believe institutional factors such as department affiliation, enrollment, highest degree awarded, and Carnegie Classification have no effect on perceptions of factors that facilitate peer tutoring programs. Differences in perception of factors that form barriers to peer tutoring. Testing was conducted using SPSS (Statistical Package for the Social Sciences) to determine the difference in the perception of factors that form barriers to peer tutoring between groups. An analysis of variance (ANOVA), a test that compares group means by analyzing comparisons of variance estimates, was done in order to determine which groups differ from each other and how they differ (Plonsky, 2011). An average mean across all 26 factors was used to compare groups. Table 68 summarizes the differences in the perception of factors that form barriers to peer tutoring between groups based on ANOVA for the following dependent variables: a) department affiliation, b) enrollment, c) highest degree awarded, and d) Carnegie classification. The probability that there was a significant difference in perception between groups was set at $\mathrm{p}<.05$. 
Table 68

Differences in Perception of Factors that Form Barriers to Peer Tutoring Based on ANOVA

\begin{tabular}{|ll|r|r|r|r|r|}
\hline $\begin{array}{l}\text { Demographic Category } \\
\text { (Dependent Variables) }\end{array}$ & $\begin{array}{c}\text { Sum of } \\
\text { Squares }\end{array}$ & \multicolumn{1}{c|}{ df } & $\begin{array}{c}\text { Mean } \\
\text { Square }\end{array}$ & $F$ & $\begin{array}{c}\text { Sig. } \\
(\mathrm{p})\end{array}$ \\
\hline Department Affiliation & Between Groups & .254 & 2 & .127 & .618 & .540 \\
& Within Groups & 30.777 & 150 & .205 & & \\
& Total & 31.031 & 152 & & & \\
\hline Enrollment & Between Groups & 2.992 & 3 & .997 & 5.448 & .001 \\
& Within Groups & 29.656 & 162 & .183 & & \\
& Total & 32.647 & 165 & & & \\
\hline Degrees Awarded & Between Groups & .889 & 4 & .222 & 1.137 & 1.137 \\
& Within Groups & 31.445 & 161 & .195 & & \\
& Total & 32.333 & 165 & & & \\
\hline Carnegie Classification & Between Groups & 1.566 & 7 & .222 & 1.133 & .345 \\
& Within Groups & 31.164 & 159 & .196 & & \\
& Total & 32.721 & 166 & & & \\
\hline
\end{tabular}

As indicated in Table 68, there were no significant differences in the perception of factors that form barriers to peer tutoring between groups for the following demographic factors at $\mathrm{p}<.05$ level: a) department affiliation, b) degrees awarded, and c) Carnegie classification. However, there was a significant difference in the perception of factors that form barriers to peer tutoring based on enrollment at the $\mathrm{p}<.05$ level $[\mathrm{F}(3,162)=5.448, \mathrm{p}=.001]$.

A post hoc test, the Bonferroni correction, was also calculated to determine the significance of the difference. This test is commonly used with ANOVA when there is a predetermined number of outcomes in advance ("Bonferroni's method," n.d.). Table 69 shows the differences in the perception of factors that form barriers to peer tutoring based on the Bonferroni correction for the following demographics: a) department affiliation, b) enrollment, c) highest degree awarded, and d) Carnegie classification. The probability that there was a significant difference in perception between groups was set at $\mathrm{p}<.05$. 
Table 69

Differences in Perception of Factors that Form Barriers to Peer Tutoring Based on the Bonferroni Correction

\begin{tabular}{|c|c|c|c|c|c|}
\hline $\begin{array}{l}\text { Dependent } \\
\text { Variable }\end{array}$ & (I) Affiliation & (J) Affiliation & $\begin{array}{c}\text { Mean } \\
\text { Difference } \\
(\mathrm{I}-\mathrm{J})\end{array}$ & $\begin{array}{l}\text { Std. } \\
\text { Error }\end{array}$ & $\begin{array}{l}\text { Sig. } \\
\text { (p) }\end{array}$ \\
\hline \multirow{6}{*}{$\begin{array}{l}\text { Difficulty } \\
\text { Mean }\end{array}$} & \multirow[t]{2}{*}{ Student Affairs } & Academic Affairs & -.078 & .084 & 1.000 \\
\hline & & $\begin{array}{l}\text { Both Academic and } \\
\text { Student Affairs }\end{array}$ & .008 & .104 & 1.000 \\
\hline & \multirow[t]{2}{*}{ Academic Affairs } & Student Affairs & .078 & .084 & 1.000 \\
\hline & & $\begin{array}{l}\text { Both Academic and } \\
\text { Student Affairs }\end{array}$ & .086 & .096 & 1.000 \\
\hline & \multirow{2}{*}{$\begin{array}{l}\text { Both Academic and } \\
\text { Student Affairs }\end{array}$} & Student Affairs & -.008 & .104 & 1.000 \\
\hline & & Academic Affairs & -.086 & .096 & 1.000 \\
\hline $\begin{array}{l}\text { Dependent } \\
\text { Variable }\end{array}$ & (I) Enrollment & (J) Enrollment & $\begin{array}{c}\text { Mean } \\
\text { Difference } \\
(\mathrm{I}-\mathrm{J})\end{array}$ & $\begin{array}{l}\text { Std. } \\
\text { Error }\end{array}$ & $\begin{array}{l}\text { Sig. } \\
(p)\end{array}$ \\
\hline \multirow{12}{*}{$\begin{array}{l}\text { Difficulty } \\
\text { Mean }\end{array}$} & \multirow[t]{3}{*}{ Under 5,000 } & $5,000-10,000$ & .016 & .092 & 1.000 \\
\hline & & $10,001-20,000$ & .199 & .090 & .170 \\
\hline & & Over 20,000 & .330 & .091 & .002 \\
\hline & \multirow[t]{3}{*}{$5,000-10,000$} & Under 5,000 & -.016 & .092 & 1.000 \\
\hline & & $10,001-20,000$ & .183 & .105 & .495 \\
\hline & & Over 20,000 & .314 & .105 & .020 \\
\hline & \multirow[t]{3}{*}{$10,001-20,000$} & Under 5,000 & -.199 & .090 & .170 \\
\hline & & $5,000-10,000$ & -.183 & .105 & .495 \\
\hline & & Over 20,000 & .132 & .103 & 1.000 \\
\hline & \multirow[t]{3}{*}{ Over 20,000} & Under 5,000 & -.330 & .091 & .002 \\
\hline & & $5,000-10,000$ & -.314 & .105 & .020 \\
\hline & & $10,001-20,000$ & -.132 & .103 & 1.000 \\
\hline
\end{tabular}


Table 69 (Cont.)

Differences in Perception of Factors that Form Barriers to Peer Tutoring Based on the Bonferroni Correction

\begin{tabular}{|c|c|c|c|c|c|}
\hline $\begin{array}{l}\text { Dependent } \\
\text { Variable }\end{array}$ & (I) Degree Awarded & $\begin{array}{l}\text { (J) Degree } \\
\text { Awarded }\end{array}$ & $\begin{array}{c}\text { Mean } \\
\text { Difference } \\
\text { (I-J) }\end{array}$ & $\begin{array}{l}\text { Std. } \\
\text { Error }\end{array}$ & $\begin{array}{l}\text { Sig. } \\
\text { (p) }\end{array}$ \\
\hline \multirow{20}{*}{$\begin{array}{l}\text { Difficulty } \\
\text { Mean }\end{array}$} & \multirow[t]{4}{*}{ Associates } & Bachelors & .026 & .153 & 1.000 \\
\hline & & Masters & .027 & .127 & 1.000 \\
\hline & & Doctorate & .062 & .115 & 1.000 \\
\hline & & $\begin{array}{l}\text { Professional (e.g. } \\
\text { JD, MD, DDS) }\end{array}$ & .223 & .130 & .869 \\
\hline & \multirow[t]{4}{*}{ Bachelors } & Associates & -.026 & .153 & 1.000 \\
\hline & & Masters & .001 & .138 & 1.000 \\
\hline & & Doctorate & .037 & .126 & 1.000 \\
\hline & & $\begin{array}{l}\text { Professional (e.g. } \\
\text { JD, MD, DDS) }\end{array}$ & 197 & .140 & 1.000 \\
\hline & \multirow[t]{4}{*}{ Masters } & Associates & -.027 & .127 & 1.000 \\
\hline & & Bachelors & -.001 & .138 & 1.000 \\
\hline & & Doctorate & .035 & .094 & 1.000 \\
\hline & & $\begin{array}{l}\text { Professional(e.g. } \\
\text { JD, MD, DDS) }\end{array}$ & 196 & .111 & .806 \\
\hline & \multirow[t]{4}{*}{ Doctorate } & Associates & -.062 & .115 & 1.000 \\
\hline & & Bachelors & -.037 & .126 & 1.000 \\
\hline & & Masters & -.035 & .094 & 1.000 \\
\hline & & $\begin{array}{l}\text { Professional (e.g. } \\
\text { JD, MD, DDS) }\end{array}$ & .161 & .097 & .980 \\
\hline & \multirow{4}{*}{$\begin{array}{l}\text { Professional } \\
\text { (e.g. JD, MD, DDS) }\end{array}$} & Associates & -.223 & .130 & 869 \\
\hline & & Bachelors & -.197 & .140 & 1.000 \\
\hline & & Masters & -.196 & .111 & .806 \\
\hline & & Doctorate & -.161 & .097 & 980 \\
\hline
\end{tabular}


Table 69 (Cont.)

Differences in Perception of Factors that Form Barriers to Peer Tutoring Based on the Bonferroni Correction

\begin{tabular}{|c|c|c|c|c|c|}
\hline $\begin{array}{l}\text { Dependent } \\
\text { Variable }\end{array}$ & $\begin{array}{l}\text { (I) Carnegie } \\
\text { Classification }\end{array}$ & $\begin{array}{l}\text { (J) Carnegie } \\
\text { Classification }\end{array}$ & $\begin{array}{c}\text { Mean } \\
\text { Difference } \\
(\mathrm{I}-\mathrm{J})\end{array}$ & $\begin{array}{l}\text { Std. } \\
\text { Error }\end{array}$ & $\begin{array}{l}\text { Sig. } \\
(\mathrm{p})\end{array}$ \\
\hline \multirow[t]{14}{*}{$\begin{array}{l}\text { Difficulty } \\
\text { Mean }\end{array}$} & $\begin{array}{l}\text { Research University } \\
\text { (Very High Research) }\end{array}$ & $\begin{array}{l}\text { Research University } \\
\text { (High Research) }\end{array}$ & -.083 & .132 & 1.000 \\
\hline & & Doctoral Research University & -.141 & .132 & 1.000 \\
\hline & & $\begin{array}{l}\text { Masters Colleges and Universities } \\
\text { (Larger Programs) }\end{array}$ & -.139 & .147 & 1,000 \\
\hline & & $\begin{array}{l}\text { Masters Colleges and Universities } \\
\text { (Medium Programs) }\end{array}$ & -.315 & .124 & .336 \\
\hline & & $\begin{array}{l}\text { Masters Colleges and Universities } \\
\text { (Smaller Programs) }\end{array}$ & -.124 & .132 & 1.000 \\
\hline & & Baccalaureate Colleges & -.223 & .128 & 1.000 \\
\hline & & Associates Colleges & -.208 & .132 & 1.000 \\
\hline & $\begin{array}{l}\text { Research University } \\
\text { (High Research) }\end{array}$ & $\begin{array}{l}\text { Research University } \\
\text { (Very High Research) }\end{array}$ & .083 & .132 & 1.000 \\
\hline & & Doctoral Research University & -.058 & .140 & 1.000 \\
\hline & & $\begin{array}{l}\text { Masters Colleges and Universities } \\
\text { (Larger Programs) }\end{array}$ & -.056 & .154 & 1.000 \\
\hline & & $\begin{array}{l}\text { Masters Colleges and Universities } \\
\text { (Medium Programs) }\end{array}$ & -232 & .131 & 1.000 \\
\hline & & $\begin{array}{l}\text { Masters Colleges and Universities } \\
\text { (Smaller Programs) }\end{array}$ & -.040 & 140 & 1.000 \\
\hline & & Baccalaureate Colleges & -.140 & .138 & 1.000 \\
\hline & & Associates Colleges & -.125 & .140 & 1.000 \\
\hline
\end{tabular}


Table 69 (Cont.)

Differences in Perception of Factors that Form Barriers to Peer Tutoring Based on the Bonferroni Correction

\begin{tabular}{|c|c|c|c|c|c|}
\hline $\begin{array}{l}\text { Dependent } \\
\text { Variable }\end{array}$ & $\begin{array}{l}\text { (I) Carnegie } \\
\text { Classification }\end{array}$ & $\begin{array}{l}\text { (J) Carnegie } \\
\text { Classification }\end{array}$ & $\begin{array}{c}\text { Mean } \\
\text { Difference } \\
(\mathrm{I}-\mathrm{J})\end{array}$ & $\begin{array}{l}\text { Std. } \\
\text { Error }\end{array}$ & $\begin{array}{l}\text { Sig. } \\
(\mathrm{p})\end{array}$ \\
\hline \multirow[t]{14}{*}{$\begin{array}{l}\text { Difficulty } \\
\text { Mean }\end{array}$} & $\begin{array}{l}\text { Doctoral Research } \\
\text { University }\end{array}$ & $\begin{array}{l}\text { Research University } \\
\text { (Very High Research) }\end{array}$ & .141 & .132 & 1.000 \\
\hline & & $\begin{array}{l}\text { Research University } \\
\text { (High Research) }\end{array}$ & .058 & .140 & 1.000 \\
\hline & & $\begin{array}{l}\text { Masters Colleges and Universities } \\
\text { (Larger Programs) }\end{array}$ & .002 & .154 & 1.000 \\
\hline & & $\begin{array}{l}\text { Masters Colleges and Universities } \\
\text { (Medium Programs }\end{array}$ & -.174 & .133 & 1.000 \\
\hline & & $\begin{array}{l}\text { Masters Colleges and Universities } \\
\text { (Smaller Programs) }\end{array}$ & .017 & .140 & 1,000 \\
\hline & & Baccalaureate Colleges & -.082 & .137 & 1.000 \\
\hline & & Associates Colleges & -.067 & .140 & 1.000 \\
\hline & $\begin{array}{l}\text { Masters Colleges } \\
\text { and Universities } \\
\text { (Larger Programs) }\end{array}$ & $\begin{array}{l}\text { Research University } \\
\text { (Very High Research) }\end{array}$ & .139 & .147 & 1.000 \\
\hline & & $\begin{array}{l}\text { Research University } \\
\text { (High Research) }\end{array}$ & .056 & .154 & 1.000 \\
\hline & & Doctoral Research University & -.002 & .154 & 1.000 \\
\hline & & $\begin{array}{l}\text { Masters Colleges and Universities } \\
\text { (Medium Programs) }\end{array}$ & -.176 & .148 & 1.000 \\
\hline & & $\begin{array}{l}\text { Masters Colleges and Universities } \\
\text { (Smaller Programs) }\end{array}$ & .015 & .154 & 1.000 \\
\hline & & Baccalaureate Colleges & -.084 & .151 & 1.000 \\
\hline & & Associates Colleges & -.069 & .154 & 1.000 \\
\hline
\end{tabular}


Table 69 (Cont.)

Differences in Perception of Factors that Form Barriers to Peer Tutoring Based on the Bonferroni Correction

\begin{tabular}{|c|c|c|c|c|c|}
\hline $\begin{array}{l}\text { Dependent } \\
\text { Variable }\end{array}$ & $\begin{array}{l}\text { (I) Carnegie } \\
\text { Classification }\end{array}$ & $\begin{array}{l}\text { (J) Carnegie } \\
\text { Classification }\end{array}$ & $\begin{array}{c}\text { Mean } \\
\text { Difference } \\
(\mathrm{I}-\mathrm{J})\end{array}$ & $\begin{array}{l}\text { Std. } \\
\text { Error }\end{array}$ & $\begin{array}{l}\text { Sig. } \\
\text { (p) }\end{array}$ \\
\hline \multirow[t]{12}{*}{$\begin{array}{l}\text { Difficulty } \\
\text { Mean }\end{array}$} & $\begin{array}{l}\text { Masters Colleges } \\
\text { and Universities } \\
\text { (Medium Programs) }\end{array}$ & $\begin{array}{l}\text { Research University } \\
\text { (Very High Research) } \\
\text { Research University } \\
\text { (High Research) }\end{array}$ & $\begin{array}{l}.315 \\
233\end{array}$ & $\begin{array}{l}.124 \\
.133\end{array}$ & 1.000 \\
\hline & & $\begin{array}{l}\text { Doctoral Research University } \\
\text { Masters Colleges and Universities } \\
\text { (Larger Programs) }\end{array}$ & $\begin{array}{l}.174 \\
.176\end{array}$ & $\begin{array}{l}.133 \\
.148\end{array}$ & $\begin{array}{l}1.000 \\
1.000\end{array}$ \\
\hline & & $\begin{array}{l}\text { Masters Colleges and Universities } \\
\text { (Smaller Programs) }\end{array}$ & .192 & .133 & 1.000 \\
\hline & & Baccalaureate Colleges & .092 & .129 & 1.000 \\
\hline & & Associates Colleges & .107 & 133 & 1.000 \\
\hline & $\begin{array}{l}\text { Masters Colleges } \\
\text { and Universities }\end{array}$ & $\begin{array}{l}\text { Research University } \\
\text { (Very High Research) }\end{array}$ & .124 & .132 & 1.000 \\
\hline & & $\begin{array}{l}\text { Research University } \\
\text { (High Research) }\end{array}$ & .040 & .140 & 1.000 \\
\hline & & Doctoral Research University & -.017 & .140 & 1.000 \\
\hline & & $\begin{array}{l}\text { Masters Colleges and Universities } \\
\text { (Larger Programs) }\end{array}$ & -.015 & .154 & 1.000 \\
\hline & & $\begin{array}{l}\text { Masters Colleges and Universities } \\
\text { (Medium Programs) }\end{array}$ & -.192 & .133 & 1.000 \\
\hline & & Baccalaureate Colleges & -.099 & .137 & 1.000 \\
\hline & & Associates Colleges & .085 & .140 & 1.000 \\
\hline
\end{tabular}


Table 69 (Cont.)

Differences in Perception of Factors that Form Barriers to Peer Tutoring Based on the Bonferroni Correction

\begin{tabular}{|c|c|c|c|c|c|}
\hline $\begin{array}{l}\text { Dependent } \\
\text { Variable }\end{array}$ & $\begin{array}{l}\text { (I) Carnegie } \\
\text { Classification }\end{array}$ & $\begin{array}{l}\text { (J) Carnegie } \\
\text { Classification }\end{array}$ & $\begin{array}{c}\text { Mean } \\
\text { Difference } \\
(\mathrm{I}-\mathrm{J}) \\
\end{array}$ & $\begin{array}{l}\text { Std. } \\
\text { Error }\end{array}$ & $\begin{array}{l}\text { Sig. } \\
(\mathrm{p})\end{array}$ \\
\hline \multirow[t]{12}{*}{$\begin{array}{l}\text { Difficulty } \\
\text { Mean }\end{array}$} & Baccalaureate Colleges & $\begin{array}{l}\text { Research University } \\
\text { (Very High Research) } \\
\text { Research University } \\
\text { (High Research) }\end{array}$ & $\begin{array}{l}.223 \\
.140\end{array}$ & $\begin{array}{l}.128 \\
.137\end{array}$ & $\begin{array}{l}1.000 \\
1.000\end{array}$ \\
\hline & & $\begin{array}{l}\text { Doctoral Research University } \\
\text { Masters Colleges and Universities } \\
\text { (Larger Programs) }\end{array}$ & $\begin{array}{l}.082 \\
.084\end{array}$ & $\begin{array}{l}.137 \\
.151\end{array}$ & $\begin{array}{l}1.000 \\
1.000\end{array}$ \\
\hline & & $\begin{array}{l}\text { Masters Colleges and Universities } \\
\text { (Medium Programs) }\end{array}$ & -.092 & .129 & 1.000 \\
\hline & & $\begin{array}{l}\text { Masters Colleges and Universities } \\
\text { (Smaller Programs) }\end{array}$ & .099 & .137 & 1.000 \\
\hline & & Associates Colleges & .014 & .136 & 1.000 \\
\hline & Associates Colleges & $\begin{array}{l}\text { Research University } \\
\text { (Very High Research) }\end{array}$ & .208 & .132 & 1.000 \\
\hline & & $\begin{array}{l}\text { Research University } \\
\text { (High Research) }\end{array}$ & 125 & .140 & 1.000 \\
\hline & & Doctoral Research University & .067 & 140 & 1.000 \\
\hline & & $\begin{array}{l}\text { Masters Colleges and Universities } \\
\text { (Larger Programs) }\end{array}$ & .069 & .154 & 1.000 \\
\hline & & $\begin{array}{l}\text { Masters Colleges and Universities } \\
\text { (Medium Programs) }\end{array}$ & -.107 & .133 & .429 \\
\hline & & $\begin{array}{l}\text { Masters Colleges and Universities } \\
\text { (Smaller Programs) }\end{array}$ & .085 & .140 & 1.000 \\
\hline & & Baccalaureate Colleges & -.014 & .137 & 1.000 \\
\hline
\end{tabular}


As indicated in Table 69, there were no significant differences in the perception of factors that form barriers to peer tutoring between groups for the following demographic factors at $p<.05$ level: a) department affiliation, b) degrees awarded, and c) Carnegie classification. However, there was a significant difference based on enrollment between the following groups: a) over $20,000$ and under 5,000 ( $\mathrm{p}=.002)$ and $\mathrm{b})$ over 20,000 and 5,000-10,000 $(\mathrm{p}=.020)$. The following conclusion can be drawn from Tables 68 and 69:

- Administrators in Region II NASPA institutions believe institutional size (enrollment) is a barrier to peer tutoring.

- Furthermore, administrators in Region II NASPA institutions believe that the larger the Enrollment, the more barriers there are to peer tutoring.

\section{Discussion}

This section addresses the following questions:

a) Why did fewer faculty respond to this study?

b) Why do administrators believe that faculty present barriers to peer tutoring?

c) How can we improve peer tutoring based on the results of this study?

d) Can peer tutoring programs become institutionalized?

e) What makes for a successful peer tutoring program?

Question one. Why did fewer faculty respond to this study? This study was conducted in the summer of 2011. Two thousand one hundred fifty-nine surveys were delivered to administrators and faculty who were identified from a list of members of Region II NASPA institutions as having an interest in and knowledge about peer tutoring programs, and who were involved in their supervision, evaluation, and delivery of services. Out of the 488 ( 23 percent) surveys that were returned, only 192 were completed, which made 296 (61 percent) of the 
surveys unusable. A review of the incomplete surveys revealed that most of the respondents had only completed the demographic portion of the survey and identified themselves as faculty who were not involved in the day-to-day operations of peer tutoring. Of the respondents who completed the survey, the majority (167 or 87 percent) were administrators who had administrative oversight, but were not involved in the day-to-day operation of peer tutoring. Of the remaining 25 respondents who completed the survey, only 9 (4.7) percent identified themselves as faculty and 10 (5.2 percent) identified themselves as both an administrator and faculty member.

Factors that may have influenced participation in the survey included a) the time of year the survey was sent to participants, b) the perception of faculty roles and department allegiance, c) the lack of support and recognition for participating in academic support programs, and d) the amount of time required to oversee the program.

Time of year. The survey was sent out for the first time in June 2011 and again in August 2011, close to the beginning of the academic year, to those who had not yet completed it. Most administrators are twelve month employees and would be in their offices during the summer, while most faculty are nine or ten month employees, and more likely to be out of the office. The selection of the dates was to target both groups; however, the researcher found that at the beginning of the academic year faculty were busy planning their courses and less likely to participate.

Faculty roles and department allegiance. Before the survey was sent out, reliability was established by "using a pilot test to collect data from...subjects not included in the sample" (Radhakrishna, 2007, para. 10). This study recruited ten participants for a pilot study from a group of professionals at West Virginia University who were interested in and have knowledge 
about academic tutoring programs, and who were involved in their supervision, evaluation, and delivery of services from outside the sample. The researcher contacted department chairs and college deans for the names of faculty and administrators who were in charge of peer tutoring programs in their particular department or college. Although they were considered to have a supervisory role in peer tutoring, it is interesting to note that most of the faculty did not see themselves involved in peer tutoring. This might be another reason more faculty did not complete the survey; they tend not to see themselves as being involved enough in peer tutoring programs to have the knowledge to answer the survey questions.

Also, while responsibility for meeting academic goals has been given to faculty, responsibility for developing educational support programs has been taken from faculty and given to administrators (Turoff, 2006). Berge and Muilenburg (2001) reported that faculty participation in academic programs can be problematic in most existing organizational structures with faculty answering to an administrator. In addition, although administrators agreed that faculty should be involved in academic support services, the trend has been to place peer tutoring programs under the guidance of student affairs rather than academic affairs, resulting in less faculty participation (Tinto, 1997). From personal experience with peer tutoring, it seems that faculty may also feel alienated from decision-making, and therefore less willing to participate.

Lack of support and recognition. The lack of faculty compensation and recognition for their time and service have been identified as a barrier to the development of and participation in academic support programs in higher education (Berge \& Muilenburg; 2001; Levine \& Sun, 2002; Moser, 2007). Research indicated that before new academic programs can be developed and implemented and before we can expect faculty to participate, a reward system of faculty compensation and recognition must be in place (Diamond 2006). Additional factors that deter 
faculty from participating in academic support programs included the lack of credit towards promotion and tenure, lack of support from department heads and colleagues, and lack of grants and/or merit pay (O'Quinn \& Corey, 2002).

Time commitment. Support for the time commitment necessary to participate in academic support programs was identified as a critical factor in their success (Berge \& Schrum, 1998; Moser, 2007). In fact, the number one concern among faculty in taking on more responsibility, such as the oversight of peer tutoring in their department, was the additional time needed to prepare and the time it would take away from the research, teaching, and service required for tenure and promotion (Maguire, 2005). Therefore, untenured faculty and faculty who are working towards promotion may not participate in peer tutoring because they are concerned that the time commitment may prevent them from getting promotion and tenure.

\section{Question two: Why do administrators believe that faculty present barriers to peer}

tutoring? Research has indicated that the retention rate of students is greatly affected by the level and quality of their interactions with faculty (Astin 1993) and relationships between students and faculty are essential to the development of students' attitudes towards learning (Thomas, 2002). However, the move of peer tutoring programs in many institutions from academic affairs to student affairs may have caused changes in faculty roles within their departments and the institution, and created roadblocks to the implementation of supplemental academic programs (Berge \& Muilenburg, 2001). Also, at a time when the demand for academic support programs is growing, most college campuses do not have the financial resources to implement programs and make changes that will meet the demand (Berge \& Schrum, 1998).

Faculty roadblocks to peer tutoring. Results of this study indicated that administrators in Region II NASPA institutions perceived that there are faculty roadblocks to peer tutoring and 
identified the following barriers to faculty participation in peer tutoring: the lack of a) professional and financial incentives; b) a shared vision among departments; c) collaboration between faculty and administrators to decide the peer tutoring budget, plan programs, implement programs, and access and evaluate programs; and d) communication between faculty and students that supports both different teaching styles and different learning styles.

Though administrators have not ignored the importance of faculty participation in peer tutoring, "most have not seen it as the centerpiece of their efforts to promote student persistence, preferring instead to locate those efforts outside the classroom in the domain of student affairs" (Tinto, 1997, p. 599). From personal experience in peer tutoring, it appears that some administrators may want to make all of the decisions, causing a decline in faculty interest and a roadblock to faculty involvement in peer tutoring.

Furthermore, in some institutions, faculty have been put in charge of academic programs in the residence halls to promote student success because of the faculty's vested interest in the students' academic success; however, administrators may not want to hear how faculty think the programs should be run. It is this researcher's opinion that the lack of collaboration on peer tutoring between administrators and faculty may create another roadblock to faculty participation and a reason faculty are seen by administrators as barriers to peer tutoring. If peer tutoring programs are to work, there must be a shared vision among departments and collaboration with faculty and administrators on factors such as planning, costs, compensation, distribution of revenue, and schedules (Burge \& Muilenburg, 2001).

Question three: How can we improve peer tutoring based on the results of this study?

Factors that contribute to the growth of peer tutoring. Bastedo (2007) reported that in 
order to be successfully implemented, programs must be compatible to the goals and mission of the institution; and in order to be successful, ideas and decision making must be shared among members of the college community. Furthermore, to centralize or decentralize has been an ongoing question within higher education. Once an institution begins to increase its programs it faces two choices: a) remain decentralized with each department responsible for its own programs or b) establish an institution-wide tutoring program that is overseen by one department (Pina, 2008b), Cho and Berge (2002) reported that centralization ensures consistency in management, supervision, and training.

In an effort to create programs that support their mission and culture, many institutions have moved to creating a senior-level position, such as an assistant provost who has ties to both student affairs and academic affairs, to coordinate the implementation and supervision of these programs (Holland, 2009). However, it is very important that everyone is on the same page before peer tutoring can be implemented (Bastedo, 2007).

There has to be clear objectives agreed on and understood by the proponents and the commitment needed for success has to be understood and agreed by all involved: coordinators...faculty, sponsors etc.; sustainability must be a priority and, to ensure credibility, evaluation must be a built-in component, not an after-thought. (Elsegood, 2003, para. 4)

Furthermore, because the collaboration of student affairs and academic affairs is necessary for the implementation of new student support programs (Kezar, 2003), the support of campus leaders is essential to the success of campus programs (Berge \& Schrum, 1998). A shared vision, a strategic plan, and leaders within the institution who are knowledgeable and 
supportive of student support programs are essential to implementing new programs (Cho \& Berge, 2002).

According to administrators in Region II NASPA who responded to this study, the following factors must be in place before peer tutoring can be implemented:

- One central office that oversees the implementation, supervision, and assessment of the peer tutoring program.

- Peer tutoring practices that are oriented toward developing a climate in which students' responsibility and active participation are promoted.

- Communication between faculty and students that encourages student engagement, and supports different teaching and learning styles.

- Regular evaluations of the peer tutoring program to ensure that educational goals are met.

- Ongoing assessments to determine student, faculty, and institutional needs in the area of peer tutoring.

- Visibility of the peer tutoring program on campus.

- Permanent funding for the peer tutoring program and staff on the institutional budget.

- Program compatibility with the institution's mission and goals.

- Formal policies and procedures for peer tutoring.

- Ongoing staff development on peer tutoring best practices.

- A master plan outlining relevance, importance, objectives, and costs of peer tutoring.

- A program director for peer tutoring with decision-making authority.

- A shared vision of peer tutoring among departments.

- Collaboration between administrators and faculty to plan, implement, and evaluate program effectiveness. 
- A peer tutoring program that is a campus-wide function and not part of a specific school, department, or academic discipline.

From personal experience in a residential peer tutoring program, it is the opinion of this researcher that although all of the factors that facilitate peer tutoring as identified by administrators in Region II NASPA are important, two critical factors are a) there must be a shared vision of peer tutoring among departments (Student Affairs and Academic Affairs) and b) collaboration between administrators and faculty on the planning, implementation, and assessment of peer tutoring is essential. If Academic Affairs and Student Affairs do not agree on the importance of peer tutoring and not only support faculty, but encourage faculty to participate, academic support programs cannot be successful.

\section{Question four: Can peer tutoring programs become institutionalized?}

Institutionalization in higher education occurs when an idea that has been implemented becomes part of an ongoing practice (Pina, 2008a). When a program becomes institutionalized "it is no longer considered to be an innovation - it is now looked upon as a normal and vital part of the organization" (Pina, 2008a, p. 428). Pina (2005) found that in order for an institutional program to be implemented and become part of an ongoing practice, it must be first be advertised by the administration as a vital part of the intuition's goals and mission. Second, in order for programs to be successful once they become institutionalized, faculty must be loyal to the university rather than his/her individual department (Bastedo, 2007).

This study identified four factors that are critical to the institutionalization of peer tutoring:

- One central office must oversee the implementation, supervision, and assessment of the peer tutoring program. 
- Peer tutoring practices must be oriented toward developing a climate in which students' responsibility and active participation are promoted.

- There must be regular communication between faculty and students that encourages student engagement.

- Regular evaluations of the peer tutoring program must be done to ensure that educational goals are met.

This study also identified four factors that were both facilitators to the institutionalization of peer tutoring and potential barriers to the institutionalization of peer tutoring. Therefore, before peer tutoring can become institutionalized, the following factors must be in place:

- There must a shared vision of peer tutoring among departments.

- Faculty and administrators must collaborate on peer tutoring to plan programs.

- Faculty and administrators must collaborate on peer tutoring to implement programs.

- Faculty and administrators must collaborate on peer tutoring to access and evaluate program effectiveness.

From personal experience in peer tutoring, it is this researcher's opinion that peer tutoring can only become institutionalized when these factors are in place.

Question five: What makes for a successful peer tutoring program? Rendon (1995)

identified two critical factors that influence students' decision to remain in college as a) successfully making the transition to college supported by tutoring programs and b) making positive connections with faculty. "Institutions not set up to accommodate [students] create an invalidating environment for students who do not "fit the mold" "(Rendon, 1995, p. 9), which may lead to the students leaving the institution. 
Lau (2003) reported that student retention is directly related to students' institutional experiences and one of the main reasons students leave an institution is that the institution has not provided programs that meet their learning and educational needs. Therefore, if institutions want to increase retention, one of the most important roles of higher education is to ensure student success by providing academic support programs to meet students' learning and educational needs.

Factors that contribute to the success of peer tutoring. Administrators in Region II NASPA identified the following four factors as most important to the institutionalization of peer tutoring: a) centralization - having one central office oversee the implementation, supervision, and assessment of the peer tutoring program, b) responsibility - developing a climate in which students' responsibility and active participation are promoted, c) communication - encouraging communication between faculty and students that encourages student engagement and supports different teaching and learning styles, and d) evaluations - having regular evaluations of the peer tutoring program to ensure that educational goals are met.

Other factors identified as important, but not critical were a) a shared vision among departments and collaboration on planning, implementing, and evaluating the peer tutoring program; b) regular assessments to determine student, faculty, and institutional needs; c) visibility of the program on campus; d) permanent funding in the institution's budget; and e) implementation of formal policies and procedures that are compatible with the institution's mission and goals.

The role of peer tutoring in retention. Pressure from college presidents to increase retention and grade point averages (GPAs) has caused retention in higher education to become one of the most significant issues today (Lau, 2003). According to the most recent data collected 
by Act, Inc. (2011), a research group that has compiled a comprehensive database of first-year to second-year retention rates since 1983, average retention rates for first-year college students returning to the same institution for their second year of college remained stable for the 2010-11 academic year at 67 percent. This means that approximately two-thirds of all first-year students at U.S. two-year and four-year colleges returned for their second year of school. What is alarming, however, is that retention rates have dropped significantly since 1989 , when retention rates for four-year institutions was as high as 74 percent (Act, Inc. 2010b). An article in Activity (“College Retention Rates Improving," 2011, Spring) reported that if higher education wants to increase retention, it is going to have to provide tutoring programs to ensure students' academic success.

Peer tutoring programs have been found to be effective in retaining students (Brawer, 1996). At many academic resource centers, the goal of tutoring is "to provide assistance that will ultimately lead to increased student success and graduation rates" ("Goals of the Academic Resource Centers," 2012, para. 1). Peer tutoring provides students with a social and academic support system that ties them to the college community and encourages their continued attendance (Beal \& Noel, 1980; Bean, 1985; Higgins, 2004; Luca \& Clarkson, 2002; Pascarella \& Terenzini, 1991; Pendleton, 2005; Tinto, 1997). The more academically involved students are and the more they interact with other students, the more comfortable they feel in their new environment and the more likely they are to remain in college (Benjamin, 2001; Chickering \& Gamson, 1987; Tinto, 1998a).

Decreases in federal and state funding have caused some colleges to recruit less qualified students to bring in revenue (Aho, 2011). For example, due to budget cuts "some state schools are rejecting in-state applicants in favor of less qualified out-of-state students" (Aho, 2011, para. 
1). Although this may also be a reason for a decrease in retention rates over the years, it is this researcher's opinion that the recruitment of less qualified students has also increased the need for student support services; and if we are going to recruit these students, it is our duty to provide programs to retain them.

The role of faculty/student relationships in retention. Research has indicated that the retention rate of students is greatly affected by the level and quality of their interactions with faculty (Astin 1993) and students who interact with faculty tend to stay in college longer

(Gardner \& Jewler, 1997). It

...is now a widely accepted notion that the actions of the faculty... are key to institutional efforts to enhance student retention. Though it is true...that student retention is everyone's business, it is now evident that it is the business of the faculty in particular. (Tinto, 2006-7, p. 5)

O’Neil (2009) identified communication between faculty and students as a factor that influences student success. In addition, one of the elements of a successful tutoring program is communication between faculty and students that a) encourages student engagement and b) supports different learning styles (Lau, 2003; O’Neil, 2009). Research on peer tutoring has shown that relationships between students and faculty are essential to the development of students' attitudes towards learning and coping with academic difficulties, (Thomas, 2002). As a result, retention can be highly affected by increasing a) student interaction with faculty (Leone $\&$ Tian, 2009) and b) student support services, such as peer tutoring (Bean, 1985). This success might be attributed to the fact that faculty have a vested interest in student success.

\section{Recommendations}

This section addresses recommendations for administration, practice, and research. 
Administration. This study examined institutional practices that lead to the implementation and institutionalization of peer tutoring programs and identified factors that lead to successful peer tutoring programs; however, there was a lack of literature on how the success of peer tutoring is measured. The difficult task of evaluating the success of peer tutoring must include not only looking at the presence of these factors, but also examining the following:

- Who is using peer tutoring.

- What retention rates are.

- Organizational structure.

- Differences in peer tutoring programs that are centralized verses those that are decentralized.

- Who has decision-making authority?

- Who supports peer tutoring.

- Adequacy of funding.

- What should be included in staff development and training?

Practice. This study can serve as a guide for best practices in peer tutoring, which can be used for a) establishing policies and procedures for peer tutoring, b) assessing and improving current peer tutoring programs, c) establishing priorities for developing new peer tutoring programs, and d) making decisions that will lead to the institutionalization of peer tutoring. With the current trend to centralize the supervision, evaluation, and assessment of institutional programs, there needs to be regular meetings and ongoing communication between those who are overseeing peer tutoring and those who are involved in the day-to-day-operations of peer tutoring. The results of this study indicate that if there is to be cooperation between 
departments that leads to the successful implementation and institutionalization of peer tutoring programs, there must be:

- collaboration between Academic Affairs and Student Affairs on the planning, implementation, evaluation, and assessment of peer tutoring.

- a mission and goals of peer tutoring that are consistent with the institution's missions of goals.

- permanent funding for peer tutoring on the institution's budget.

- ongoing training and professional development for peer tutoring administrators and staff.

- a high level of visibility of peer tutoring, this will lead to cooperation between departments.

Research. The findings of this study were based on the completion of a survey on a) factors that facilitate peer tutoring and b) factors that form barriers to peer tutoring as perceived by administrators in a particular group (NASPA). The study looked at the following demographics: a) department affiliation, b) enrollment, c) degrees awarded, and d) Carnegie classification. Research in the following areas may lead to a better understanding of peer tutoring programs:

- The results of this study present new research on peer tutoring and provide guidance that may be used by administrators and faculty to a) evaluate existing peer tutoring programs to determine strengths, weaknesses, and areas for improvement; b) establish priorities in developing new peer tutoring programs; and c) develop strategies that will lead to the improvement and institutionalization of peer tutoring. Although this study identified factors that lead to the successful implementation of peer tutoring programs, there was a lack of research on measuring the success of peer tutoring. Further research on exploring 
what constitutes a successful peer tutoring program would establish a matrix that could be used as a tool for a) evaluating peer tutoring, b) identifying factors that are in place in successful peer tutoring programs, and c) understanding why peer tutoring is successful at some institutions and not successful at others.

- The findings of this study have positive implications for institutions wishing to institutionalize peer tutoring and identify key factors that support the endurance of peer tutoring programs: a) collaboration between administrators and faculty on planning, implementation, and assessment of peer tutoring; b) communication between faculty and students to encourage student engagement and support different teaching and learning styles; c) centralization of the supervision and evaluation of peer tutoring; d) ongoing staff development; and e) permanent funding for peer tutoring. However, there was a lack of research on whether institutions where programs are supervised by one central office are more successful when each of the above factors have been implemented. Further research on the centralization of peer tutoring could identify factors that are present in peer tutoring programs that have become institutionalized.

- Although the institutionalization factors identified in this study provide a model for cooperation between those who oversee the supervision, evaluation, and assessment of peer tutoring (administrators) and those who oversee the day-to-day operations of peer tutoring (faculty); there was a gap in the research on the relationship between the administrators and faculty who are involved in the supervision, evaluation, and day-today operations of peer tutoring that needs to be addressed.

- This study did not look at the role of funding of peer tutoring as a demographic factor for success in the implementation and institutionalization of peer tutoring. Research on 
whether schools with more funding for peer tutoring have more successful tutoring programs would provide insight into what is necessary for the institutionalization of peer tutoring.

- Although faculty are expected to participate in the oversight of peer tutoring in their departments, they are not always trained. Therefore, research should be conducted on staff development and faculty training in the supervision, evaluation, and assessment of peer tutoring.

- This study did not address faculty views on peer tutoring. Future research on factors that faculty perceive as a) facilitators of and b) barriers to peer tutoring would significantly contribute to the literature on the implementation and institutionalization of peer tutoring and provide a list of factors that would lead to the cooperative efforts of administrators and faculty who are involved in the day-to-day-operation, supervision, evaluation, and assessment of peer tutoring.

- Although this study indicated that there is a link between peer tutoring, academic success, and retention, there was a gap in the literature on the retention rates of students who participate in peer tutoring. A future study on the graduation rates of students who participate in peer tutoring would create a tool that could be used for planning strategies for increasing graduation rates.

- This study was sent to a group of administrators whose views may not be representative of the entire population. A future study with a random sample of administrators across the country would provide further insight into factors that contribute the success of peer tutoring and enable peer tutoring programs to endure and become institutionalized. 


\section{References}

About the Carnegie classifications. (n.d.) Retrieved from The Carnegie Foundation for the Advancement of Teaching website at http://classifications.carnegiefoundation.org/

About us. (n.d.). Retrieved from the National Association of Student Personnel Administrators (NASPA) website at http://naspa.org/about/default.cfm

Academic learning center objectives. (2010). Retrieved from the Argosy College website at http://www.auchicagolib.org/ALCobjectives.htm

Act, Inc. (2010a). National collegiate retention and persistence to degree rates. Retrieved from http://www.act.org/research/policymakers/pdf/retain_2010.pdf

Act, Inc. (2010b). 2010 Retention/completion summary tables. Retrieved from http://www.act.org/research/policymakers/pdf/10retain_trends.pdf

Act, Inc. (2011). National collegiate retention and persistence to degree rates. Retrieved from http://www.act.org/research/policymakers/pdf/retain_2011.pdf

Adams, C. J. (2011). Colleges try to unlock secrets to student retention. Education Week, 31(4), 16-17. Retrieved from http://www.edweek.org/ew/articles/2011/09/21/04college_ep.h31.html?tkn=YVWF4w9 UBHU\%2Fai\%2B0qMuSZmbu9m9LIroCflVc\&cmp=ENL-EU-NEWS2

Ad Hoc Committee for First Year \& Second Year Experiences at West Virginia University. (2010, September). Enduring academic success in the first and second years. A report submitted to West Virginia University, Morgantown, WV.

Aho, K. (2011, May 10). 'A' average isn't enough for college. Retrieved from the MSN Money website at http://money.msn.com/college-savings/an-a-average-is-not-enough-forcollege.aspx 
Altman, D., Burton, N., Cuthill, I., Festing, M., Hutton, J., \& Playle, L. (2006). Why do a pilot study? Retrieved from http://www.nc3rs.org.uk/downloaddoc.asp?id=400

Analyzing and interpreting data. (n.d.). Retrieved from the Syracuse University Office of Institutional Research and Assessment website at https://oira.syr.edu/oira/Assessment/AssessPP/Analyze.htm

Analyzing and interpreting data: Making sense of it all. (n.d.). Retrieved from http://www.unf.edu/dept/fie/sdfs/publications/7Analyzing.pdf

Astin, A. (1993). What matters in college? Liberal Education, 79(4), 4-15.

Bastedo, M. (2007). Bringing the state back in: Promoting and sustaining innovation in public higher education. Higher Education Quarterly, 61(2), 155-170.

Beal, P., \& Noel, L. (1980). What works in student retention: The report of a joint project of the American College Testing Program and the National Center for Higher Education Management Systems. (Report No. HE013350). Iowa City, IA: American College Testing Program. (ERIC Document Reproduction Service No. ED197635).

Bean, J. P. (1985). Interaction effects bases on class level in an explanatory model of college student dropout syndrome. American Educational Research Journal, 22(1), 35-64.

Beck, P. (1978). Peer tutoring at a community college. College English, 40, 437-439.

Benjamin, M. (2001). A qualitative study of the experiences of learning center peer mentors at Iowa State University. A study submitted to the Peer Mentor Subcommittee. Retrieved from www.lc.iastate.edu/QualitativeStudyPM.pdf

Berge, Z. L., \& Muilenburg, L. Y. (2001), Obstacles faced at various stages of capability regarding distance education in institutions of higher education: Survey results. Tech Trends, 46(4), 40-45. 
Berge Z. L., \& Schrum, L. (1998).Linking strategic planning with program implementation for distance education. Cause/Effect Journal, 21(3), 31-38

Bevea, S. C., \& Nicoll, L. H. (1997, October). Selecting samples for research studies requires knowledge of the populations of interest. AORN Journal, 1-4. Retrieved from http://findarticles.com/p/articles/mi_m0FSL/is_n4_v66/ai_19996778/?tag=content;col1

Blair, J. (2011). Pretesting. Retrieved from http://www.abtassociates.com/Page.cfm?PageID=40513\&FamilyID=40312\&T2=40511

Blanc, R. A., DeBuhr, L. E., \& Martin, D. C. (1983). Breaking the attrition cycle: The effects of supplemental instruction on undergraduate performance and attrition. Journal of Higher Education, 54(1), 80-90.

Blustain, H, Goldstein, P., \& Lozier, G. (1998). Assessing the new competitive landscape. Cause/Effect Journal, 21(3), 19-27.

Boggs, G. R. (1998). Accepting responsibility for student learning. On the Horizon, 6(1), 5-6.

Bonferroni's method. (n.d.). Retrieved from the Engineering Statistics Handbook website at http://itl.nist.gov/div898/handbook/prc/section4/prc473.htm

Bowyer-Bower, T. A. (1954). A pioneer of army education: The Royal Military Asylum, Chelsea, 1801-1821. British Journal of Educational Studies, 2(2), 122-132. doi: 10.1080/00071005.1954.9972916

Brawer, F. B. (1996). Retention-attrition in the nineties. ERIC Digest. Retrieved from http://www.ericdigests.org/1996-4/retention.htm

Brown, J. D. (1997). The reliability of surveys. Shiken: JALT Testing \& Evaluation SIG Newsletter, 1(2), 18-21. 
Brown, J. D. (2002). The Cronbach alpha reliability estimate. Shiken: JALT Testing \& Evaluation SIG Newsletter, 6(1), 17-18.

Bruffee, K.A. (1980). Two related issues of peer tutoring: Program structure and tutor training. College Composition and Communication, 31(1), 76-80.

Buelo, J., \& Hinkle, J. (2008.). Why are reliability and validity important to neuroscience nurses? Journal of Neuroscience Nursing, 40(6), 369-372.

Bushong, S. (2009, January 30). Freshman retention drops, except at 2-year colleges. The Chronicle of Higher Education, p. A17. Retrieved from http://chronicle.com/article/Freshman-RetentionDrops/30306/?otd=Y2xpY2t0aHJ1Ojo6c293aWRnZXQ6OjpjaGFubmVsOm5ld3MsYXJ 0aWNsZTpmemVzaG1hbi1yZXRlbnRpb24tY29udGludWVzLXRvLWRIY2xpbmUtcm Vwb3J0LXNheXM6OjpjaGFubmVsOnN0dWRlbnRzLGFydGljbGU6ZnJlc2htYW4tcm V0ZW50aW9uLWRyb3BzLWV4Y2VwdC1hdC0yLXIlYXItY29sbGVnZXM=

Can anyone explain the meaning of "Cronbach Alpha" to me in layman's terms? (2009, November 20). [Web log post]. Retrieved from http://www.linkedin.com/answers/management/business-analytics/MGM_ANA/590209315595

Canadian Psychological Association. (1996). Guidelines for educational and psychological testing. Retrieved from http://www.umdnj.edu/idsweb/idst5350/test_reliability_validity.htm

Cherry, K. (2011). What is reliability? Retrieved from the About.com website at http://psychology.about.com/od/researchmethods/f/reliabilitydef.htm 
Chickering, A. W., \& Gamson, Z. F. (1987). Seven principles for good practice in undergraduate education. Paper presented to the American Association in Higher Education at Wingspread Foundation, Racine, WI. Abstract retrieved from http://learningcommons.evergreen.edu/pdf/fall1987.pdf

Cho, S. K., and Berge, Z. L. (2002). Overcoming barriers to distance training and education. Education at a Distance, 16(1). Retrieved from http://www.usdla.org/html/journal/JAN02_Issue/article01.html

Classification description/Enrollment profile classification. (n.d.). Retrieved from the Carnegie Foundation for the Advancement of Teaching website at http://classifications.carnegiefoundation.org/descriptions/enrollment_profile.php

Classification description/Graduate instructional program classification. (n.d.). Retrieved from the Carnegie Foundation for the Advancement of Teaching website at http://classifications.carnegiefoundation.org/descriptions/grad_program.php

Classification description/Size and setting classification. (n.d.). Retrieved from the Carnegie Foundation for the Advancement of Teaching website at athttp://classifications.carnegiefoundation.org/descriptions/size_setting.php

Classification descriptions. (n.d.). Retrieved from the Carnegie Foundation for the Advancement of Teaching website at http://classifications.carnegiefoundation.org/descriptions/

Clemence, R.V. (1961). The Wellesley undergraduate tutorial. The American Economic Review, 51(3), 385-388.

Cohen, P. A., Kulik, J. A., \& Kulik, C. C. (1982). Educational outcomes of tutoring: A metaanalysis of findings. American Educational Research Journal, 19(2), 237-248. 
College retention rates improving at two-year schools, declining at four-year schools. (2011, Spring). Activity, 49(2). Retrieved from the ACT website at http://www.act.org/activity/spring2011/retention.html

Collie, S. L., \& Rine, P. J. (2009). Survey design: Getting the results you need. Retrieved from the University of Virginia Office of Process Simplification website at http://www.virginia.edu/processsimplification/resources/survey_design.pdf

Cronon, W. (2009). The importance of a good research question. Retrieved from http://www.williamcronon.net/researching/questions.htm

Cronbach's alpha. (n.d.). Retrieved from the McGill University website at http://www.medicine.mcgill.ca/strokengine-assess/definitions-en.html

Cronbach's alpha. (2011). Retrieved from the Wikipedia website at http://dictionary.sensagent.com/Cronbach\%27s_alpha/en-en/

Dabkowski, B. (2000). The history of peer tutoring. Retrieved from http://wrt-intertext.syr.edu/VIII/dabkowski.html

Danya International, Inc. (2003). The relationship between the research question, hypotheses, specific aims, and long-term goals of the project. Retrieved from http://www.theresearchassistant.com/tutorial/2-1.asp

Davis, T. M., \& Murrell, P. H. (1993). Turning teaching into learning: The role of student responsibility in the collegiate experience. ASHE-ERIC Higher Education Report No. 8. Washington, DC: George Washington University. (ERIC Document Reproduction Service No. ED372703). Retrieved from http://www.eric.ed.gov/PDFS/ED372703.pdf

Developing a survey. (n.d.). Retrieved from http://www.innonet.org/client_docs/File/Survey_Dev_Tips.pdf 
Diamond, R. M. (2006, September 8). Why colleges are so hard to change. Inside Higher Ed. Retrieved from http://www.insidehighered.com/views/2006/09/08/diamond

Difference between T-TEST and ANOVA. (2012). Retrieved from http://www.differencebetween.net/miscellaneous/difference-between-t-test-and-anova/

Elsegood, R. (2003, July.) The integration of peer tutoring schemes into academic programmes/subjects to enhance learning and teaching in universities in Hong Kong. Retrieved from ptrc.edc.polyu.edu.hk/evaluation/assess_rpt02.doc

Experiment resources. (2008). Types of Research Designs. Retrieved from http://www.experiment-resources.com/research-designs.html

Faculty compensation. (2009). Retrieved from https://www.nln.org/aboutnln/reflection_dialogue/refl_dial_4.htm

Fantuzzo, J. W., Riggio, R. E., Connelly, S., \& Dimeff, L. A. (1989). Effects of reciprocal peer tutoring on academic achievement and psychological adjustment: A component analysis. Journal of Educational Psychology, 81(2), 173-177.

Field, A. (2005). Discovering statistics using SPSS. London, England: Sage Publications Ltd.

Formula: Standard deviation. (n.d.). Retrieved from http://easycalculation.com/statistics/learnstandard-deviation.php

French, T. (2008, May 19). Export Data from an Excel Sheet to a Word Document. Retrieved from the About.com website at http://spreadsheets.about.com/b/2008/05/19/export-datafrom-an-excel-sheet-to-a-word-document-2.htm

Gaberson, K. B. (2007, December). Measurement reliability and validity. AORN Journal, 1-5. Retrieved from http://findarticles.com/p/articles/mi_m0FSL/is_n6_v66/ai_20157980/?tag=rbxcra.2.a.11 
Galusha, J. M. (1997). Barriers to learning in distance education. Interpersonal Computing and Technology: An Electronic Journal for the 21st Century, 5(3-4), 6-14. Retrieved from http://www.emoderators.com/ipct-j/1997/n4/galusha.html

Gardner, J. N., \& Jewler, A. J. (1997). Your college experience: Strategies for success. Retrieved from http://www.amazon.com/Your-College-Experience-StrategiesSuccess/dp/0312687745\#reader_0312687745

Gilroy, I. D. (n.d.). The Rev Dr Andrew Bell: Founder of Madras College. A talk at the University Open Association, University of St. Andrews, Fife, Scotland, United Kingdom. Retrieved from http://www.madras.fife.sch.uk/archive/articles/therevdrandrewbell.html

Goals. (n.d.). Retrieved from the National Association of Student Personnel Administrators (NASPA) website at http://www.naspa.org/about/goals.cfm

Goals of the Academic Resource Centers. (2012). Retrieved from the WVU Office of Retention and Research website at http://retention.wvu.edu/academic_resource_centers

Goldschmidt, B., \& Goldschmidt, M. L. (1976). Peer teaching in higher education: A review. Higher Education 5, 9-33.

Good, J. M., Halpin G., \& Halpin, G. (2000). A promising prospect for minority retention: Students becoming peer mentors. The Journal of Negro Education, 69(4), 375-383.

Goodlad, S. (1998). Mentoring and tutoring by students [Sinclair Goodlad, Ed.]. London, England: Kogan Page Limited. Retrieved from http://books.google.com/books?hl=en\&lr=\&id=DGe0v6oANi4C\&oi=fnd\&pg=PR8\&dq= articles+on+tutoring+by+Goodlad+and+Hirst\&ots=3uuwjJLwdW\&sig=JiXVwrZZ3hzS Z9LuHPFdyLYj1OQ\#v=onepage\&q\&f=false 
Griswold, G. (2003). Writing centers: The student retention connection. Academic Exchange Quarterly, 7(4), 277-281.

Hawkins, T. (1980). Intimacy and audience: The relationship between revision and the social dimension of peer tutoring. College English, 42(1), 64-68.

Hendriksen, S. I., Yang, L., Love, B., \& Hall, M. C. (2005). Assessing academic support: The effects of tutoring on student learning outcomes. Journal of College Reading \& Learning, $35(2), 56-65$.

Higgins, B. (2004). Relationship between retention and peer tutoring for at-risk students. Journal of Nursing Education 43(7), 319-321.

Higher Education Academy. (n.d.). Using students as peer tutors or assessors. Retrieved from http://www.materials.ac.uk/pub/Peer-tutors.pdf

Holland, B. A. (2009). Will it last? Evidence of institutionalization at Carnegie classified community engagement institutions. New Directions for Higher Education, 147, 85-98. doi: $10.1002 /$ he. 361

Houston, A. (n.d.). Survey handbook. A handbook for the Department of the Navy Total Quality Leadership Office, Washington, D.C. Retrieved from http://www.uiowa.edu/ cqi/surveybk.pdf

Hyman, L., Lamb, J., \& Bulmer, M. (2006, April 26). The use of pre-existing survey questions: Implications for data quality. Paper presented at the European Conference on Quality in Survey Statistics, Cardiff, England. Abstract retrieved from http://epp.eurostat.ec.europa.eu/portal/page/portal/quality/documents/Preexisting\%20surveys 
Importance of literature review. (2009). Retrieved from http://primedissertations.com/blog/importance-of-literature-review/

Internal consistency reliability. (n.d.). Retrieved form the Changing Minds website at http://changingminds.org/explanations/research/design/types_reliability.htm

Jenkins, L. (2009). Fundamentals of quantitative research. Retrieved from http://www.suite101.com/content/fundamentals-of-quantitative-research-a149406

Joseph Lancaster. (2010). Retrieved from http://en.wikipedia.org/wiki/Joseph_Lancaster Kay, J. P. (1997). Reliability and validity. Retrieved from http://www.okstate.edu/ag/agedcm4h/academic/aged5980a/5980/newpage18.htm

Kezar, A. (2003). Achieving student success: Strategies for creating partnerships between Academic and Student Affairs. NASPA Journal, 41(1), 1-22.

Kitchenham, B. A., \& Pfleeger, S. L. (2002a). Principles of survey research part 2: Designing a survey. ACM SIGSOFT Software Engineering Notes, 27(1), 18-20. doi: $10.1145 / 566493.566495$

Kitchenham, B. A., \& Pfleeger, S. L. (2002b). Principles of survey research part 3: Constructing a survey instrument. ACM SIGSOFT Software Engineering Notes, 27(2), 20-24 doi: $10.1145 / 511152.511155$

Lane, R. (2010). The importance of communication within a learning team. Retrieved from the eHow website at http://www.ehow.com/about_6549583_importance-communicationwithin-learning-team.html

Lash J. (2008). Understand qualitative vs. quantitative research. Retrieved from http://www.goodproductmanager.com/2008/01/22/understand-qualitative-vs-quantitativeresearch/ 
Lau, L. K. (2003). Institutional factors affecting student retention. Education, 124(1), 126-138.

Learning Center/Academic Resources. (2010). Retrieved from the GateWay College website at www.gatewaycc.edu/Academic/LearningCenter/

Leone, M., \& Tian, R. (2009). Push vs. pull: Factors that influence student retention. American Journal of Economics and Business Administration, 1(2), 122-132.

Leung, M., \& Bush, T. (2003). Student mentoring in higher education: Hong Kong Baptist University. University Mentoring and Tutoring, 11(3), 263-271. doi: $10.1080 / 1361126032000149319$

Levine, A., \& Sun, J. C. (2002). Barriers to distance education. A report submitted to the American Council on Education Center for Policy Analysis, Washington, DC.

Lohr, S. (2010, October 11). In higher education, a focus on technology. The New York Times, B3.

Loos, S., Menzel, S., \& Poparad, M. (2004). Three perspectives on peer tutoring for CS1 [Unpublished manuscript]. Indiana University, Bloomington, IN. Retrieved from http://www.cs.indiana.edu/cgi-pub/midwic/papers/uploads/loos.pdf

Luca, J., \& Clarkson, B. (2002). Promoting student learning through peer tutoring - A case study. (Report No. IR021786). Edith Cowan University, Australia. (ERIC Document Reproduction Service No. ED477058).

Maguire, L. (2005). Literature review - Faculty participation in online distance education: Barriers and motivators. Online Journal of Distance Learning Administration, 8(1). Retrieved from http://www.westga.edu/ distance/ojdla/spring81/maguire81.htm McCollough, D. (n.d.). Quantitative vs. qualitative marketing research. Retrieved from http://www.macroinc.com/html/art/s_qua.html 
MGT of America, Inc. (2009). Review of the Resident Faculty Leader Program for West Virginia University. A report submitted to West Virginia University, Morgantown, WV.

Miller, M. J. (n.d.). Reliability and validity. Retrieved from http://michaeljmillerphd.com/res600_lecturenotes/Reliability_and_Validity.pdf

Milne, J. (1999, March 25). Questionnaires: Advantages and disadvantages. Evaluation Cookbook. Retrieved from http://www.icbl.hw.ac.uk/ltdi/cookbook/info_questionnaires/index.html

Moser, F. Z. (2007). Faculty adoption of educational technology. Educause Quarterly, 30(1), 6669.

Moust, J. H. C., \& Schmidt, H. G. (1995). Facilitating small-group learning: A comparison of student and staff tutors' behavior. Instructional Science, 22, 287-301.

Muilenburg, L. Y., \& Berge, Z. L. (2005). Student barriers to online learning: A factor analytic study. Distance Education, 26(1), 29-48.

Mynard, J., \& Almarzouqi, I. (2006). Investigating peer tutoring. ELT Journal, 60(1), 13-22. doi: 10.1093/elt/cci077

Nightingale, P. (n.d.). Submission to the review of higher education financing and policy. A report submitted to the Higher Education Research and Development Society of Australia, Sydney, Australia. Retrieved from http://www.dest.gov.au/archive/highered/hereview/submissions/submissions/H/HERDSA .$h t m l$

Omara-Otunnu, E. (2004, October 25). Changes in higher education: Redefining faculty roles. The UConn Advance, 23(9). Retrieved from http://advance.uconn.edu/2004/041025/04102504.htm 
O’Neill, M. (2009). Research case study: Design for learning spaces in higher education. A report submitted to Knoll, Inc., East Greenville, PA. Retrieved from http://www.knoll.com/research/downloads/wp_LearningSpacesHigherEd.pdf

O’Quinn, L., \& Corey, M. (2002). Factors that deter faculty from participating in distance education. Online Journal of Distance Learning Administration, 5(4), 1-16. Retrieved fromhttp://www.westga.edu/ distance/ojdla/winter54/Quinn54.pdf

Pariser, D. J. (2007). Qualitative research on the effects of peer tutoring on academic achievement [Unpublished paper].West Virginia University, Morgantown, WV.

Pascarella, E. T., \& Terenzini, P. T. (1991). How college affects students. San Francisco: JosseyBass.

Pascarella, E. T., \& Terenzini, P. T. (2005). How college affects students, volume 2, a third decade of research. San Francisco: Jossey-Bass. Retrieved from https://apps.lis.illinois.edu/wiki/download/attachments/32452/distance_learning.pdf?versi on $=1$

Patterson, J. C. (2001, February). The Carnegie Classifications - profiles in change classification of institutions of higher education. Matrix: The Magazine for Leaders in Education. Retrieved from http://findarticles.com/p/articles/mi_m0HJE/is_1_2/ai_79961258/

Pendleton, M. (2005). Student mentoring and peer tutoring: A literature review. A report prepared for RMIT University, Melbourne, Australia. Retrieved from http://www.docstoc.com/docs/18668230/student-mentoring-and-peer-tutoring-aliterature-review-mark

Penner, R. (2001). Mentoring in higher education. Direction, 3(1), 45-52. 
Pfleeger, S. L., \& Kitchenham, B. A. (2001). Principles of survey research part 1: Turning lemons into lemonade. ACM SIGSOFT Software Engineering Notes, (26)6, 16-18. doi: $10.1145 / 505532.505535$

Pina, A. A. (2005). Distance learning: The importance and implementation of factors affecting its institutionalization (Doctoral dissertation). La Sierra University, Riverside, CA.

Pina, A. A. (2008a). Factors influencing the institutionalization of distance learning in higher education. Quarterly Review of Distance Education 9(4), 427-438.

Pina, A. A. (2008b). Making e-learning permanent: What can institutions do? Midwest Journal of Educational Communications \& Technology, 2(1), 2-14.

Plonsky, M. (2011). Psychological statistics. Retrieved from http://www4.uwsp.edu/psych/stat/12/anova-1w.htm

Postsecondary institutions. (n.d.). Retrieved from the U.S. Education website at E:Lissertation ResearchlCarnegie ClassificationsIU_S_EDUCATION The U_S_Education System Overview Organization of the U_S_Education System Postsecondary Institutions.mht

Questionnaire design. (2009). Retrieved from the Statistics Canada website at http://www.statcan.gc.ca/pub/12-539-x/2009001/design-conception-eng.htm

Radhakrishna, R. (2007). Tips for developing and testing questionnaires/instruments. Journal of Extension, 45(1). Retrieved from http://joe.org/joe/2007february/tt2.php

Ramirez, C. (2002, November). Strategies for subject matter expert review in questionnaire design. Paper presented at the Questionnaire Design, Evaluation and Testing Conference, Charleston, S.C. Abstract retrieved from http://www.jpsm.umd.edu/qdet/final_pdf_papers/ramirez.pdf 
Reliability of measurement. (n.d.). Retrieved from http://psych.csufresno.edu/price/psych144/reliability.html

Rendon, L. I. (1995, March). Facilitating retention and transfer for the first generation students in community colleges. Paper presented at the New Mexico Institute, Rural Community College Initiative, Espanolo, NM. (ERIC Document Reproduction Service No. ED383359). Abstract retrieved from http://www.eric.ed.gov/PDFS/ED383369.pdf

Reporting survey results. (2011). Retrieved from the eSurveyspro website at http://www.esurveyspro.com/article-reporting-survey-results.aspx

Response rates. (2006). Retrieved from http://www.ncdot.org/financial/productivity/Resources/download/2006/ThePulseMay06.pdf

Review of literature. (n.d.). Retrieved from http://ludwig.missouri.edu/405/review.html

Rings, S., \& Sheets, R. A. (1991). Student development and metacognition: Foundations for tutor training. Journal of Developmental Education, 15(1), 30-32.

Saunders, D. (1992). Peer tutoring in higher education. Studies in Higher Education, 17(2), 211218. doi: $10.1080 / 03075079212331382677$

Schotka, R. (n.d.). Peer Tutor training at Northeastern: A worthwhile investment for student success. Retrieved from http://www.northeastern.edu/cietl/publications/documents/peer.html

Schramm, C., Brown, S., \& Street, D. (2009, October). Peer tutors' perceptions of the in-class peer tutoring program in mechanics of materials. Paper presented at the $39^{\text {th }}$ ASEE/IEEE Frontiers in Education Conference, San Antonio, TX. Abstract retrieved from http://www.fie-conference.org/fie2009/papers/1201.pdf 
Shea, P. (2006). Bridges and barriers to teaching online college courses: A study of experienced online faculty at thirty-six colleges. Journal of Asynchronous Learning Networks, 11, 73128.

Schweitzer, G. (2009, July 24). Quantitative versus qualitative research. Retrieved from the SetTheStageForSuccess website at http://www.setthestageforsuccess.com/articles/31341/1/Quantitative-Versus-QualitativeResearch/Page1.html

Shumow, L., Farlowe, A., \& Bray, M. (2002). Tutoring - higher education. Retrieved from http://education.stateuniversity.com/pages/2516/Tutoring.html

Sivo, S., Saunders, C., Chang, Q., \& Jiang, J. (2006, June 1). How low should you go? Low response rates and the validity of inference in IS questionnaire research 1. Retrieved from http://www.allbusiness.com/reports-reviews-sections/polls-surveys/10552193-1.html

SPSS FAQ: What does Cronbach's alpha mean? (n.d.). Retrieved from http://www.ats.ucla.edu/stat/spss/faq/alpha.html

Standard deviation, What does it mean? (2011). Retrieved from http://answers.yahoo.com/question/index?qid=20080309080517AANah6X

Strachota, E. (2006, October). The use of survey research to measure student satisfaction in online courses. Paper presented at the Midwest Research-to-Practice Conference in Adult, Continuing, and Community Education, St. Louis, MO. Abstract retrieved from http://www.umsl.edu/continuinged/education/mwr2p06/pdfs/D/Strachota_Use_of_Survey Research.pdf

Strachota, E., Schmidt, S. W., \& Conciecao, S. O. (2006, October). The development and validation of a survey instrument for the evaluation of instructional aids. Paper presented 
at the Midwest Research-to-Practice Conference in Adult, Continuing, and Community Education, St. Louis, MO. Abstract retrieved from http://www.umsl.edu/continuinged/education/mwr2p06/pdfs/D/Strachota_Schmidt_Conc eicao_The_Development_and_Validation_of_a_Survey_Instrument.pdf

Statistical analysis (1-way ANOVA). (2003). Retrieved from http://www.chem.agilent.com/cag/bsp/products/gsgx/Downloads/pdf/one_way_anova.pdf

Street, D. (2010). Engineering student social capital within an in-class peer tutoring program: Sources and preferences. (Doctoral dissertation). Retrieved from http://www.dissertations.wsu.edu/Thesis/Spring2010/d_street_031010.pdf

Street, D., Brown, S., Schramm, C., \& Gillespie, K. (2009, October). The impact of an in-class peer tutoring program on student social capital. Paper presented at the $39^{\text {th }}$ ASEE/IEEE Frontiers in Education Conference, San Antonio, TX. Abstract retrieved from http://ieeexplore.ieee.org/stamp/stamp.jsp?arnumber=05350569

Survey design: Writing great questions for online surveys. (2011). Retrieved from the eSurveyspro website at http://www.esurveyspro.com/article-online-survey-designquestions.aspx

Survey methodology: Reliability and validity. (n.d.). Retrieved from http://www.tulane.edu/ hivstd/epi626/sm12web.ppt\#256,1,Survey Methodology Reliability and Validity

SurveyMonkey. (n.d.). Considerations for creating effective survey questions. Retrieved from http://help.surveymonkey.com/app/answers/detail/a_id/101

SurveyMonkey. (2007). Smart survey design. Retrieved from http://www.marketingscoop.com/Article_Tools/SmartSurvey.pdf 
Surveys and sampling. (2011). Retrieved from http://www.utc.edu/Faculty/MichaelBiderman/PSY513/Lecture4_SurveysAndSampling.DOC

Suskie, L. A. (1996). Questionnaire survey research: What works. Tallahassee, FL: Association for Institutional Research.

Taylor, D. (n.d.). The literature review: A few tips on conducting it. Retrieved from http://www.writing.utoronto.ca/advice/specific-types-of-writing/literature-review

The ANOVA. (n.d.). Retrieved from http://isogenic.info/html/the_anova.html

The mission of West Virginia University. (2011). Retrieved from http://about.wvu.edu/

Thelin, J., Edwards, J., \& Moyen, E. (2010). Higher education in the United States: Historical development. Retrieved from http://education.stateuniversity.com/pages/2044/HigherEducation-in-United-States.html

Thomas, L. (2002). Student retention in higher education: The role of institutional habitus. Journal of Education Policy, 17(4), 423-442.

Tinto, V. (1997). Classrooms as communities: Exploring the educational character of student persistence. The Journal of Higher Education, 68(6), 599-623.

Tinto, V. (1998a). Colleges as communities: Taking research on student persistence seriously. The Review of Higher Education, 21(2), 166-177.

Tinto, V. (1998b). Learning communities: Building gateways to student success. The National Teaching \& Learning Forum, 7(4). Retrieved from www.ntlf.com/html/lib/suppmat/74tinto.htm

Tinto, V. (2002, April). Taking student retention seriously: Rethinking the first year of college. Paper presented at the annual meeting of the American Association of Collegiate 
Registrars and Admission Officers, Minneapolis, MN. Abstract retrieved from http://www.mcli.dist.maricopa.edu/fsd/c2006/docs/rethinkfirstyearcollege.pdf

Tinto, V. (2006-7). Research and practice on student retention: What next? Journal of College Retention: Research, Teaching, and Practice, 8(1), 1-19.

Tinto, V., Goodsell, A., \& Russo, P. (1993). The impact of college collaborative learning on student experience in the first year of college [Unpublished manuscript]. Syracuse University, Syracuse, NY. Retrieved from http://www.iier.org.au/iier13/darlastonjones2.html

Topping, K. J. (1996). The effectiveness of peer tutoring in further and higher education: A topology and review of the literature. Higher Education, 32, 321-345.

Tovar, E., \& Simon, M. A. (2003). Facilitating student success for entering California community college students: How one institution can make an impact. EJournal for Research, Planning, and Practice, 1(1), 1-9. Retrieved from http://www.staging.rpgroup.org/publications/eJournal/volume_1/Tovar\&Simon_article. pdf

Trochim, W. (2006a). Internal consistency reliability. Retrieved from http://www.socialresearchmethods.net/kb/reltypes.php

Trochim, W. (2006b). Reliability. Retrieved from http://www.socialresearchmethods.net/kb/variable.php

Trochim, W. (2006c). The qualitative-quantitative debate. Retrieved from http://www.socialresearchmethods.net/kb/qualdeb.htm

Turocy, P. S. (2002). Survey research in athletic training: The scientific method of development and implementation. The Journal of Athletic Training, 37(4 Supplement), S174-S179. 
Turoff, M. (2006). The changing role of faculty and online education. Sloan-C Series, 10(4), 2938. Retrieved from http://sloanconsortium.org/sites/default/files/v10n4_turoff_0.pdf University Leadership Council. (2009). Hardwiring student success: Building disciplines for retention and timely graduation. Washington, D.C.: The Advisory Board Company. Validity and reliability. (n.d.). Retrieved from the Columbia University website at http://ccnmtl.columbia.edu/projects/qmss/measurement/validity_and_reliability.html

Wells, C. S., \& Wollack, J. A. (2003). An instructor's guide to understanding test reliability. Testing and Evaluating Services, University of Wisconsin: Madison, WI. Retrieved from http://testing.wisc.edu/Reliability.pdf

Whelchel, N. (n.d.). Survey research. Retrieved from http://www.ncsu.edu/assessment/presentations/assess_process/survey_research.pdf

Williams, C. (2007). Research methods. Journal of Business \& Economic Research, 5(3), 65-71.

Xu, Y., Hartman, S., Uribe, G., \& Mencke, R. (2001, September). The effects of peer tutoring on undergraduate students' final examination scores in mathematics. Journal of College Reading and Learning, 31(2). Retrieved from http://findarticles.com/p/articles/mi_hb3247/is_1_32/ai_n28876964/?tag=content;col1

Yu, A. (n.d.). Using $S A S$ for item analysis and test construction. Retrieved from http://www.creative-wisdom.com/teaching/assessment/alpha.html 


\section{Appendix A}

\section{Sample Letter of Solicitation for Participation on Panel of Experts}

Dr. Anthony Pina

Dean of Online Studies

Sullivan University System

2100 Gardiner Lane, Suite 220

Louisville, KY 40205

March 10, 2011

Dr. Pina,

I am an assistant Resident Faculty Leader (RFL) at WVU and a doctoral student in Educational Leadership Studies. I am doing my dissertation on the institutionalization of peer tutoring programs in higher education, which was recommended as a topic for future research in an article by Dr. Vincent Tinto entitled "Research and Practice on Student Retention: What Next?". In a literature review on institutionalization, I came across your study on "Distance Learning: The Importance and Implementation of Factors Affecting Its Institutionalization," which I have cited in my research and used as a model for my work on peer tutoring. I am putting together a panel of experts to look over my survey instrument before I do a pilot study and I would be honored if you could serve on my panel of experts.

The objective of my study is to identify institutional policies and procedures that will help administrators and faculty understand which institutional practices lead to the successful implementation of peer tutoring programs. The sample includes administrators and faculty from Region II, NASPA - Student Affairs Administrators in Higher Education who are interested in and have knowledge about academic tutoring programs and are involved in their supervision, evaluation, and delivery of services. WVU is a member of Region II, NASPA, which is comprised of 2176 administrators and faculty in higher education from 233 institutions.

The study seeks to answer the following research questions:

a) What institutional factors facilitate peer tutoring programs in Region II NASPA institutions, according to administrators and faculty who are members of Region II?

b) What factors are barriers to peer tutoring programs in Region II NASPA institutions, according to administrators and faculty who are members of Region II?

c) What are the differences in perceptions of these factors between administrators and faculty?

I look forward to hearing from you.

Sincerely, Debbi Pariser, Doctoral Student in EDLS

Phone: (304) 216-6301

Email: debbi.pariser@mail.wvu.edu 


\section{Appendix B}

\section{Sample Letter of Response from Perspective Panel of Experts}

Dear Ms. Pariser,

I would be honored and pleased to serve on your panel to review your survey instrument. In my own research of institutionalization, using distance learning as my innovation of study, I noticed that much of the literature focused upon implementation as the sign of an innovation's success. In so many of the studies, if an organization adopted the innovation, then the study had a happy ending. However, what I also found was that implementation is not institutionalization. Many of these wonderful innovations did not last after the grant funding ran out, or if a new administrator arrived on the scene who was not a champion of the innovation. So I am very pleased that you are looking at what will make peer tutoring a normal, regular, integrated and lasting part of an organization's operation.

I wish you the very best and look forward to seeing your survey.

\section{Anthony Piña}

Dr. Anthony Piña

Dean of Online Studies

Sullivan University System

2100 Gardiner Lane \#220

Louisville, Kentucky 40205

apina@sullivan.edu 


\section{Appendix C}

\section{Reviewer Directions for Panel of Experts}

\section{Dear Colleague:}

I am doing my dissertation on the institutionalization of peer tutoring programs in higher education, which was recommended as a topic for future research in an article by Dr. Vincent Tinto entitled "Research and Practice on Student Retention: What Next?". Although there has been considerable research on peer tutoring in higher education, there is a gap in the literature on institutional policies and practices that lead to the institutionalization of peer tutoring programs. The objective of my study is to identify institutional policies and procedures that will help administrators and faculty identify which institutional practices facilitate the implementation of peer tutoring programs and which are barriers to peer tutoring programs.

This survey consists of 8 demographic questions about the participant and their institution and 28 items that they will be asked to rate as critically important, very important, moderately important, of minor importance, or not important for institutionalizing peer tutoring programs. Each of the 28 items is a factor that colleges and universities can implement to help make peer tutoring a permanent part of the institution. Participants will also be asked to rate the difficulty of implementation of each factor at their institution.

As you review the survey items, please keep in mind the following points (Ramirez, 2002, p. 3):

"• Content of questionnaire

- Importance/meaningfulness of question areas to research aims

- Wording and terminology of items

- Comprehensiveness/mutual exclusivity of answer choices

- Respondent identification - titles/roles of best respondent

- Respondent motivation/knowledge/ability to answer questions

- Sensitivity/threat of information request

- Cost/burden to respondent population

- Appropriate incentives and/or fieldwork methods for the population"

Your participation in this study is voluntary and very much appreciated.

Sincerely,

Debbi Pariser

Doctoral Student in EDLS

West Virginia University

Phone: (304) 216-6301

Email: debbi.pariser@mail.wvu.edu 
Appendix D

Survey Instrument 


\section{Administrative and Faculty Factors that Contribute to the Institutionalization}

1.

Dear Participant,

This letter is a request for you to take part in a research project to identify factors that lead to the institutionalization of peer tutoring programs in higher education. This study is being conducted by Debbi Pariser at West Virginia University with the supervision of Dr. Helen M. Hazi, professor of Educational Leadership Studies in the College of Human Resources and Education, in partial fulfillment of a Doctorate in Educational Leadership Studies. Your participation in this project is greatly appreciated and will take approximately 10-15 minutes to complete this voluntary and anonymous online survey.

The project seeks to answer the following research questions:

a) What institutional factors facilitate peer tutoring programs in Region II NASPA institutions, according to administrators and faculty who are members of Region II?

b) What factors are barriers to peer tutoring programs in Region II NASPA institutions, according to administrators and faculty who are members of Region II?

c) What are the differences in perceptions of these factors between administrators and faculty?

I am requesting your participation in the study as an administrator or faculty member in Region II of NASPA. All data will be reported in the aggregate. I will not ask any information that will lead back to your identity as a participant. Your participation is completely voluntary and anonymous. You may skip any question that you do not wish to answer and you may discontinue at any time. West Virginia University's Institutional Review Board approval of this research project is on file.

I hope that you will participate in this research project, as it could be beneficial in understanding which institutional practices facilitate peer tutoring programs and which are barriers to the institutionalization of peer tutoring programs. In addition to administrators and faculty, this study will also be of benefit to all peer tutoring professionals.

In order to be entered into a drawing for one of four $\$ 50$ gas cards to reward you for your participation, you will be directed to a different website at the end of this survey. If you want to be entered in the drawing, please give an address to which you would like your reward sent if you are selected as a winner. You address will in no way be connected to your answers on this survey.

Thank you very much for your time. Should you have any questions about this survey or research project, please feel free to contact Debbi Pariser at (304) 216-6301 or by e-mail at debbi.pariser@mail.wvu.edu, or Dr. Helen M. Hazi at (304) 293-1885 or by email at Helen.hazi@mail.wvu.edu.

Thank you for your time and help with this project.

Sincerely,

Debbi Pariser, Primary Contact

Doctoral Student

Dr. Helen M. Hazi, Principle Investigator

Professor of Educational Leadership Studies 


\section{Administrative and Faculty Factors that Contribute to the Institutionalization}

2. Demographics

1. What is your position? (Check all that apply.)

Administrator

$\square$ Faculty

Other (please specify)

2. How are you involved in peer tutoring on your campus? (Check all that apply.)

Administrative oversight of peer tutoring (not involved in day-to-day operation)

Directing or coordinating peer tutoring (involved in day-to-day operation)

Evaluating the peer tutoring program

Recruiting tutors

Training tutors

Not involved

Other (Please specify.)

3. Where does peer tutoring programs occur on your campus? (Check all that apply.)

Residence hall

Tutoring center or other academic center

Classroom

Other (Please specify.)

4. Which unit supervises peer tutoring at your institution? (Check all that apply.)

Student Affairs

Academic Affairs

I don't know.

Other (please specify)

\section{Is your institution public or private?}

$\bigcirc$ Public

Private non-profit

Private for-profit 
Administrative and Faculty Factors that Contribute to the Institutionalization

\section{What is the highest degree awarded by your institution?}

Associates

Bachelors

$\bigcirc$ Masters

Doctorate

Professional (e.g. JD, MD, DDS)

\section{What is the enrollment at your institution?}

Less than 1000

$\bigcirc 1001-5000$

$\bigcirc 5001-10,000$

(10,001-20,000

More than 20,000

\section{Which Carnegie classification best describes your institution?}

$\bigcirc$ Research University (Very High Research)

Research University (High Research)

$\bigcirc$ Doctoral Research University

Master's Colleges and Universities (larger programs)

$\bigcirc$ Master's Colleges and Universities (medium programs)

Master's Colleges and Universities (smaller programs)

Baccalaureate Colleges (all subtypes)

$\bigcirc$ Associate's Colleges (all subtypes)

None of the above 
Administrative and Faculty Factors that Contribute to the Institutionalization

3. Survey

\section{Please rate importance and difficulty of implementation for each of the following factors to peer tutoring.}

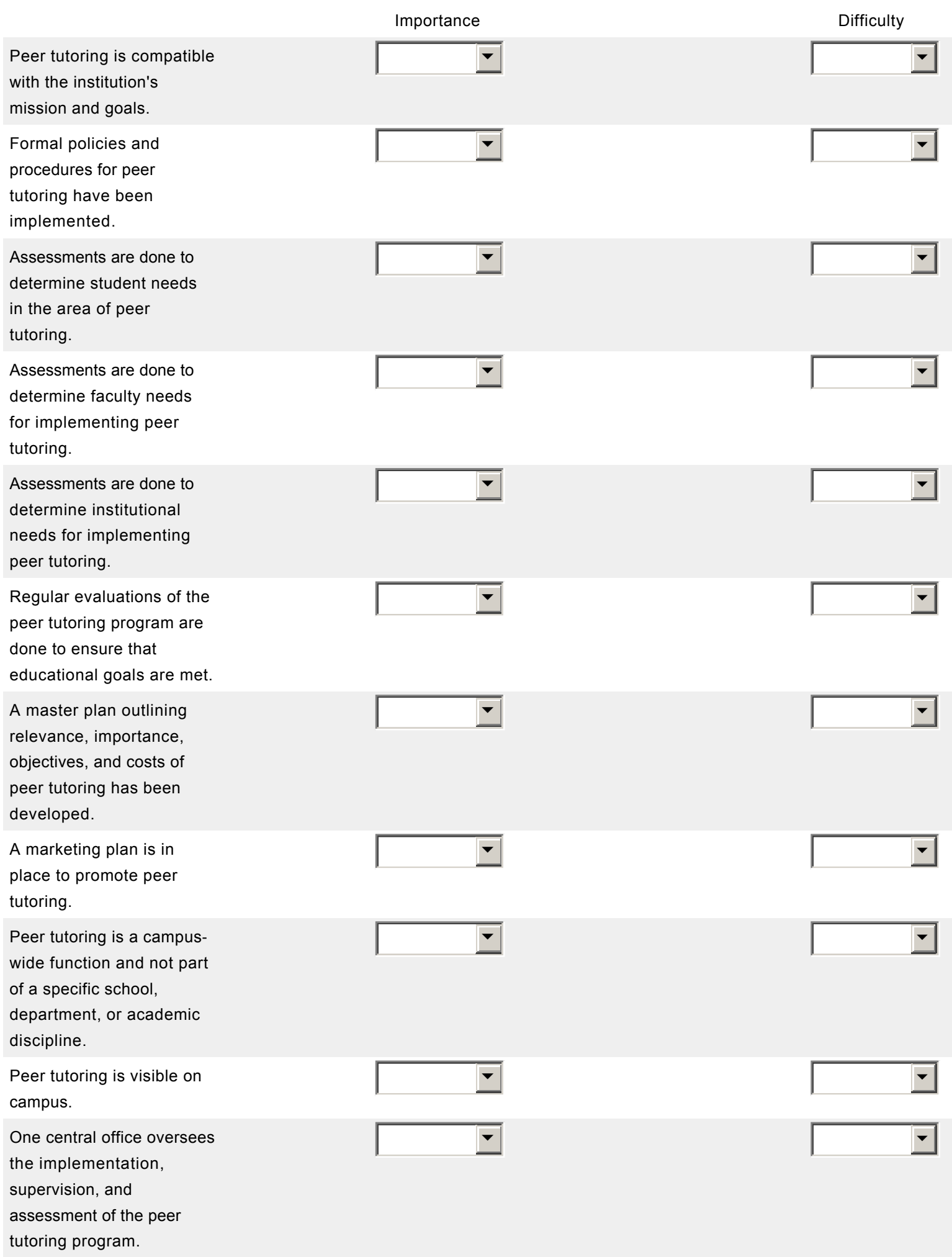




\section{Administrative and Faculty Factors that Contribute to the Institutionalization}

A program director for peer tutoring with decision-

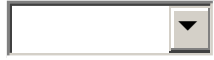

making authority has been

appointed.

\section{Peer tutoring}

administrators and staff
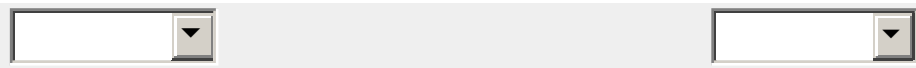

meet regularly with other

campus groups to ensure

support.

The peer tutoring program and staff are a permanent

part of the institutional

budget.

There is a shared vision of peer tutoring among

departments.

Faculty and administrators collaborate on peer

tutoring to plan programs.

Faculty and administrators collaborate on peer tutoring to implement programs.

Faculty and administrators collaborate on peer

tutoring to decide the program budget.

Faculty and administrators collaborate on peer tutoring to access program effectiveness.

\section{Ongoing staff}

development on peer

tutoring best practices is in place.

Professional incentives to participate in peer tutoring
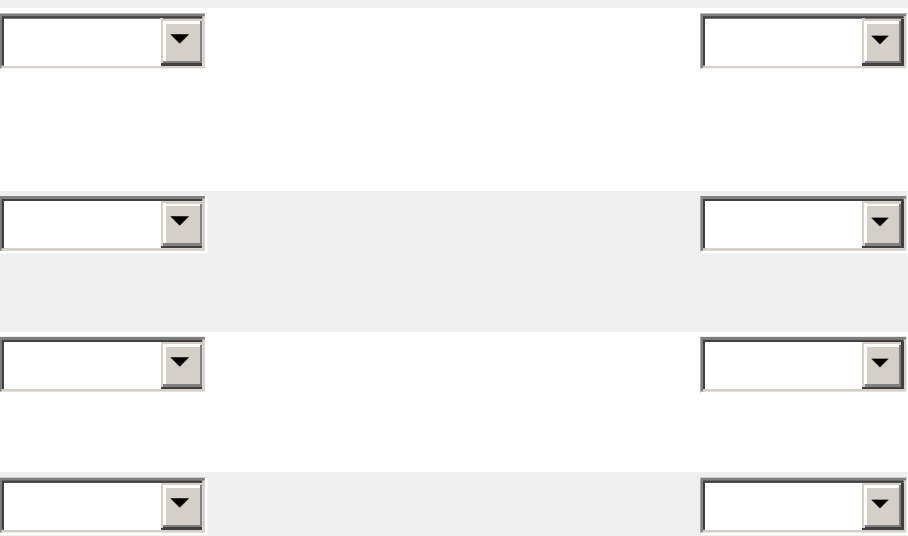
programs are available (i.e. credit towards promotion and tenure, flexibility in time teaching).

Financial incentives to participate in peer tutoring are available (i.e. merit pay, grants for future research, new computer).

Communication between faculty and students encourages student engagement. 


\section{Administrative and Faculty Factors that Contribute to the Institutionalization}

Communication between

faculty and students

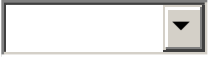

supports different teaching

styles.

Communication between

faculty and students
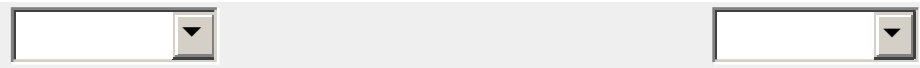

supports different learning

styles.

Peer tutoring practices are

oriented toward

developing a climate in

which students'

responsibility and active

participation are

promoted. 